\title{
Exploratory Elattery Technology Development and Testing Report for 1989
}

\author{
Nicholas J. Magnani \\ Power Sources Department \\ Ronald B. Diegle, Jeffrey W. Braithwaite, \\ Donald M. Bush, James M. Freese, \\ Abbas A. Akhil, and Stephen E. Lott \\ Storage Batteries Division \\ Sandia National Laboratories \\ Albuquerque, NM 87185
}

\begin{abstract}
Sandia National Laboratories, Albuquerque, has been designated as Lead Center for the Exploratory Battery Technology Development and Testing Project, which is sponsored by the U.S. Department of Energy's Office of Energy Storage and Distribution. In this capacity, Sandia is responsible for the engineering development of actvanced rechargeable batteries for both mobile and stationary energy storage applications. This report details the technical achievements realized in pursuit of the Lead Center's goals during calendar year 1989.
\end{abstract}




\section{Contents}

Acronyms and Abbreviations $\ldots \ldots \ldots \ldots \ldots \ldots \ldots \ldots \ldots \ldots$

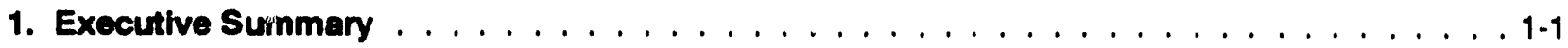

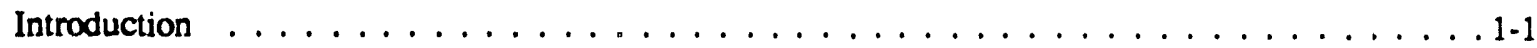

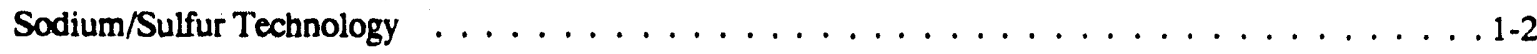

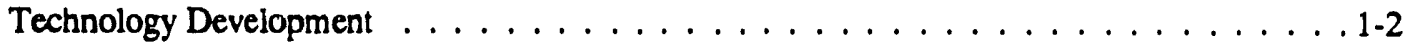

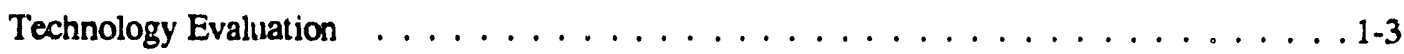

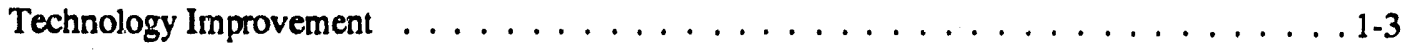

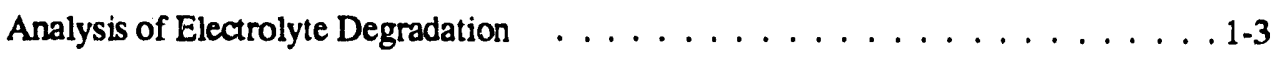

Component Stress During F/T Cycling $\ldots \ldots \ldots \ldots \ldots \ldots$

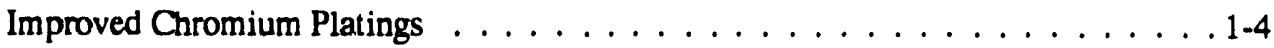

Zinc/Bromine Technology . . . . . . . . . . . . . . . . . . . . . 1-4

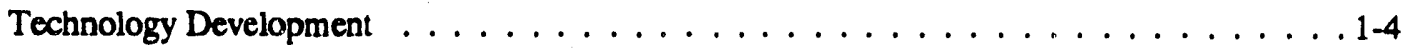

FY89 Highlights - ERC $\ldots \ldots \ldots \ldots \ldots \ldots \ldots \ldots \ldots$

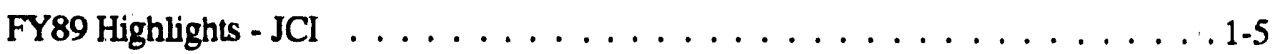

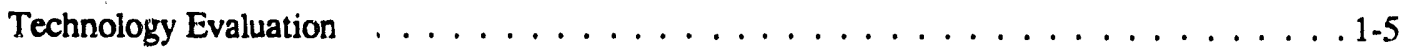

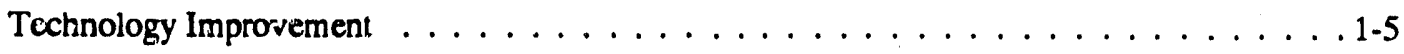

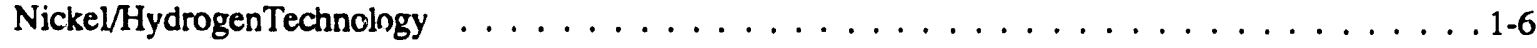

Technology Development . . . . . . . . . . . . . . . . . . 1-6

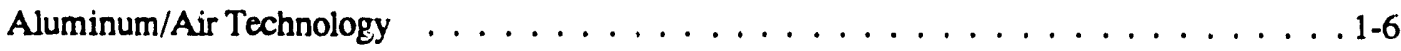

Technology Development . . . . . . . . . . . . . . . . . . . . . . 1-6

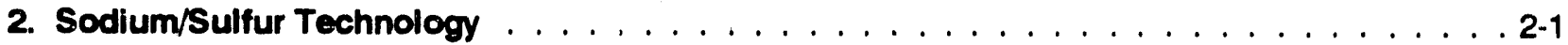

Techrology Development . . . . . . . . . . . . . . . . . . . 2-1

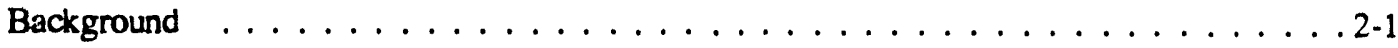

Task 1 - Core Technology Research and Development . . . . . . . . . . . . . 2-2

Subtask 1.1. Electrolyte Research and Development . . . . . . . . . . . . . 2-2

Subtask 1.2. Materials Development and Qualification . . . . . . . . . . . . . 2-3

Subtask 1.3. Cell Development . . . . . . . . . . . . . . . . 2-11

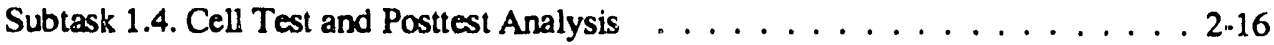

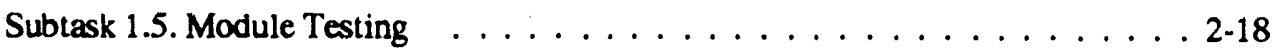

Task 2 - Battery Engineering and Testing $\ldots \ldots \ldots \ldots \ldots \ldots$ 2-20 


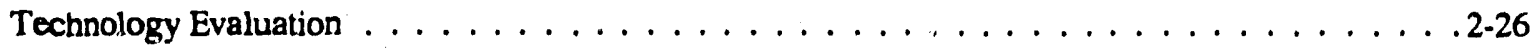

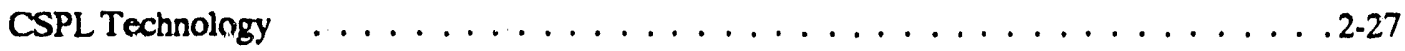

Powerplex Technology . . . . . . . . . . . . . . . . . . . . . . . . . . . . . . . . . . . . . . . .

Ceramatec Technology . . . . . . . . . . . . . . . . . 2-32

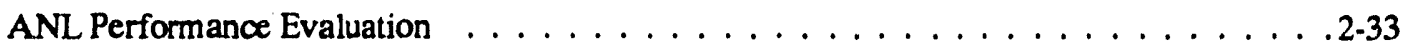

Posttest Analysis of CSPL Sodium/Sulfur Cells . . . . . . . . . . . . 2.38

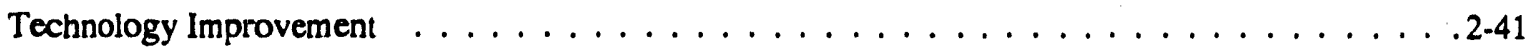

Analysis of Electrolyte Degradation . . . . . . . . . . . . . . 2-41

Composite Fabrication . . . . . . . . . . . . . . . . . 2-41

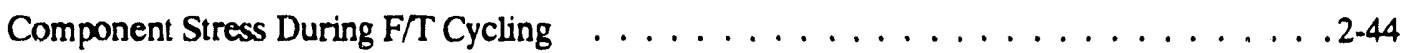

Improved Chromium Plating of Sodium/Sulfur Cell Containers $\ldots \ldots \ldots . . .250$

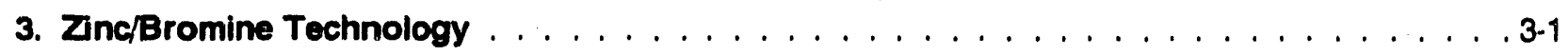

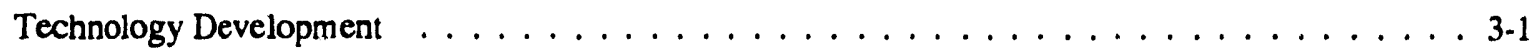

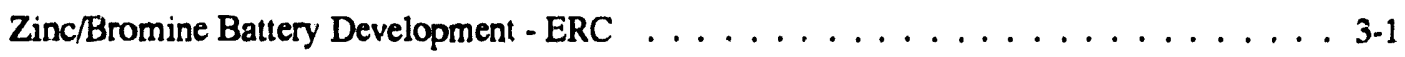

Hardware Development . . . . . . . . . . . . . . . . . 3-1

Material Stability Studies . . . . . . . . . . . . . . . . . . 3-10

Development of a Zinc/Bromine Load Management Battery - JCI . . . . . . . . 3-13

Load Leveling Z-20LL Battery . . . . . . . . . . . . . . . . . . . . 3-13

Z20-LL Test Results . . . . . . . . . . . . . . . 3-15

Other Activities . . . . . . . . . . . . . . . . . .15

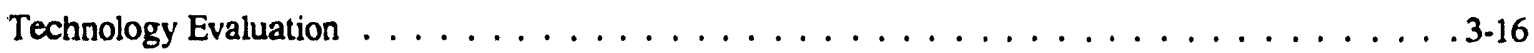

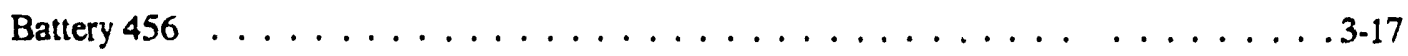

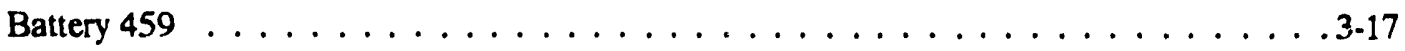

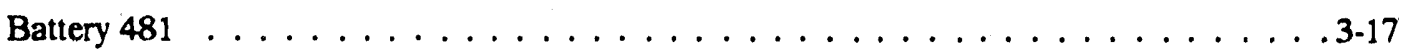

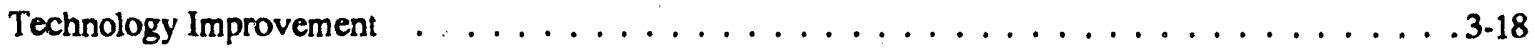

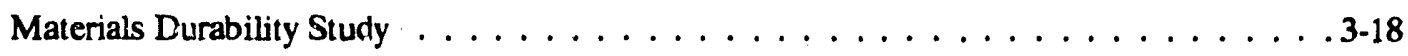

Advanced Membrane Development $\ldots \ldots \ldots \ldots \ldots \ldots \ldots \ldots \ldots$. . . . . . . . . .

4. Nickel/Hydrogen Technology . . . . . . . . . . . . . . . . . . . . 4-1

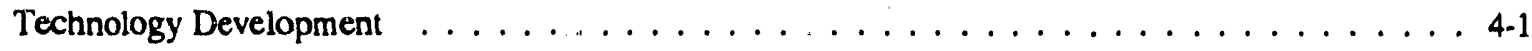

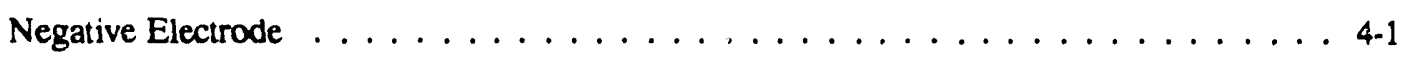

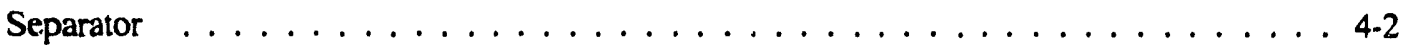

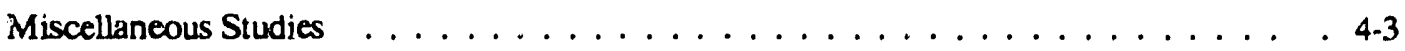

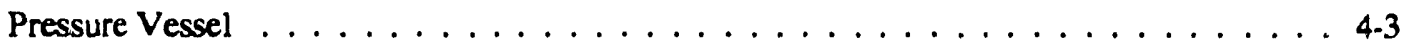

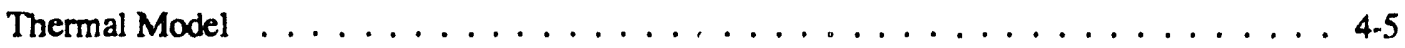

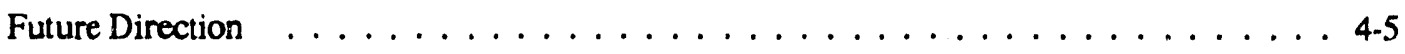




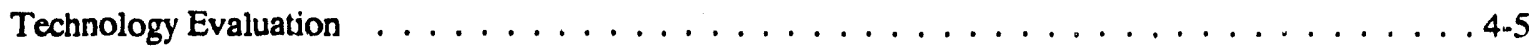

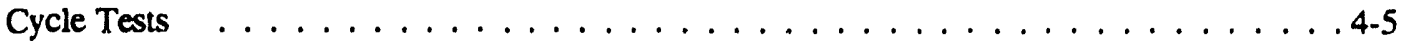

Solar Tests . . . . . . . . . . . . . . . . . . . . . . . 4-9

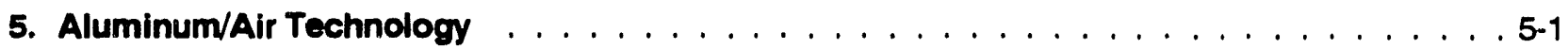

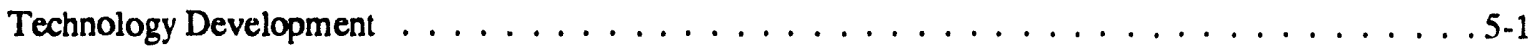

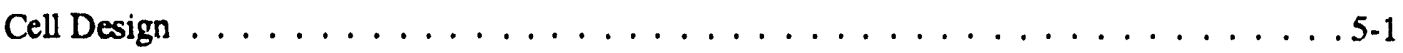

Mathematical Model of the B-300 Cell $\ldots \ldots \ldots \ldots \ldots \ldots \ldots \ldots$. . . . . . . . .

Electrolyte Management . . . . . . . . . . . . . . . . . . 5-3

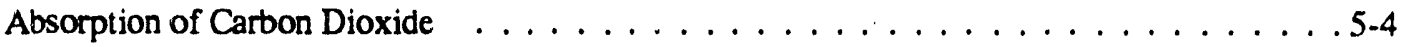

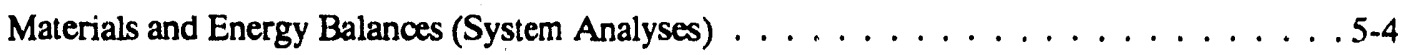

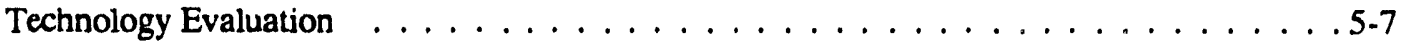

Modified B-300 Cell (SNL) . . . . . . . . . . . . . . . . . . . . . 5-7

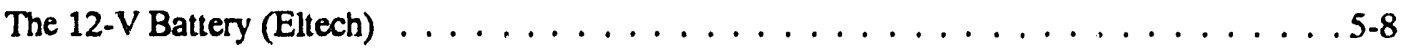

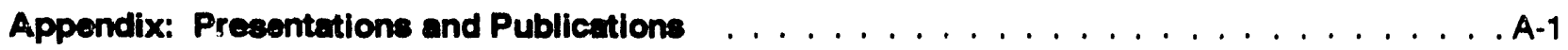

\section{Figures}

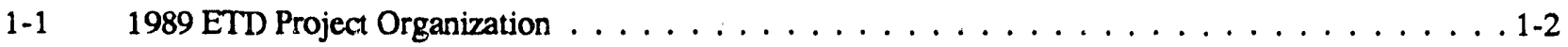

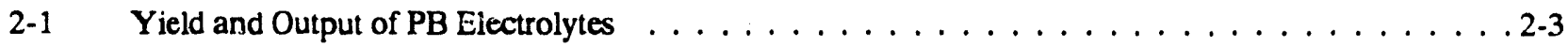

$2-2 \quad$ XPB Electroltye Production . . . . . . . . . . . . . . . . . . . . 2-4

$2-3$ Performance of Cells with MkIV Type Sodium Electrode Stals . . . . . . . . . . . . . 2-5

2-4 Cyclic Amperometry of Cell $10269 \ldots \ldots \ldots \ldots \ldots \ldots$

2-5 $\quad R_{c} / R_{d}$ Values for MkIIl SF Cells from Production $\operatorname{Line} \ldots \ldots \ldots \ldots \ldots \ldots$

2-6 Effect of Recharge Current on Cell Resistance . . . . . . . . . . . . . . . . . . . . 2-8

2-7 Effect of Discharge Current on Cell Resistance . . . . . . . . . . . . . . . . . . . 2-9

2-8 Effect of Current Density on Cell Charge and Discharge Resistances . . . . . . . . . . . . 2-10

2-9 Improvements in PB Cell Absolute Resistance . . . . . . . . . . . . . . . . . . . . 2-11

2-10 Improvements in $\mathrm{PB}$ Cell Kesistance . . . . . . . . . . . . . . . . . . . . 2-12

2-11 Improvements in PB Cell Capacity Retention . . . . . . . . . . . . . . . . . . 2-12

2-12 Resistance and Capacity of MkIII SF Cells to 1,000 Cycles . . . . . . . . . . . . . . . 2-13

2-13 Safety Test Data on 117 PB MkIII SF PB Cells . . . . . . . . . . . . . . . . . 2-14

2-14 Rapid Quench Testing of MkIII SF PB Cells . . . . . . . . . . . . . . . . . . 2-15

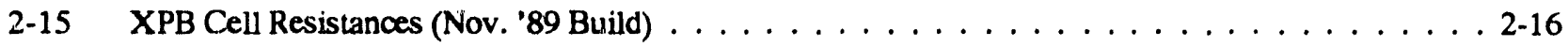

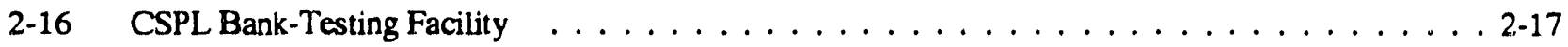

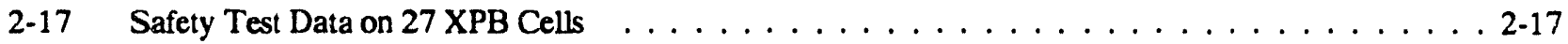

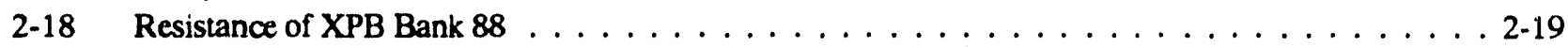

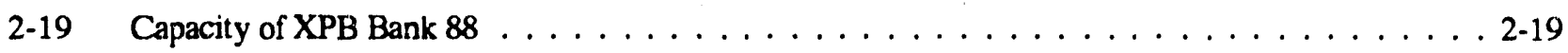

2-20 Final Design Concept for 200 XPB Battery Sub-module . . . . . . . . . . . . . . . . 2-20

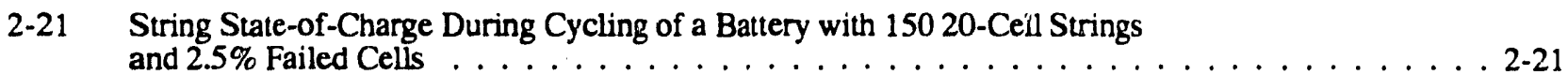


2-22 String Currents During Discharge of a Battery with 15020 -Ceil Strings

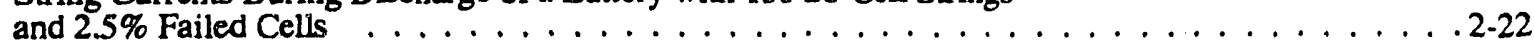

2-23 String Currents During Charge of a Battery with 150 20-Cell Strings

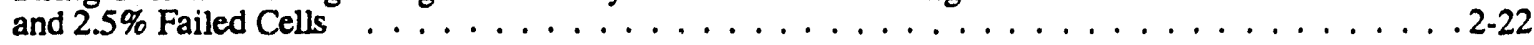

2-24 String Currents During Discharge of a Battery with 150 20-Cell Strings and $10 \%$ Failed Cells . . . . . . . . . . . . . . . . . . . . . . . . . 2-23

2-25 String Currents During Charge of a Battery with 150 20-Cell Strings and $10 \%$ Failed Cells . . . . . . . . . . . . . . . . . . . . . . . . . . . . 2-24 Comparison of 20-Cell and 40-Cell String Battery Capacity . . . . . . . . . . . . . . . . . . 2-24 Equilibration Currents After Discharge of a Battery with 150 20-Cell Strings

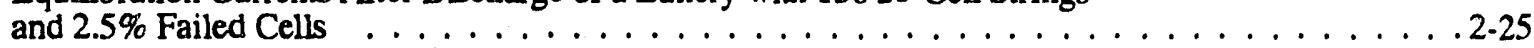

2-28 Capacity Degradation Due to EPRI Battery Cycling Regime $\ldots \ldots \ldots \ldots \ldots \ldots \ldots \ldots \ldots$ Monobloc Concept for SES Battery Design . . . . . . . . . . . . . . . . . . . . . . . 2-27 SES Battery Conceptual Design Based on Monobloc Concept . . . . . . . . . . . . . . . . . . 2.27

Charge Acceptance vs Charge Rate at lour Temperatures for CSPL Cell $469 \ldots \ldots$. . . . . . . . . . . 2-30

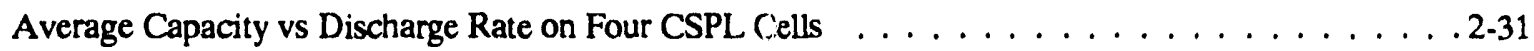

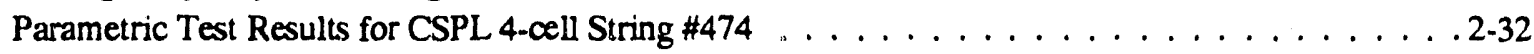
Parametric Test Results for Powerplex Cell \#477 . . . . . . . . . . . . . . . . . . . . . 2-34 Capacity and Resistance History of 24 Cell CSPL Sodium/Sulfur Module $\# 2 \ldots \ldots \ldots \ldots$. . . . . . . . . . . . . . . CSPL Sodium/Sulfur Module \#2 Peak Power vs DOD with Life (50\% Burden) $\ldots \ldots \ldots \ldots \ldots$ Capacity and Resistance History of 24 Cell CSPL Sodium/Sufur Module \#3 . . . . . . . . . . 2-38 Capacity vs Discharge Rate of 24 Cell CSPL Sodium/Sulfur Modules $\# 2$ and \#3 . . . . . . . . . . 2-39 Corrosion of the Chromized Cell Case as a Function of Cycle Life for PB and XPB Cells . . . . . . 2-40 Calcium Contamination of the Electrolyte as a Function of Cycle Life for PB and XPB Cells . . . 2-42 A Schematic of Beta"-Alumina/Zirconia Three Layer Composite . . . . . . . . . . . . . . . . 2-43 A Schematic of a Partially Ground Off Three Layer Composite with a Strain Gage on One

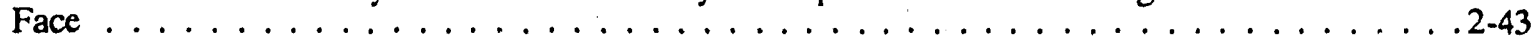

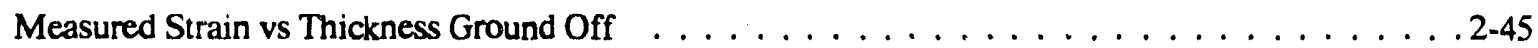

Measured Mechanical Strain on the Stainless Steel Container as a Function of Temperature

During the Freeze Cycle of a Discharged SNL Lab Cell (OCV =1.9 V.) . . . . . . . . . . . . 2.46 Comparison of Calculated and Measured Hoop Strain from the Freezing of an SNL Lab Cell . . . . 2-47 Calculated Coefficient of Thermal Expansion for the Positive Electrode of SNL Lab Cells. . . . . . 2-48 Schematic Diagram of the Apparatus Used to Vacuum-Cast a Sodium Tetrasulfide/Graphite Felt Composite Sample . . . . . . . . . . . . . . . . . . . . . . . . . . . . . . . . . . . . 2-49 The Effect of Temperature on the Elastic Moduli and the Coeffiecient-of-Thermal Expansion (CTE) for a Cast Sodium Tetrasulfide/Graphite Felt Composite . . . . . . . . . . . . . . 2-50 Chromium-Plated 1018-Steel Rod Prior to Corrosion Testing . . . . . . . . . . . . . . . . 2-52

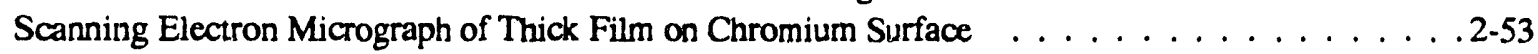
Scanning Electron Micrograph of Chromium Surface Under the Film . . . . . . . . . . . . 2-54 Scanning Electron Micrograph of Chromium Surface Under the Film . . . . . . . . . . . . 2-55 Scanning Electron Micrograph of the Control Sample . . . . . . . . . . . . . . 2-56 Scanning Electron Micrograph of the Control Sample . . . . . . . . . . . . . . . . . . . 2-57 Auger Sputter Analysis of Film from Rod . . . . . . . . . . . . . . . . . . . . . 2-58 Exploded View of $1,500 \mathrm{~cm}^{2}$ ERC Zinc/Bromine Battery $\ldots \ldots \ldots \ldots \ldots \ldots \ldots \ldots$ Cycle Performance, 5-cell, $1,500 \mathrm{~cm}^{2}$ Battery, 1500-5-2. . . . . . . . . . . . . . . . 3-4 Cycle Performance $1,500 \mathrm{~cm}^{2}, 5-c e l l$ Battery, 1500-5-3. . . . . . . . . . . . . . . 3-5 Cycle Performance, $5-c e l l, 1,500 \mathrm{~cm}^{2}$ Battery, 1500-5-3. . . . . . . . . . . . . . . 3-6 
3-5 Cycle Performance, 52-cell, 1,500 $\mathrm{cm}^{2}$ Battery, 1500-52-1 . . . . . . . . . . . . . . . 3-7

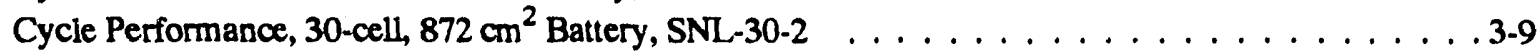

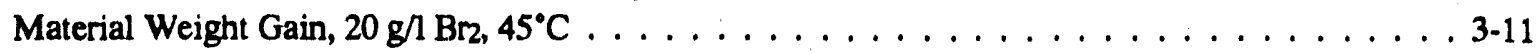

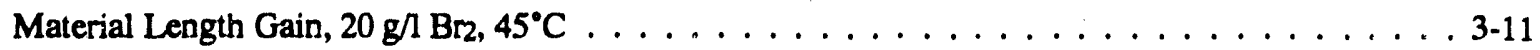

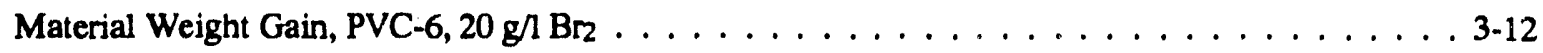

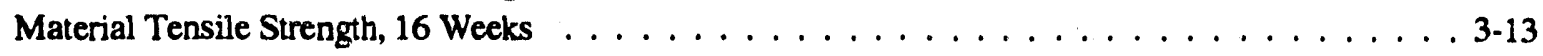

20-kWh JCI Load Leveling Battery . . . . . . . . . . . . . . . . . . . . . . . . 3-14

20-kWh Battery Cycle Performance . . . . . . . . . . . . . . . . . . 3-15

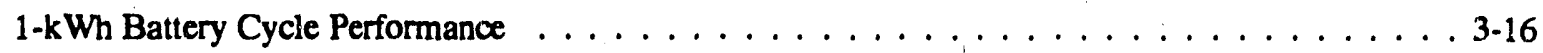

Modulus Measurements of Battery 456 Flow Frame . . . . . . . . . . . . . . . . . 3-19

Modulus of Aged Materials . . . . . . . . . . . . . . . . . . . . 3-21

Normalized Resistance and Permeation of Nafion Impregnated Asahi SF-400 . . . . . . . . . . 3.23

Price of a Nickel Hydrogen Battery . . . . . . . . . . . . . . . . . . . . . 4-2

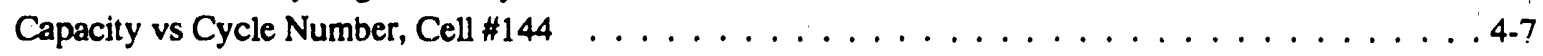

Pressure vs Cycle Number, Cell $\# 144 \ldots \ldots \ldots \ldots \ldots \ldots \ldots \ldots \ldots \ldots \ldots \ldots$

EOD Pressure vs Cycle Number, Cell \#161; Cycle 20-0-20\% SOC . . . . . . . . . . . . . 4-8

EOD Pressure vs Cycle Number, Cell \# 161; Cycle 100-80-100\% SOC $\ldots \ldots \ldots \ldots \ldots \ldots$. . . . 4-8

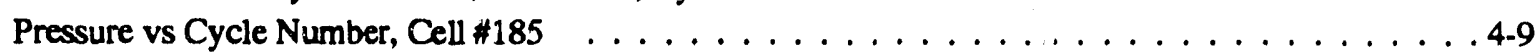

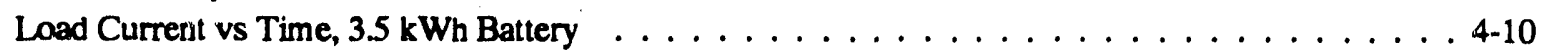

State-of-Charge vs Time, $3.5 \mathrm{kWh}$ Battery . . . . . . . . . . . . . . . . . . 4-10

Array and Load Ah vs Time, $3.5 \mathrm{kWh}$ Battery . . . . . . . . . . . . . . . . 4-11

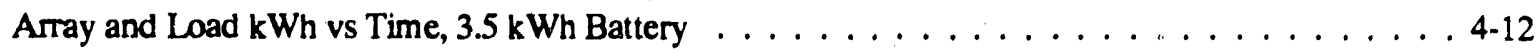

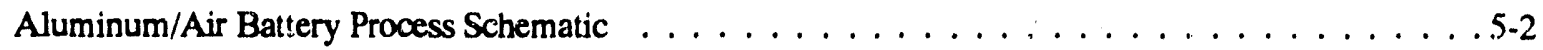

Aluminum/Air Bipolar Battery $\ldots \ldots \ldots \ldots \ldots \ldots \ldots \ldots \ldots \ldots$

Equilibrium $\mathrm{CO}_{2}$ Capacity of Soda Lime at $25^{\circ} \mathrm{C} \ldots \ldots \ldots \ldots \ldots \ldots \ldots \ldots$

Aluminum/Air Battery System SFUDS Base Case . . . . . . . . . . . . . . . 5-6

Eltech Ten Cell B-300 Tests - Test $1 \ldots \ldots \ldots \ldots \ldots \ldots \ldots \ldots \ldots$

\section{Tables}

2-1 Temperature Rise During High Current Discharge . . . . . . . . . . . . . . . . . . . 2-10

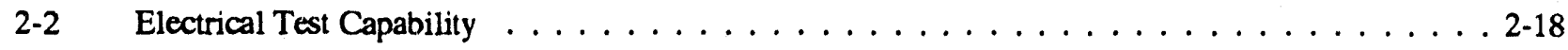

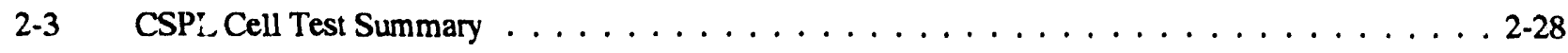

2-4 CSPL Cell Test Summary . . . . . . . . . . . . . . . . . . . . . . . . . . . . 2-29

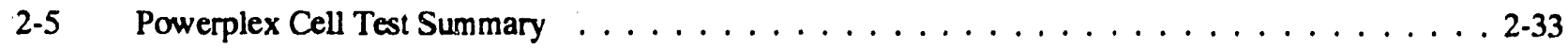

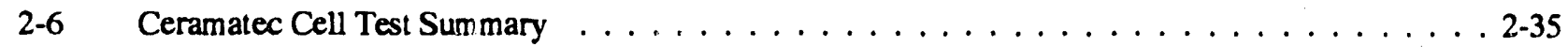

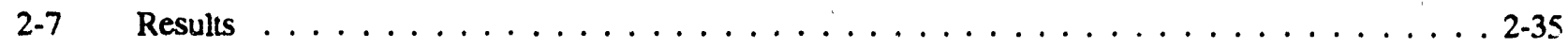

3-1 SNL Test Results for ERC Load-Leveling Zinc/Bromine Batteries . . . . . . . . . . . . . . . . 3-17

3-2 Coulombic, Energy, and Voltaic Efficiencies for Battery $481 \ldots \ldots \ldots \ldots \ldots \ldots$

3-3 Single Cell Test Results . . . . . . . . . . . . . . . . . . . . . . . . . 3-21

4-1 Negative Design Variation Cell Testing $\ldots \ldots \ldots \ldots \ldots \ldots \ldots \ldots \ldots \ldots \ldots$

4-2 Separator Material Cell Testing $\ldots \ldots \ldots \ldots \ldots \ldots \ldots \ldots \ldots \ldots \ldots \ldots$

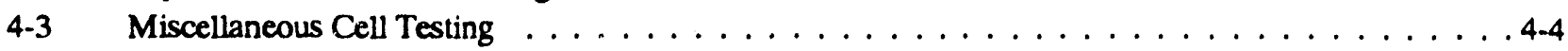

4-4 Configuration and Test Conditions $\ldots \ldots \ldots \ldots \ldots \ldots \ldots \ldots \ldots \ldots$ 


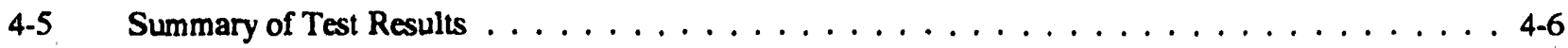

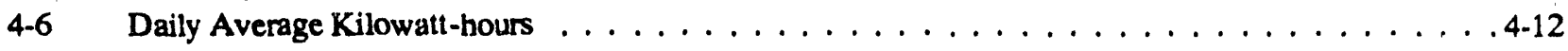

5-1 Eltech Aluminum/Air Cell Tests at SNL Cell 479 - June 30, $1989 \ldots \ldots$. . . . . . . . . . . . . . . . 5-7

$5-2 \quad$ Summary of $10-$ Cell Battery Test $1 \ldots \ldots \ldots$ 


\section{Acronyms and Abbreviations}

\begin{tabular}{|c|c|}
\hline ABS & Advanced Battery Systems \\
\hline ADL & Analysis and Diagnostic Laboratory \\
\hline ANL & Argonne National Laboratory \\
\hline AOC & alloy-on-carbon \\
\hline $\mathrm{BBC}$ & Brown, Boveri, and Cie \\
\hline BEST & Battery Energy Storage Test Facility \\
\hline BET & Brunauer, Emmett, and Teller (method for determining particle surface area) \\
\hline BSI & British Standards Institute \\
\hline COMSAT & Communications Satellite Corporation \\
\hline CPVC & chlorinated polyvinyl chloride \\
\hline CSPL & Chloride Silent Power, Ltd. \\
\hline CTE & coefficient of thermal expansion \\
\hline DCOV & discharge cut-off voltage \\
\hline DMA & dynamic mechanical analysis \\
\hline DMF & dimethylformamide \\
\hline DOD & depth-of-discharge \\
\hline DOE & Department of Energy \\
\hline DSEP & Dual Shaft Electric Propulsion Program \\
\hline EHP & Electric and Hybrid Propulsion (a branch of DOE/OTS) \\
\hline EMS & energy management system \\
\hline EPD & electrophoretic deposition \\
\hline EPI & Eagle-Picher Industries \\
\hline EPRI & Electric Power Research Institute \\
\hline ERC & Energy Research Corporation \\
\hline ETD & Exploratory Battery Technology Development and Testing Project \\
\hline ETX & Electric Transaxle Experimental Test Vehicle Pruject \\
\hline EV & electric vehicle \\
\hline FACC & Ford Aerospace and Communications Corporation \\
\hline FRP & fiber-reinforced epoxy \\
\hline $\mathrm{F} / \mathrm{T}$ & freeze/thaw \\
\hline FTIR & Fourier transform infrared analysis \\
\hline
\end{tabular}




\begin{tabular}{|c|c|}
\hline GPC & gel peimeation chromatography \\
\hline HNEI & Hawaii Natural Energy Institute \\
\hline IDSEP & improved DSEP \\
\hline IEC & ion exchange capacity \\
\hline IR & internal resistance; infrared analysis \\
\hline $\mathrm{JCI}$ & Johnson Controls, Inc. \\
\hline LL “ & load leveling \\
\hline LVDT & linear variable differential transformer \\
\hline $\mathbf{M}$ & molar \\
\hline NBTL & National Battery Test Laboratory \\
\hline NMR & nuclear magnetic resonance \\
\hline OCV & open-circuit voltage \\
\hline OESD & DOE Office of Energy Storage and Distribution \\
\hline OTS & DOE Office of Transportation Systems \\
\hline PAA & polyacrylic acid \\
\hline PASTF & Photovoltaic Advanced Systems Test Facility \\
\hline PB & designation for the standard CSPL sodium/sulfur cell \\
\hline PTA & posttest analysis \\
\hline PV & photovoltaic \\
\hline PVC & polyvinyl chloride \\
\hline PVDC & polyvinylidene chloride \\
\hline PVDF & polyvinylidene flouride, also known as Kynar \\
\hline SES & Stationary Energy Storage \\
\hline SFS & sulfonatcd polysulfone \\
\hline
\end{tabular}

SFUDS Simplified Federal Urban Driving Schedule

SNL Sandia National Laboratories

SOC state-of-charge

TD Technology Demonstration

XPB designation for an expanded-size CSPL sodium/sulfur cell 


\section{Executive Summary}

\section{Introduction}

This report documents the activities of the Exploratory Battery Technology Development and Testing (ETD) Lead Center for fiscal year 1989, ETD's ninth program year. (See SAND89-3039, Exploratory Battery Technology Development and Testing Report for 1988, for a description of the previous years activities.) The ETD Project, directed by Sandia National Laboratories (SNL), is supported by the U.S. Department of Energy, Offict of Energy Systems Research, Energy Storage and Distribution Division (DOE/OESD). This project is operated in conjunction with the Technology Base Research (TBR) Project, under the direction of Lawrence Berkeley Laboratory. Together, the ETD and TBR projects seek to establish the scientific feasibility of advanced electrochemical energy storage systems and to conduct the initial el:gineering development on systems suitable for mobile and stationary applications in the commercial sector.

The ETD Project is responsible for the engineering development of electrochemical couples whose feasibility has been demonstrated either by the TBR Project or other technically sound investigations. Upon mature development, these systems will be incorporated into batteries for use in electric and hybrid vehicles, electric utility/industrial energy storage, and photovoltaic and wind-based electricity generating systems. Battery development is accomplished through cost-sharing contracts with industrial partners. SNL is responsible for the technical direction of the development contracts and lead center project management. Additionally, SNL conducts various applied-research activities that support the development of the basic technology. Testing and analysis of the resulting batteries or components are performed either at SNL or at Argonne National Laboratory (ANL). SNL also undertakes a variety of battery cost-and-performance studies and analyses in connection with the ETD Project.

The ETD Lead Center is directed by Dr. Nicholas J. Magnani, Manager of SNL's Power Sources Department. Lead Center operations are managed by $\mathrm{Dr}$. Ronald B. Diegle, Supervisor of SNL's Storage Batteries Division.

During the 1989 fiscal year, the ETD Project focussed on the development of four advanced secondary battery technologies:
- $\quad$ sodium/sulfur

- zinc/bromine

- nickel/hydrogen

- aluminum/air.

Supporting elements include Budget and Project Analysis and Planning. Each element is supported by one or more staff members who are responsible for activities within that element.

The organization of the ETD project for 1989 is illustrated in Figure 1-1. Its technical work is divided into three elements.

- Battery Technology Development

- Battery Technology Evaluation

- Battery Technology Improvement

The objectives of each element follow.

Battery Technology Development. The objective is to further the engineering-level development of advanced secondary batteries. Many different basic types of technologies (e.g., aqueous, high-temperature) are being pursued because of the recognition that each has significant advantages and disadvantages compared to the others. In the final analysis, these batteries must have the technical performance and economic and environmental characteristics to meet the diverse requirements of stationary energy-storage and/or mobile applications.

Battery Technology Evaluation. This element evaluates advanced secondary cells, modules, and batteries from developers working under ETD contracts. Performance and operating characteristics, as well as cycle life and failure modes, are determined and used to improve the design of all battery technologies.

Battery Technology Improvement. In this element, specific problems encountered during the development of advanced secondary batteries are investigated and solved. These studies are normally performed at SNL. Individual tasks are selected and continued based on the following criteria:

1) the prime contractor does not have the adequate resources to address the problem, 


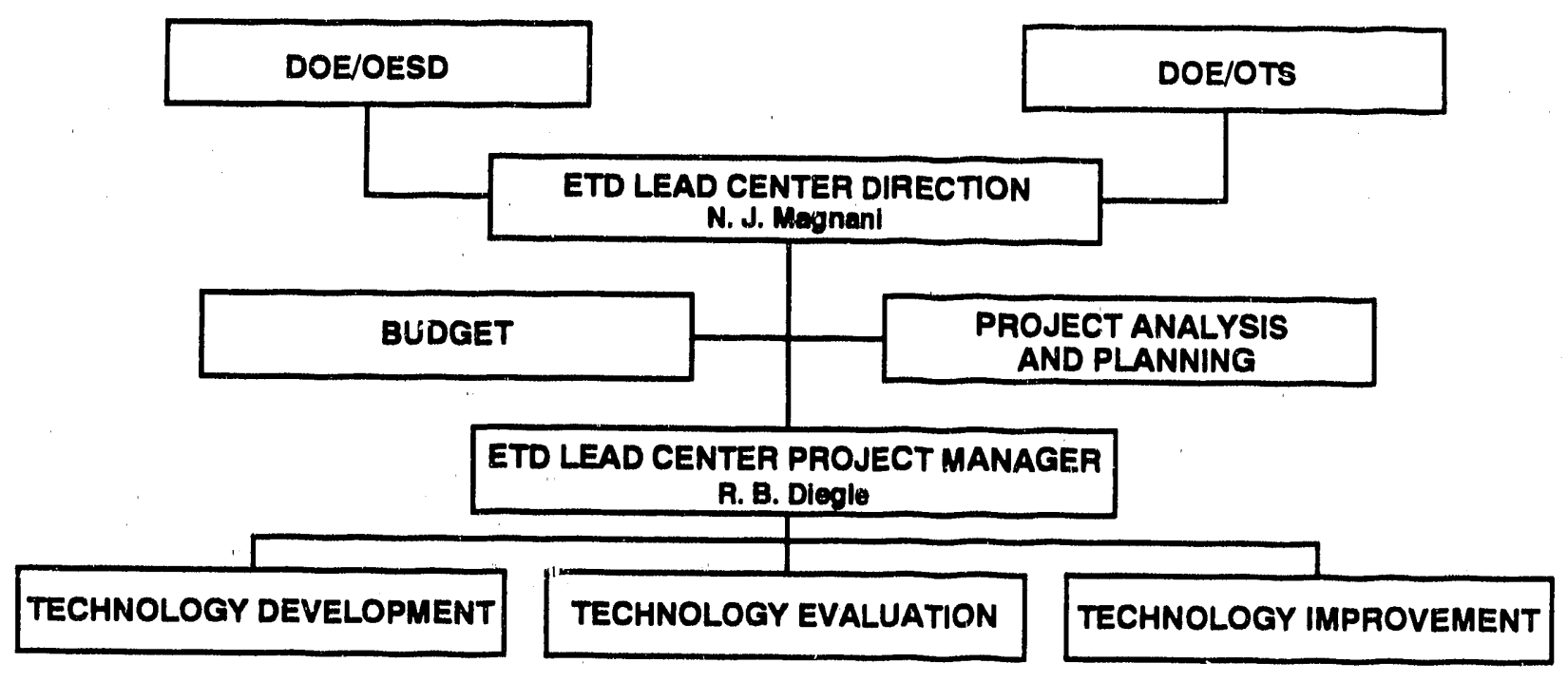

Figure 1-1. 1989 ETD Project Organization

2) the solution to the problem is important to the continued development of the technology, and

3) resources are available at SNL to allow a timely contribution.

During FY89, five tasks were being performed within this element. The first three focus on improving the reliability of sodium/sulfur cells and the other two are related to material developments that support the zinc/bromine technology.

A summary of the highlights of the ETD Project, organized by technology, follows. More detailed information on each of the four technologies is contained in Chapters 2 thrugh 5 of this report.

\section{Sodium/Sulfur Technology}

\section{Technology Development}

The end of FY89 marked the conclusion of the fourth year of a contract with Chloride Silent Power, Ltd. (CSPL) to further the generic development of the sodium/sulfur technology and to perform initial battery engineering for stationary-energy-storage (SES) applications. The important activities performed by CSPL during the year can be divided into the following categories: (1) the completion of the redesign and qualification of their small, $10 \mathrm{Ah}$, "PB" cell (designated the MkIII SF), (2) the design of a new PB cell that is more suitable for automated production (MkIV), (3) the transfer of the developed MkIII SF technology to the larger, $30 \mathrm{Ah}$, "XPB" cell design, and (4) the design of a first-generation 200-cell stationaryenergy-storage (SES) module.

The following significant accomplishments were made relative to these activities:

- Improvements made under this program in cell/module performance and process automation provided the basis for the commitment by the CSPL sponsors (Chlnrid, Group PLC and the U.K. Electricity Council) to begin construction of the first sodium/sulfur pilot production plant. This facility is being located at Chloride's Clifton Junction lead-acid battery plant and will be on-line in May 1990. Its 1shift/day capacity is 5,000 cells/week and it will provide sufficient cells to allow serious battery engineering and evaluations to be performer.

- Due to several problems related to cell performance, safety and reliability that were encountered during FY88, a number of design changes were implemented and qualified in the baseline PB sodium/suifur cell technology. The new cell design is designated as the MkIII SF. Documented improvements included the following:

- The safety performance of the cell dramatically increased. Safety testing showed that a probability of only 0.0001 exists that a cell will reach $450^{\circ} \mathrm{C}$ when catastrophically failed, a result considerably better than program goals. No cell breaches have been 
observed for over two years during either regular life-cycle testing or even with mechanical and thermal-shock abuse testing.

- Capacity retention remains excellent at 80 to $85 \%$ of theoretical. Additionally, this level has now been demonstrated to 1,000 cycles compared previously to 500 cycles.

- Cell resistance decreased from an average of 35 mohms to 32 mohms. This reduction may have a very significant effect in that it could eliminate the need for an active thermal management system in EV batteries and, if applicable to larger cells, possibly in SES systems.

- The freeze/thaw (F/T) durability of the cell was demonstrated to be excellent with the completion of $640 \mathrm{~F} / \mathrm{T}$ cycles on a single cell (up from 147 cycles). The average number of cycles prior to failure was determined to be 435 .

- The recent successful introduction of several additional design modifications (MkIV) that were all qualified separately showed that the understanding of production processes and cell operation is now sufficient that significant redesign can now be implemented without a major new development effort. The changes involved both components and the fabrication process itself (primarily the sodium seal, the sodium safety can, and the sulfur electrode).

- The development of an SES battery technology was initiated with the design of a 200-cell "XPB" module and the fabrication and evaluation of a 16-cell "XPB" module. The thermal, electrical, and safely performance of this module has been excellent for over $200+$ cycles. Fabrication of the 200-cell module will commence near the beginning of 1990 .

- Analyses performed under a subcontract with SAIC identified the effects of string length on battery reliability and performance. The modelling showed that cell failures in seriesstring batteries lead to substantial current imbalances between strings during charge and discharge.

\section{Technology Evaluation}

Life cycle testing of a CSPL 24-cell sodium/sulfur module (6 parallel-strings of 4 series-connected celis) was terminated in July 1989 at the request of CSPL and SNL. The module retained $-84 \%$ of its initial $52-\mathrm{Ah}$ (403-Wh) capacity after accruing a total of 339 cycles. A capacity decline of $-0.08 \%$ /cycle was exhibited during the last 200 life cycles. At this rate, a module life ( $80 \%$ of initial capacity) of -420 cycles was projected. "The module has been returned to CSPL.

Performance characterization tests were initiated on a new CSPL 24-cell module (safety cell design) in August 1989. During the following month, these tests were completed and cycle-life studies started. Life testing was halted after 108 cycles due to an abrupt loss of capacity. The module atiained a maximum capacity of 62.5 Ah (473 Wh).

A detailed posttest analysis was performed on a first-generation CSPL "XPB" cell at ANL during FY89. These studies characterized morphological changes in the sulfur electrode, and assessed the performance of other hardware components. Overall, this examination confirmed that the recent design changes provided benefits in cell performance as well as cell safety. The sodium wick promoted low resistance by providing excellent wicking action for maximized usage of the electrolyte surface. The deficiencies noted for this cell stemmed from the externporized changes in this early development cell. The two-piece case construction impaired the quality of the chromized coating and the use of the older MkIIA seal led to the accumulation of corrosion products on the outer electrolyte surface. Completing the transition to the newer design should eliminate these problems.

\section{Technology Improvement}

\section{Analysis of Electrolyte Degradation}

In an earlier analysis of failures of beta"-alumina electrolytes from CSPL cells, fractographic evidence indicated that a compressive stress layer present on the surface may have influenced the electrolytic degradation of the electrolyte. This study is intended to investigate the effect of stress on degradation and try to determine how the compressive stress layer might have been generated. During FY89, activity focused mainly on two specific aspects. the fabrication of a model material with a thin compressive layer on the surface and the evaluation of the potential for moisture to induce residual stresses.

The model material was fabricated as a sandwich composite consisting of a layer of beta"-alumina containing 10 vol\% partially stabilized zirconia between layers of beta"-alumina containing 10 vol\% unstabilized 
zirconia. The technique was success ful in that the calculated and measured strain values were in agrcement. The surface stress was approximately $140 \mathrm{MPa}$. Electrolytic crack growth rate studies are currently in progress.

To evaluate the potential effect of moisture, beta"alumina was reacted with water (using $100 \% \mathrm{RH}$ atmosphere) and the strain in the sample monitored. Results showed that very little stress is generated in the beta". alumina by this reaction.

\section{Component Stress During F/T Cycling}

This task is being performed to provide developers with the unders.anding and methodology to improve the $\mathrm{F} / \mathrm{T}$ durability of their sodium/sulfur cells. In FY88, the feasibility and usefulness of mathematically mocieling the processes occurring in sodiur./suls!r! ceils during F/T cycling was demcnstrated. During FY89, the materials-behavior models were refined to enable calculations to be consistent with experimental strain measurements and the measurement of the physical properties of sodium polysulfide/graphite composites was completed.

As an aid to develop information concerning the positive-electrode maierials, an analytical (non-numerical) solution to the governing stress and strain equations was derived and its accuracy verified. Several numerical simulations were then performed to calculate bounding values of the coefficient of thermal expansion (CTE) for a soujium tetrasuliide/graphite composite. The calculated CTE values are slightly higher than those measured directly for pure and composite sodium polysulfide samples.

The physical property measurements on sodium tetrasulfide/graphite composite samples were also completed. Thermal-Mechanical-Analysis (TMA) was used to determine CTE values and the elastic moduli were measured with the Dynamic-Mechanical-Analysis (DMA) technique. The elastic modulus is not very temperature dependent and not significantly different than the value that was assumed in the modeling calculations (5 GPa). Similarly, the CTE values for a cast composite and a sample extracted from a CSPL cell also have little temperature dependence.

\section{Improved Chromium Platings}

One of the promising materials to use to impart significant corrosion protection to a sodium/sulfur cell container is chromium. The objective of this task is to improve chromium electroplating techniques when applied to the fabrication of sodium/sulfur cells.
During FY89, the initial screening of potential plating tectiniques was completed. In this activity, the effect of three different elcctrolyte compositions on deposit quality and performance was studied. These electrolytes included (1) a standard chromium. oxide/sulfuric acid electrolyte suitable for use with pulse and pulse-reverse platines techniques, (2) a commercial electroiyte formulation that produces crack-free deposits that was modified by adding vanadium pentaoxide, and (3) a second commercial electrolyte that produces highly cracked deposits.

Encouraging results were obtained with the vanadium pentaoxide-modified commercial electrolyte that produces crack-free deposits. Analysis of the plating quality showed no cracking, to co-deposition of vanadium, and the stress in the deposit reduced to 300 psi compressive. Similar electroplated cell containers were given a proprietary thermal treatment at CSPL and then fabricated into actual cells. Results from post-mortem analysis of these celis following cycling showed that the performance of the treated electroplate is superior to that achieved with cells having a thermal chromized layer.

\section{Zinc/Bromine Technoiogy}

\section{Technology Development}

\section{FY89 Highlighte - ERC}

A system design effort was completed which included the development of a comprehensive engin ring design for a $36 \mathrm{kWh}$ proof-of-concept battery. The design utilized two $18 \mathrm{kWh} 52$-cell stacks $\left(1,500 \mathrm{~cm}^{2}\right.$ electrode area) in a common flowsystem. The entire system is contained in an enclosure with capabilities for vapor containment and containment of a spill from both electrolyte tanks. Because the $1,500 \mathrm{~cm}^{2}$ frame design was implemented late in the program, the $36 \mathrm{kWh}$ system was not built. The completed design, along with the strategies evolved for sysiem control and the safety design, can be used in the future for fabrication of 36 $\mathrm{kWh}$ systems or as a starting point for the design of larger modules. Battery tests conducted in 1989 included the continued cycle testing of one five-cell stack and one 30-cell stack, using the $872 \mathrm{~cm}^{2}$ flow frame hardware. These tests are continuing, with the stacks having logged up to 400 cycles so far. Testing was also initiated on the first $1,500 \mathrm{cril}^{2} 52$-cell stack. In addition to demonstrating system performance and life capabilities, the stack tests have been used to evaluate 
imiprovements to hardware and system instrumentation and control issues.

Material stability studies conducted in 1989 included the continuation of the expanded stability test program for candidate battery materials. These studies followed a series of screening studies that evaluated several different plastics. The new tests focus on the most promising mate $c_{1}$ als identified in the screening tests, looking at fewer materials in more detail. The plastics currently on test are all polyvinyl chloride (PVC) injection molding resins. A simuar test is being conducted on separator and gasket materials.

\section{FY89 Highlights - JCl}

A battery based on the Exxon design (Z20-LL), tujlt with polypropylene electrodes and Daramic separators, was decomissioned in 1989. Z20-LL achieved a total of 182 cycles with an average coulombi: etticiency of $79 \%$ and an average energy efficiency of $60 \%$. The cause of failure was an external short near a terminal of one of the stacks. Gradual leakage of electrolyte breached a protective coating on one of the stack bolts, and formed an external conduction path. An analysis of energy losses to subsystems showed that shunt current losses were approximately $0.7 \%$, based on total system input energy. Pumping losses were approximately $18 \%$, using the same basis. The pumps were oversized for the application, and were unnecessarily run 24 hours a day. By downsizing the pumps and periodically turning them off during stripping, pumping, losses could be cut by a factor of four.

Polyvinylidene fluoride (PVDF) based electrode plastic was tested for expansion in bromine vapor. The initial expansion was very low, and gradually increased to about the half the rate of extruded glass-reinforced polyethylene electrodes. Additional tests with polyethylene electrodes reinforced with very high levels of long glass fiber have exhibited less expansion than PVDF electrodes.

An 8-cell battery (Z1-51), made with improved separator and electrodes and cycled with load-levelling type electrolyte, attained 415 cycles. Before the performance started to gradually decline around cycle 300 , the coulombic and energy efficiencies had averaged about $87 \%$ and $70 \%$ respectively. The battery degradation was caused by a flow system valve failure and was not due to a battery stack failut 2.

\section{Technology Evaluation}

Three zinc/bromine batteries from ERC were evaluated at SNL during FY89. Two of these batteries had an electrode area of $872 \mathrm{~cm}^{2}$ and completed approximately 100 cycles before they were removed from test. Failure of these was due to an enlarged gasket which partially blocked the electrode flow channels for certain cells. The third battery on test had an electrode area of $1,500 \mathrm{~cm}^{2}$. This battery completed only 52 cycles before it was removed from test due to declining performance.

\section{Technology Improvement}

Post-mortem analysis of a $1 \mathrm{ft}^{2}$ ERC flow frame by modulus profiling has indicated that chemical degradation by the electrolyte was minimal after 100 charge-discharge cycles. However, madulus profiling has shown that a wide variation of mechanical properties within the flow frame exist. The variation may be attributed to process related factors that occur during molding.

Accelerated aging studies have shown that Tefzel, a DuPont material made of $1 / 1$ copolymer of ethylene and tetrafluoroethylene, is more stable than PVC toward bromine-containing electrolytes.

Single cell tests with Daramic separators treated with sulfonated polysulfone (SPS) had coulombic efficiencies increased from 84 to $93 \%$ during cycles that did not follow complete zinc stripping. However, the coulombic efficiency of a cycle following a complete zinc strip was lower with the SPS treated Daramic in comparison to the untreated Daramic separator.

A favorable resistivity-bromine transport tradeoff was achieved with a composite membrane made by impregnating a microporous separator, Asahi SF -400 , with a relatively small amount $(2 \%)$ of a soluble perfluorsulfonate ionomer (Nafion).

It was found that Nafion treated membranes were not stained by bromine. This observation is consistent with the low bromine permeation rates observed in laboratory screening tests.

\section{Nickel/HydrogenTechnology}

\section{Technology Development}

The primary goal of the core technology development effort is to reduce battery component cost without compromising performance. Ongoing efforts have focussed on the negative electrode which represents over $30 \%$ of the battery cost. Several approaches to reducing electrode cost were identified and part of the 
technology development effort in FY89 was devoted to the demonstration of the performance of these improvements in laboratory test cells.

Environmental concerns regarding the use of fuel cell grade asbestos as the separator material prompted the effort to find a replacement for it. Several promising materials from various suppliers, including material from Celanese, Gelman and RAI were selected and these progressed to the miniature cell testing stage. The RAI material looks particula.ly promising and has outperformed the original asbestos in early cycling tests.

Development of the pressure vessel has been focussed on a vessel consisting of a fiber/epoxy winding around a metal shell. The continuous fiber winding provides the required strength, while the metal shell acts as a hydrogen barrier. A burst pressure of over 2,000 psi was demonstrated, easily exceeding the required 5-to-1 safety factor. An alternative design with a plastic liner was temporarily discarded due to difficulties encountered in bonding the end domes and cylinder to form the liner.

Due to the continuing success of the program, the technical effort under contract $57-4683$ has been extended through June 30,1990 . The extension includes the development of a detailed paper design for a 40-100 $\mathrm{kWh}$ battery intended as a system building block for remute village and other errestrial applications.

Original plans for the delivery of the four $2 \mathrm{kWh}$ batteries to SNL have brien revised due to the opportunity to test them outside of the laboratory. Two of these batteries will be delivered and tested at the South- west Residential Experiment Station (SWRES) in Las Cruces, NM, and the other two batteries will be tested at the Southeast Residential Experiement Station (SERES) in Cape Canaveral, FL. Both sets of batteries will be delivered in early 1990 and coupled to existing photovoltaic arrays for testing.

\section{Aluminum/Air Technology}

\section{Technology Development}

A 12-volt, 10-cell, battery based on the B-300 was fabricated, assembled, and operated. The battery displayed stable performance with uniform metal dissolution within each of the cells, indicating that the distribution of electrolyte and air was satisfactory. It is evident that the weight and volume of the battery were to large to be considered viable for an electric vehicle. An independent Eltech program has developed a smaller, sealed cell with dissolution from both sides for the aluminum anode.

The performance of the air cathode in the alkaline electrolyte is sensitive to the presence of carbon dioxide in the air feed stream. Various technologies to absorb carbon dioxide were evaluated. In terms of weight and cost, the use of soda lime was clearly preferred.

A material and energy balance study was initiated with the objective to generate material and energy balances, process flow diagrams, and perform system analyses for the aluminum/air system. 


\section{Sodium/Sulfur Technology}

The sodium/sulfur technology is one of the leading candidates for large-scale mobile and stationary-energystorage applications because of its potential for low cost, excellent performance (e.g., energy and power density, electrical efficiency), long life, and reliable operation. During FY89, advancement of this technology continued under ETD Project support. The primary development effort was performed under a contract with Chloride Silent Power, Ltd. (CSPL), Runcorn, Engiand. Additionally the performance of their technology was evaluated at $\mathrm{SNL}$ and $\mathrm{ANL}$ and several activities that directly supported the improvement of the CSPL technology were conducted at SNL. FY89 accomplishments in each of these areas are reported separately in the following three sections.

\section{Technology Development}

A three-year contract with CSPL was placed in September 1985 to advance the development state of the technology with respect to components, cells, and small batteries for both stationary and mobile applications. Overall, CSPL is cost-sharing $35 \%$ of this $\$ 9.2 \mathrm{M}$ effort. The final deliverables from the program include qualified cells suitable for use in both mobile and stationary applications and a subscale battery module (200 ceils) that will be evaluated in a stationary-energystorage (SES) mode.

The DOE-funded program at CSPL was intended to complement a parallel effort sponsored by the Electric Power Research Institute (EPRI). The objective of the EPRI contract was to design and construct a $500-\mathrm{kWh}$ sodium/sulfur battery for evaluation in the BEST facility. The EPRI contract was effective in December 1985 , but was substantially reduced in content during February 1986. At that time, plans to construct the 500$\mathrm{KWh}$ battery were deferred. Because of the EPRI action, the DOE/ETD program at CSPL was extended by one year to reduce the annual program costs and to allow the statement-of-work and the contract deliverables to be appropriately adjusted. Subsequently, a \$1.5M 1-year extension to this contract became effective during the first quarter of FY90. During this final year, the design, development and qualification of the "XPB-cell" technology and the refinement of the conceptual design of a SES battery is to be completed. This effort will provide the needed solid foundation for initiating the first major SES battery-engineering development program.

The activity at CSPL is divided into the following two tasks:

Task 1 - Core Technology Research and Development

Task 2 - Battery Engineering and Testing

Task 1 is devoted to research and development in the areas that are generic to both stationary and electric vehicle applications. Major emphasis of the program are improving cell performance, reliability, safety and cost. The following subtasks are part of Task 1:

Subtask 1.1. - Electrolyte Research and Development

Subtask 1.2. - Materials Development and Qualification

Subtask 1.3. - Cell Development

Subtask 1.4. - Cell Testing and Posttest Analysis

Subtask 1.5. - Module Development and Testing

The Task 2 effort is directed towards the design and fabrication of batteries for SES applications. A substantial part of the program is subcontracted to Science Applications International Corporation (SAIC). A description of the results from the CSPL and the supporting SAIC programs is contained in the remainder of this section.

\section{Background}

The CSPL sodium/sulfur cell design strategy is based on a family of cells designated the "PB" cells. Two specific sizes are currently being developed, a 45 $\mathrm{mm}$ diameter by $45 \mathrm{~mm}$ high cell called the "PB" cell and a $45 \mathrm{~mm}$ diameter by $110 \mathrm{~mm}$ high cell, called the "extended PB or XPB" cell. The cells are both central sodium designs and are based on identical components as far as possible, particularly in the seals.

The XPB has been proposed for stationary applications and the PB for electric vehicle (EV) applications, although it is the intention to develop generic technology. This generic technology will enable the commercialization of optimized cell designs that are close in size to those for which a performance database has been 
established. Selection of optimum cell size for any application is a complex issue that involves interactions with battery voltage, capacity, cell reliability, physical dimensions of the battery, and cost.

CSPL has a long term technology database from their evaluation of two earlier, central sulfur cells: 150 Ah NaS7 and 30-Ah TD cells. These designs have now been tested for up to 7,100 deep discharge cycles. The longest lived operating cell has completed more than 60,000 hours on test ( 6.75 years). The longest lived $P B$ cell has completed 1,900 cycles and the longest lived XPB cell has completed 1,400 cycles. Several networks of PB cells have exceeded 500 charge/discharge cycles.

During 1987, the production capability of PB cells was increased to 350 per week. A substantial proportion of the output was used in the construction of a battery for a Bedford CF delivery van. This vehicle was powered for more than 100 miles on the second battery discharge and added considerably to CSPL's experience in terms of road trials, cell production and design. During the evaluation, deficiencies in the cell and battery were observed and modifications were made and qualified during 1988. These improvements were embodied in a sub-battery designed and fabricated under a complementary DOE/OTS funded program with CSPL (EV Battery Engineering). This sub-battery was tested at ANL and completed 241 electrical cycles. Following this test, another EV battery was built and delivered (Nov. 89) under a separate, non-DOE contract, to Electrotek Concepts Inc. for testing on their track at Chattanooga, 'TN. This battery has already successfully powered a GM Griffon van for more than 1,300 miles.

A significant milestone for CSPL was reached in 1988 when approval was given for the construction of a pilot production facility at Chloride Industrial Batteries' Clifton Plant near Manchester, U.K. This facility has been designed for an initial production rate of 5,000 cells per week (one shift/day) of either the PB or XPB design. The output will be used in the construction of batteries for extensive field trials. At the time of writing, construction of the facility was well advanced.

Finally, a significant effort commenced during 1989 to transfer the CSPL technology to their U.S. subsidiary, Beta Power Inc. This transfer is being accomplished by means of a phased schedule in which parts of the manufacturing processes are introduced into the Beta Power operation at Salt Lake City, Utah. Beta Power will then have the ability to manufacture cells (and ultimately batteries) using the CSPL technology.

For reference when reading the remainder of this section, some background on the various modifications of the PR cell that have existed will be useful. The PB cell has undergone a variety of design changes since the idea of using small cells was conceived in June 1981. The metal-to-ceramic seal component is of critical impcitance to the satisfactory life and performance of any sodium/sulfur cell. Many of the cell variations have been designated according to the seal type employed. Two basic seal concepts have been studied at CSPL: a direct metal-to-ceramic bonded seal (designated MkII) and one employing an aluminium interstrate between a chromised steel component and the alpha-alumina header (Mkl). In 1986, a hybrid of the two seal concepts was selected for further development and designated the MkIII. This design, which was being progressed under this program, then became the mainstream design of all CSPL's efforts.

A major advance in the $\mathrm{PB}$ cell technology involved the incorporation of a closed end tube in the sodium electrode (a component added to improve the safety performance of the cell). This variation came to be known as the MkIII SF. The suffix "SF" was added in order to differentiate it from the MkIII cell without this feature, the latter referred to as the MkIII NSF. The MkIII SF became the production standard in 1988 and the majority of cells were made to this design.

While the production of batteries that used the MkIIl SF cell was ongoing, further analysis was being conducted by the CSPL engineering teams to assess the manufacture of PB cells at high production rates. As a result of this analysis, the MkIV cell concept was developed. This design represents the status of the CSPL program at mid-1989 and is intended for the initial output of the Clifton Production Facility.

\section{Task 1 - Core Technology Research and Development}

\section{Subtask 1.1. Electrolyte Research and Development}

The emphasis of the electrolyte subtask changed in 1989 as the core development was essentially complete. The effort was transferred to the work required for the upcoming larger scale manufacture in the Clifton Production Facility. This latter effort was funded by CSPL. The year was characterized by a continued improvement in output culminating in the highest output ever in the quarter July-September 1989. A total of 5,765 grade 1 PB electrolytes were fabricated. The output of PB electrolyte and the yield of grade 1 shapes is shown in Figure 2-1. 


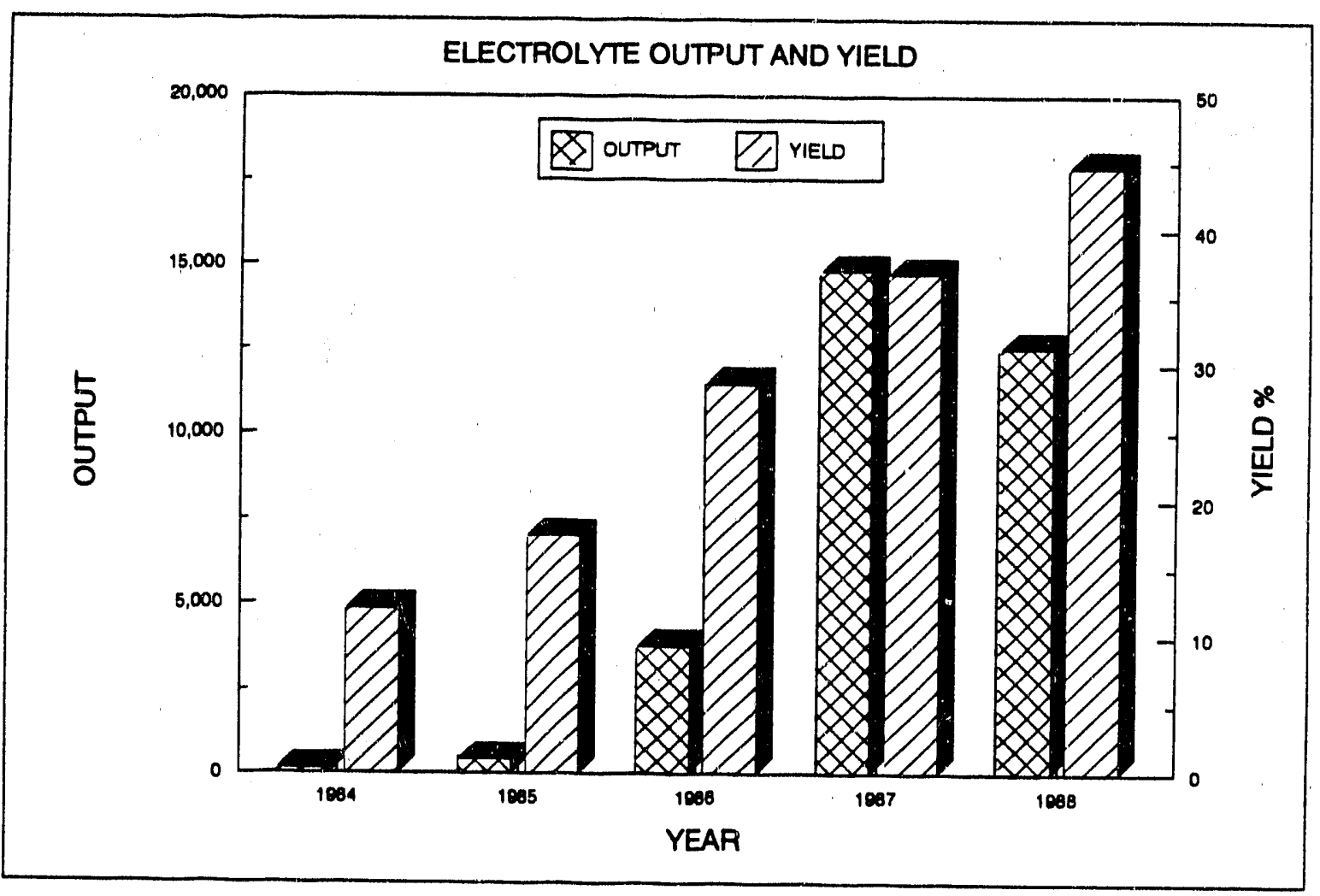

Figure 2-1. Yield and Output of PB Electrolytes

\section{Zirconia Toughening}

A group of cells containing beta"-alumina electrolytes toughened by the addition of zirconia com. menced test before the start of the DOE/ETD contract. A failure occurred in a cell containing a non-optimized zirconia addition in 1986 at 949 cycles (ETD Annual Report for 1986, page 47). Since that time the cells have continued to cycle and have been supplemented by the storage experiment described in ETD Report for 1987 (page 58). The total population became 20 with the additional cells that are all of the $30 \mathrm{Ah}$, central sulfur, TD cell design. A cell failed in 1988 at 3,383 cycles and another failed in early 1989 at 3,005 cycles. The longest running cells have exceeded 4,800 cycles and the accumulated cell-cycles are 71,600 (i.e., more than 3,500 per cell average). With so few failures after 4.6 years of testing, it is still not possible to compute meaningful Weibull statistics although the eventual values will be in excess of any produced by cells containing non-zirconia electrolytes.

\section{XPB Elc trolyte Manufacture}

In order to address the needs of the DOE/ETD contract and also to take account of CSPL's desire to effect cost savings via a larger cell, the capabilities of XPB electrolyte production were scaled up during 1989. A significant effort was devoted to the automation of the electrophoretic deposition (EPD) process on a parallel CSPL-funded production engineering program. The technologies developed were transferred to the 4-chamber EPD rig. XPB electrolytes are now made by a fully automated process that includes control of the deposition and green shape extraction. The processes are significant advances on the previous manual methods, improving both quality and yield. To increase the output still further, modifications have been made to the 12-chamber production rig so that it can produce XPB electrolytes. The rig can be converted once the production of PB electrolytes is moved onto the 24chamber units intended for the pilot production facility. XPB shapes awaiting automatic extraction are shown in Figure 2-2.

\section{Subtask 1.2. Materials Development And Quallfication}

The major objective of this subtask is to qualify cost effective candidate materials for cell and system design. The subtask includes the following activities: alphaalumina to beta"-alumina glass seal development, alphaalumina ceramic-to-metal seal development, sulfur 


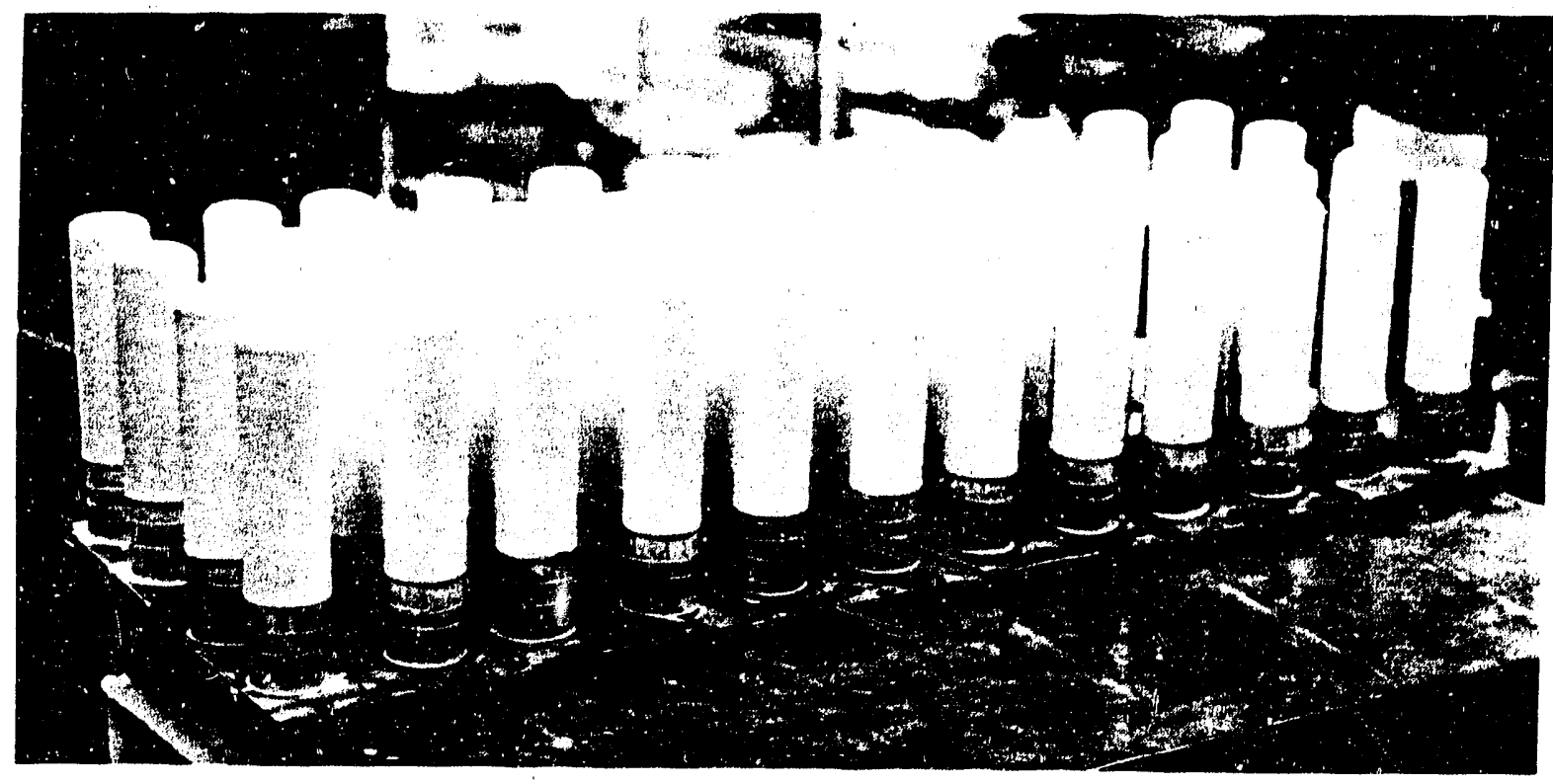

Figure 2-2. XPB Electrolyte Production

electrode and sodium electrode design, and improvement of sulfur electrode containment.

A materials performance database had been established before the start of this program. This was based on CSPL's NaS7 and TD cell designs that contain materials and materials combinations pertinent to the present PB family of cells as stated earlier. This database matured to over 7,000 electrical cycles during 1989 , approaching 7 years of operation.

\section{Alpha-Alumina to Beta"-Alumina Glass Seals}

A glass joint is used to hermetically seal the alphaalumina seal header to the beta"-alumina electrolyte. CSPL's longest lived cell contains a barium aluminoborate glass modified with silica in a TD type of cell. The cell contains two glass seals, one at each end of the electrolyte and it had completed 7,118 deep discharge cycles to 1.76 volts open circuit ( $V o c$ ) in 59,784 hours (6 years, 9 months) at the time of writing. The present composition, employed in all standard production cells, is also an aluminoborosilicate glass. This has been tested for 6,239 cycles in 52,368 hours.

The incorporation of the safety tube in the sodium electrode of the PB cell necessitated changes to the glazing procedures employed to join the beta"-alumina electrolyte to the alpha-alumina header. Testing of two different procedures commenced in 1988 and these experiments matured in 1989. Significant differences were detected in both the cell life statistics and microstructural quality of the joints. The lifetimes of the intermediate deliverable battery for the EV Battery Development program, a 24-cell module for test at ANL, and cells tested at SNL were all affected by the glass joint quality. Failure of this component was shown by posttest analysis to be the dominant mode of failure. Comparison of cell life statistics on a population of more than 300 cells from a variety of experiments indicated considerable consistency in cell lifetimes, governed principally by the glazing process employed. As a result of the statistical analysis and parametric studies conducted during the diagnostic investigations, an improved specification of glass joint and glazing procedure was implemented during 1989. The performance of one of the groups of cells is described in the section on Subtask 1.3 (see Figure 2-12). The study siguificantly advanced CSPL's knowledge of the glazing technology and the discovery of some unexpected interactions led to yet further refinements.

\section{Metal to Alpha-Alumina Seals}

As part of the development of the MkIV cell concept (described in more detail in Subtask 1.3), a group of cells was constructed with the MkJV st $\rfloor$ le of ceramic to metal seal. This forerunner group of 14 cells completed 11,769 cumulative cell cycles, with three failures at 387,796 and 1,042 cycles. Resistance and capacity behavior throughout the test are shown in Figure 2-3. 

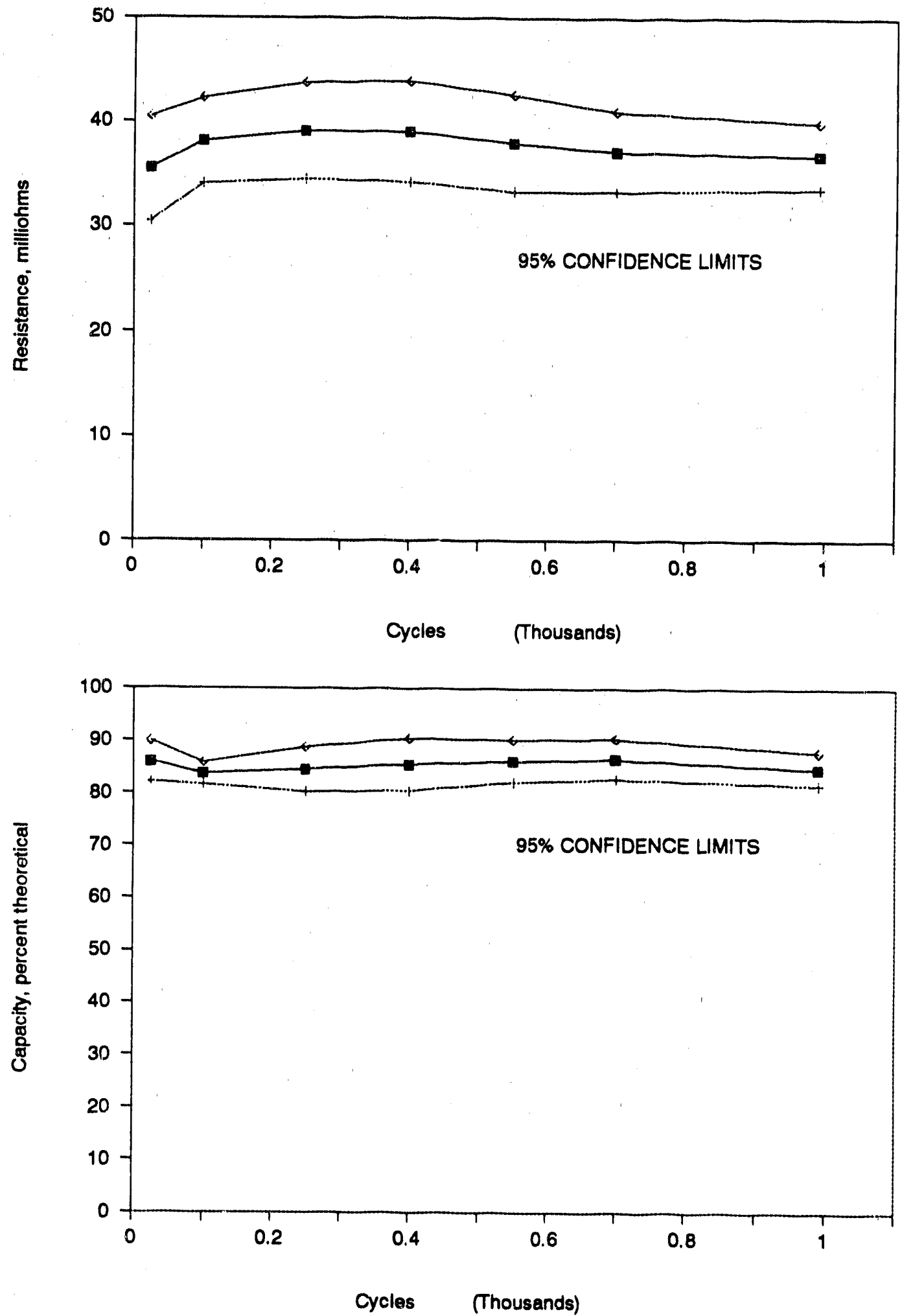

Figure 2-3. Performance of Cells witt MkIV Type Sodium Electrode Seals 
Seven cells remained on test at 1,180 cycles. Their mean cell capacity was $85 \%$ of theoretical and the mean resistance was 36.7 mohm. This performance is similar to that observed in cells with MkII sodium electrode seals.

\section{Sulfur Electrode}

Studies of the recharge performance of the CSPL sulfur electrode were continued during 1989. In a parallel program of work, significant diagnostic analysis enabled the construction of sulfur electrodes by a high speed method suitable for use in the automated Clifton Production Facility. For this program, efforts were concentrated on the more fundamental aspects of recharge performance. Recharge polarization occurs in the two phase region of operation of the sulfur electrode when the rate of formation of elemental sulfur exceeds the rate of removal from the reaction sitc. There must be, therefore, a critical current density beyond which recharge polarization occurs. This critical current density was determined by cyclic amperometry. This technique is similar to the more familiar technique of cyclic voltammetry, the only difference being that current rather than voltage is varied as a linear function of time. This method is preferred as knowledge of the critical current density is more useful in the context of battery performance than critical overpotential.

The critical current density for a selection of cells was determined by the following procedure. The cells were first discharged to $56 \%$ depth of discharge, i.e., to the boundary of the two-phase region of operation of the sulfur electrode, where polarization is known to be the most severe. The cells were then subjected to three cycles of a triangular galvanostatically controlled waveform of amplitude 20 amps. These experiments were repeated for a range of frequencies and at vartious charge states within the two phase region.

Figure 2-4 shows a typical cyclic amperommagram. The change in slope of the anodic portion of the wave

\section{CYCLIC AMPEROMETRY: CELL 10269}

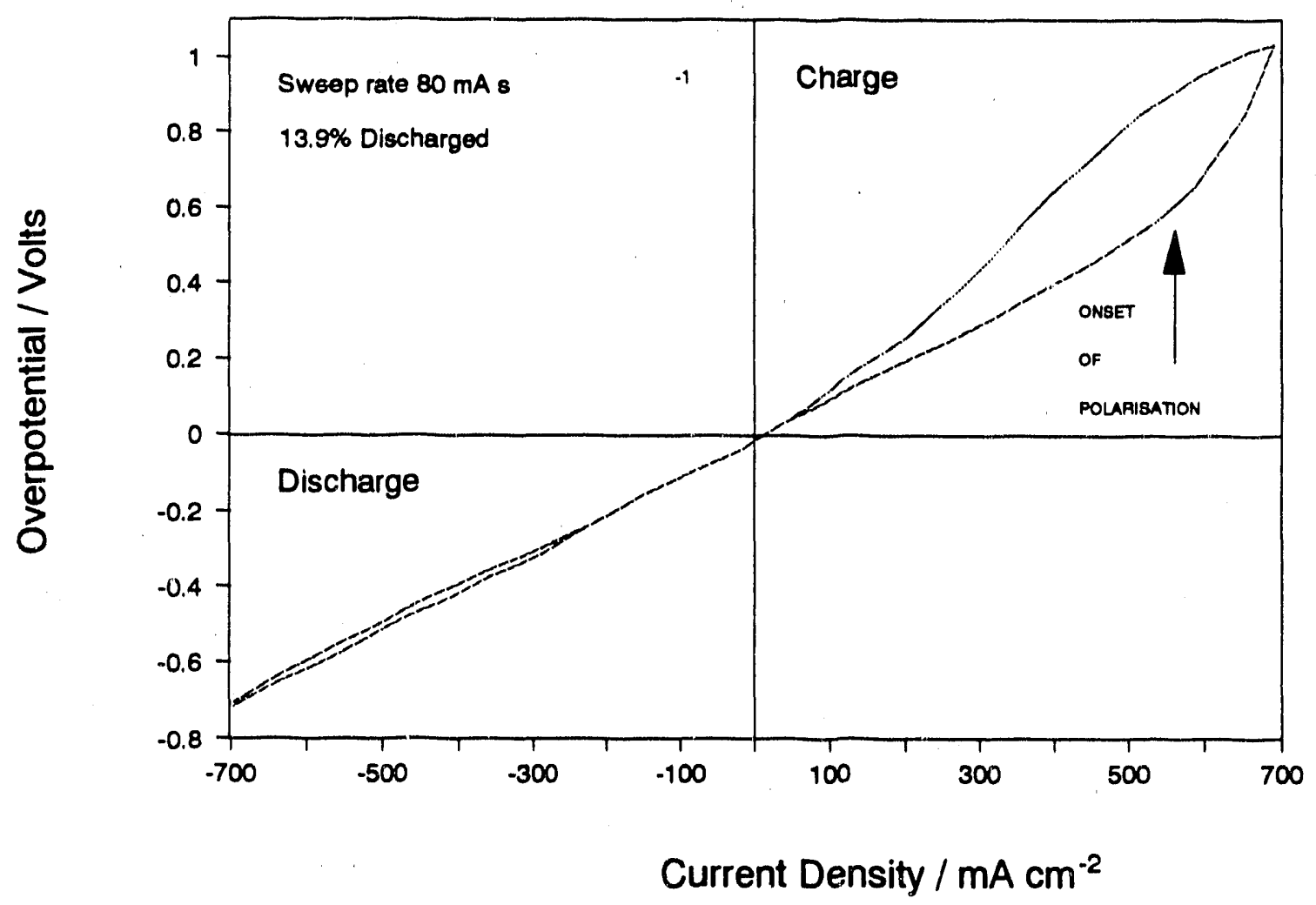

Figure 2-4. Cyclic Amperometry of Cell 10269 
indicates the critical current density. The following conclusions were drawn from this series of experiments:

- The critical current density is depetident on the immediate history of the cell. It cannot be determined after a standard (5 amp) discharge, i.e., the critical current density exceeds 700 $\mathrm{mA} / \mathrm{cm}^{2}$. The value is of the order of 600 $\mathrm{mA} / \mathrm{cm}^{2}$ for a non-polarized cell (as in Figure $2-4$ ) and it falis to around $100 \mathrm{~mA} / \mathrm{cm}^{2}$ for a cell on a constant current charge.

- Recharge polarization is dependent on the immediate polarization history of the cell. This explairis why it is absent in cells subject to SFUDS cycling, where short charging periods are always preceded by aischarges.
- Except near the very top of charge (i.e., within $5 \%$ ) the ritical current density is independent of depth of discharge in the two-phase region.

- The generation of cells tested did not exhibit any resistance asymmetry under normal operating conditions where recharge current is not expected to exceed $150 \mathrm{~mA} / \mathrm{cm}^{2}$ (continuous charging) or $300 \mathrm{~mA} / \mathrm{cm}^{2}$ (e.g., regenerative braking).

- The present test regime employed at CSPL is one of near constant current recharge. The results obtained from this type of testing must be considered as the worst possible case within the context of recharge polarization. The overall conclusion must be that in operational

PRODUCTION CELLS SAMPLED FOR QC TESTING

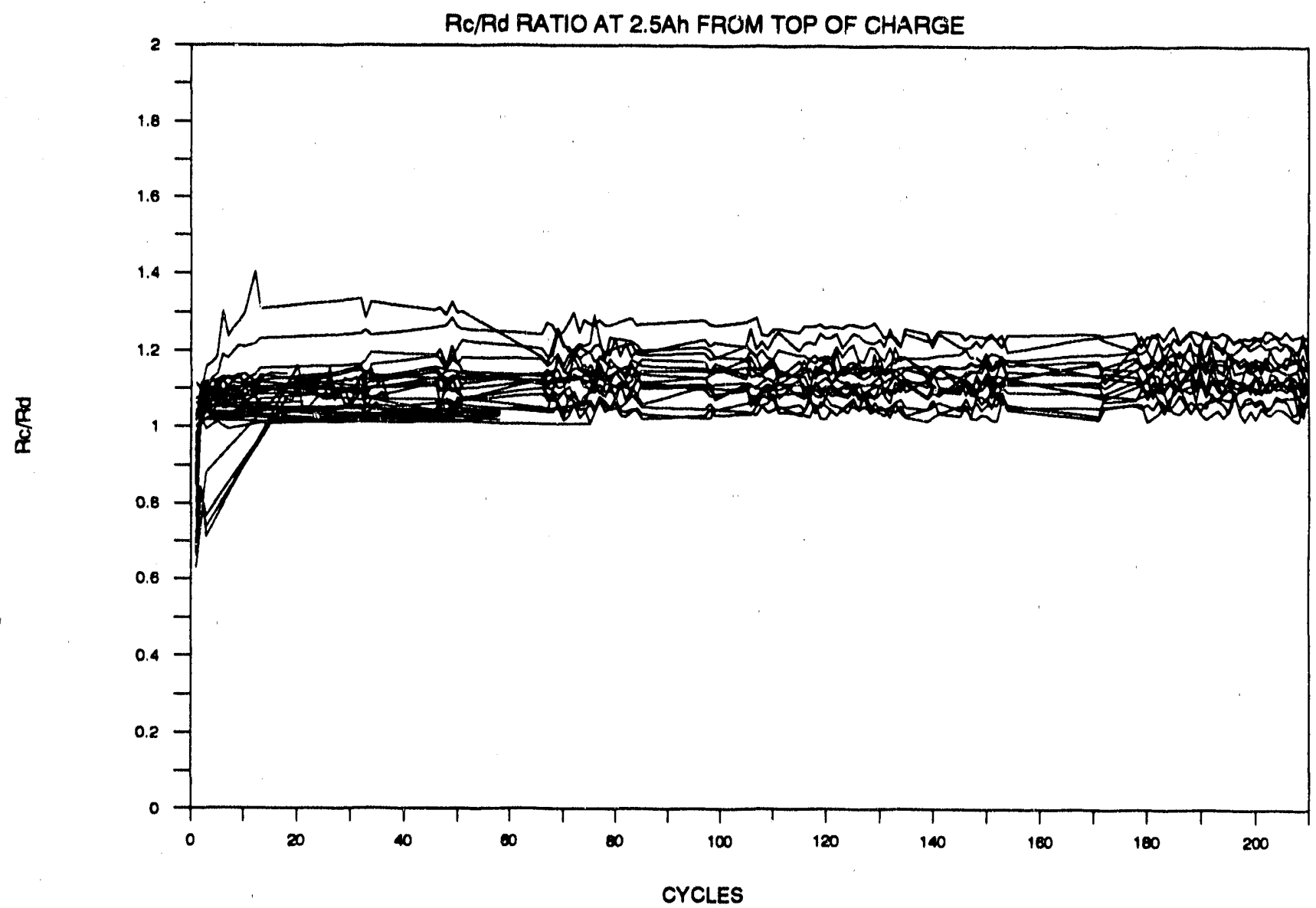

Figure 2-5. $\mathbf{R}_{d} / \mathbf{R}_{d}$ Values for MkIII SF Cells from Production Line 
batteries recharge polarization will be a much less critical problem than the cell test data might first suggest.

Recharge polarization was not detected on cells tested as part of the ongoing QC testing during 1989. Figure 2-5 shows an $\mathbf{R}_{\mathbf{c}} / \mathbf{R}_{\mathbf{d}}$ plot for a group of standard MkIII SF cells taken from the production line and tested with a $3 \mathrm{~h}$ discharge and $5 \mathrm{~h}$ recharge. The $R_{c} / R_{d}$ values (a ratio of charge to discharge resistance at $2.5 \mathrm{Ah}$ ) are typically in excess of 2.0 in cells that are polarizing and have been recorded as high as 5.0.

As well as the tests above, a series of parametric tests was conducted that were intended to explore the effect of high charge and discharge rates on the PB cell. A MkIII PB cell was selected from the QC samples on test and discharged at between 4 and 30 amps. A second series of constant current recharge tests was limited to 4.2 amps by the equipment and is to be completed after installation of higher rating power supplies. Data plots from both series of tests are shown in Figures 2-6 and 2-7. The charge plots show that no polarization occurred up to 4.2 amps, when the equipment limit was reached. The discharge plots show the effect of rising temperature upon the cell resistance. Table 2-1 lists the temperature rises during each of the discharges.
A computer model was developed to assess the effect of cell heating in a battery environment. This model was then modified to calculate the effect of various rates of discharge on cells in a CSPL single cell test position. These data are shown in Figure 2-7 and demonstrate good agreement. The computer code will next be modified to allow studies to be conducted on the XPB cell in the close packed configurations described under Task. 2.0.

In adcition to the thermal tests described above, tests were also carried out to assess the effect of polaronic conduction in the carbon fibers. A $30 \mathrm{~Hz}$ sinusoidal current was applied in both the charge and discharge directions. The current was applied for a maximum of 12 seconds with an equilibration time of 1 hour between measurements. The rapid sweep was carried out so that there was insufficient time for any significant heating of the cell to take place. A plot of the average of cell charge and discharge resistance against current density is shown in Figure 2-8. This clearly illustrates the effect of polaronic conduction in the carbon fibers, but the effect is small in comparison to the bulk heating effect of sustained high current discharge. The test shown was conducted when the cell was discharged by

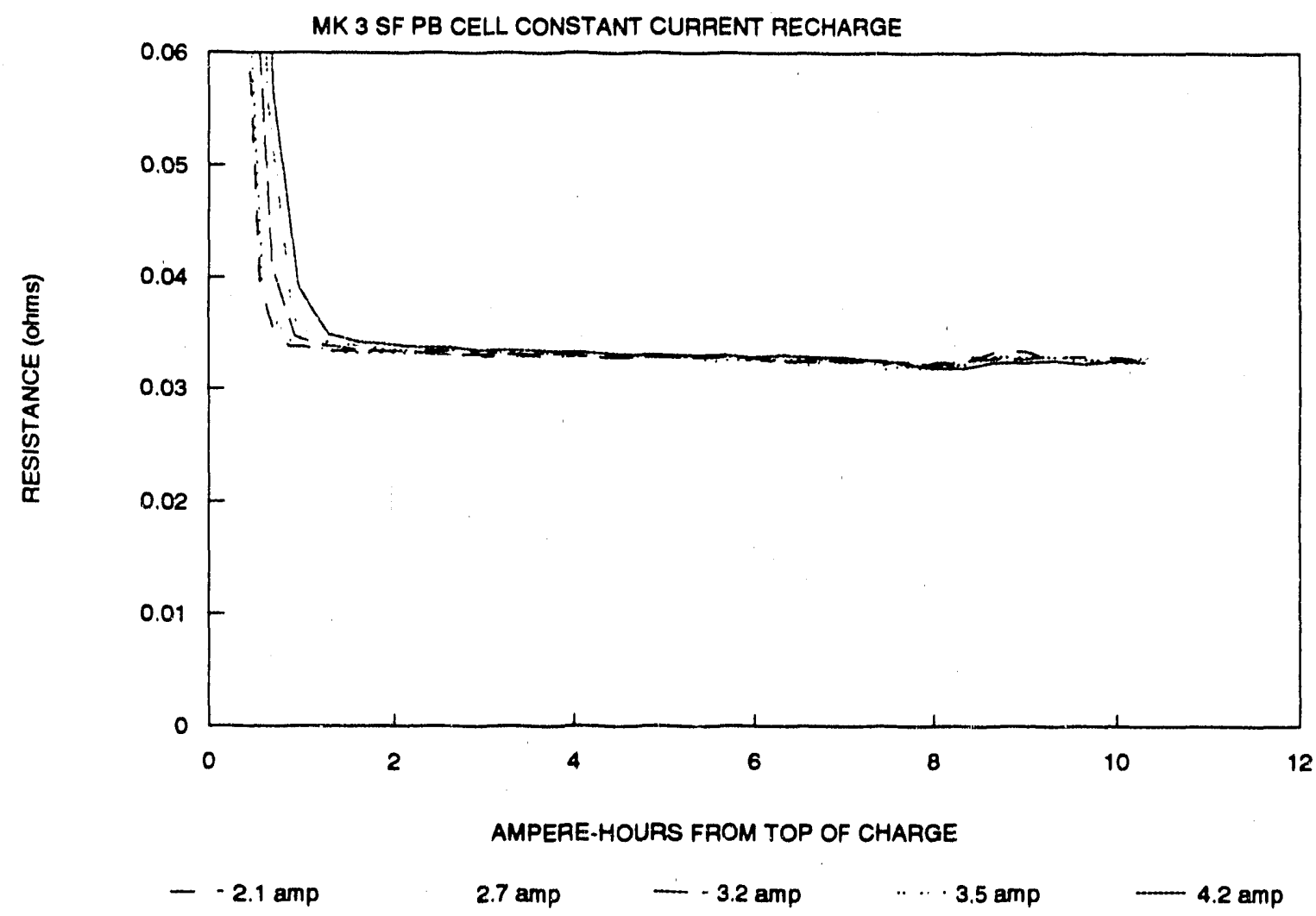

Figure 2-6. Effect of Recharge Current on Cell Resistance 
PAEDICTEU VALUES

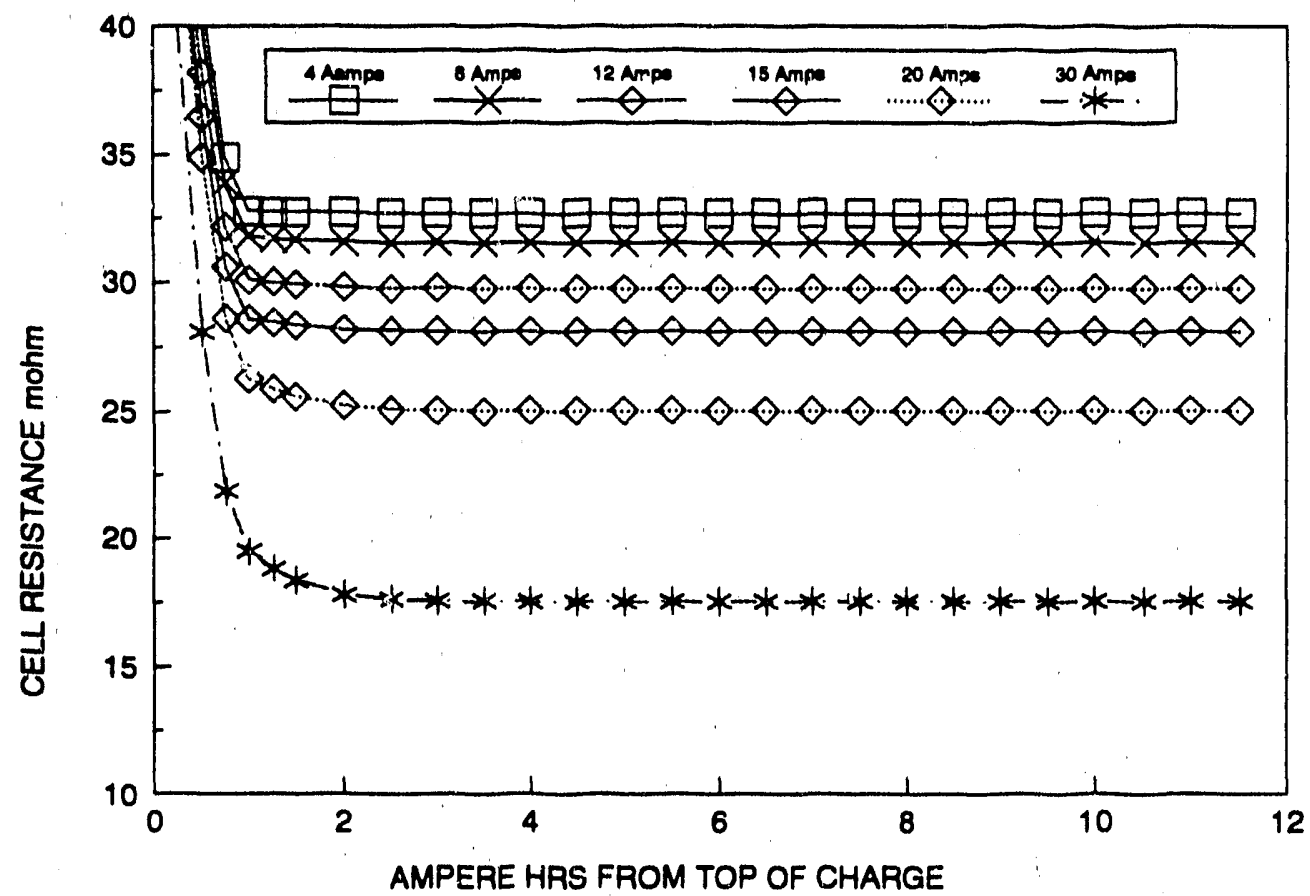

actual VALUES

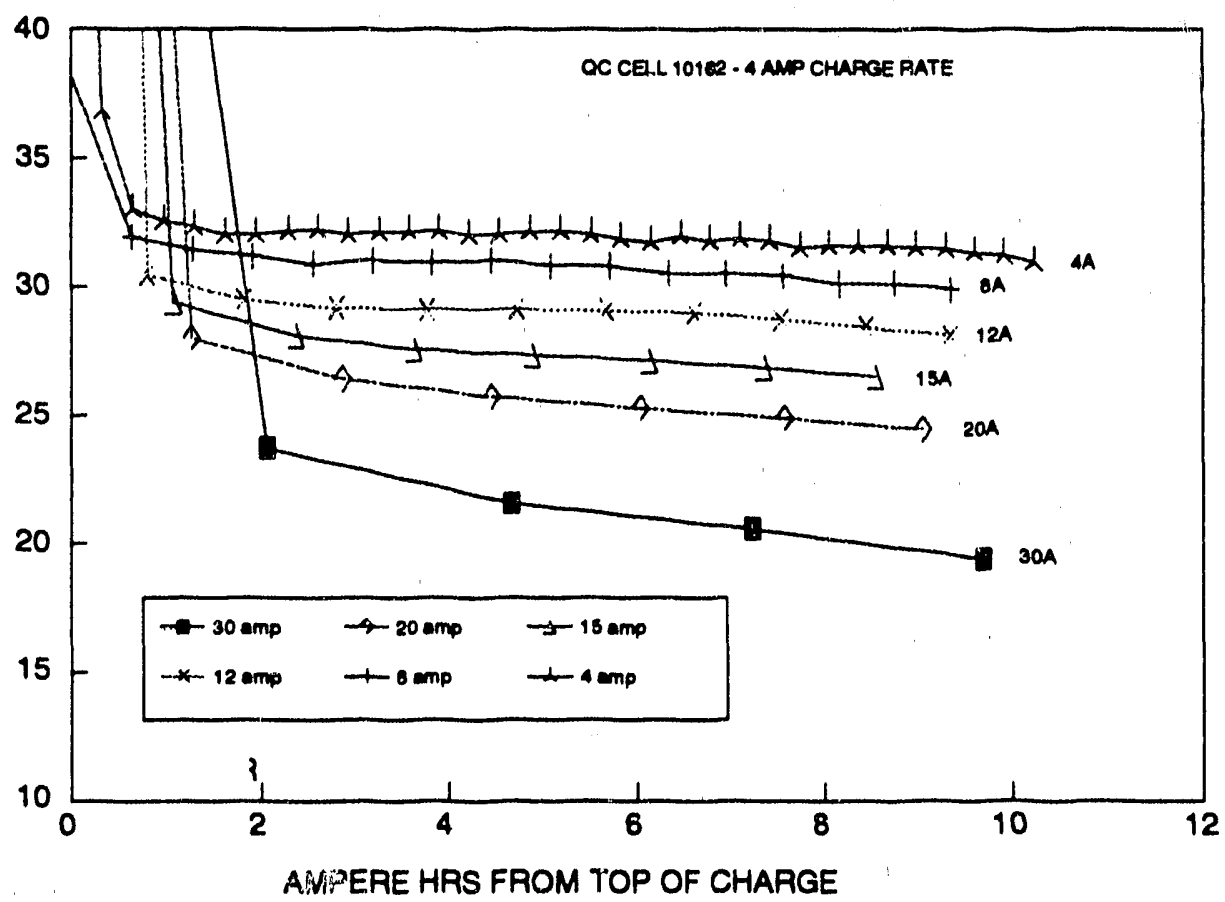

Figure 2-7. Effect of Discharge Current on Cell Resistance 
Table 2-1. Temperature Rise During High Current Discharge

\begin{tabular}{|c|c|c|c|}
\hline $\begin{array}{l}\text { Discharge } \\
\text { Current (A) } \\
\end{array}$ & $\begin{array}{c}\text { Start } \\
\text { Temp (C) }\end{array}$ & $\begin{array}{l}\text { Finishing } \\
\text { Temp (C) }\end{array}$ & $\begin{array}{c}\text { Temperature } \\
\text { Rise (C) }\end{array}$ \\
\hline 30 & 351 & 435 & 84 \\
\hline $2 C$ & 351 & 394 & 43 \\
\hline 15 & 358 & 381 & 23 \\
\hline 12 & 353 & 365 & 12 \\
\hline 8 & 347 & 353 & 6 \\
\hline 4 & 345 & 348 & 3 \\
\hline
\end{tabular}

\section{EFFECT OF CURRENT DENSITY ON CELL RESISTANCE}

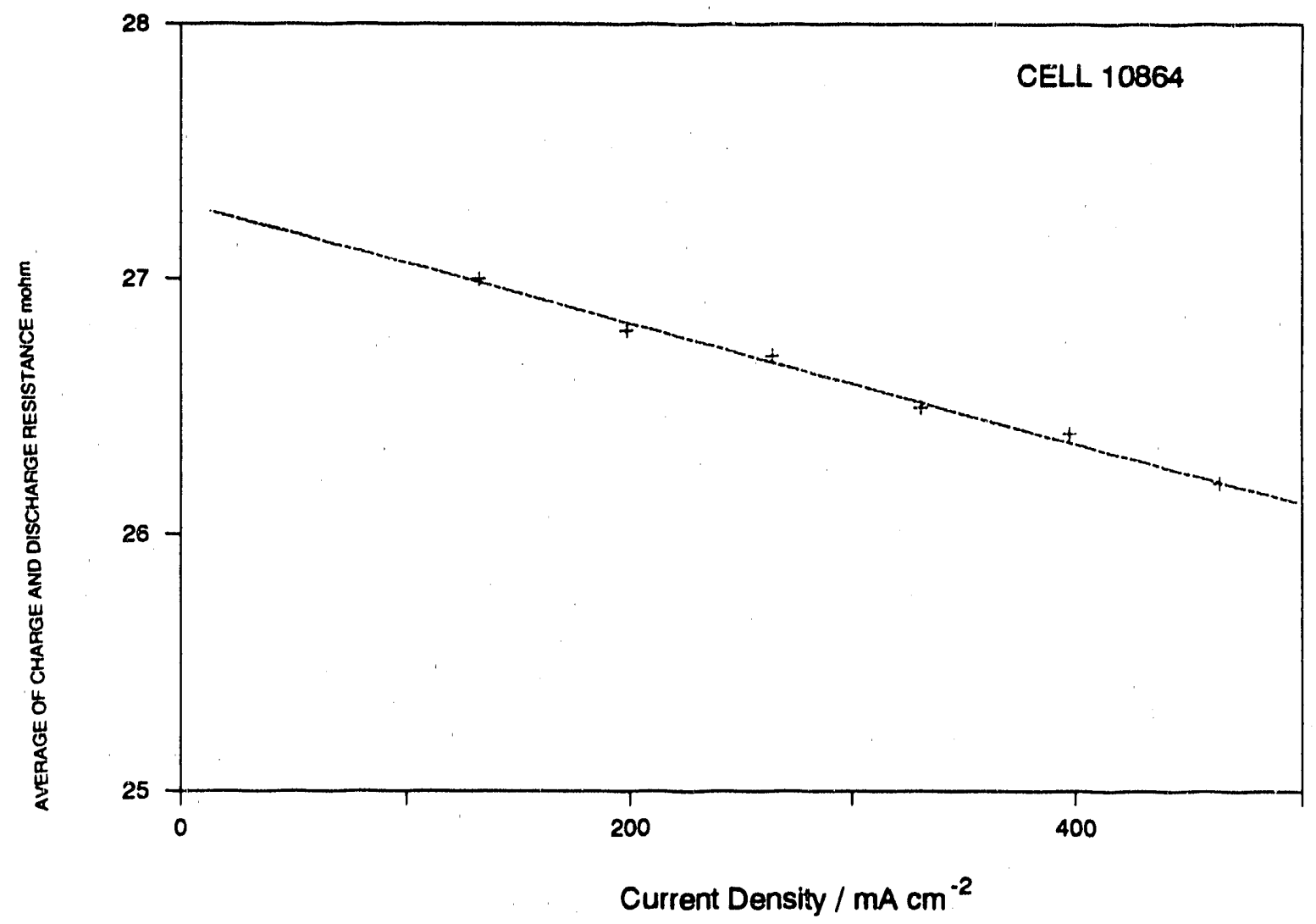

Figur- 2-8. Effect of Current Density on Cell Charge and Discharge Resistances

$9 \mathrm{Ah}$. Similar results were obtained for both 2 and $4 \mathrm{Ah}$ discharge states.

SAIC studied the operating characteristics of two MkIII SF cell during 1989 using real-time-radiography.
A cell was charged at high rates to induce polarization during radiographic examination. Good $x$-ray images were obtained and the video data were being examined at the time of writing. Further lests were conducted in 
which a cell was deliberately failed while under radiographic observation.

\section{Containment}

The production of a long-term corrosion resistant container is one of the major challenges of this program. The presently preferred approach is the use of a duplex chromised sieel container and these were used in all the cells made and tested under this program in 1988. Other coating methods were developed during 1988 at CSPL and in collaboration with SNL (see Technology Improvement section in this Chapter). These tests reached maturity during 1989. A group of cells was constructed and split into static corrosion trials and electrical cycling tests. The maximum cycle life reached was 654 at the time of writing and of the 12 cells on test, 9 had exceeded 450 cycles. The average cell resistance was $32.6+/-0.8$ mohm (1 SD) measured between 400 and 650 cycles, the average capacity retention was $88+/-3 \%$ of theoretical at the same cycle level. This represents one of the best cell groups iested at CSPL to date. Static corrosion testing showed that the new coating outperformed the standard chromising.

\section{Subtask 1.3. Cell Development}

The objective of subtask 1.3 is to design a cell for both stationary and motive power applications, and to characterize cell performance, reliability, safety, cost and freeze/thaw $(F / T)$ survivability. This subtask changed emphasis during 1989 in that the main effort involved the XPB cell. Although the development of the PB cell is continuing under CSPL funding (and significant advances continue to be made), it is timely to review the status of the PB development and its performance.

\section{PB Cell Development}

The various versions of the PB ce!l that have existed were discussed earlier in the Background section above. The effects of the evolution of both cell design and processing are summarized by Figures 2-9 to 2-11.

\section{PB CELL RESISTANCE IMPROVEMENTS}

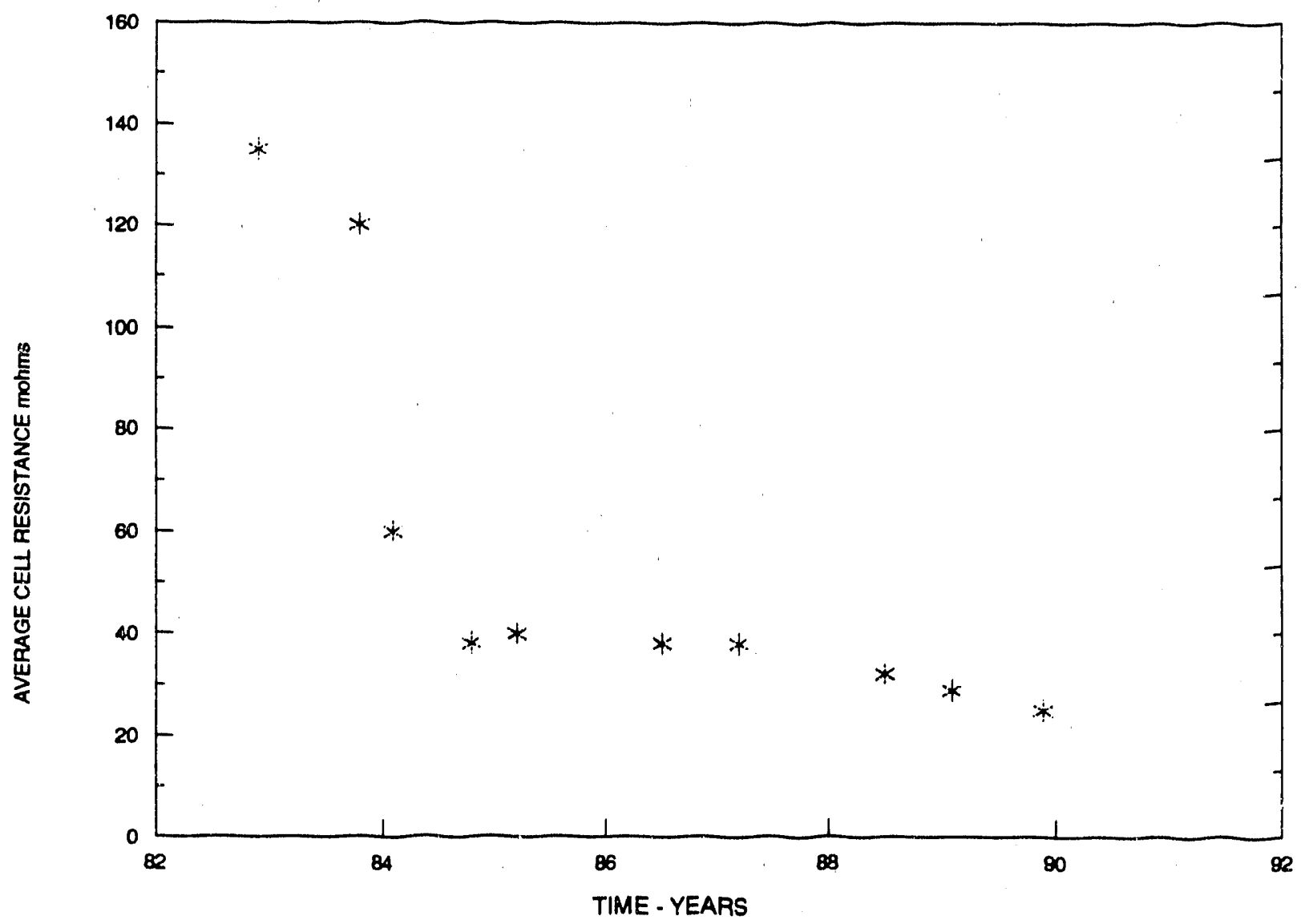

Figure 2-9. Improvements in PB Cell Absolute Resistance 


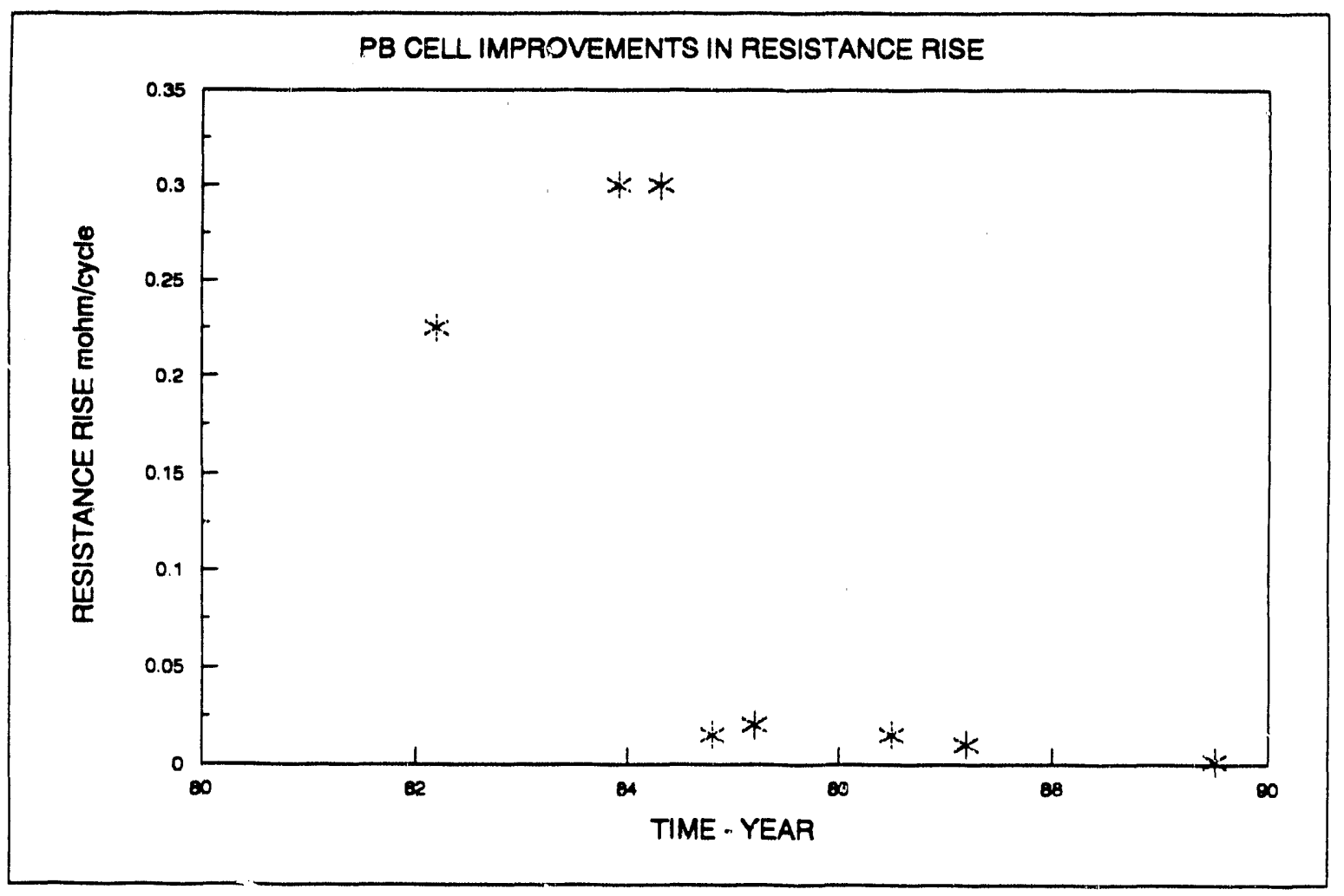

Figure 2-10. Improvements in PB Cell Resistance Rise

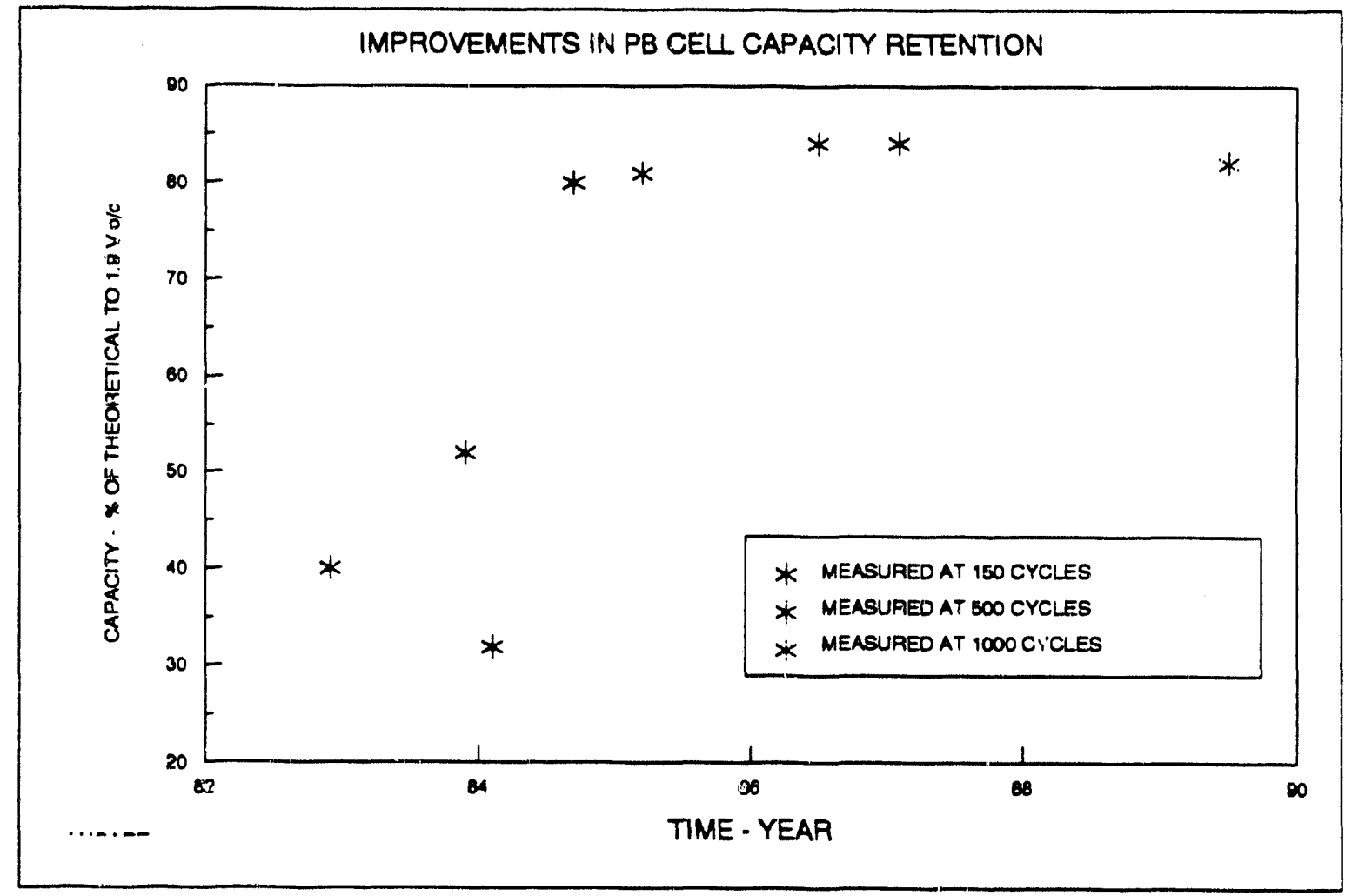

Figure 2-11. Improvements in PB Cell Capacity Retention 

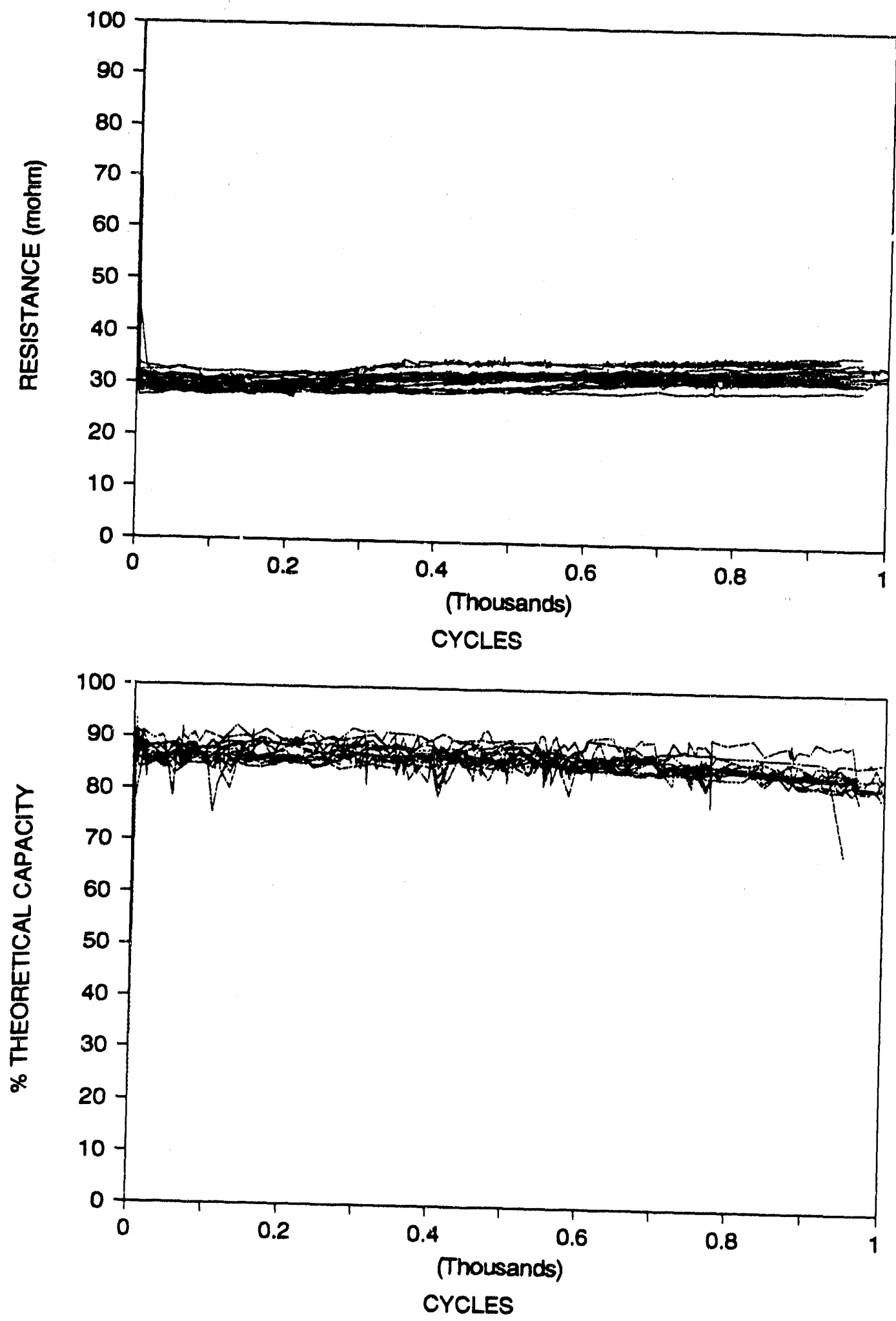

Figure 2-12. Resistance and Capacity of MkIII SF Cells to 1,000 Cycles 
These graphs illustrate the improvements in the best performing cell groups.

The state of the art of the developinents in this program are best illustrated by the performance of the MkIII SF cell. The most mature group of cells contains glass joints made by a method that was subsequently modified following the investigations described in Subtask 1.2. Despite the non-optimum glass seal processing this forerunner group of cells demonstrated excellent life and purformance. Of 17 cells in the forerunner group, only 2 failures had occurred at 968 and 980 cycles. The remaining cells had completed between 1,092 and 1,523 cycles. Figure 2-12 shows the resistance and capacity retention of the cell group out to 1,000 cycles. All of the cycling cells had exceeded 10,000 hours of testing at the time of writing.

The safety testing of the MkIII SF cell also continued during 1989. The population of safety tested cells was extended to 117 . The temperature excursion data resulting from an electrolyte failure is summarized in the probability plot shown in Figure 2-13. Mechanical impact testing was described in the 1988 ETD Annual Report. Abuse testing in 1989 was extended to include rapid quenching into cold water. Cells were removed from the test overs at $350^{\circ} \mathrm{C}$ and plunged directly into a vessel of water. Figure 2-14 shows the resulting temperature profiles. The outer case reached ambient temperature in approximately 2 seconds and the cell open circuit voltage was lost over a further 60 seconds. Following the quench, the cell was brought to operating temperature again and given an electrical cycle. Having ascertained that no change in either capacity or resistance had occurred, the quenching process was repeated for a second time. The graph in Figure 2-14 was made on the second quench. No leakage of cell reactants was observed during any of these tests. Collectively, these data show that the intrinsic safety performance of the MkIII SF cell is excellent.

The first phase of evaluating the F/T performance of PB cells was completed during 1989. A detailed analysis was included in the 1988 ETD Annual Report but since that time all the cells have been tested to failure. A highlight of the testing was the survival of 8 cells beyond $540 \mathrm{~F} / \mathrm{T}$ cycles and a maximum achieved value of $644 \mathrm{~F} / \mathrm{T}$ cycles. Only one incidence of electrolyte fracture has been observed in this phase of testing

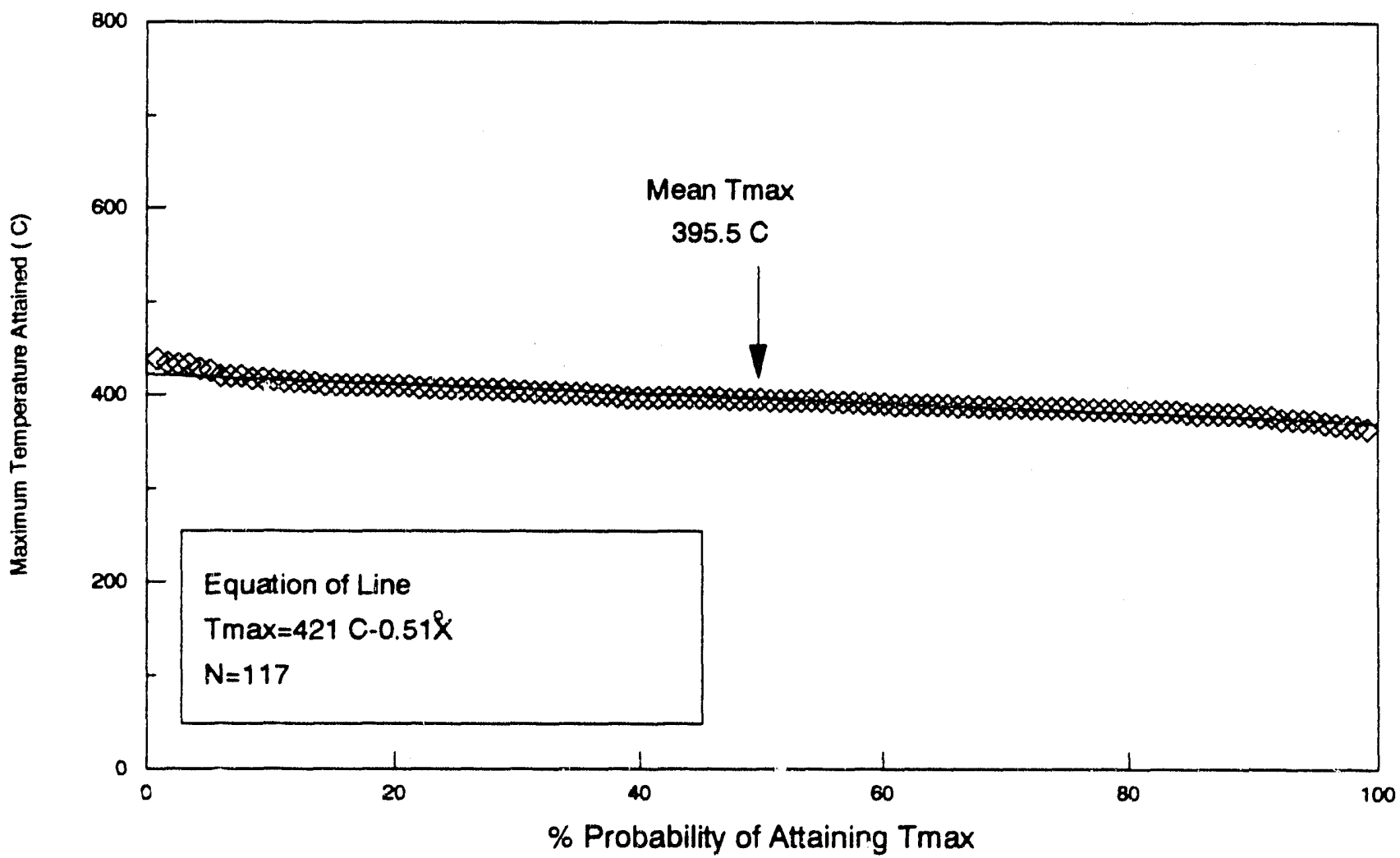

Figure 2-13. Safety Test Data on 117 PB MkII SF PB Cells 
CELL R2043.5 FAST QUENCH TEST

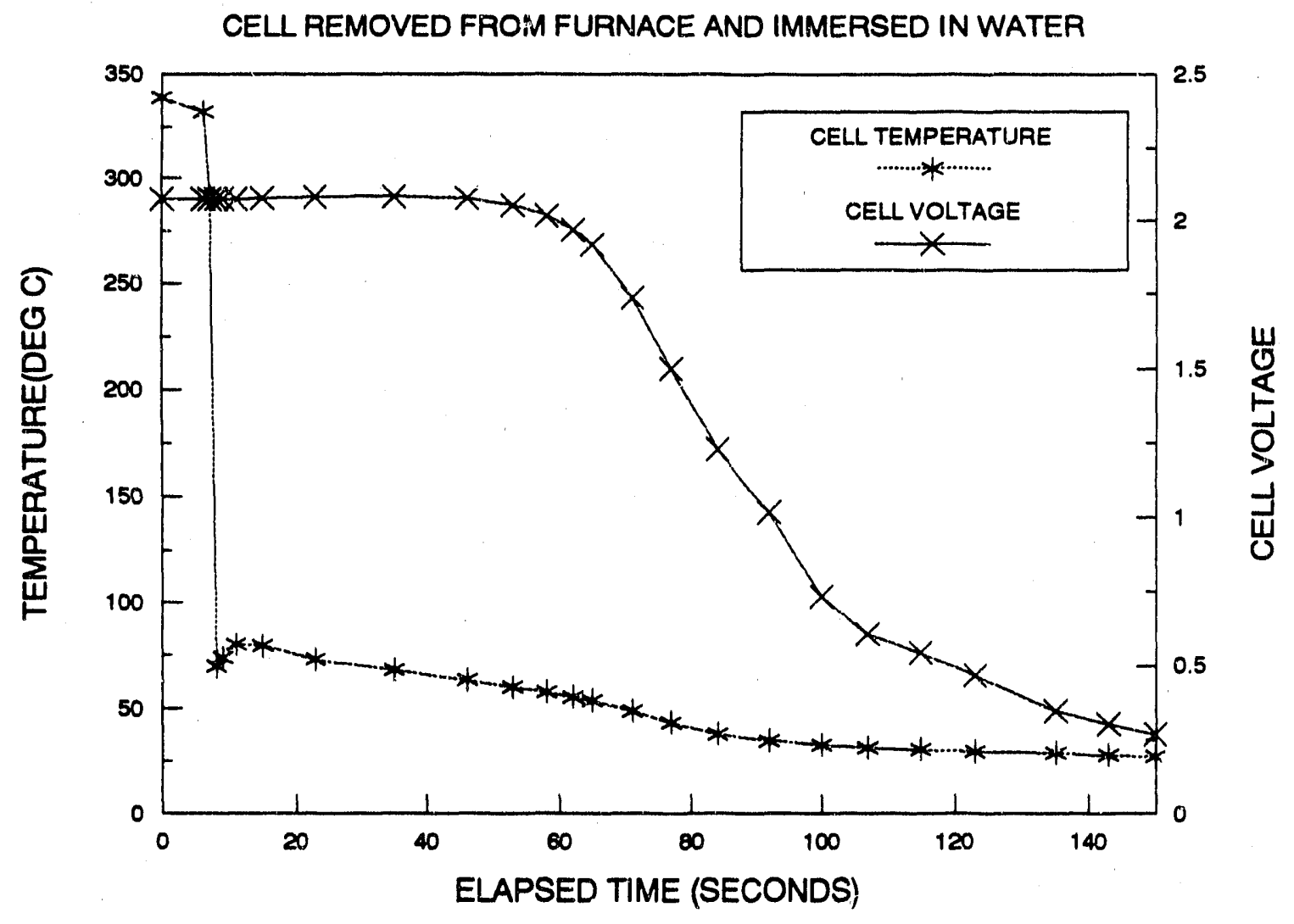

Figure 2-14. Rapid Quench Testing of MkIII SF PB Cells

suggesting that the electrolyte is not a critical component in the F/T failure of the PB cell.

Conclusions from the F/T studies conducted to date are as follows:

- The baseline Weibull statistics for virgin PB cells, F/T cycled at the top of charge are a characteristic life of 400 to 500 FT cycles with an associated shape parameter of between 2 and 3. These values form the basis for comparison against other mixed parameter testing regimes.

- There is no difference in $F / T$ characteristics between the MkIII NSF and MkIII SF cell when $\mathrm{F} / \mathrm{T}$ cycled at the lop of charge.

- The predominant mode of failurs is loss of hermeticity of the sulfur electrode seal. Methods of strengthening this seal have already been identified. No electrolyte or glass sep.: failures were observed in cells that had been $\mathrm{F} / \mathrm{T}$ cycled only.
- F/T cycling at $1.76 \mathrm{Voc}$ is more severe than at top of charge reducing the Weibull characteristic life to approximately $100 \mathrm{~F} / \mathrm{T}$ cycles.

- Vibration of virgin cells prior to F/T cycling is detrimental. The Weibull characteristic life is reduced to approximately $100 \mathrm{~F} / \mathrm{T}$ cycles.

\section{XPB Cell Development}

Many features developed for the PB cell were transferred to the XPB design. An XPB design was then fixed and a group of cells was manufactured prior to the time of the 1988 ETD Annual Report. These cells produced the lowest and most consistent resistance achieved up to that time for XPB cells. The 15-cell group completed up to 522 cycles, although some of the population was removed from the testing and used as spares in a XPB module (B88). The service lives of the cells were ultimately limited by the same faulty glass seals (as discussed under Subtask 1.2). In addition, some of the cells suffered from discharge polarization, a 


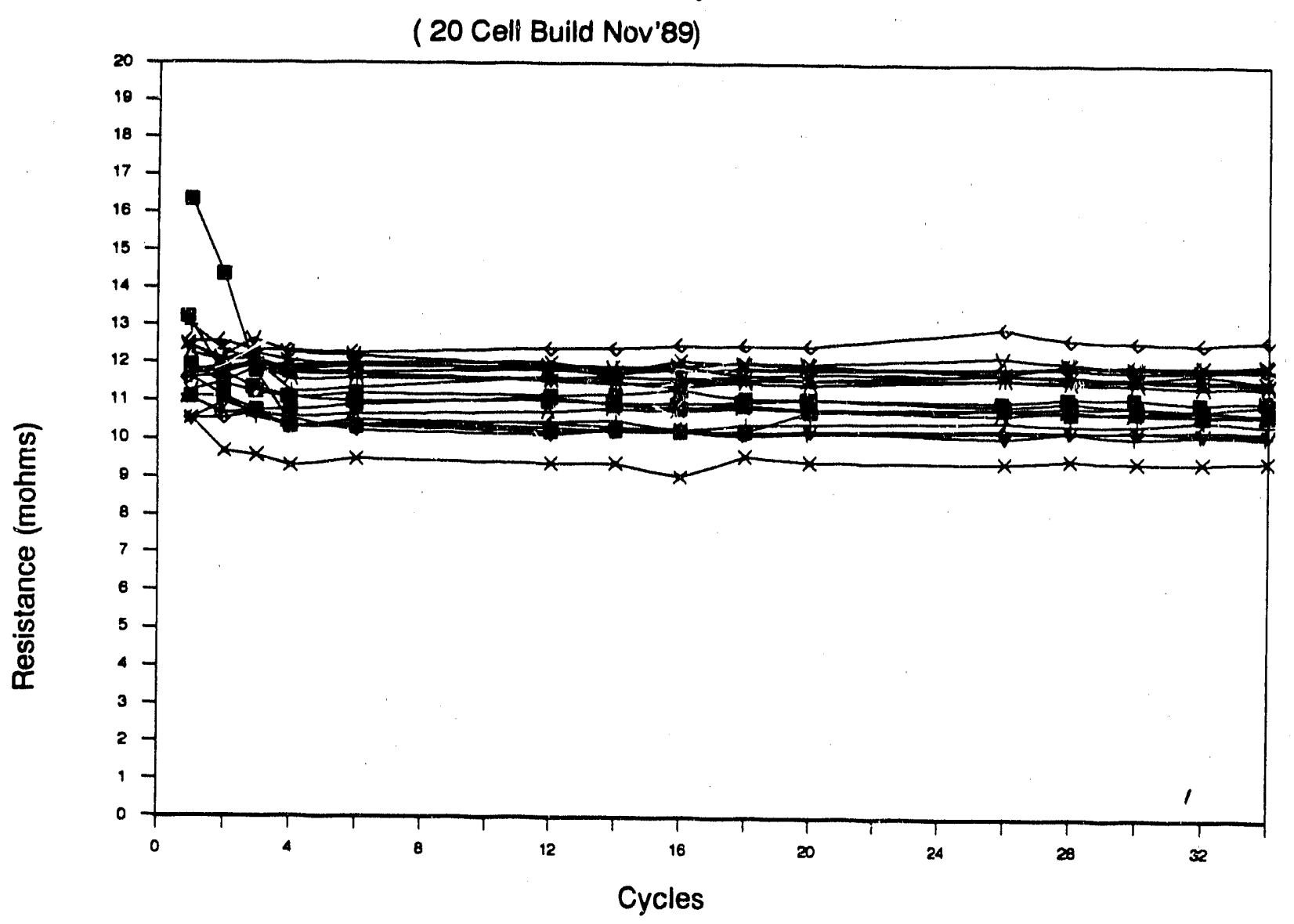

Figure 2-15. XPB Cell Resistances (Nov. ' 89 Build)

problem that was eventually solved. A further 20-cell build was completed that contained improvements intended to address the polarization. At the time of writing, this group of cells had exhibited polarization free performance out to 160 cycles in both the single cells and also a 16-cell module.

Having established a design with a sufficient background of high and consistent performance, the production of XPB cells was scaled up. In particular, the electrolyte manufacture was upgraded as described in Subtask 1.1. The first build of 20 cells was completed in November 1989 and the cells had completed 30 cycles at the time o: writing. As shown in Figure 2-15, the cell resistances were low and consistent, averaging $11.1+1$ $0.8 \mathrm{mohm}$ (1 SD). The average cell capacity for the group was $31.7 \mathrm{Ah}, 92 \%$ of theoretical to $1.9 \mathrm{Voc}$. In order to verify that control of build and process parameters had been achieved, a 40-cell build was underway at the time of writing. It was planned to follow this with the construction of a 40-ce 4 module for testing in the new bank-test facility (shown in Figure 2-16), followed by construction of the first 200-cell SES module.
The safety test database of XPB cells was increased during 1989. A total of 27 electrolyte-failure safety tests was conducted and the data is summarized in Figure 2-17. The single outlier in the data led to the planning of further trials, to be made on cells containing modifications to the sodium electrode to imitate the conditions prevailing in the PB cell. The initial batch of 20 cells was awaiting test at the time of writing and a further group of $\mathbf{3 0}$ was planned.

\section{Subtask 1.4. Cell Test And Posttest Analysis}

The objective of this subtask is to provide test support and posttest analysis for other subtasks and as such the results are reported in the appropriate sections of this document. The current CSPL testing capability is listed in Table 2-2, and a photograph of a new, 12 station, bank-testing facility is shown in Figure 2-16.

The scale of module testing increased during 1988. The performance of 19 modisles was evaluated in a variety of trials including qualification testing, high rate discharge, safety testing, $F / T$ testing, pre-qualification studies, XPB thermal manigement tests, and several 


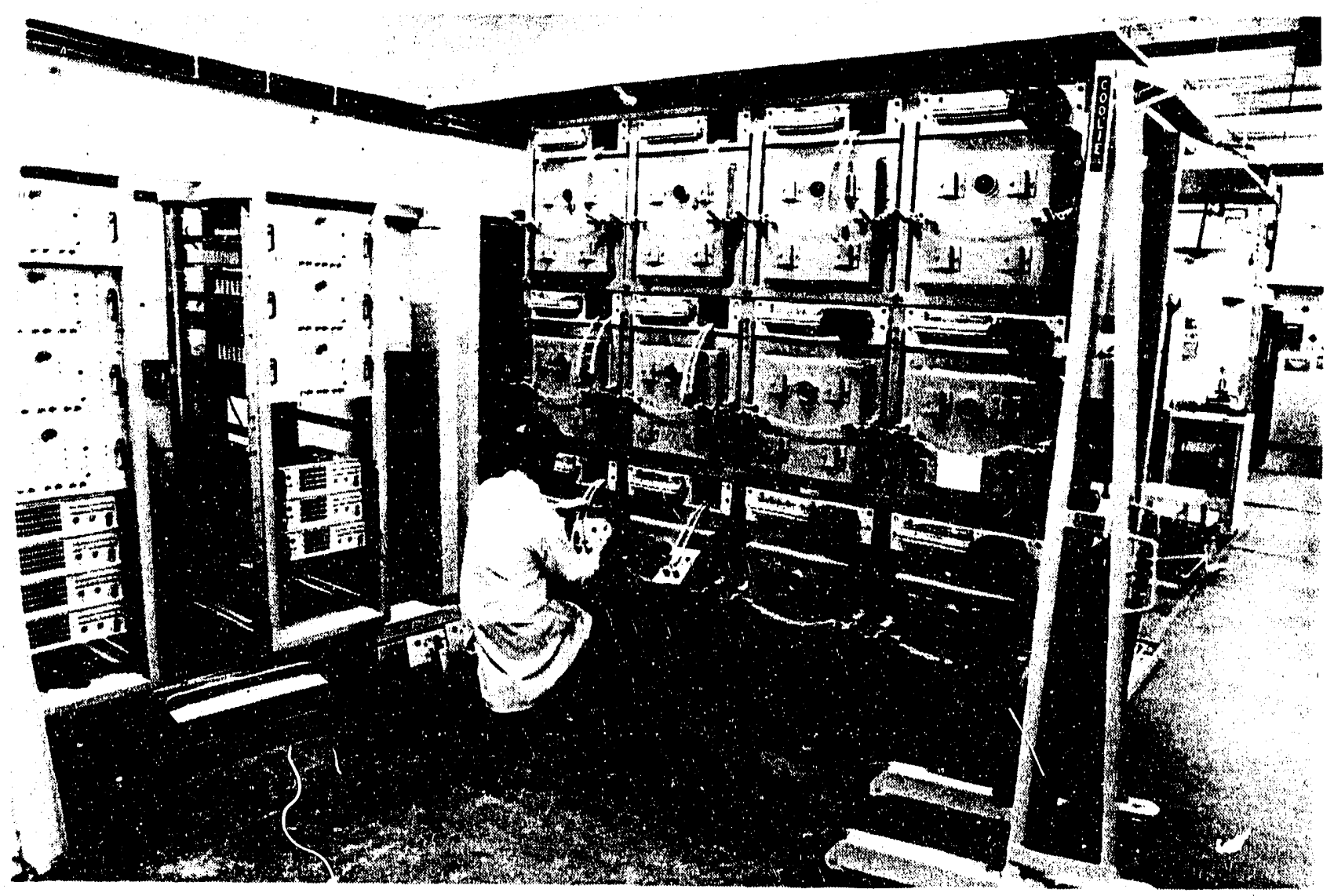

Figure 2-16. CSPL Bank-'Testing Facility

XPB Safety Data

(27 Electrical Safery Tests)

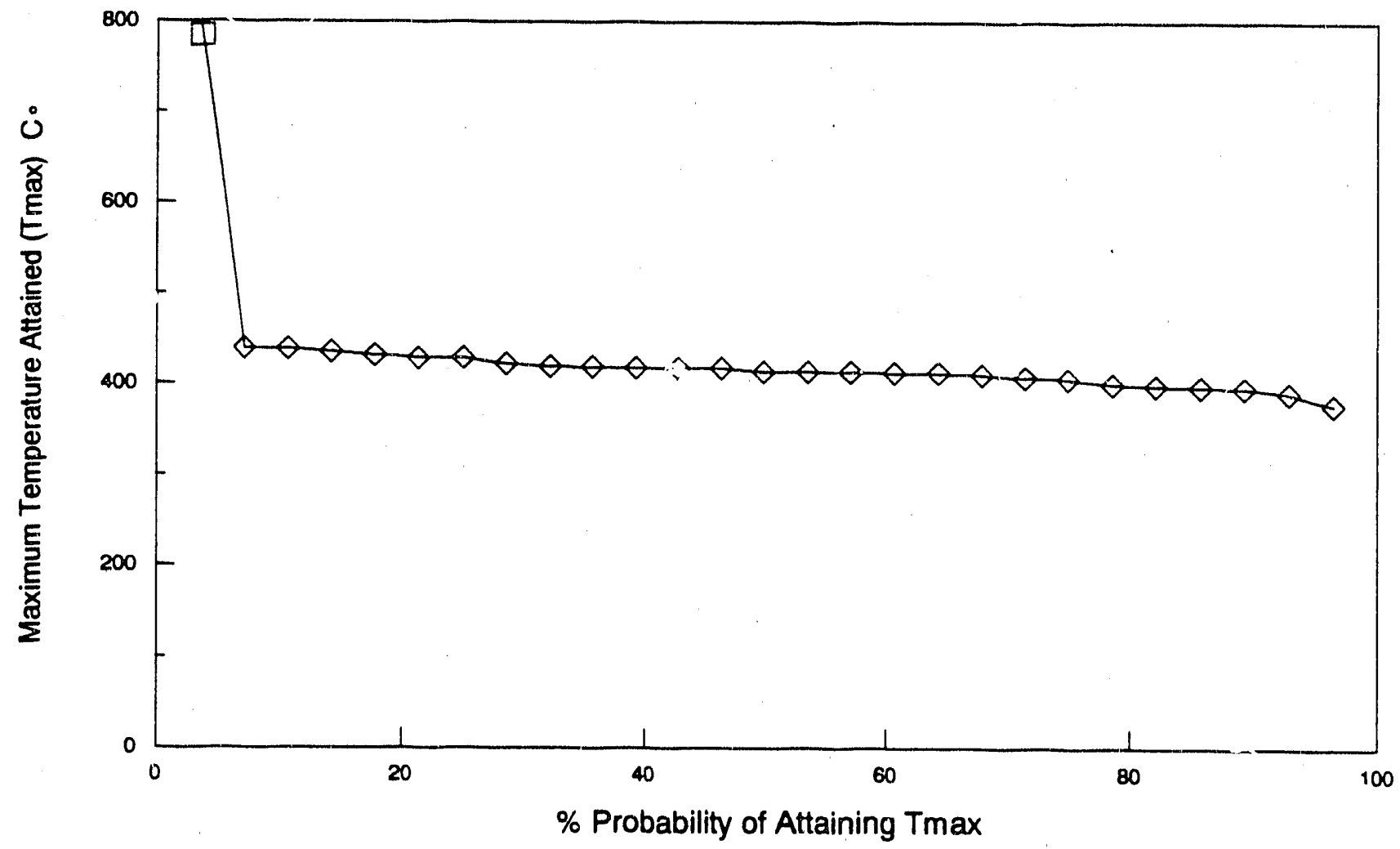

Figure 2-17. Safety Test Data on 27 XPB Cells 


\section{Table 2-2. Electrical Test Capability}

Cell Type/Test

PB Single Cell

XPB Single Cell

PB 4 Cell Strings

PB 120 Cell Banks

PB 120 Cell Series Bank (6)

PB 120 Cell Series Bank (8).

PB 120 Cell Bank

XPB 40 Cell Bank
No. of Positions

168

96

72

3

1

1

9

3
No. of Cells

168

96

298

360

720

960

1,080

120

Under Construction

PB Single Cell

specialized tests for other programs. During the later years of this contract, the 120-PB cell module (or bank) has been used as the standard test unit vihen cell design or process qualification is required.

\section{Subtask 1.5. Module Testing}

The objective of this subtask is to develop and test sub-modules of larger battery designs in order to explore the interactions of cell connection strategy and to test groups of cells against application specific requirements. Other objectives are to study the effect of cell failure interactions and the effect that varying cell performance has in an interconnected group of cells. More than 150 modules had been constructed by the end of 1989 , the majority of which were in 120-cell units.

\section{XPB Moduie Testing}

A 16-cell (4 series $x 4$ parallel) module of XPB cells (B88) was constructed in January 1989 and commenced test. The module had completed 43 electrical cycles at the time of the 1988 ETD Annual report. This module was removed from test after 200 electrical cycles during which time it had also been subjected to $4 \mathrm{~F} / \mathrm{T}$ cycles. The F/T cycles were required to enable cell changes to ic :erformed. As mentioned in Subtask 1.3, a problem had arisen with discharge polarization of the cells (this was eliminated on subsequent cell and module builds).

A series of parametric tests was also performed with module B88 to determine the thermal uniformity obtained with (1) the use of a convective air, recirculatory cooling system and (2) operation at different temperatures and discharge regimes. The resistance and capacity of the module are plotted in Figures 2-18 and 2-19. The cell terminations and current shunts provided a significant contribution to the total resistance of 20 mohm to 25 mohms. Equivalent cell resistances (less terminations) were measured and shown to be similar to those of single cells (11 mohm). Different interconnections were developed that contribute only $2.5 \mathrm{mohm}$ to the cell resistance. The testing of the module was voluntarily terminated when one of the cells laad polarized at arcund 200 cycles. A decision was taken to remove the rnodule from test and use the mature cells for safety testing to see if any change in safety had occurred after extended cycle testing. None was detected.

A second 16-cell module, designated B136, was constructed and at the time of writing had completed more than 200 cycles without a cell failure. The expected improvements in base line resistance were achieved and the module resistance was at 16 mohm on its 4 th cycle, as annotated on Figure 2-18. A capacity plot is included in Figure 2-19. The module was operated at both $330^{\circ} \mathrm{C}$ and $350^{\circ} \mathrm{C}$ and the temperature rise during discharge was monitored. For a test temperature of $330^{\circ} \mathrm{C}$, the temperature rose to $347^{\circ} \mathrm{C}$ on discharge, whereas for a test temperature of $350^{\circ} \mathrm{C}$, the temperature rose to $365^{\circ} \mathrm{C}$. The resistance penalty for a reduction of $20^{\circ} \mathrm{C}$ in operating temperature was around $10 \%$. During the parametric testing it was noted that the module resistance was rising steadily with cycle life. 
Bank 88.Resistance vs Cycles

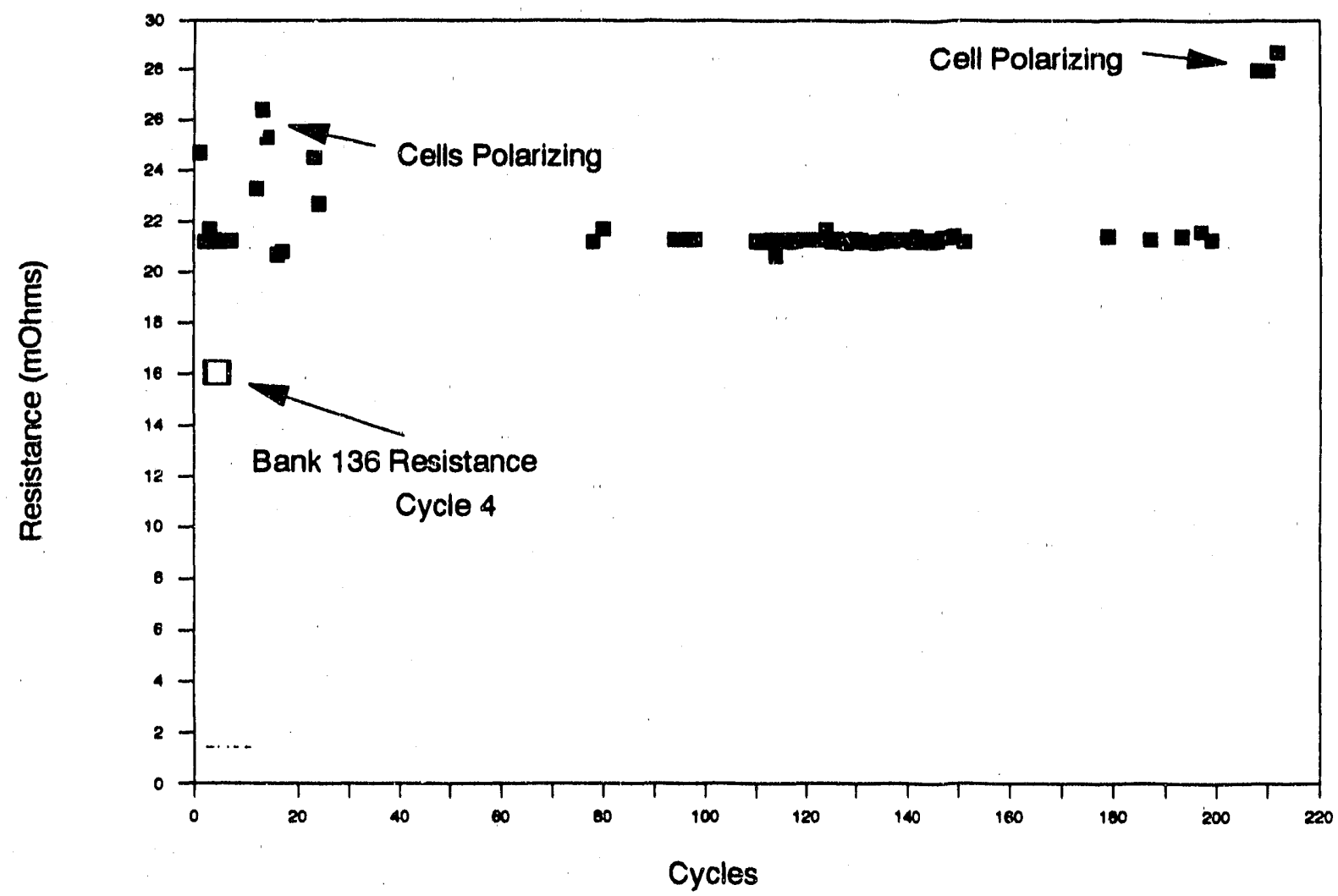

Figure 2-18. Resistance of XPB Bank 88

CAPACITY OF XPB MODULES B88 \& B136

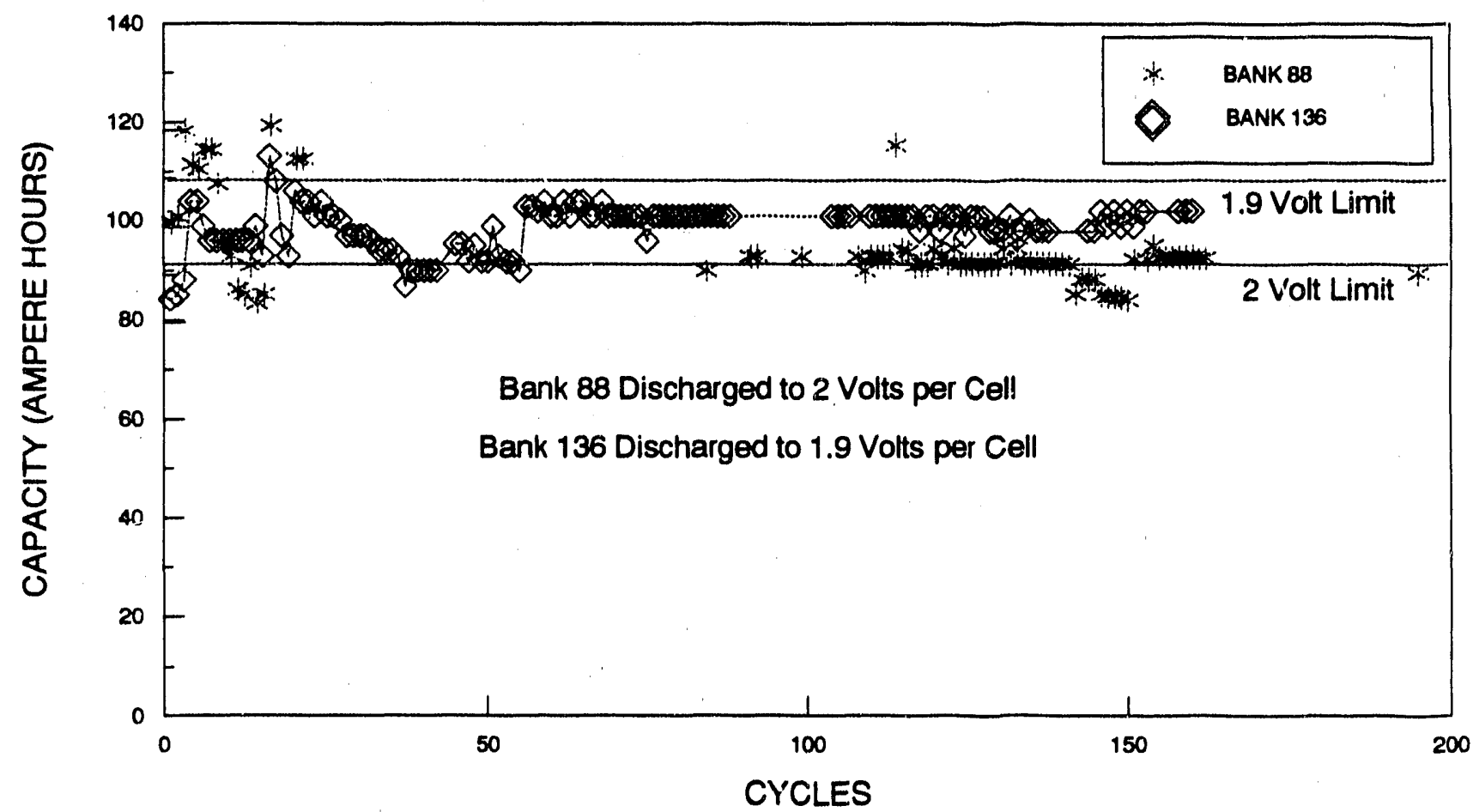

Figure 2-19. Capacity of XPB Bank 88 
This was also noted on a peer group oî single cell tests and was subsequently isoiated to the electrolyte batch by means of out-of-cell sodium/sodium testing. Investigations revealed a cross-contamination problem in a small batch of powder. Such problems are not expected to recur and subsequent cell testing substantiated this belief.

\section{Task 2 - Battery Engineering and Testing}

CSPL's original design concept for utility batteries was based upon a proposal to EPRI (RFP 2123-4) in which a 100-MWh unit consisted of ten $10 \mathrm{MWh}$, circular unit batteries. Origina ly, the EPRI program was scherduled to deliver a $500-\mathrm{kWh}$ battery for evaluation at the BEST facility in New Jersey. As staied in the introduction to this section, this EPRI-program deliverable was deferred. The final, Task 2, deliverable battery for the DOE program remained defined as a 100-cell module of a design that was based upon stationary battery concepts. This module was to contain the development experience of Task 1.

Evolving from the design studies conducted under the remnant "Phase P" of the EPRI 2123-4 contract was a stationary battery design utilizing a moving air flow as a thermal management strategy. At a June 1988 review meeting, a proposal for a revised 200 XPB-cell battery deliverable was accepted. The design of this deliverable is based on the new EPRI battery design. Furthermore, the decision was made, mainly due to cost and safety considerations, to test this deliverable at CSPL. The rationale behind the design of this module was described in detail in the 1988 ETD Annual Report. The final module design concept is shown in Figure 2-20. Plans for the fabrication and evaluation of this sub-unit were well advanced at the time of writing.

In addition to the CSPL design work for the 200-cell module, modeling of larger networks was conducted by SAIC. The effects of string length on overall battery performance was modeled to aid the conceptual design

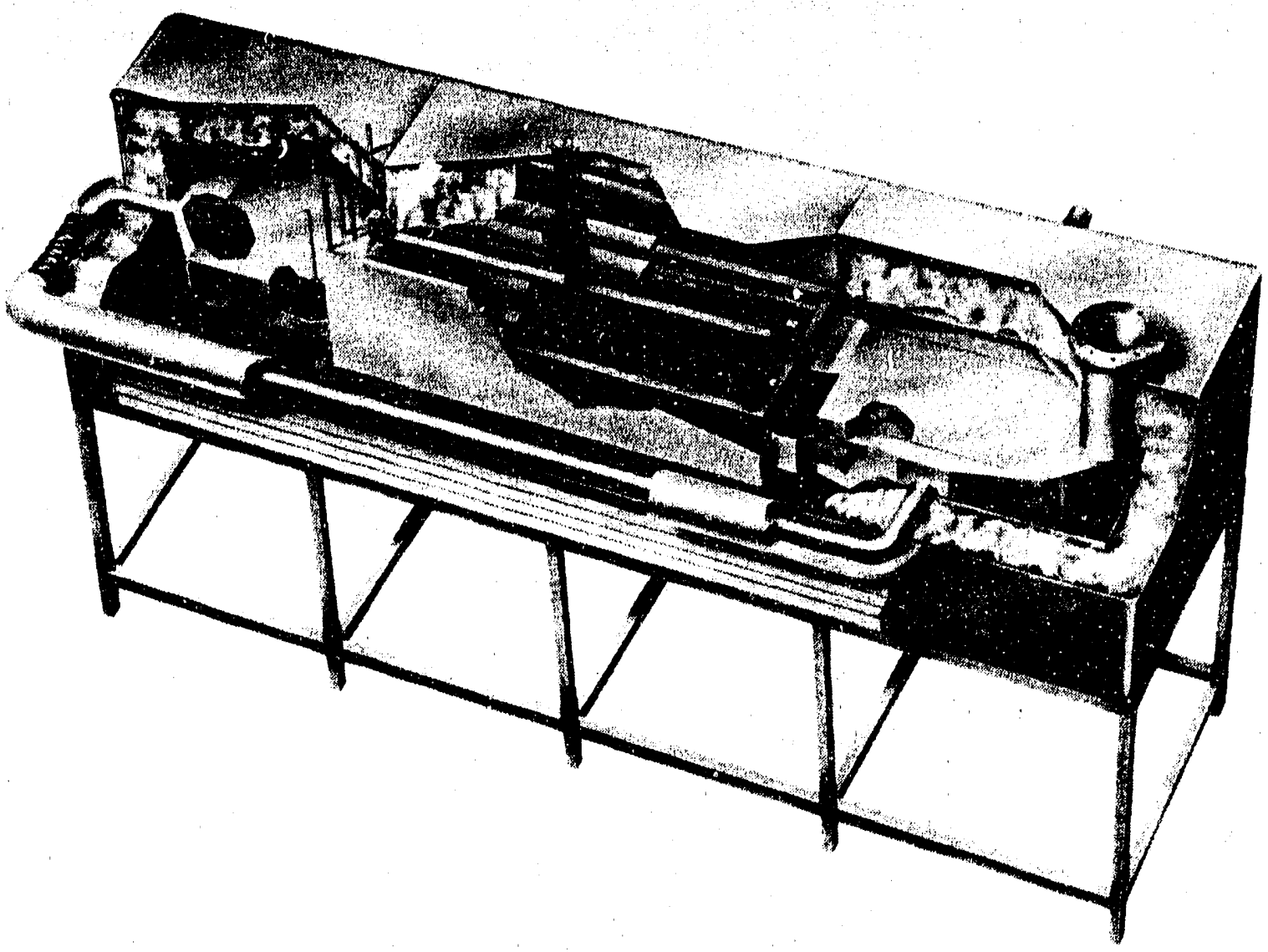

Figure 2-20. Final Design Concept for 200 XPB Battery Sub-module 
logic for larger scale units. The study considered a $20-$ cell series string battery with 150 strings in parallel. The cells were CSPL high-capacity XPB cells, designated $\mathrm{XPB}_{\text {hc. This }}$ battery configuration is identical to that of the EPRI 100-MWh battery being studied in a detailed manner through charge and discharge cycles. Effects of cell failures during the life of the battery were calculated using the approach taken in the EPRI modeling, in which battery performance is calculated as a function of the fraction of failed cells, and the effects of cell durability characteristics are considered separately.

The study yielded the current-time behavior for each of the strings in the battery. From the results, data for representative strir.gs with differing numbers of failed cells were chosen for further analysis and presentation. Figure 2-21 shows typical results from this analysis; in the figure are plotted the states-of-charge of representative strings with zero, one, two, and three failed cells (i.e., 20,19,18 and 17 active cells) as the battery is cycled through a complete discharge and charge.

The modeling showed that the cell failures in seriesstring batteries lead to substantial current imbalances between strings during discharge and charge. Figures
2-22 and 2-23 show the string currents during the discharge and charge cycles, respectively, of the battery with $2.5 \%$ failed cells. The $2.5 \%$ failed cell level was chosen arbitrarily as one in which enough cells had failed to give significant effects on the performance of the battery, but not so many as to make the battery inoperable. In Figure 2-22, currents in individual strings range from zero amperes to over 20 amperes at the end of discharge. Similar variations are seen durin/z charging. The data also show that the current through a particular string varies significantly with time during the course of charging and discharging the battery. For instance, as shown in Figure 2-23, strings with 20 active cells begin charging at about 10 amperes; then the current increases to over 20 amperes before dropping to nearly zero amperes at end-of-charge.

An important result from Figures 2-22 and 2-23 is that the presence of only a few failed cells in a string are enough to completely prevent it from participating in the battery cycling. At $2.5 \%$ failed cells, for instance, strings with only three failed cells (17 active cells) do not contribute at all to the discharging or charging of the battery. Those strings sit idle in the battery until later in its life, when they begin to contribute again.

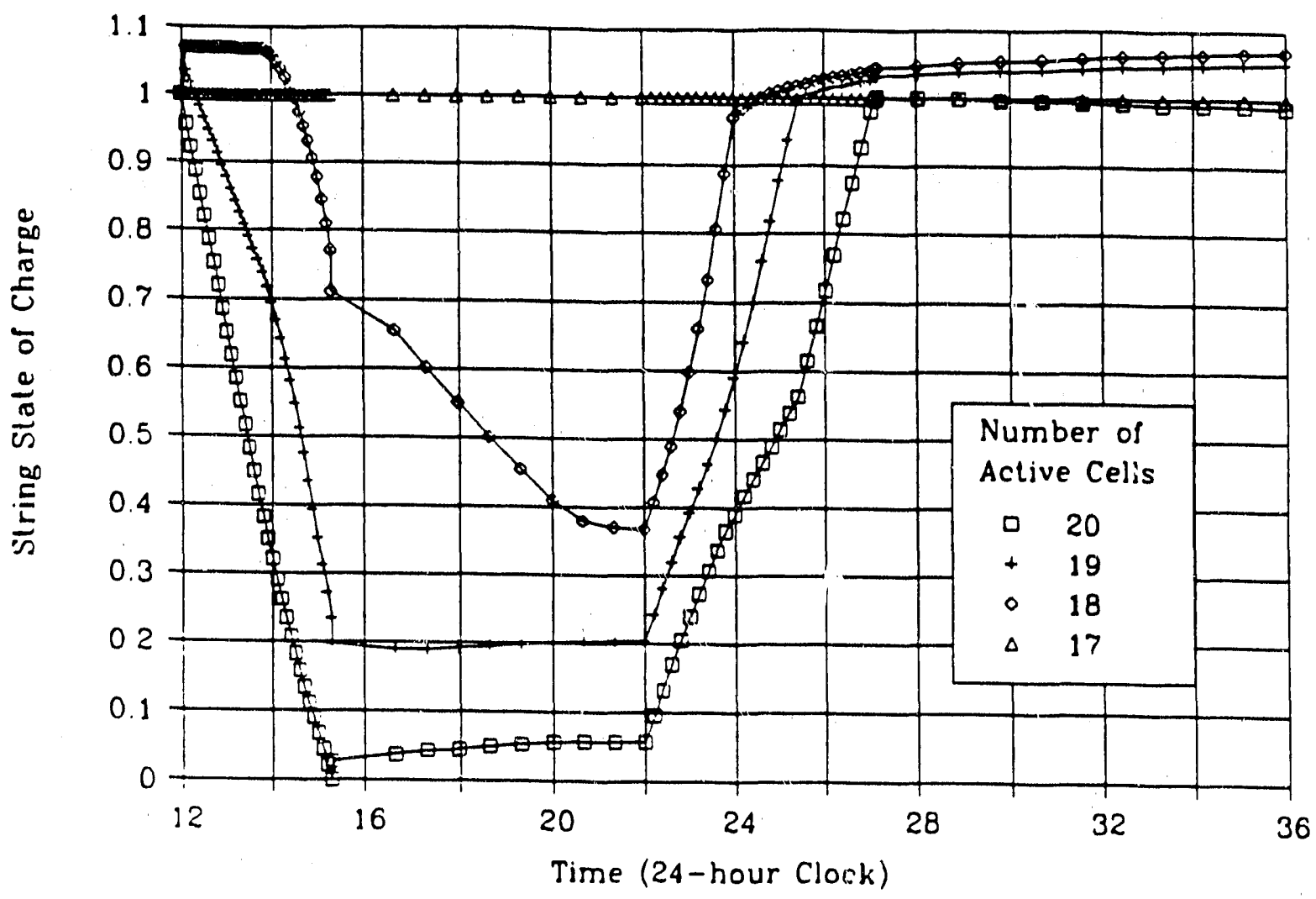

Figure 2-21. String State-of-Charge During Cycling of a Battery with $1502 \%$-Cell Strings and 2.5\% Failed Cells. 


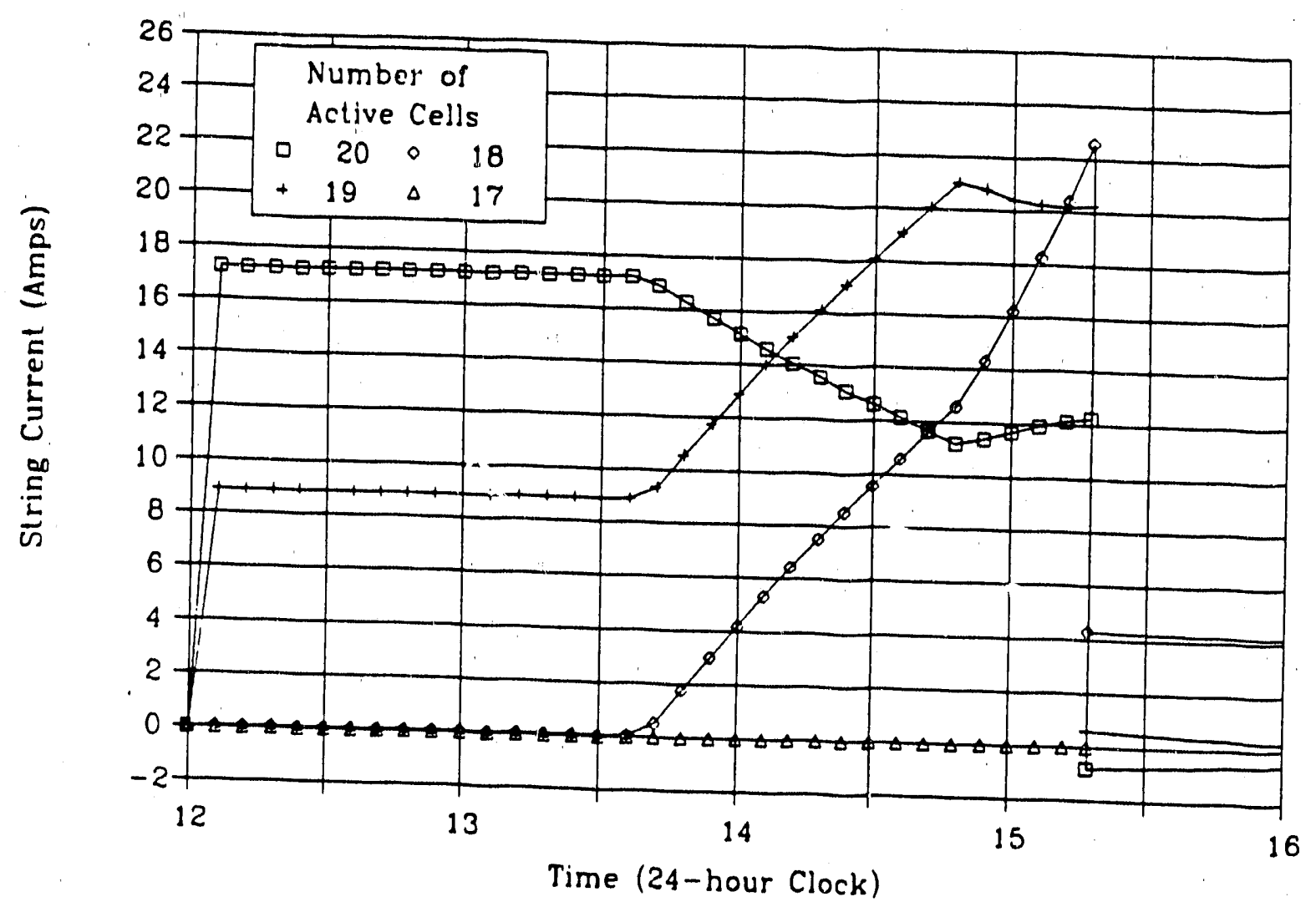

Figure 2-22. String Currents During Discharge of a Battery with 150 20-Cell Strings and 2.5\% Failed Cells

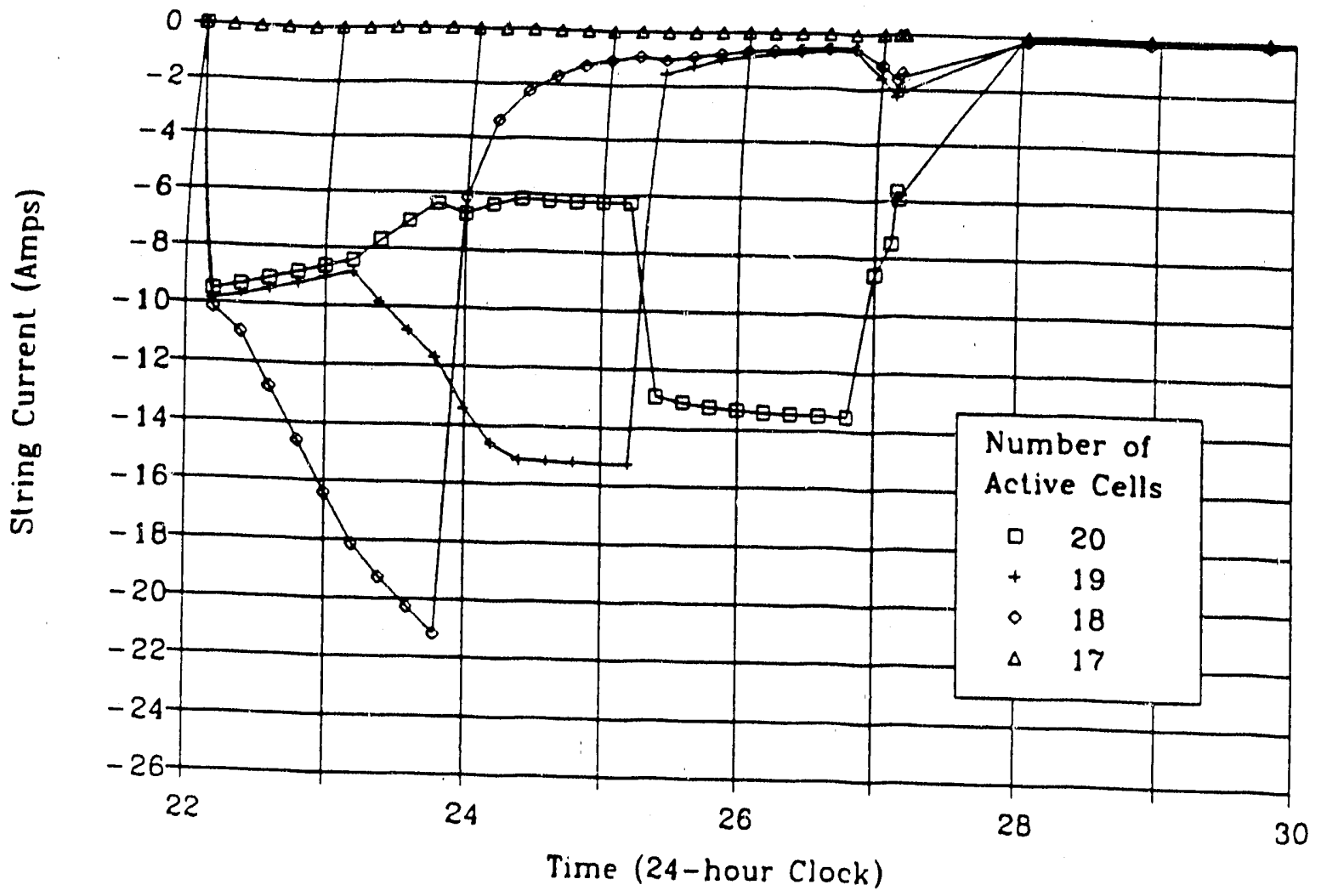

Figure 2-23. String Currents During Charge of a Battery with 150 20.Cell Strings and 2.5\% Failed Cells 
The current imbalances observed between strings at $2.5 \%$ failed cells were seen to worsen as the battery ages and more cells failed. Figures 2-24 and 2-25 show string currents during discharge and charge, respectively, with $10 \%$ failed cells in the battery. As shown in the figures, the magnitudes of the string currents are increased significantly at this larger number of failed cells. Also, due to the decrease in the battery open ircuit voltage strings with 17 cells are now able to contribute to the battery cycling. However, note that strings with 16 good cells are still not involved in the cycling at this point.

It was thought that longer cell strings might ameliorate the situation of current imbalances, since variations in open-circuit voltage between strings would be smaller as a percentage of total voltage with longer strings. Therefore, under the parallel EPRI program, modeling of a comparable 40-cell string battery was conducted and compared to the 20-cell string results. For completeness, some results of that study are shown in Figure 2-26. In the figure, the capacity degradation of the 40-cell string battery is seen to be worse than that for the 20-cell string configuration. The larger variations in the string currents for the 40-cell string battery result from the larger absolute variations in open-circuit voltage between strings.
Effects of the battery operation schedule were also determined in this study. The effect of a 3.33-hour discharge beginning at noon followed by a 5-hour charge starting at 10:00 p.m. was compared to continuous discharge/charge cycling. The noon/10:00 p.m. cycle regime was chosen to represent a possible load profile for a utility battery used for load-levelling. During the open-circuit period following a discharge, differences in string voltage arise due to differing numbers of failed cells between strings and differences in the string statesof-charge (hence cell open-circuit voltages). These voltage differences between strings lead to significant equilibration currents, that were found to exist at levels of several amperes over periods of a few hours after the end of discharge.

Figure 2-27 shows these equilibration currents at the end of discharge for a 20.cell string battery with $2.5 \%$ failed cells. At the top-of-charge, equilibration currents are much less important than they are at the end of discharge. This is primarily due to two effects. The most important effect is that as cells come to top-ofcharge, the resistance becomes very high that tends to block further current flow into the strings to which they belong. Thus, even though voltage differences exist between strings at top-of-charge, equilibration currents are

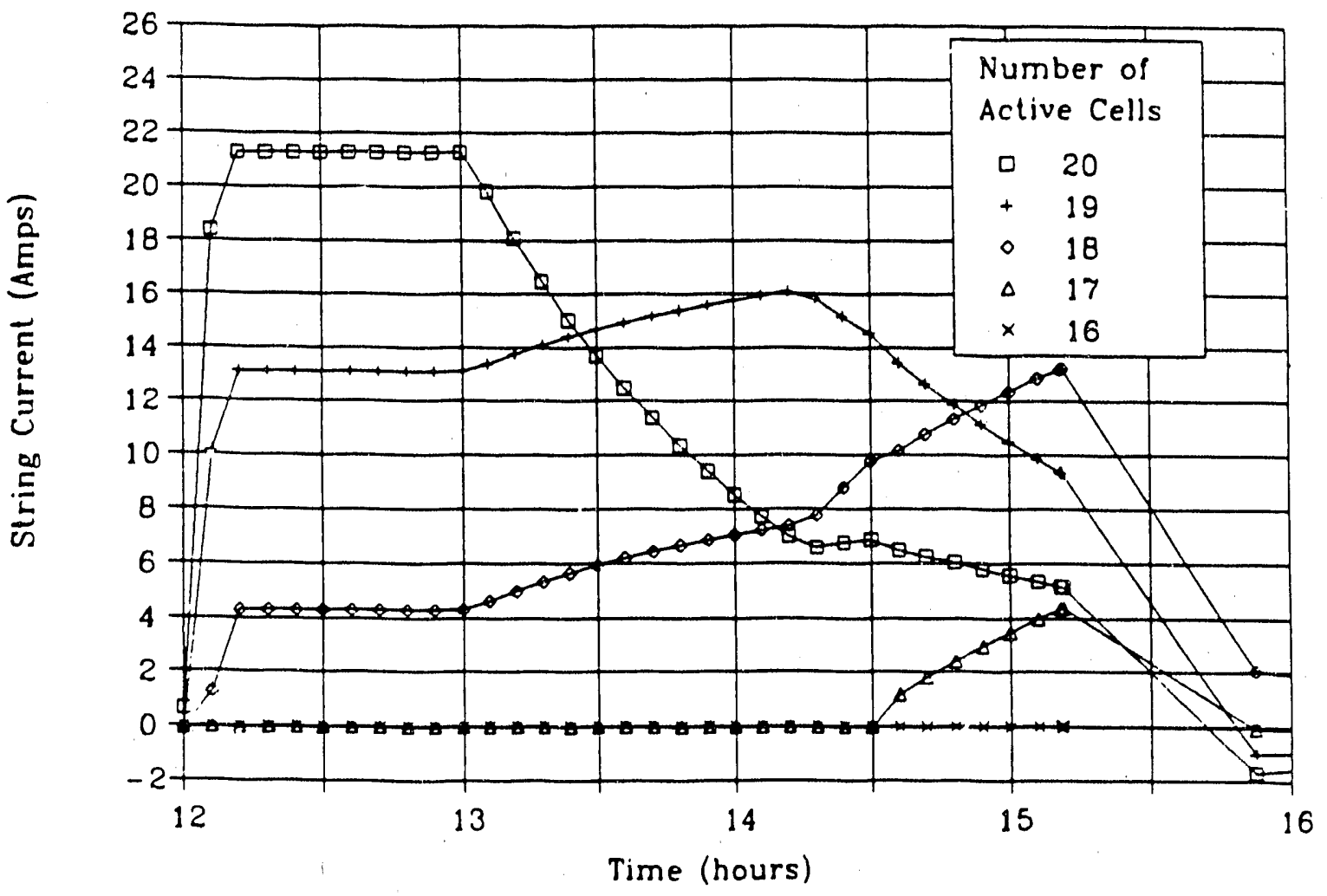

Figure 2-24. String Currents During Discharge of a Batiery with 150 20.Celi Strings and $10 \%$ Failed Cells 


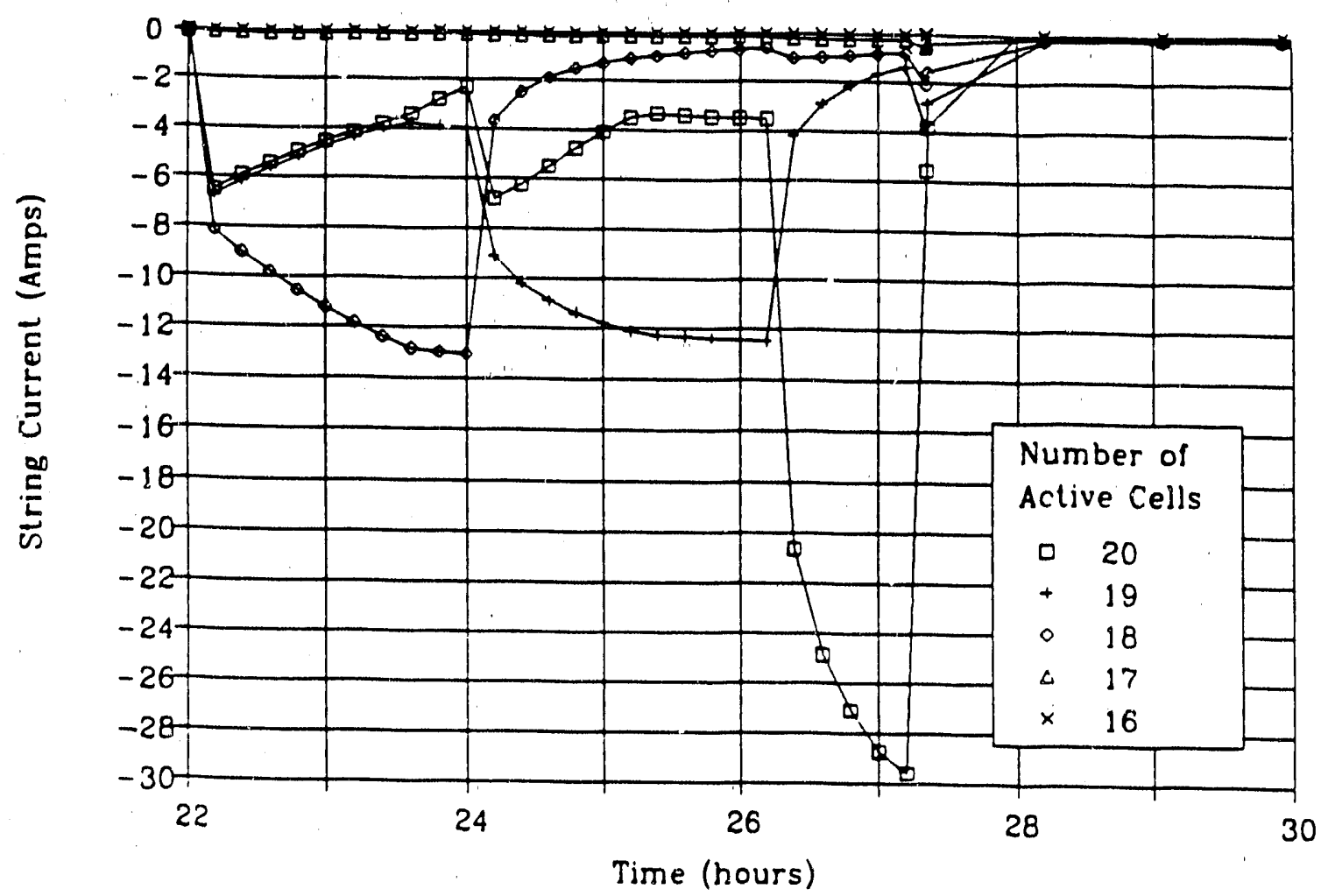

Figure 2-25. String Currents During Charge of a Battery with 150 20-Cell Strings and 10\% Failed Cells

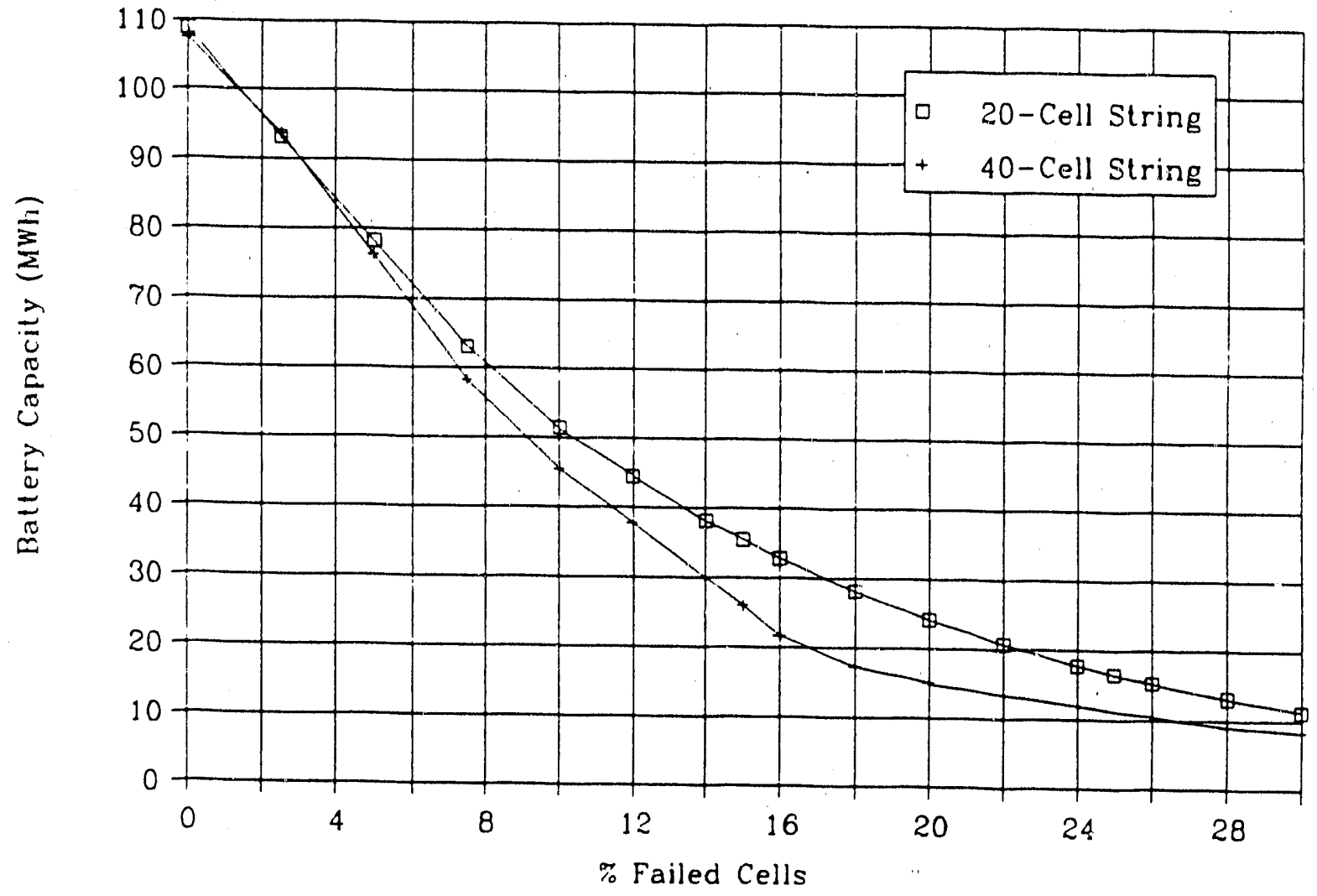

Figure 2-26. Comparison of 20-Cell and 40-Cell String Battery Capacity 


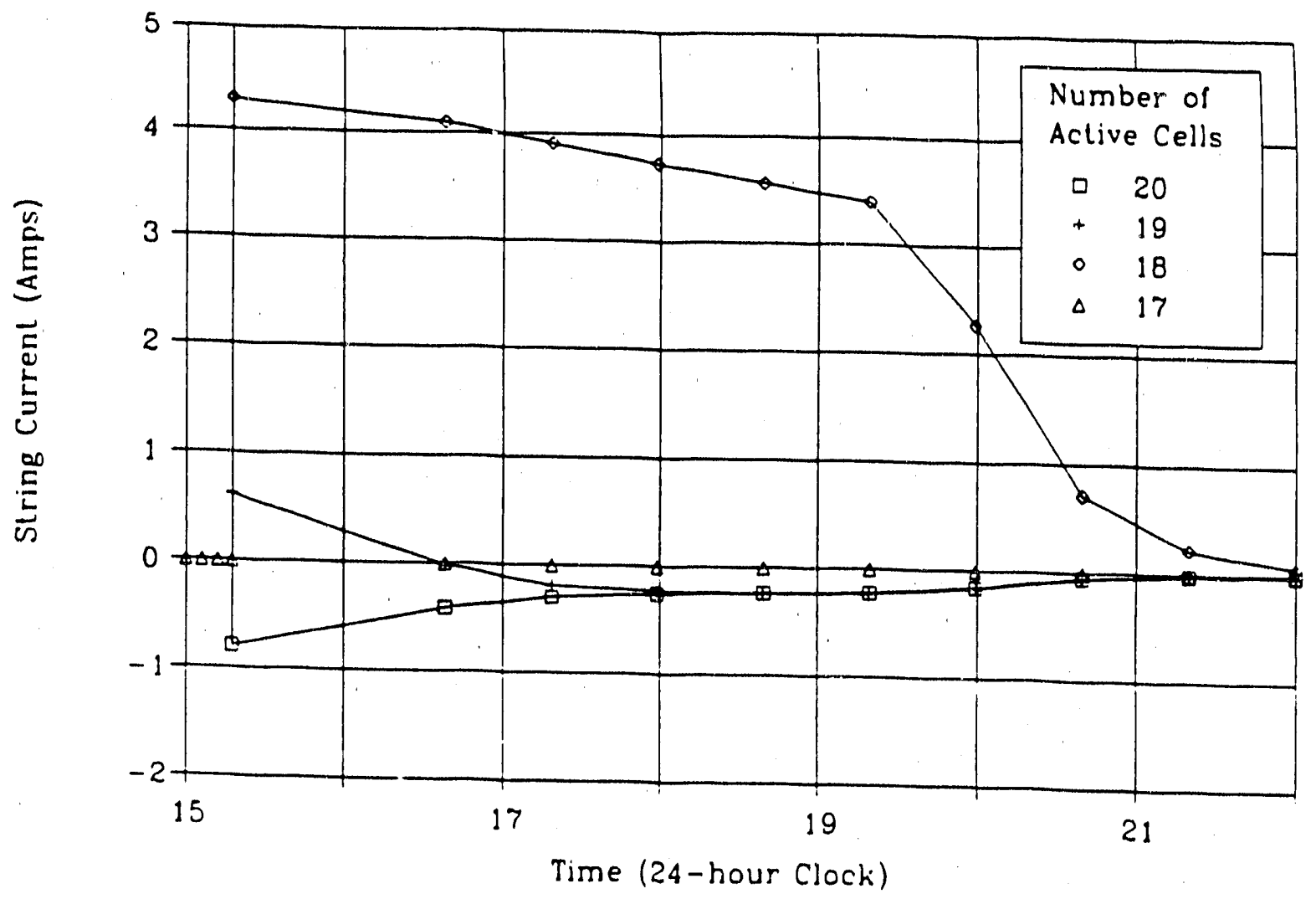

Figure 2-27. Equilibration Currents After Discharge of a Battery with 150 20-Cell Strings and 2.5\% Failed Cells

reduced due to the high resistances of the fully-charged strings. This does not happen at end-of-discharge because under those conditions, none of the strings approach a fully-charged condition. The second effect at top-of-charge is that all strings are at their maximum open-circuit voltages, minimizing the voltage differences between strings. In contrast, at end-of-discharge the cells in the "best" strings are fully discharged while those in strings with several failed cells are nearly charged or fully charged, leading to significant potential differences between strings.

Finally, Figure 2-28 shows the degradation in capacity of a battery operated under continuous cycling and one operated on the noon/10:00 p.m. utility battery cycle. The capacity degradation resulting from the equilibration currents that flow in the battery operated on the utility battery cycles increases in a nearly linear fashion with the percentage of failed cells. The overall magnitude of the degradation is only a few percent up to $10 \%$ failed cells in the battery.

\section{Conceptual Battery Design}

Consideration was given to the overall design of large-scale batteries. The use of active thermal management (e.g., air flow cooling) adds to the cost and space requirement of an SES system. It also penalizes the footpr $t$ of the battery. Siudies conducted under the EPRI Phase P contract identified the costs of thermal management as being a significant item. Cell and module testing conducted during this program suggests that it might be possible to operate the battery at lower temperatures without significant performance degradation. This option opens the possibility of allowing the battery to therma!ly float during non-operational periods at a temperature of around $300^{\circ} \mathrm{C}$ and then allowing the temperature to rise during the discharge. A a rect outcome of successful implementation of this stt tegy is the ability to simplify the battery structure.

A conceptual design was formulated in which the principle of using discrete, self-contained, sub-scale batteries (called monobloes) was considered. A proposed monobloc is shown in Figure 2-29. This unit consists of $448 \mathrm{XPB}$ cells arranged as 8-cell strings, each delivoring 3,2" $\mathrm{Ah}$ at a nominal 16 volts. These monoblocs were networked into a $100-\mathrm{MWh}$ SES battery as shown in Figure 2-30, 132 monoblocs are connected in series and 6 of these 2,000-volt chains are connected to each of 3,10-MW power conditioning systems (PCS). Each 132 monobloc unit is housed in its own thermal environment and could be changed out as a 


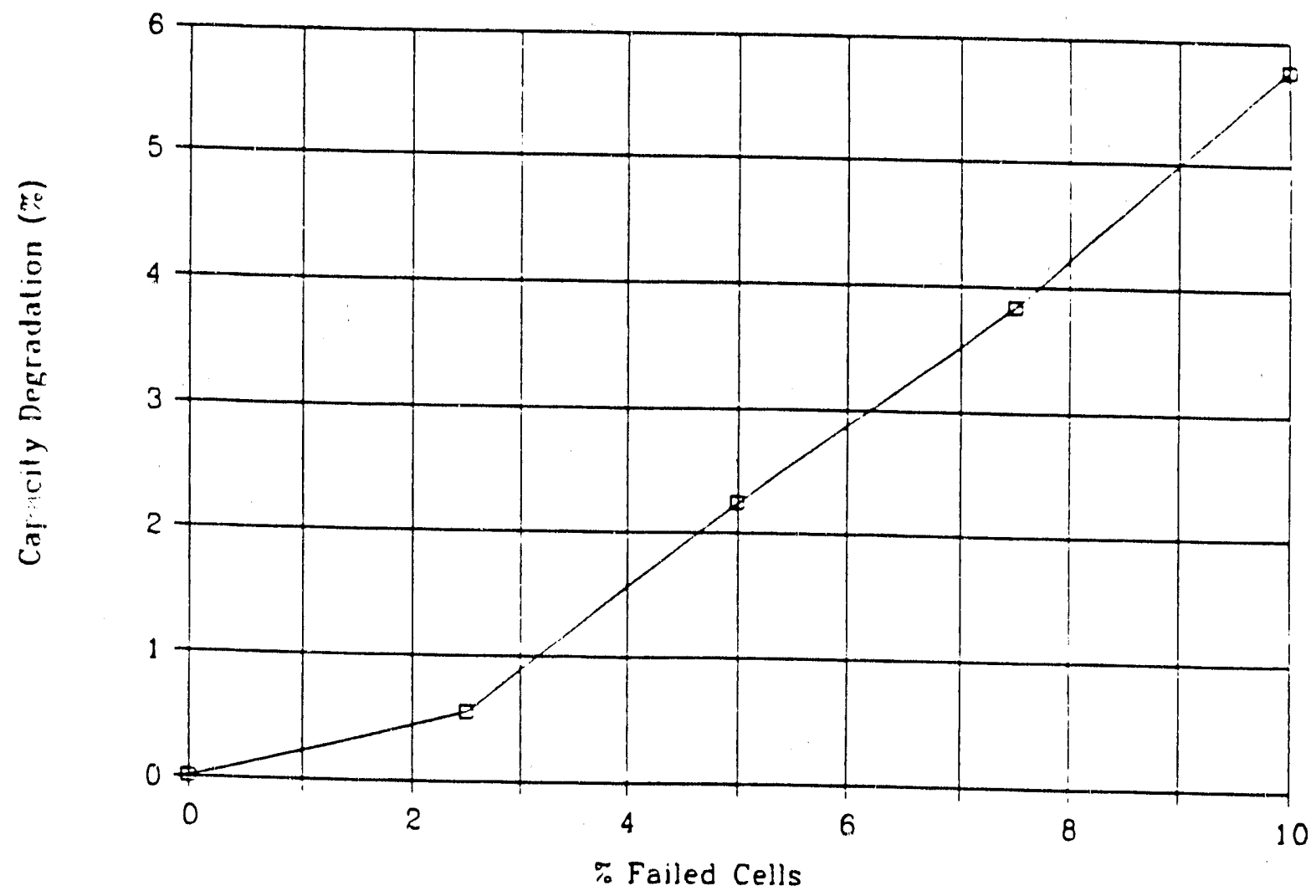

Figure 2-28. Capacity Degradation Due to EPRI Battery Cycling Regime

maintenance procedure without cooling the entire battery. Conceptually, maintenance would be performed by means of the crane system that is shown at the far side of the diagram. This crane would be capable of moving across the battery, removing the insulated lid to the chamber and extracting the monoblocs vertically. The advantage of the concept is its small footprint. The building dimensions are a nominal $90 \mathrm{ft}$. by $100 \mathrm{ft}$., excluding the PCS and transformer gear.

\section{Technology Evaluation}

The status of the sodium/sulfur technology was evaluated in 1989 at SNL and ANL. SNI, studied the performance of cells from CSPL, Powerplex, and Ceramatec. At ANL, the performance of two 24-cell CSPL modules was characterized and the first detailed examination of a CSPL "XPB" cell was completed. Results for each of these activities are presented in the remainder of this section.

During FY89, SNL evaluated sodium/sulfur cells and cell strings from the following developers:
- CSPL - Eighteen 10-Ah cells and four 4-cell strings from three groups of deliverables.

- Powerplex - Four 40-Ah cells from three groups of deliverables.

- Ceramatec - Two 40-Ah cells from one group.

Tables 1 through 4 provide the following informa. tion on each cell and cell string.

- SNL identification numbers

- Rated and initial capacities

- Total number of charge/discharge cycles accumulated

- Test regimes performed

- Capa:ity of the cells or strings expressed as a percent of initial capacity and measured at the same charge/discharge rate at which the initial capacity was determined.

Numerous types of tests were performed on the cells from the three developers. These tests included capacity vs charge or discharge rate, parametric, deep 


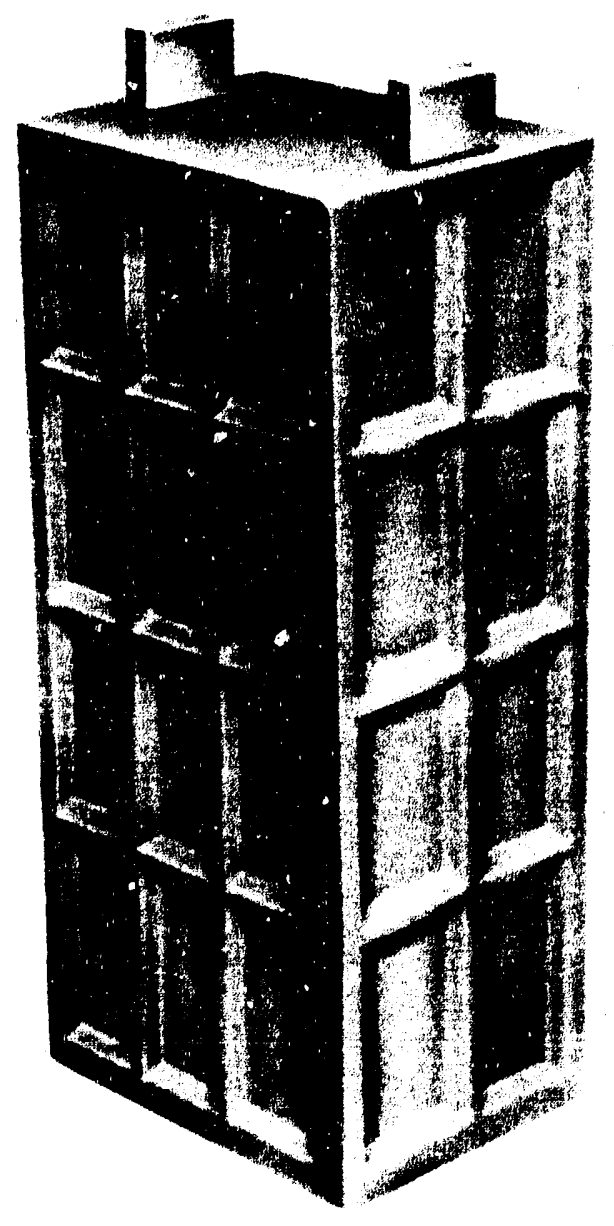

depth-of-discharge, constant powir, peak power, SFUDS, and life cycle.

\section{CSPL Technology}

During 1989, SNL evaluated CSPL PB cells and 4-cell strings which were made up of $\mathrm{PB}$ cells in series. Three groups of deliverables were tested during this time period. The first two groups of deliverables had the MKIII seal design (direct metal-bonded sodiumelectrode closure and a sulfur-electrode closure that employs chromized mild steel and an aluminum interstrate). However, these cells did not feature the totally enclosed safety containment of the sodium electrode. A summary of the testing activities conducted on the first two groups of cells is shown in Table 2-3.

The newest group of cells and strings (group three) were all equipped with a metal tube that acts as a safety containment device of the sodium electrode. The rated capacity of these cells and strings is $10.06 \mathrm{Ah}$. This value is somewhat higher than that of previously tested cells and is due to an increase in sulfur weight. Several of these cells and strings had been on test at CSPL and had experienced 47 cycles while others had never been heated. These previously tested cells were placed on test at SNL to compare the results obtained by CSPL and to determine if failure problems could be linked to shipping virgin cells. Due to a fabrication error, this entire group of cells had a glass sealing problem between the alfa cap and beta" alumina. CSPL indicated that this problem would not affect the performance of the cells but could limit the life of the cells to approximately 200 cycles. The summary of testing activities for these cells

Figure 2-29. Monobloc Concept for SES Battery cells is shown in Table $2-4$.

\section{Design}

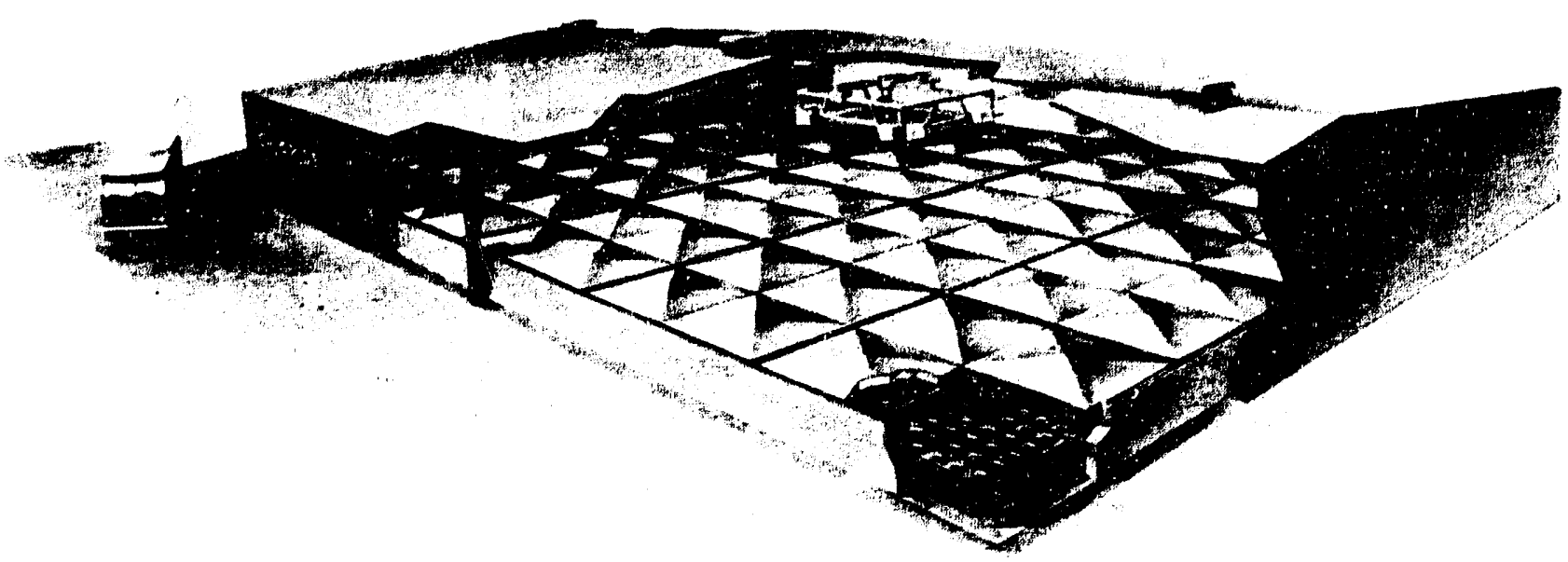

Figure 2-30. SES Battery Conceptual Design Based on Monobloc Concept 


\section{Table 2-3. CSPL Cell Test Summary}

\begin{tabular}{|c|c|c|c|c|c|}
\hline $\begin{array}{c}\text { SNL } \\
\text { Number } \\
\end{array}$ & $\begin{array}{r}\text { Cape } \\
\text { Rated } \\
\end{array}$ & $\begin{array}{l}\text { (Ah) } \\
\text { Initial } \\
\end{array}$ & $\begin{array}{c}\text { Number } \\
\text { of } \\
\text { Cycles }\end{array}$ & $\begin{array}{l}\text { Test } \\
\text { Regimes } \\
\text { Run }\end{array}$ & $\begin{array}{c}\text { Present or Final } \\
\text { Capacity } \\
\text { (\% of Initial) }\end{array}$ \\
\hline 464 (PB) & 8.5 & 8.0 & $457^{\star}$ & $1,2,7$ & 94 \\
\hline 465 (PB) & 8.5 & 8.0 & $487^{*}$ & $1,2,4,5$ & 97 \\
\hline 469 (PB) & 8.6 & 8.0 & 780 & $1,2,5,6,7,8$ & 69 \\
\hline 470 (PB) & 8.6 & 8.1 & 923 & $1,2,8$ & 85 \\
\hline 471 (PB) & 8.6 & 8.0 & 795 & $1,2,3$ & 85 \\
\hline 472 (PB) & 8.5 & 7.6 & $398^{\star}$ & $1,2,4$ & 100 \\
\hline 475 (PB) & 8.5 & 8.0 & $569^{*}$ & $1,4,8$ & 96 \\
\hline 476 (PB) & 8.6 & 7.9 & $307^{*}$ & 1,4 & 97 \\
\hline 480 (PB) & 8.7 & 7.9 & $166^{\star}$ & 1,4 & 100 \\
\hline 473 (STR) & 8.8 & 8.1 & $394^{*}$ & 1,8 & 94 \\
\hline 474 (STR) & 8.7 & 8.1 & 634 & $1,3,8$ & 91 \\
\hline $\begin{array}{l}\text { apacity: Dische } \\
\text { Capacity: Disc } \\
\text { from test } \\
\frac{5}{\text { vs Charge Rate }} \\
\text { \&s Discharge R } \\
\text { c Tests } \\
D \text { Test to } 1.74 \\
\text { Power Tests } \\
\text { er Tests } \\
\text { ests } \\
\text { Tests }\end{array}$ & pen-Ci & 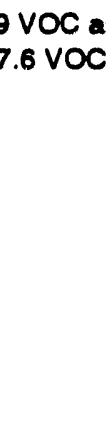 & Ialgo a & $6 \mathrm{~V}$ & \\
\hline
\end{tabular}

Charge-Rate Tests. Early in cycle life, charge-rate tests were conducted on the first and second groups of cells from CSPL in order to define a recharge phenomenon (i.e., the strong, inverse dependence of cell capacity on charge rate). The charge current was varied from $1 \mathrm{~A}$ ( $\mathrm{C} / 8$ rate) to $3 \mathrm{~A}$ (C/3 rate) in $0.5 \mathrm{~A}$ steps, and the cell temperature was varied from 330 to $375^{\circ} \mathrm{C}$ at each charge rate. Four cycles per charge rate were run at each temperature, from which average capacities were determined.

Figure 2-31, a charge-acceptance plot for cell 469 , shows that cell capacity diminished with increasing charge rate. At $375^{\circ} \mathrm{C}$, there was alınost no charge acceptance problem; however, at the lower temperatures, charge acceptance diminished dramatically. For example, at $350^{\circ} \mathrm{C}$, there was an $18 \%$ loss in capacity when the charge current varied from $1.0 \mathrm{~A}$ to $3.0 \mathrm{~A}$. For the most part, the greatest capacity losses occurred at charge rates above $2.5 \mathrm{~A}$, regardless of the operating temperature. All CSPL cells and 4-cell strings showed results similar to those of cell 469.
Discharge-Rate Tests. Discharge-rate tests were conducted on the majority of the cells of the three deliverable groups. Figure 2-32 shows test results on average capacity versus discharge rate for cells 469 , 470,471 , and 472 . The tests were run the $3 \mathrm{~A}$ (C/3 rate), $4.5 \mathrm{~A}(\mathrm{C} / 2$ rate) and $9 \mathrm{~A}(\mathrm{C} / 1$ rate $)$ to an end-of-discharge open-circuit voltage of $1.9 \mathrm{~V}$. An additional test was conducted at the $C / 3$ rate to ensure that the capacities returned to their original $C / 3$ rate values. A total of four cycles was run at each discharge rate, from which an average capacity value was determined for each rate. The capacity profiles for these cells tracked each other as the discharge rate was varied. All cells lost approximately one ampere-hour of capacity at the $\mathrm{C} / 1$ rate. This loss in capacity at the $\mathrm{C} / 1$ rate was also observed on other cells and 4-cell strings tested.

Parametric Tests. Parametric tests were conducted on a cell and 4-cell string during this reporting year. A plot of results for the parametric tests on the 4-cell string is shown in Figure 2-33. In these tests, the charge and discharge rates were varied while the cell temperature was held constant at $340^{\circ} \mathrm{C}$. This plot indi- 
Table 2-4. CSPL Cell Test Summary

\begin{tabular}{|c|c|c|c|c|c|}
\hline $\begin{array}{c}\text { SNL } \\
\text { Number }\end{array}$ & $\begin{array}{l}\text { Capacity } \\
\text { Rated }\end{array}$ & $\begin{array}{l}\text { (Ah) } \\
\text { Initial } \\
\end{array}$ & $\begin{array}{c}\text { Number } \\
\text { of } \\
\text { Cycles } \\
\end{array}$ & $\begin{array}{c}\text { Test } \\
\text { Regimes } \\
\text { Run }\end{array}$ & $\begin{array}{c}\text { Present or Final } \\
\text { Capacity } \\
\text { (\% of Initial) }\end{array}$ \\
\hline 482 (PB) & 10.06 & 8.7 & $68^{1}$ & 1 & 100 \\
\hline 483 (PB) & 10.06 & 9.7 & $53^{1,2}$ & 1 & 100 \\
\hline 484 (PB) & 10.06 & 9.1 & $69^{1}$ & 1 & 100 \\
\hline 485 (PB) & 10.06 & 9.4 & $147^{2}$ & 1,4 & 100 \\
\hline 488 (PB) & 10.06 & 10.2 & 98 & 1,3 & 0 \\
\hline 489 (PB) & 10.06 & 9.7 & $113^{2}$ & $1,2,3$ & 100 \\
\hline 491 (PB) & 10.06 & 9.6 & $107^{2}$ & 1,2 & 100 \\
\hline 492 (PB) & 10.06 & 10.2 & 93 & 1,2 & 100 \\
\hline 493 (PB) & 10.06 & 9.1 & $137^{2}$ & 1,3 & 95 \\
\hline 486 (STR) & 10.06 & 10.0 & $126^{2}$ & $1,2,3$ & 98 \\
\hline 487 (STR) & 10.06 & 10.0 & 95 & 1,2 & 0 \\
\hline
\end{tabular}

Notes:

Coll Initial Capacity: Discharge at $\mathrm{C} / 3$ to $1.9 \mathrm{VOC}$ and Charge at $2.0 \mathrm{~A}$ to $2.4 \mathrm{~V}$

String Initial Capacity: Discharge at $C / 3$ to $7.6 \mathrm{~V}$ and Charge at $2.0 \mathrm{~A}$ to $9.6 \mathrm{~V}$

1. Removed from tost

2. Cell or string cycled 47 times at CSPL prior to SNL for testing; thus, 47 cycles must be added to the total number of cycles Test Rogimes

1. Capacity vo Charge Rate

2. Capacity vo Discharge Rate

3. Constant Power Test

4. Peak Power Tests

5. SFUDS Tests

cates that the capacity of the string decreased with an increase in charge or discharge rate.

Deep-Discharge Tests. SAIC accidentally discharged a cell to $1.74 \mathrm{~V}$ and reported that the charge-acceptance phenomenon at the higher charge rates $(3 \mathrm{~A}$ and greater) was eliminated. Deep-discharge cycles were run on a few CSPL cells at SNL in an attempt to duplicate these results. Upon completion of the tests, no conclusive evidence was observed that would indicate the elimination of the charge-acceptance phenomenon when a cell was deeply discharged. CSPL also indicated that the charge-acceptance phenomenon diminishes after a cell has completed more than 100 cycles. Indications of this have been observed on a few SNL cells and strings however, additional testing is needed to confirm these results.

Constant Power Tests. Constant power tests were performed on four cells and one 4-cell string. The unencumbered cell or string weight was used in the calculations to determine the specific energy values. Two cells weighed $0.012 \mathrm{~kg}$ and the other iwo weighed $0.130 \mathrm{~kg}$. The 4-cell string weighed $0.520 \mathrm{~kg}$. Three cycles each were run at five different specific power values $(10$
$\mathrm{W} / \mathrm{kg}, 20 \mathrm{~W} / \mathrm{kg}, 30 \mathrm{~W} / \mathrm{kg}, 40 \mathrm{~W} / \mathrm{kg}$, and $50 \mathrm{~W} / \mathrm{kg}$ ), from which average values for watt-hours removed from the cell or string were obtained. A specific energy value was then calculated for each specific power value. A Ragone plot was then generated for each cell or string. The maximum specific power for a cell or string was obtained at a specific power value of $10 \mathrm{~W} / \mathrm{kg}$. The maximum specific power for a cell was $190 \mathrm{~W} / \mathrm{kg}$.

Peak Power Tests. Peak power tests were performed on several CSPL cells. This peak power value was measured at four different depths of discharge $(0 \%$, $20 \%, 50 \%$, and $80 \%$ ). At each of these depths of discharge, the open-circuit voltage was measured. A load was then placed on the cell for approximately 2 seconds until the voltage dropped to $2 / 3$ (or in some cases $1 / 2$ ) of the open-circuit value at the given depth of discharge. At that point, the current was identified and the load was removed. Next, the cell was discharged at a constant current (determined from the 2-second discharge) for 30 seconds. The peak power was then calculated based on the current and the average discharge voltage. Specific peak power was calculated by dividing the weight of the cell into the peak power at each 


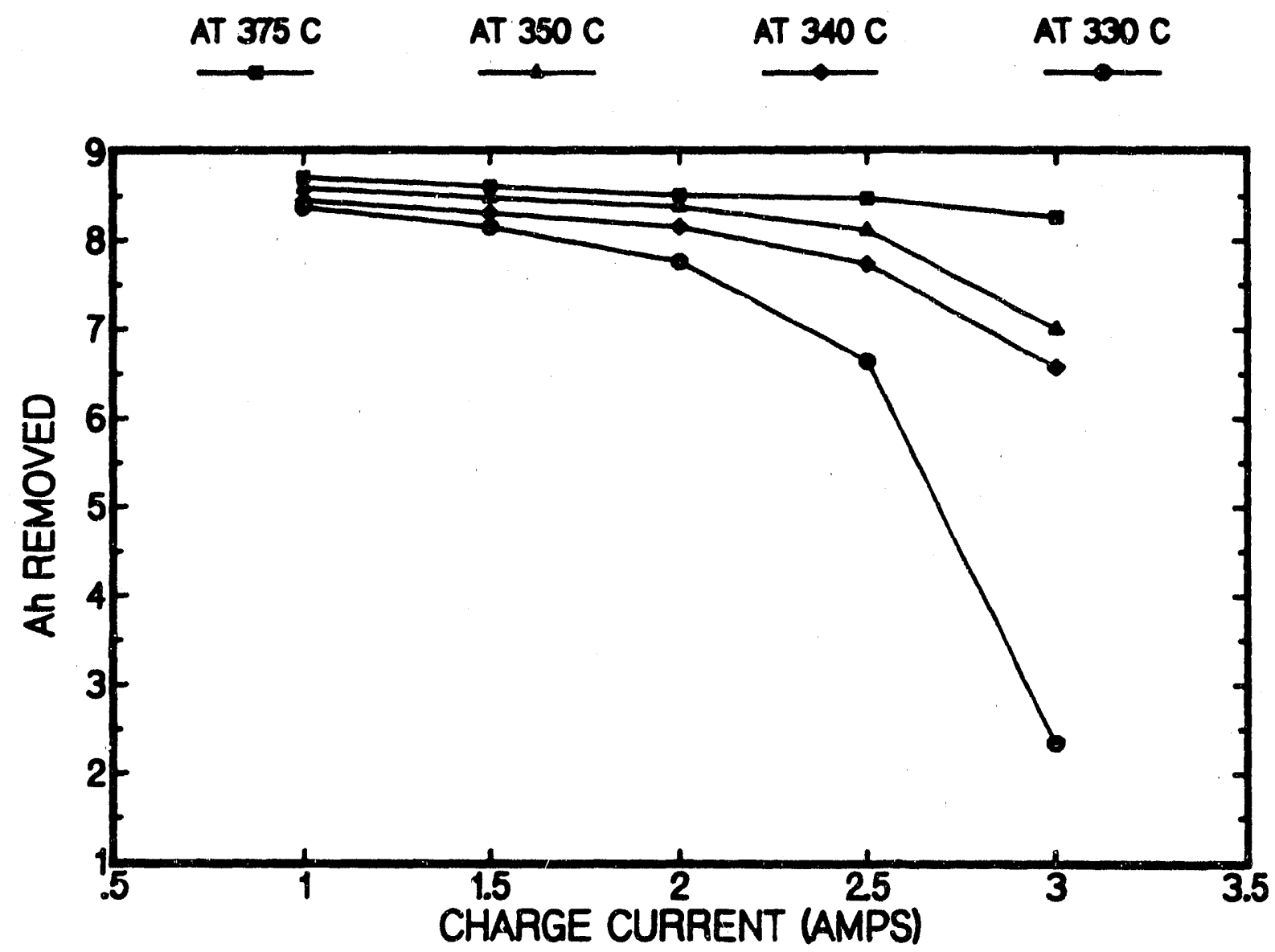

Figure 2-31. Charge Acceptance vs Charge Rate at Four Temperatures for CSPL Cell 469

depth of discharge. Specific peak power values on CSPL cells varied from approximately $170 \mathrm{~W} / \mathrm{kg}$ to $190 \mathrm{~W} / \mathrm{kg}$.

SFUDS79 Tests. SFUDS79 tests were conducted on two CSPL cells (464 and 469 ) during the reporting year. The SFUDS79 software, which was incorporated into a portable test system, consists of a power profile that is repeated until a cell can no longer provide 50 $\mathrm{W} / \mathrm{Kg}$ specific power. At that point, the test is terminated, and the number of power profile cycles (or reps) is determined. This number of power profile reps times 1.9 corresponds to the equivalent number of driving miles a cell can complete before it needs to be recharged. A typical number of reps for CSPL cells is approximately 133 . The unencumbered weight of the cell was used to define various parameters in the test. Because of this, the driving distance of a cell will always be further than a battery.

Life Cycle Tests. Two cells and a 4-cell string were placed on life cycle tests after completing other tests. These cells came from the second group of deliverables. Cell number 470 has completed 923 cycles and its present capacity is $85 \%$ of the cell's initial value of $8.1 \mathrm{Ah}$. Cell 469 was extensively tested before being placed on a life cycle test. This cell has completed 780 cycles and has only $69 \%$ of its initial capacity (8.0 Ah) remaining. The 4-cell string on life cycle has completed 634 cycles and the present capacity of the string is $91 \%$ of the initial value of $8.1 \mathrm{Ah}$.

Other Observations. No failures were observed in the cells and strings from the first two groups of deliverables from CSPL however, six cells and one 4cell string from those groups were removed from test to make room for the third group of cells. There were also three cells from the third group that were removed due to high end-of-discharge resistance. The resistance of these cells ranged from 45 mohms to 55 mohms. One additional cell and 4-cell string (SNL 488 and 487 respectively) was removed from group three due to loss of capacity. Table 2-7 shows the "best effort" results for CSPL on various tests that were performed at SNL. 


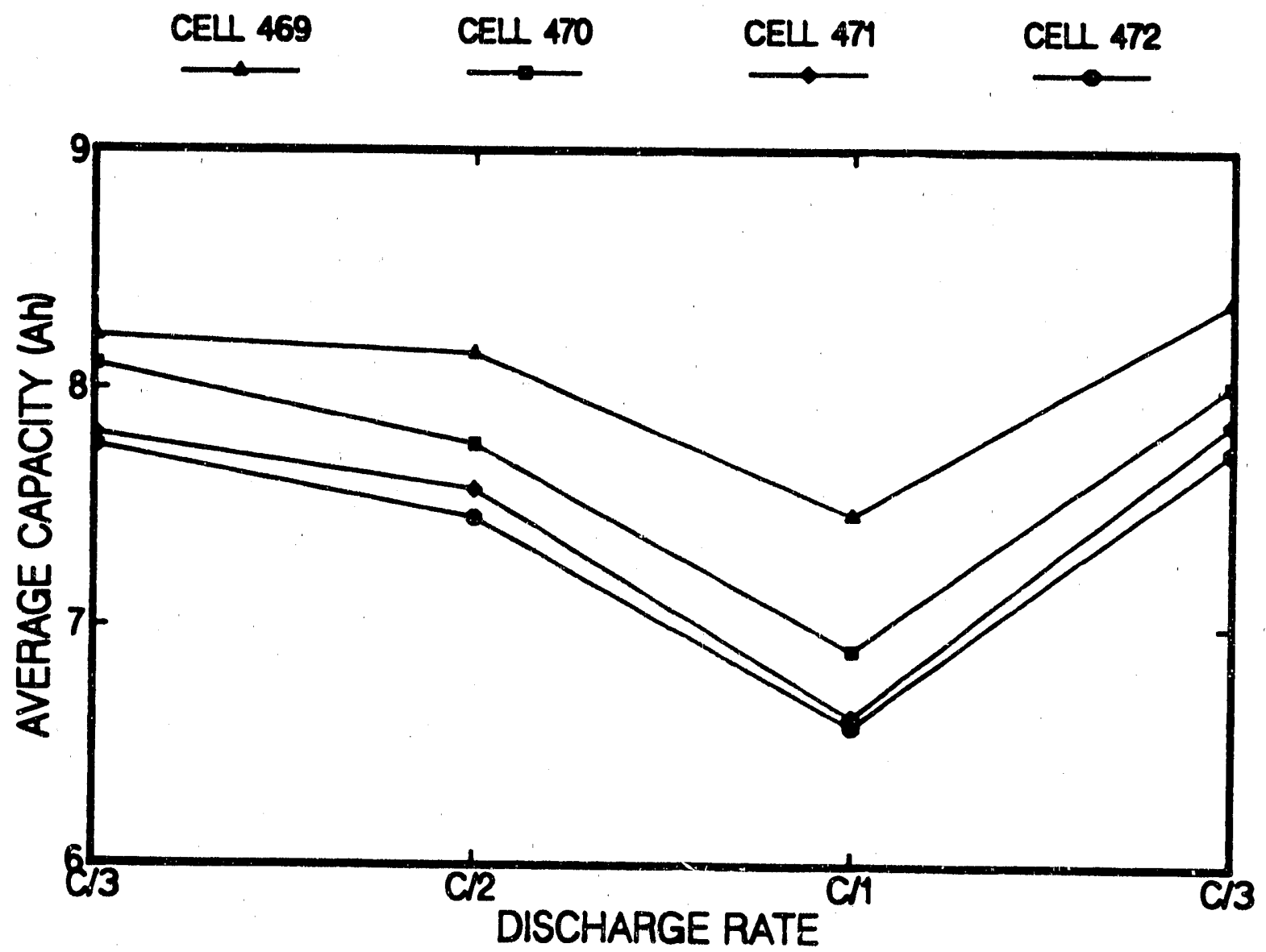

Figure 2-32. Average Capacity vs Discharge Rate on Four CSPL Cells

These tests include capacity, specific peak power, maximum specific energy, SFUDS, and life cycle.

\section{Powerplex Technology}

Four 40-Ah sodium/sulfur electric vehicle (EV) cells from Powerplex were tested at SNL during the year. As with CSPL, the cells were subjected to numerous tests. A summary of these tests is shown on Table 2-5.

Two of the four cells failed during the reporting period. Cell number 463 had been cycled 290 times and had just completed charge-acceptance tests at $375^{\circ} \mathrm{C}$ and baseline cycles were being conducted when the capacity dropped to 1.4-Ah. After unsuccessful attempts to revive the cell, it was removed from test. Close examination indicated a breach had occurred, and the cell was returned to Powerplex for posttest analysis. Shortly after completing a set of parametric tests, cell 478 failed and was removed from test. It appeared that this cell also experienced a breach. This cell completed only 267 cycles.

Parametric Tests. A parametric test plan, provided by Powerplex, was conducted on two cells. The plan suggested that the cells be discharged at a $3 \mathrm{~A}$ rate until the dynamic open-circuit voltage reaches 1.78 $\mathrm{V}+0.02 \mathrm{~V}$. The cells were then charged at four different current rates ( $3 \mathrm{~A}, 5 \mathrm{~A}, 8 \mathrm{~A}$, and $12 \mathrm{~A})$ to an end-of- charge voltage of $2.4 \mathrm{~V}$. The test was repeated six times at each of these charge rates and an average capacity was obtained. The tests started at a cell temperature of $350^{\circ} \mathrm{C}$ and were repeated at $330^{\circ} \mathrm{C}$, $310^{\circ} \mathrm{C}$, and $290^{\circ} \mathrm{C}$. Cell 477 started at the highest temperature, while cell 478 started at the lowest temperature. Discharge problems at the lower temperatures that related to the mole fraction of sulfur caused the tests to be terminated. Only the data at the higher temperatures were obtained and these results are shown in Figure 2.34. This plot illustrates how recharge capacity decreases at the higher charge rate and lower cell temperature. 


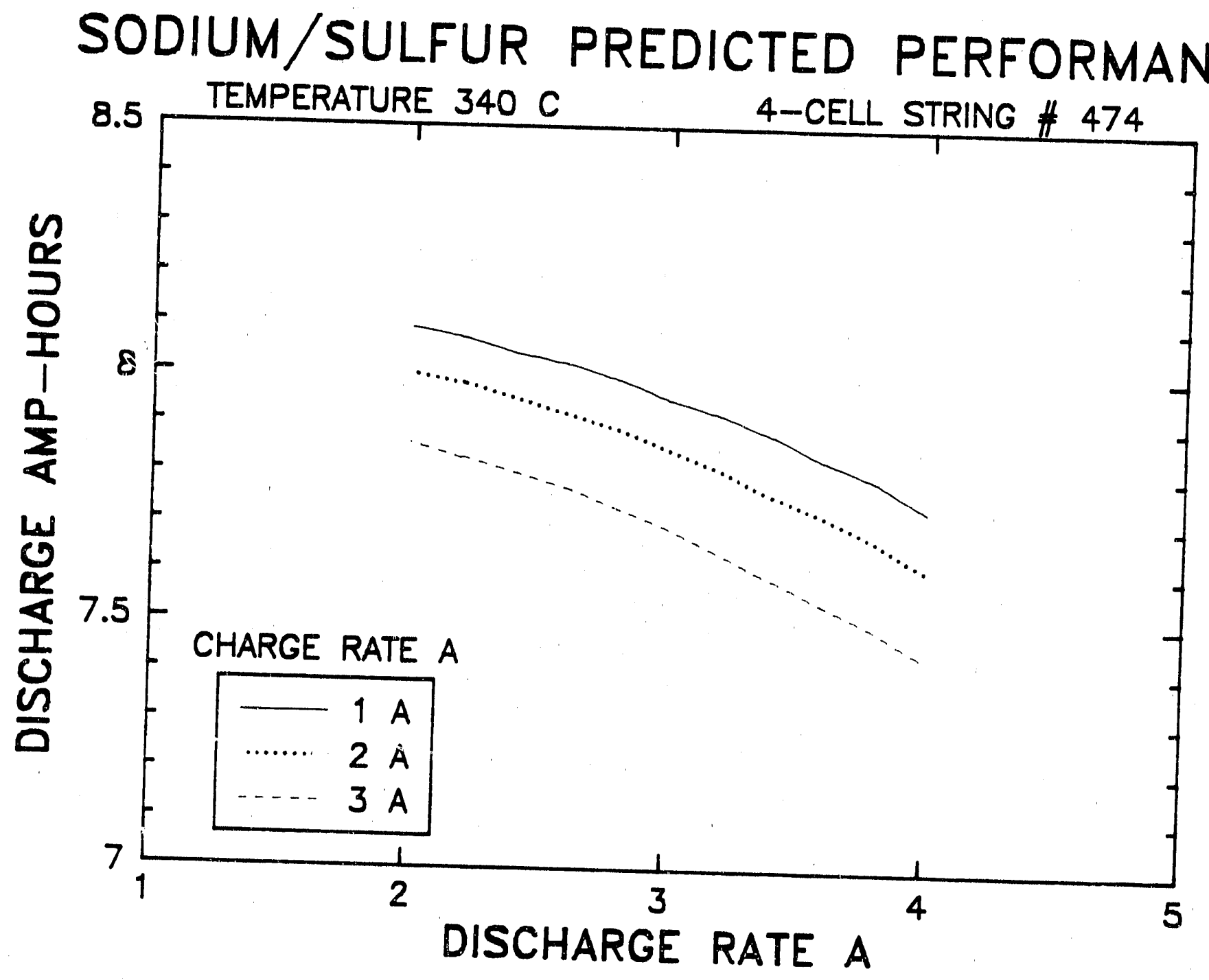

Figure 2-33. Parametric Test Results for CSPL 4-cell String \#474

Life Cycle Test. After completing several other test regimes, cell 462 was placed on a life cycle test. It has completed 1,230 cycles and the present capacity of the cell is $80.3 \%$ of its initial capacity value. Normally, cells are removed from test when the capacity falls below $85 \%$ of the initial capacity value; however, this cell will continue with the life cycle test until its capacity falls below $75 \%$ of the initial capacity.

Table 2.7 shows the best results obtained on the Powerplex cells for the various tests performed. These values compare favorably with the other teclinologies. Test equipment in the laboratory will have to be modified to accommodate the high current levels re- quired to perform peak power tests on Powerplex cells. Thus, a value for specific peak power has not been measured yet at SNL.

\section{Ceramatec Technology}

Two 40-Ah sodium/sulfur EV cells from Ceramatec have been on test for nearly two years and the majority of the test regimes were completed in 1988. Table 2-6 summarizes the characteristics of the SNL evaluation results on these cells. During most of 1989 , these two cells were on life cycle tests; however, a peak power test was conducted on cell number 454 . The maximum 


\section{Table 2-5. Powerplex Cell Test Summary}

\begin{tabular}{|c|c|c|c|c|c|}
\hline $\begin{array}{l}\text { SNL } \\
\text { Number }\end{array}$ & $\begin{array}{l}\text { Cape } \\
\text { Rated }\end{array}$ & $\begin{array}{l}y \text { (Ah) } \\
\text { Initital }\end{array}$ & $\begin{array}{l}\text { Number } \\
\text { of } \\
\text { Cvcles }\end{array}$ & $\begin{array}{l}\text { Test } \\
\text { Regimes } \\
\text { Run }\end{array}$ & $\begin{array}{c}\text { Present or Final } \\
\text { Capacity } \\
\text { (\% of Initial) }\end{array}$ \\
\hline 462 & 38. & $11.0^{1}$ & 1,230 & $1,2,3,4,8$ & $80.3^{1}$ \\
\hline 463 & 38.5 & $35.9 / 32.5^{1}$ & $290^{2}$ & $1,2,3,4$ & $0.0^{1}$ \\
\hline 477 & 38.4 & $36.4 / 34.1^{1}$ & 446 & $1,2,4,5,6,7,8$ & $96.2^{1}$ \\
\hline 478 & 39.4 & $37.4 / 33.4^{1}$ & $267^{2}$ & 1,25 & $99.7^{1}$ \\
\hline
\end{tabular}

\footnotetext{
Notos:

2. Cell Failed

Test Regimes

1. Capacity Tests at $\mathrm{C} / 8$ and $\mathrm{C} / 2,4$

2. Baseline Tosts

3. Capacity vs Discharge Rate

4. Capacity vs Charge Rate

5. Parametric Tests

6. Constant Power Tests

7. SFUDS Tests

8. Life Cycle Tests
}

Powerplex Rated Capacity: Discharged at $\mathrm{C} / 8$ to $1.8 \mathrm{VOC}$ and Charged at $8.0 \mathrm{~A}$ to $2.8 \mathrm{~V}$ at $350^{\circ} \mathrm{C}$

Initial Capacity: Discharged at $\mathrm{C} / 8$ or $\mathrm{C} / 2.4$ to $1.8 \mathrm{VOC}$ and Charged at $8.0 \mathrm{~A}$ to $2.8 \mathrm{~V}$ at $350^{\circ} \mathrm{C}$

1. Discharged at $\mathrm{C} / 2.4$ to $1.8 \mathrm{VOC}$ and Charged at $8.0 \mathrm{~A}$ to $2.8 \mathrm{~V}$

specific peak power of this cell is $185 \mathrm{~W} / \mathrm{kg}$. This value was obtained at $20 \%$ depth-of-cischarge. The cell was then placed back on the life cycle test. Cell' number 454 has completed over 1,100 cycles and cell number 455 has been cycled over 1,200 times. The capacity of these cells remains at over $98 \%$ of their initially measured values. Tabie $2-7$ shows the "best effort" results for these cells on the test regimes run.

\section{ANL Performance Evaluation}

Performance and life characterization testing was continued at the ANL Analysis \& Diagnostic Laboratory (ADL) on two 24-cell sodium/sulfur modules fabricated by CSPL. Both modules were rated at $60-\mathrm{Ah}, 480-\mathrm{Wh}$ and contained 24 cells configured into six parallelstrings of four series-connected cells. One module (\#2) was removed from test after twelve months and 339 cycles of operation and replaced with the second module (\#3) which had cells of a newer safety design. Testing of module \#3 was halted after only 108 cycles due to an abrupt loss of capacity. The capacity loss was the result of seal failures in three cells in different strings. CSPL indicated that the seal problem was due to improper glazing and an improved module is to be sent to ANL.

Module \#2 had been operated since September 1988 and had accumulated 339 cycles before its life test was voluntarily halted. This module contained MkIIa cells, which have an improved seal design. A history plot of its caracity for $3-\mathrm{h}$ rate (15-A) discharges is given in Figure 2-35. Module resistance at the end-of-discharge (EOD) is also plotted in the figure. The data plots show that on its last discharge, the module still retained $\sim 84 \%$ of its maxinum capacity (51.9-Ah, 403-Wh on cycle \#30). The plots also show that there was virtually no change in module EOD resistance ( $28 \mathrm{mohms}$ ) with life.

The first 140 cycles of operation were used for module conditioning, charging studies, and performance characterization tests. A maximum capacity of $51.9 \mathrm{Ah}(403 \mathrm{Wh})$ was obtained at a 15-A discharge rate $(3 \mathrm{~h})$ to a module IR-free cutoff voltage of $7.6 \mathrm{~V}$ (1.9 $\mathrm{V} /$ cell). Measurements of module energy vs constant power discharge rate for weight burdens of $0 \%$ and $50 \%$ were performed. The results showed that available specific energy declined from 151 to $134 \mathrm{Wh} / \mathrm{kg}$ for a 10 to $50 \mathrm{~W} / \mathrm{kg}$ increase in specific power discharge rate with a $0 \%$ burden (cell weight only). With a $50 \%$ weight burden, the specific energy decreased from $~ 99$ to $80 \mathrm{Wh} / \mathrm{kg}$ for the same increase in discharge rate. A rapid increase in module temperature (by $30^{\circ} \mathrm{C}$ ) was observed during discharges at a constant-power rate of $343 \mathrm{~W}(80 \mathrm{~W} / \mathrm{kg}, 50 \%$ burden $)$. The temperature rise resulted in increased available energy $(79 \mathrm{Wh} / \mathrm{kg})$ and 


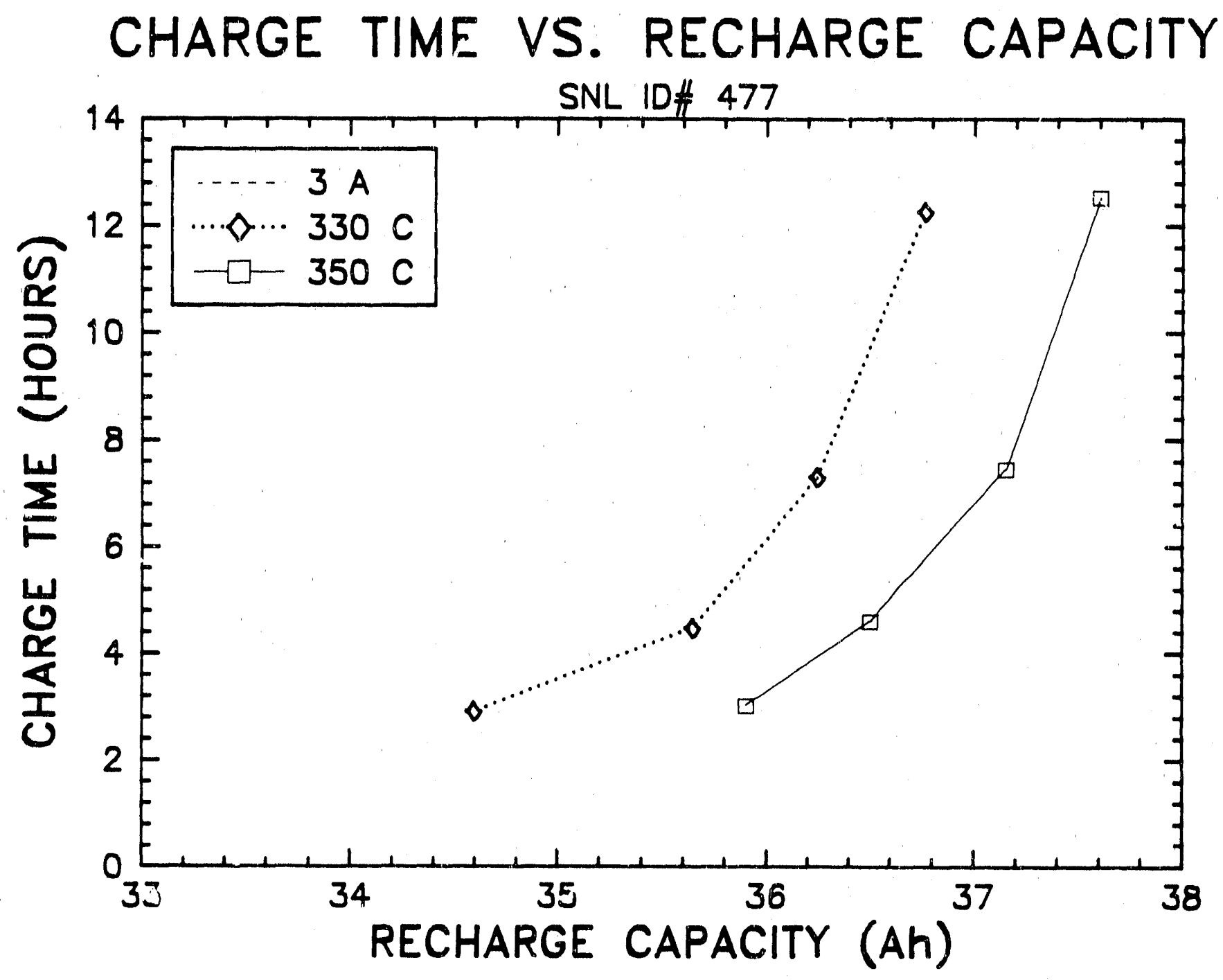

Figure 2-34. Parametric Test Results for Powerplex Cell \$477

decreased module resistance ( -24 mohms), but appears to indicate the maximum discharge rate for this module package and thermal management. Test results also show that the module (with a $50 \%$ weight burden) can provide a hill climbing power output of $45 \mathrm{~W} / \mathrm{kg}$ for $\mathrm{six}$ minutes to a DOD level of $89 \%$.

In January 1989, life tests were initiated on module \#2 using SFUDS/IDSEP discharges to 100\% DOD with a $50 \%$ weight burden. Charges were performed with a two-step constant-current $(\mathrm{CI} / \mathrm{Cl})$ method $(6-\mathrm{A} / 3-\mathrm{A})$ to 9.2 V limit. During life testing ( 200 cycles), module capacity declined at a rate of $0.08 \% /$ cycle. Prior to life testing, module \#2 exhibited a capacity decline of $-0.02 \%$ /cycle. To assess a possible relation between capacity loss and type of discharge, the module \#2 data are being reviewed and compared with those from other sodium/sulfur tests. At the increased rate of capacity loss, module life (capacity s\% of its initial 50.9 Ah) was projected to be -420 cycles. A capacity of $43.6 \mathrm{Ah}$ (336 Wh) was obtained on its last discharge. After testing, module \#2 was returned to CSPL.

A series of baseline performance tests is conducted as part of our standard set of characterization tests and at -100 cycle increments during life testing, For module \#2, these tests included (1) $100 \%$ DOD capacity verification at the $3-\mathrm{h}$ rate, (2) J227aD/IETV-1 and $\mathrm{J} 227 \mathrm{aC} / \mathrm{G}-$ Van driving profile discharges, and (3) current interrupted discharges (average 3-h rate discharge) for module peak-power evaluation. Module resistance, IR-free voltage, and peak-power vs DOD are derived from module voltage and current changes during the discharge. In this manner, the effects of age on these 


\section{Table 2-6. Ceramatec Cell Test Summary}

\begin{tabular}{|c|c|c|c|c|c|}
\hline $\begin{array}{c}\text { SNL } \\
\text { Number }\end{array}$ & $\begin{array}{r}\text { Cap } \\
\text { Rated }\end{array}$ & $\begin{array}{l}\text { ty (Ah) } \\
\text { Initital }\end{array}$ & $\begin{array}{c}\text { Number } \\
\text { of } \\
\text { Cycles }\end{array}$ & $\begin{array}{c}\text { Test } \\
\text { Regimes } \\
\text { Run }\end{array}$ & $\begin{array}{c}\text { Present or Final } \\
\text { Capacity } \\
\text { (\% of Initial) }\end{array}$ \\
\hline 45 & 36 & 36. & 1,114 & $1,2,3,4,5,6,7$ & 99 \\
\hline 455 & 36 & 35.3 & 1,259 & $1,2,4,7$ & 98 \\
\hline
\end{tabular}

Notes:

Ceramatec Rated, Initial, and Present Capacities: Discharged at $\mathrm{C} / 2$ to $1.9 \mathrm{VOC}$

Charged at $7.0 \mathrm{~A}$ to $2.3 \mathrm{~V}$ at $350^{\circ} \mathrm{C}$

Test Regimes

1. Capacity vs Dischsarge Rate

2. Capacity vs Charge Rate

3. Parametric Tests

4. Constant Power Tests

5. Peak Power Tests

6. SFUDS Tests

7. Life Cycle Tests

Table 2-7. Results

Test

Capacity (Ah)

Sp. Peak Power (W/kg)

Max Sp Energy (Wh/kg)

SUFDS (Reps.)

Life Cycle

\section{." Developer}

\begin{tabular}{ccc}
\hline CSPL & Ceramatec & Powerplex \\
\cline { 2 - 3 }$(9.5 / 10.0)$ & $41.5(36.7)$ & $40(37.4)$ \\
190 & 185 & - \\
160 & 141 & 177 \\
133 & 162 & 160 \\
923 & 1,259 & 1,230 \\
$(85 \%)$ & $(98 \%)$ & $(80 \%)$
\end{tabular}

parameters can be studied. Peak-power vs DOD (Ah) data from cycles \#86 \& 338 are plotted in Figure 2-36. The data shows that module peak power at $50 \%$ DOD had declined by only $\sim 8 \%$ in 252 life cycles. This decline was the result of an $8 \%$ increase in module resistance at $50 \%$ DOD, and a $2 \%$ decrease in module IR-Free voltage. The peak power at $100 \%$ DOD is 105 $\mathrm{W} / \mathrm{kg}$ which allowed full capacity discharges for each of the driving profiles tested. The projected driving ranges and available capacity declined by $-10 \%$ over the 252 life cycles shown in the figure.

Cell voltages and string currents were examined at the end of periodic 15-A CI discharges to compare individual cell capacities. The variation beiween string currents $(2.6-\mathrm{A} \pm 6 \%)$ increased slightly from the $2.5-\mathrm{A}$ $\pm 6 \%$ measured early in life. The cell voltages from five strings were matched to $1.8 \mathrm{~V} \pm 1.5 \%$ and one string $(\# 3)$ contained cells with the lowest $(1.705-\mathrm{V})$ and highest $(1.847-\mathrm{V})$ voltages. This string also had the lowest current (2.42-A). Early in life, all 24 cell voltages were matched to $1.8-\mathrm{V} \pm 3 \%$.

Module \#2 was replaced with the new 24-cell module (\#3) in July 1989. A history plot of module \#3 capacity for 3-h rate (20-A) and SFUDS discharges is given in Figure 2-37. Module EOD resistance is also plotted in the figure. An abbreviated set of performance characterization tests was performed during the first 54 test cycles. Life testing was started with SFUDS discharges to $100 \%$ DOD at the end of August 1989. Reproducible operation was obtained for over 40 cycles. Then, a 2-mile decline in SFUDS discharge range was observed between cycle \#97 and \#101. A capacity of 


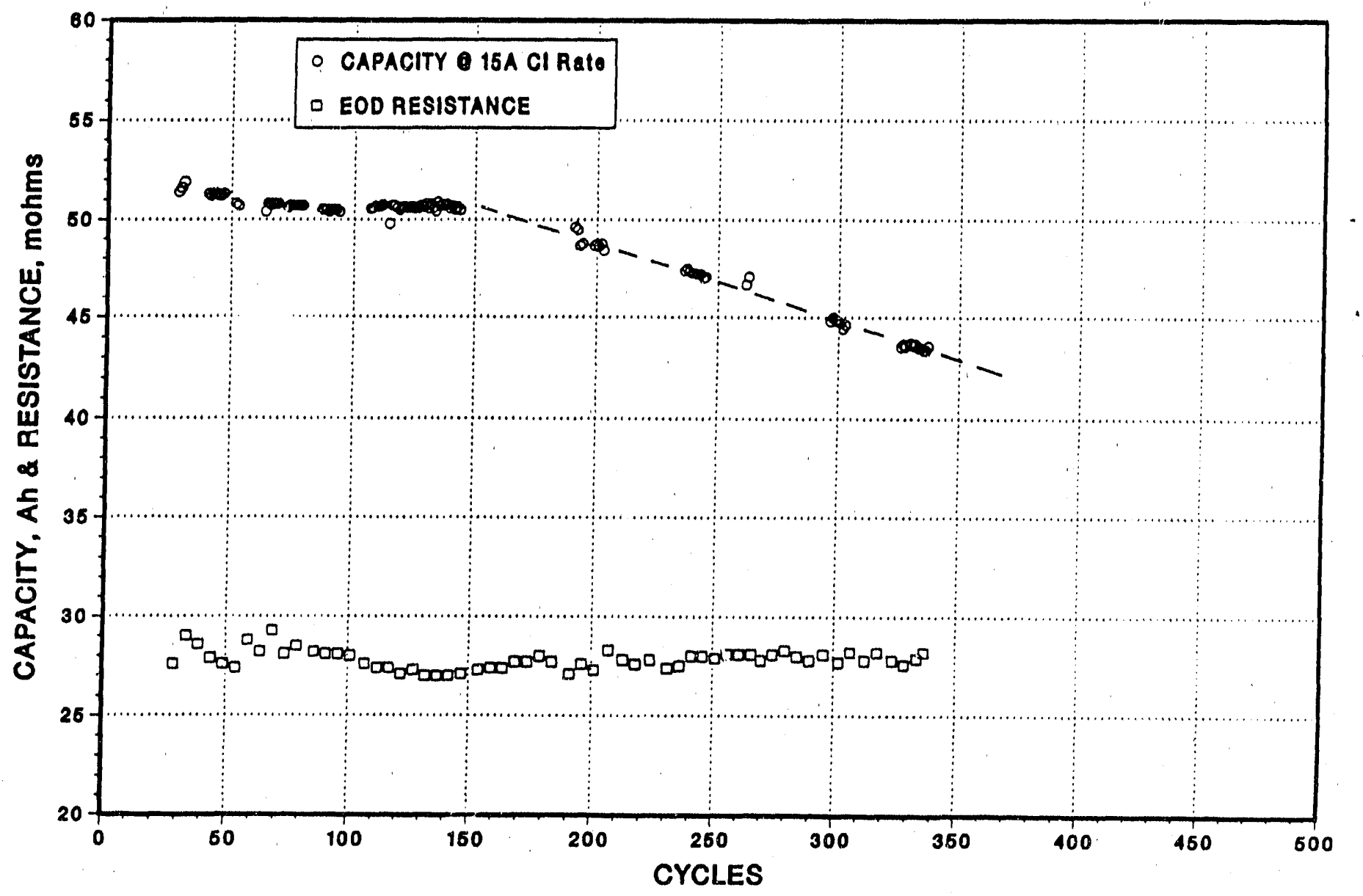

Figure 2-35. Capacity and Resistance History of 24 Cell CSPL Sodium/Sulfur Module $\$ 2$

only $54 \mathrm{Ah}$ was obtained with a $\mathrm{CI}$ discharge on cycle 102. Individual string current measurements on the 104th cycle showed that one string had a high resistance. A capacity of only 47.7 Ah was obtained ( $77 \%$ of the initial 62-Ah, 469-Wh) on that cycle. Life tests were halted after an attempt was made to operate the module with only five strings. Two more strings had become a high resistance by the 108 th cycle.

To be consistent with weight projections by CSPL for a full-size EV battery, a burden of $86 \%$ was used with module \#3 (instead of the earlier projection of $50 \%$ ). The impact of the increased burden on module available energy vs constant-power discharge rate is illustrated in Figure 2-38. Data for module $\# 3$ are plotted for burdens of 50 and $86 \%$ (module weights of $4.7 \mathrm{~kg}$ and $5.8 \mathrm{~kg}$, respectively). For comparison, data are also plotted for module $\# 2$ with a $50 \%$ burden. The safety cells in module $\# 3$ provide $-13 \%$ more specific energy than the non-safety cells in module \#2 with a $50 \%$ burden. This was anticipated based on data supplied by CSPL. However, increasing the projected battery weight by $24 \%$ ( $36 \%$ increase in burden), causes the specific energy of module $\# 3$ to decrease by $\mathbf{2 2 \%}$.
During this test, module temperature at the EOD varied with discharge rate. These results showed that the EOD resistance was -26.5 mohms at $365^{\circ} \mathrm{C}$ with a tempcrature coefficient of $-0.16 \mathrm{mohms} /{ }^{\circ} \mathrm{C}\left(356377^{\circ} \mathrm{C}\right)$.

Test results also indicated that with a $24 \%$ weight increase, the peak-power capability of module $\# 3$ at $50 \%$ DOD was decreased by $-18 \%$ (from 115 to 94 $\mathrm{W} / \mathrm{kg}$ ). These data were derived from current and voltage measurements recorded during a driving profile discharges. A range of 154 miles (capacity of $63 \mathrm{Ah}, 449$ Wh) was obtained with SFUDS discharges and an $86 \%$ weight burden. The range is increased to 200 miles (capacity of $62 \mathrm{Ah}, 459 \mathrm{Wh}$ ) with a $50 \%$ burden. Similarly, for J227aD/IETV-1 discharges, ranges of 188 and 244 miles were obtained with burdens of 86 and $50 \%$, respectively. As expected, the weight burden had no significant impict on module resistance or IR-free voltage.

The results of the module \#3 hill climb test showed that a IEVT-1 type vehicle would be able to climb a $7 \%$ grade $(45 \mathrm{~W} / \mathrm{kg})$ for 6 minutes to a DOD of $92.5 \%$. 


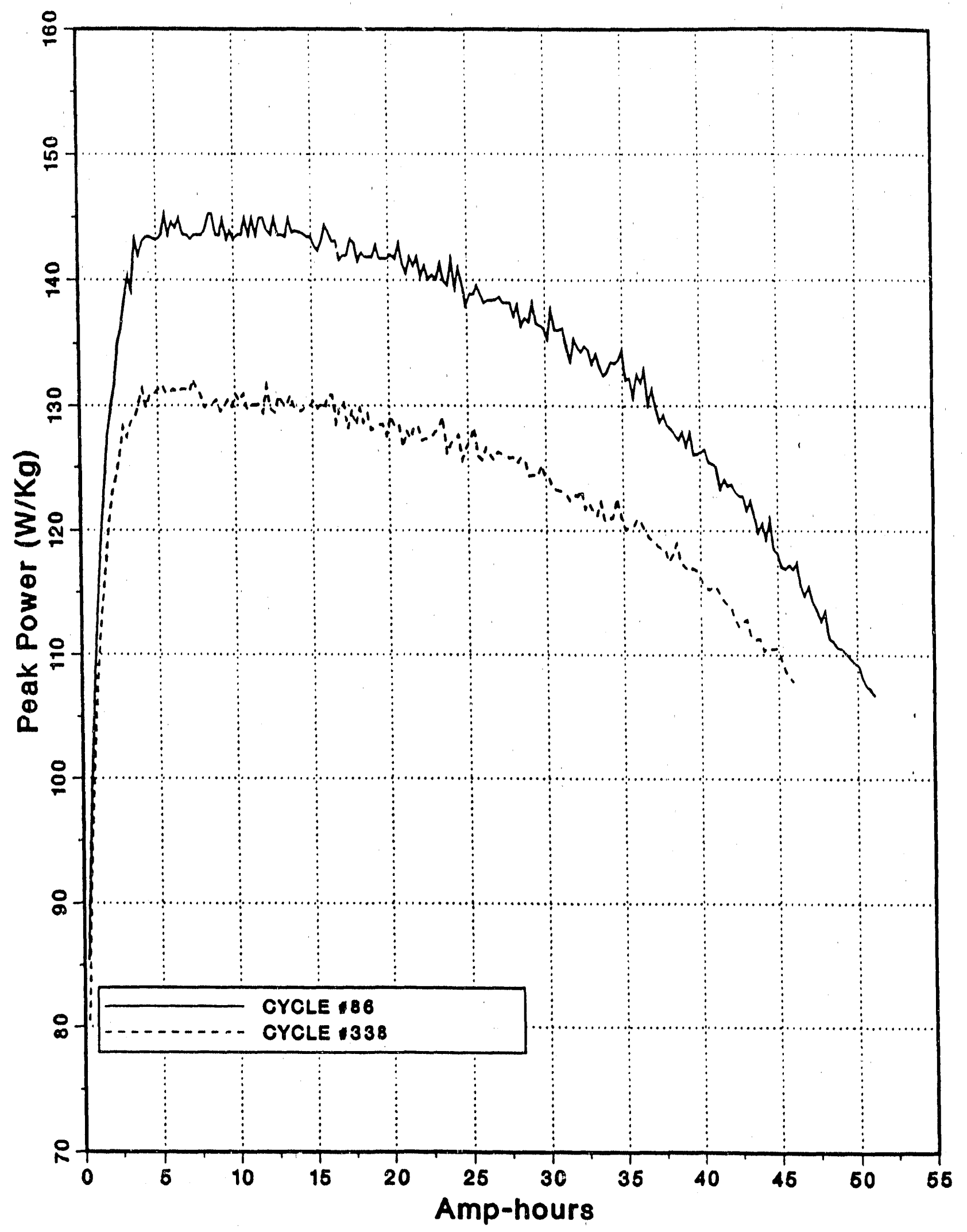

Figure 2-36. CSPL Sodium/Sulfur Module \#2 Peak Power vs DOD with Life (50\% Burden) 


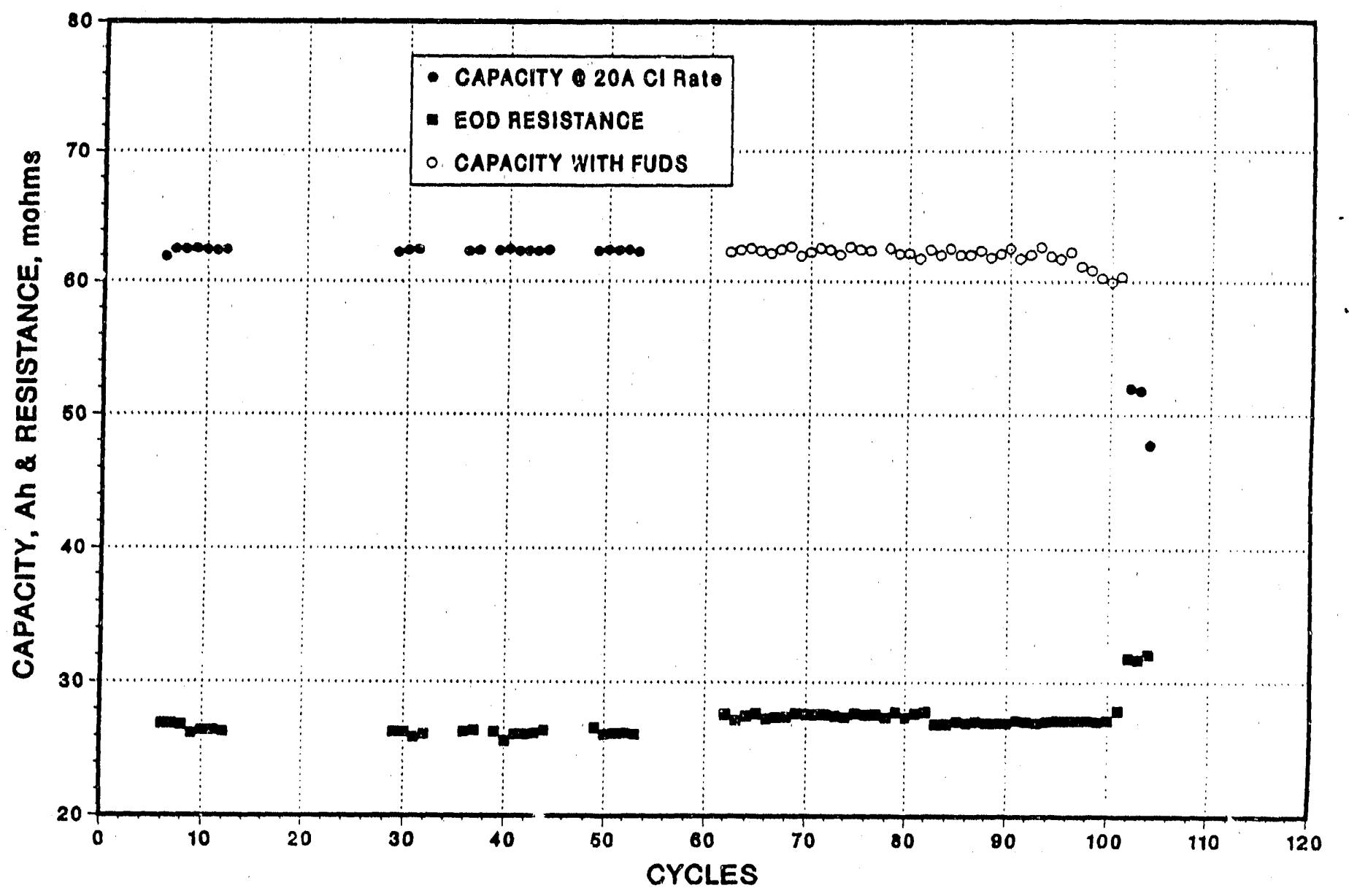

Figure 2-37. Capacity and Resistance History of 24 Cell CSPL Sodium/Sulfur Module \#3

\section{Posttest Analysis of CSPL Sodium/Sulfur Cells}

Selected sodium/sulfur cells built and tested by CSPL received detailed posttest examinstions at ANL. These studies characterized the sulfur electrode, quantified degradation of the cell components, and identified potential failure mechanisms. This activity provided direct support to CSPL in their effort to develop a battery with the requisite levels of performance and reliability.

The analysis of an "XPB" cell (\#9327) was completed during FY89. This examination extended our understanding of container corrosion, electrolyte contamination, and seal degradation. It also provided insights into the effects of design changes on these conditions. Cell 9327 represented a transitionai stage in the development of XPB cells with safety features. It incorporated a newly designed, felt-wrapped safety can instead of the powdered infill material previously used to promote uniform sodium distribution within the extended electrolyte. The container was fabricated by welding a cylindrical extension to a PB cell case. The seal was the older MkIla design. Cell 9327 had the longest operational life, 1,012 cycles prior to voluntary termination, of any CSPL cell examined at ANL.

Cell 9327 relied on a chromized coating to impart corrosion resistance to the low-carbon steel substrate used as the cell container. The chromizing process produced a duplex layer on the interior and exterior surfaces that consisted of a thin outer layer of chromium and chromium carbides and a thicker layer of iron and chromium. Corrosion penetrated the chromized layer and continued into the substrate. Measurements of the depth of penetration for this cell and previously examined cells enabled an estimate to be made of the expected life of the chromized cell case. The data are presented graphically in Figure 2-39, and lead to a projected life of around 2,300 cycles before the coll case is perforated. It should be emphasized, however, that deviations from the fixed set of conditions used to operate these cells could markedly accelerate the rate of corrosion. For these data, the conditions included continuous cycling under a constant load at a rate of three cycles a day, an operating temperature between 345 and $355^{\circ} \mathrm{C}$, and a $1.9 \mathrm{~V}$ cut-off on discharge. 


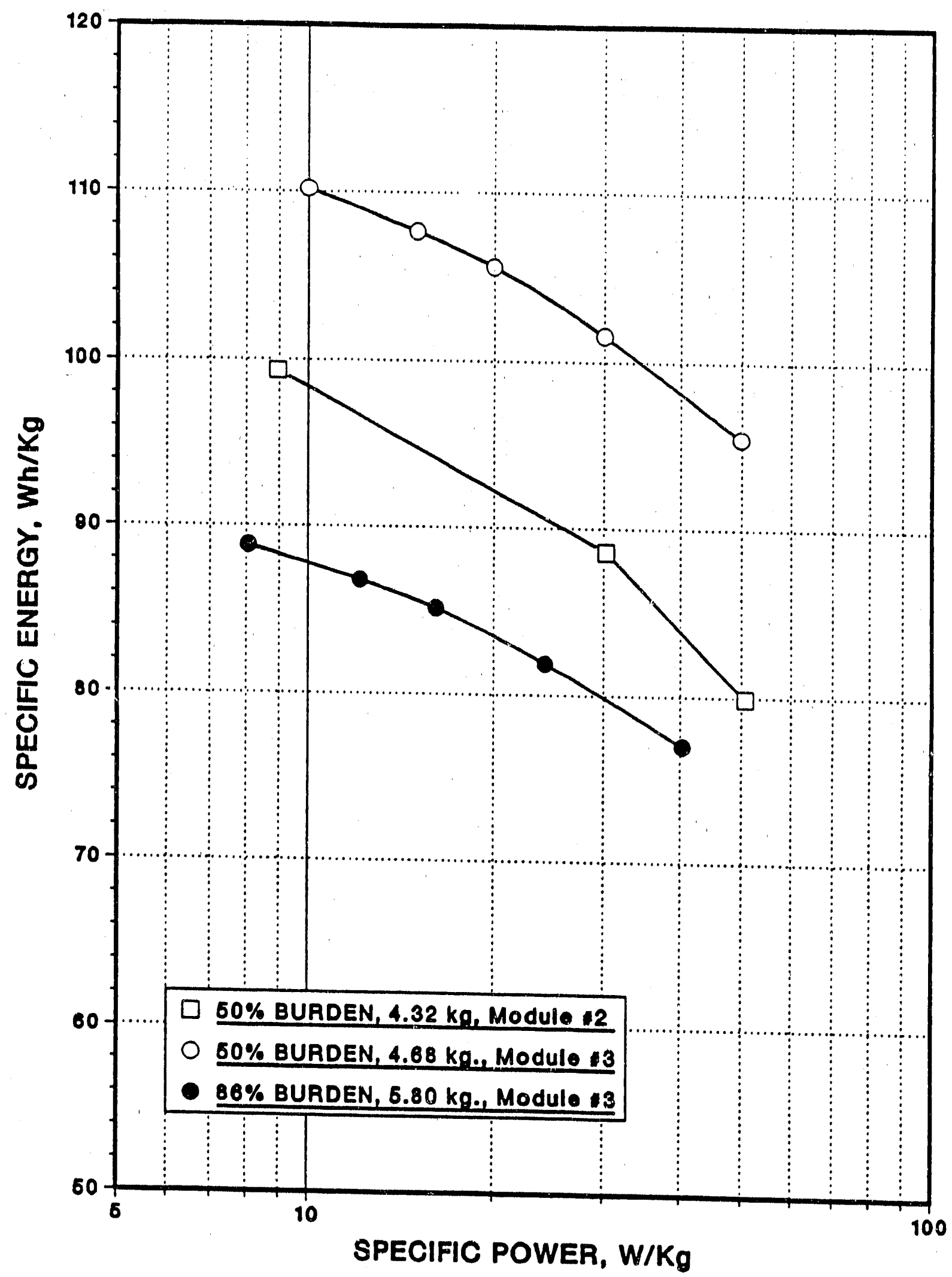

Figure 2-38. Capacity vs Discharge Rate of 24 Cell CSPL Sodium/Sulfur Modules $w_{2}$ and $* 3$ 


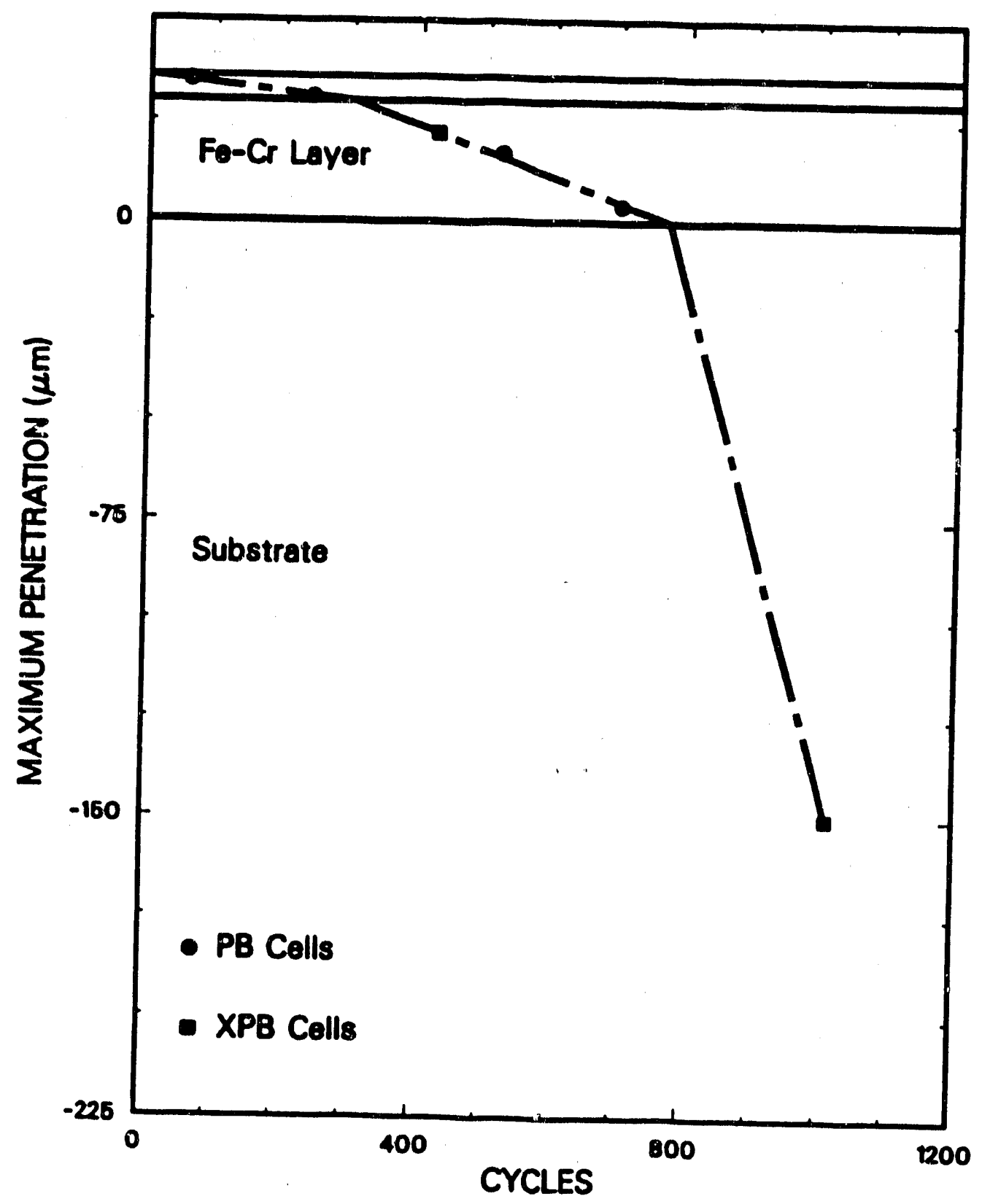

Figure 2-39. Corrosion of the Chromized Cell Case as a Function of Cycle Life for PB and XPB Cells. (The ordinate value of $-225 \mu \mathrm{m}$ represents one-half of the wall thickness for the chromized case.)

The corrosion of the 9327 cell case differed from the pattern set by other cells because the quality of th: chromized coating on the upper extension was substandard. The maximum depth of penetration still occurred in the base section as a consequence of active material settling in the sulfur electrode. However, portions of the

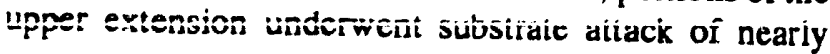

comparable magnitude. The chromized coating on the extension was more porous and showed greater variability in thickness than the base section or previously examined cases from PB cells. The same chromizing treatment produced a less protective coating because a different grade of low carbon steel was used for the extension. 
Corrosion deposits were found on the outer electrolyte surface. Twenty-five percent of the lower half of the beta"-alumina was covered with 5- to 30$\mu \mathrm{m}$-thick deposits of sodium thiochromide $\left(\mathrm{NaCrS}_{2}\right)$. Discrete crystals of iron disulfide $\left(\mathrm{FeS}_{2}\right)$ also adhered to the electrolyte wall. Although corrosion products from the case could have contributed to this accumulation, the use of a pressed liner along the inner case surface has been largely successful in preventing the migration of corrosion products. A more probable source was corrosion of the ferro-chromium alloy used as a component in the MkIla seal. This component was reduced to $25 \%$ of its initial thickness. Cells with MkIII seals use a chromized top-cap. Past examinations have shown considerably less corrosion of the chromized top-cap and no deposition of corrosion products on the electrolyte.

The safety features incorporated into this cell also had a beneficial effect on cell resistance. Previously examined $\mathrm{PB}$ cells used powdered infill to distribute sodium along the inner electrolyte surface; and, as shown in Figure 2-40, these cells were susceptible to the rapid build-up of high calcium levels with cycling. Calcium contamination has been correlated with the early resistance rise exhibited by these cells. The use of a safety tube and sodium wick in place of the infill to distribute sodium has lowered the apparent plateau level for surface contamination to a much lower value of about 2 at.\%. Cell 9327 had a stable resistance over its operational life.

Overall, this examination has confirmed that the recent design changes provided benefits in cell performance as well as cell safety. The sodium wick promoted low resistance by providing excellent wicking action for maximized usage of the electrolyte surface. The deficiencies noted for this cell stemmed from the extemporized changes. The two-piece case construction impaired the quality of the chromized coating and the use of the older MkIla seal led to the accumulation of corrosion products on the outer electrolyte surface. Completing the transition to the newer design should eliminate these problems.

\section{Technology Improvement}

As stated in Chapter 1, the objective of the SNL Technology Improvement element is to investigate and solve specific problems encountered during the development of advanced secondary batteries. During FY89, three tasks were active that supported the sodium/sulfur technology. All three focused on aspects that could lead to the improvement of cell reliability. A summary of the progress made in each during FY89 is given separately in the remaining sections of this chapter.

\section{Analysis of Electrolyte Degradation}

From CSPL cells, markings were observed on fracture surfaces that suggested compressive stress had developed in a thin layer (50 to $100 \mu \mathrm{m})$ adjacent to the interior surface of the electrolyte. Details of the fractures indicated that the compressive stress layer had exacerbated electrolytic degradation of the beta". alumina. This study is intended to investigate the effect of stress on degradation and try to determine how the compressive stress layer might have been generated. Three specific subtasks are being pursued. (1) the identification of possible mechanisms-occurring during processing of the ceramic, cell assembly or cell operation-that can result in thin compressive layers in the electrolyte surface, (2) the measurement of the growth rate of cracks within thin compressive layers, and 3 ) an evaluation of the potential for sub-critical crack growth within the electrolyte. During FY89, activity focused mainly on two aspects of Subtask 1. the fabrication of three-layer composites of beta"-alumina/zirconia and the evaluation of the potential for moisture to induce residual stresses. This work is being performed under a contract with A. Virkar at the University of Utah.

\section{Composite Fabrication}

To provide a model material with a thin compressive surface layer, three layer composites containing 10 vol.\% zirconia were fabricated in such a way that the inner layer contained partially stabilized zirconia while the outer layers contained unstabilized zirconia. A schematic of a typical sample is shown in Figure 2-41. The nominal composition of sodium beta"-alumina ${ }^{1}$ was $8.85 \mathrm{wt} \% \mathrm{Na}_{2} \mathrm{O}, 0.75 \mathrm{wt} \% \mathrm{Li}_{2} \mathrm{O}$, and $90.4 \mathrm{wt} \% \mathrm{Al}_{2} \mathrm{O}_{3}$. Samples were die-pressed in such a way that the ratio of the outer layer thickness to the inner layer thickness was typically 1:4.67. After uniaxially pressing, the powder compacts were isostatically pressed at $30 \mathrm{ksi}$. The samples were subsequentiy bisqued at $1,000^{\circ} \mathrm{C}$ and then sintered at $1,600^{\circ} \mathrm{C}$ for 10 minutes. The density of the resulting samples was typically in excess of $97 \%$ of the

1 Supplied by Ceramatec, Inc., Salt Lake City, UT. 


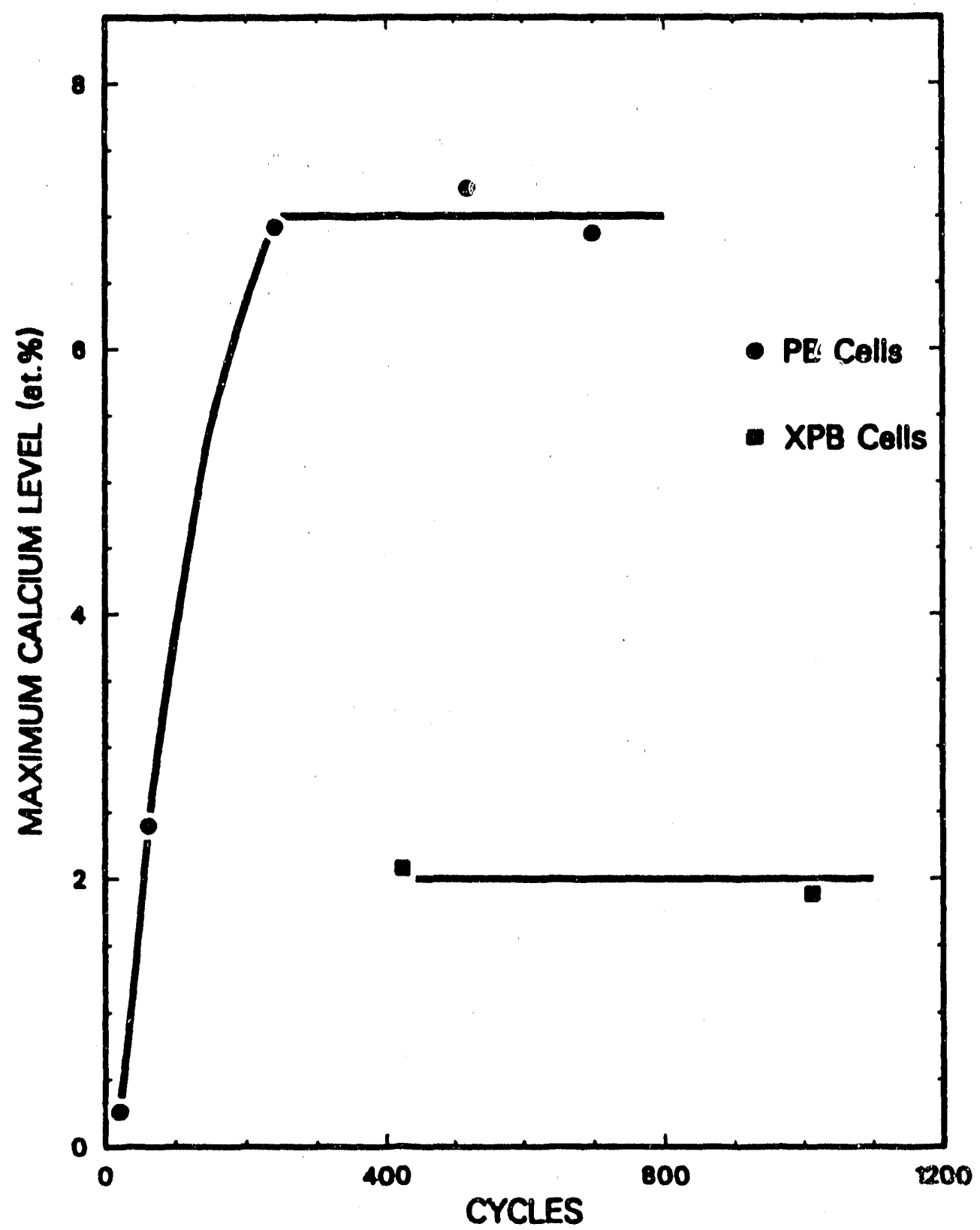

Figure 2-40. Calcium Contamination of the Electrolyte as a Function of Cycle Life for PB and XPB Cells.

theoretical density. X-ray diffraction of the outer layers showed the zirconia exisis in both tetragonal and monoclinic polymorphs. By contrast, the inner layer exhibited the presence of the tetragonal phase only. As shown previously for $\mathrm{Al}_{2} \mathrm{O}_{3} / \mathrm{ZrO}_{2}$ three layer colnposites [1-3], a compressive stress in the outer layers and balancing tensile stress in the interior arc expected.

In order to determine the k:vel of stresses, a strain gage technique was employed. In this technique, a strain gage is attached on the surface of one of the outer layers and the other surface is incrementally ground off. The magnitude of the residual stresses can be determined from the measured strain vs thickness dependence using equations given previously $[2,3]$. Figure $2-42$ shows a schematic of a three layer composite with a strain gage mounted on it. Figure 2.42 shows a plot of strain $(\varepsilon \mathrm{M}(0, \delta))$ vs thickness ground off $(\delta)$. Also shown in the figure is the theoretical curve. Note the bend in strain vs $\delta$ at $\delta=d 1$. Departure of the strain at nigner vaiues of $d$ is due to the transformation of 


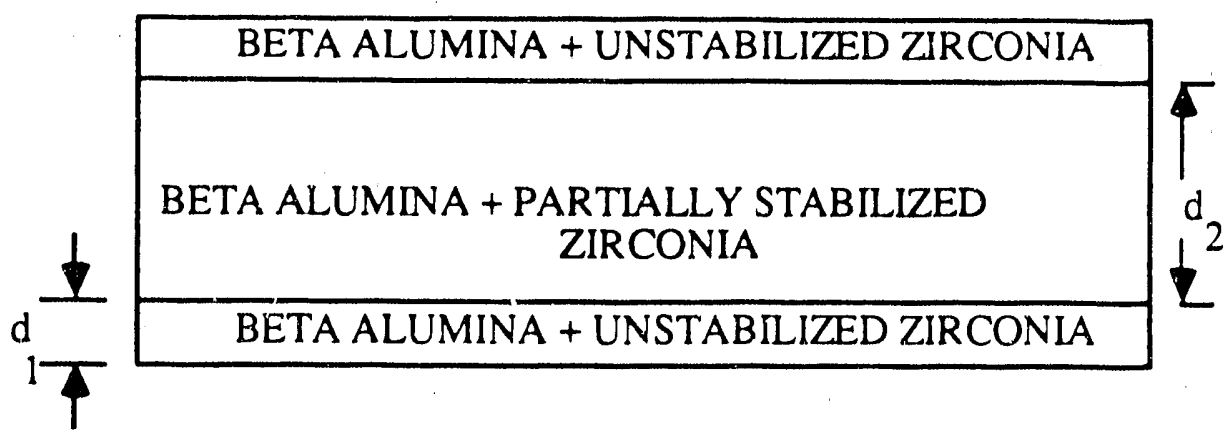

Figure 2-41. A Schematic of Beta"-Alumina/Zirconia Three Layer Composite

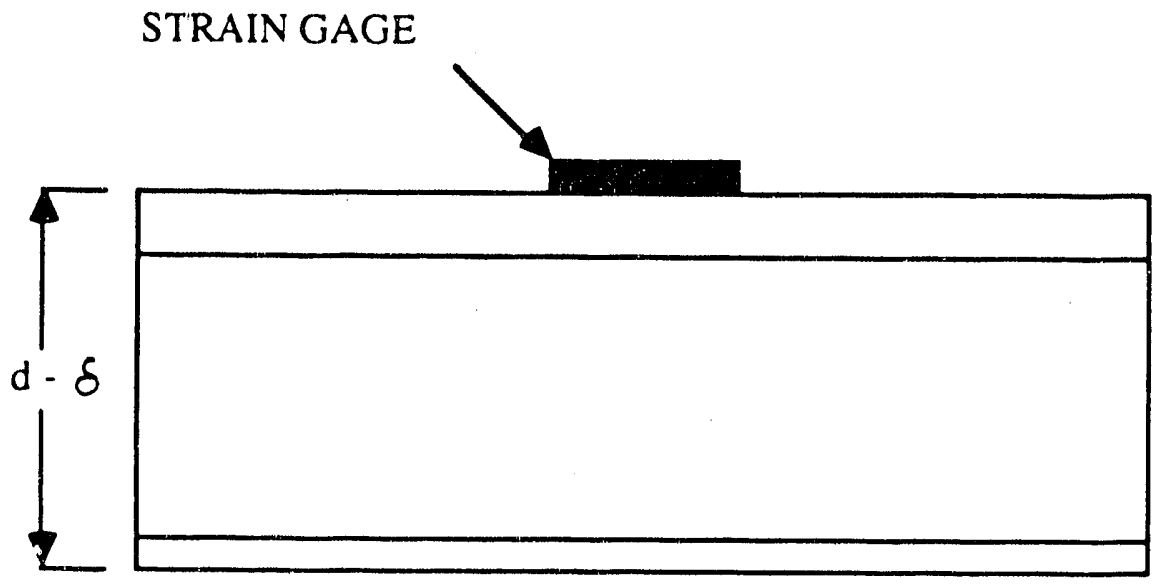

Figure 2-42. A Schematic of a Partially Ground Orf Three Layer Composite with a Strain Gage on One Face

tetragonal zirconia into the monoclinic form. The value of strain at the bend is given by

$\varepsilon_{M}\left(0, d_{1}\right)=\frac{\Delta \varepsilon_{0} d_{1} d_{2}}{\left(d-d_{1}\right)^{2}} \frac{\left(2 d+d_{1}\right)}{d}$

where $\Delta \varepsilon_{0}$ is the free strain of the outer layer in relation to the inner layer. For the data given in Figure $2-42, d_{1}$ $=0.035$ inches, $\varepsilon_{M}\left(0, d_{1}\right)=2.70 \times 10^{-4}$. The sample thickness, $d$, was 0.2125 inches. Using equation (1), $\Delta \varepsilon_{0}$ is calculated as $7.87 \times 10^{-4}$. The stress in the outer layers, $\sigma_{1}$, was estimated via

$\sigma_{1}=-\frac{\Delta \varepsilon_{0} E d_{2}}{(1-v) d}$ using E $=200 \mathrm{GPa}$ and Poisson's ratio, $v=0.25$. The $\sigma_{1}$ was determined to be $140 \mathrm{MPa}$. This shows that by the incorporation of zirconia in the manner described here and in references 1-3, surface compressive stresses can be created. Three layer composites of sodium beta"alumina are now being subjected to electrolytic testing.

One possibility for producing the compressive stress layer in the CSPL electrolytes that were previously examined at SNL was that a seal failed and allowed water to be admitted into the anode space and subsequently react with the electrolyte. 


\section{Moisture-Induced Residual Stresses}

It is well known that moisture can interact with sodium beta"-alumina in two ways. (1) reaction of water in sodium beta"-alumina to form sodium aluminates and hydroxides and (2) penetration of water in the conduction planes in sodiun beta"-alumina. The former phenomenon occurs primarily in materials that have not been fully converted to the three-block structure and occurs over a long period of time. The latter one occurs over a relatively short period of time. Incorporation of water in the conduction planes leads to the expansion of the c-parameter. If this occurs in a nonuniform manner, residual stresses can be developed that may be detrimental. In order to examine the role of moisture, the following experiments were conducted.

A strain gage was attached on the surface of a sample. The face with the strain gage and tise other four adjacent sides were coated with wax to prevent moisture penetration through these five sides. The sixth side (which was not coated with wax) was exposed to moisture (100\% relative humidity) at room temperature. The strain was recorded as a function of time. The maximum strain recorded was $23 \times 10^{-6}$ after 40 hours of exposure time. After the test, the strain gage was ground off and the sample was weighed. Subsequently, the sample was heated in air to $900^{\circ} \mathrm{C}$ for removing the water from conduction planes. The weight loss was recorded to be $0.3 \%$. The density of the as-sintered sample was $3.20 \mathrm{gm} / \mathrm{ml}$. Thus, a sample of $1 \mathrm{ml}$. volume weighed $1.003 \times 3.2=3.2096 \mathrm{gm}$ after the moisture pick up. That is the water pick up was $0.0096 \mathrm{gm}$. The strain measurement indicated that the sample size increased to $\left(1.0+23 \times 10^{-6}\right)^{3}$ i.e., to $1.000069 \mathrm{ml}$., a net increase of $0.000069 \mathrm{ml}$. The molecular weight of water is 18 . Thus, the molar volume of water in free state is $\mathbf{3 8}$ $\mathrm{ml} / \mathrm{mol}$. However, when dissolved in sodium beta". alumina, the volume per gram of water is 0.000069 / $0.0096=7.19 \times 10^{-3} \mathrm{ml} / \mathrm{gm}$. or the partial molar volume of water in sodium beta"-alumina is $7.19 \times 10^{-3} \times 18=$ $1.29 \times 10^{-1} \mathrm{ml} / \mathrm{mol}$. Note that this partial molar volume is $\pm 0.7 \%$ of that of free water. This means that very little change in the lattice parameter is expected upon introduction of moisture in sodium beta"-alumina. This was confirmed by both $x$-ray diffraction and by strain measurement. The maximum strain recorded never exceeded $23 \times 10^{-6}$. In the early stages, this strain would create compressive stress in regions containing water and tensile stress in regions free of water. As the strain gage was attached on the face opposite to the one exposed to water, the face with the strain gage would experience a tensile stress (in the early stages only). The maximum tensile stress that existed in the sample was thus on the order of $23 \times 10^{-6} \times 200 \times 109 \mathrm{~Pa}$ or 4.6 $\mathrm{MPa}$ or $667 \mathrm{psi}$. This shows that very little stress is created due to water. The important conclusion of this part of the work is that negligible stress would be created due to the absorption of water. Exposure to moisture, however, must be avoided for other reasons. These include. (1) reaction with water, and (2) poor electrode/electrolyte interface. During the next several months, the effect of moisture on three layer composites will be examined.

\section{Component Stress During F/T Cycling}

Sodium/sulfur batteries used in both motive power and utility applications will be subjected to numerous $\mathrm{F} / \mathrm{T}$ cycles during their lifetime. These thermal cycles are inevitable (power loss and scheduled maintenance) and cannot result in significant cell failures. The $F / T$ durability of cells being produced today is much better than that typically attained several years ago. For example, the CSPL PB cell has a demonstrated characteristic F/T lifetime of over 400 cycles. However, most developers, including CSPL, feel that further improvement will be needed when and if cost issues force larger cell sizes to again be considered.

The goal of this task is to provide developers with the understanding and methodology to improve the F/T durability of their sodium/sulfur cells. To accomplish the objective, three integrated subtasks are pursued. (1) mathematical model development for the relevant thermo-mechanical processes, (2) measurement of all unknown physical properties for each cell component, and (3) measurement of the strain and thermal behavior of actual sodium/suifur cells during F/T cycling. For program plan and background information for this multiyear year activity, refer to the 1987 and 1988 ETD Annual Reports.

The major effort during FY1989 was directed at completing the physical-property measurements and on refining and validating a mathematical model that will allow the state-of-stress for the primary components of a normally operating cell to be accurately predicter. Although a validated model cannot by itself be used to eliminate all $\mathrm{F} / \mathrm{T}$ problems, it will be very useful in providing an analytical tool that can inmediately be used in cell redesign/optimization and in the identification of potential failure mechanisms.

The characterization of cell behavior is made by mounting strain gauges on the extemal surface of either SNL, lab-cell or CSPL PB cell containers. The gauges are oriented to measure hoop and axial strains induced as the cell is taken through multiple F/T cycles. Strain on the container results primarily from the differential thermal expansion (contraction) of three cell components (elcetrolyie, positive clectioúce, wniainer). Tne 


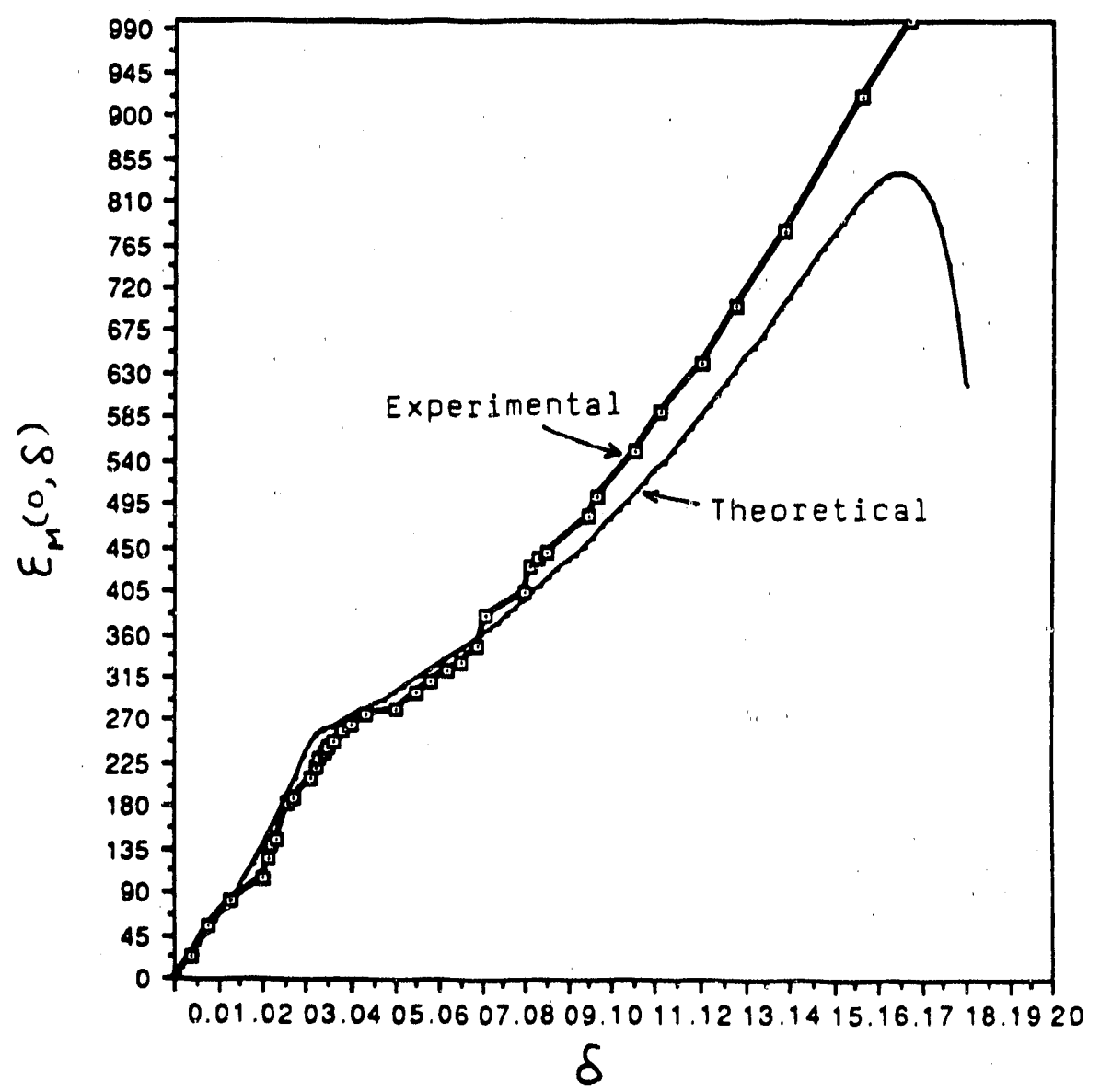

Figure 2-43. Measured Strain vs Thickness Ground Off

strain measurements to be discussed below were made near mid-height on the can, away from the effects of the stiffened ends. Three hoop gages and two axial gages were located around the container circumference to provide redundancy and to highlight any circumferential variations in the cell response. Prior to cell assembly, the empty container was heated to provide an expansion calibration curve for each gage. During $F / T$ cycling, the measured gage response is modified by the calibration curve to produce a gage response corresponding to mechanical strain. Mechanical strain is that part of the total strain directly proportional to the existing stress field.

A typical average mechanical strain response for a SNL lab cell is shown in Figure 2-44. The experiments involved cooling the cell, discharged to 1.9 volts, at a rate of $18^{\circ} \mathrm{C}$ per hour. The container began to accumulate strain at $236^{\circ} \mathrm{C}$ (which corresponds to the onset of sodium-(risulfide solidification). Until solidification began to take place, there was no mechanism for radical coupling between the electrolyte and the steel container. The axial strain shows a linear response with tempera- ture while the hoop strain shows a more complex response. One particular feature of the hoop strain curve, which is present in all of the tests, is that the maximum compressive strain occurs at approximately the same temperature, $170^{\circ} \mathrm{C}$. The strain magnitude then begins to decrease and approach zero strain at $100^{\circ} \mathrm{C}$. This type of complex strain response is produced by the interaction of the temperature-dependent material properties.

To qualify the cell model employed in the thermomechanical finite-element analysis code, comparisons are made between measured cell response (container strain) and predicted cell behavior. Of particular interest is the qualification of the material models and properties for the various cell components because, as mentioned above, the container strain is determined by the interaction of all the cell materials. Both onedimensional and two-dimensional finite element models of the lab cell have been used to study the stress and strain state in the individual components. Attempts to correlate the numerical results with the experimental strain data have shown that the response is directly tied 


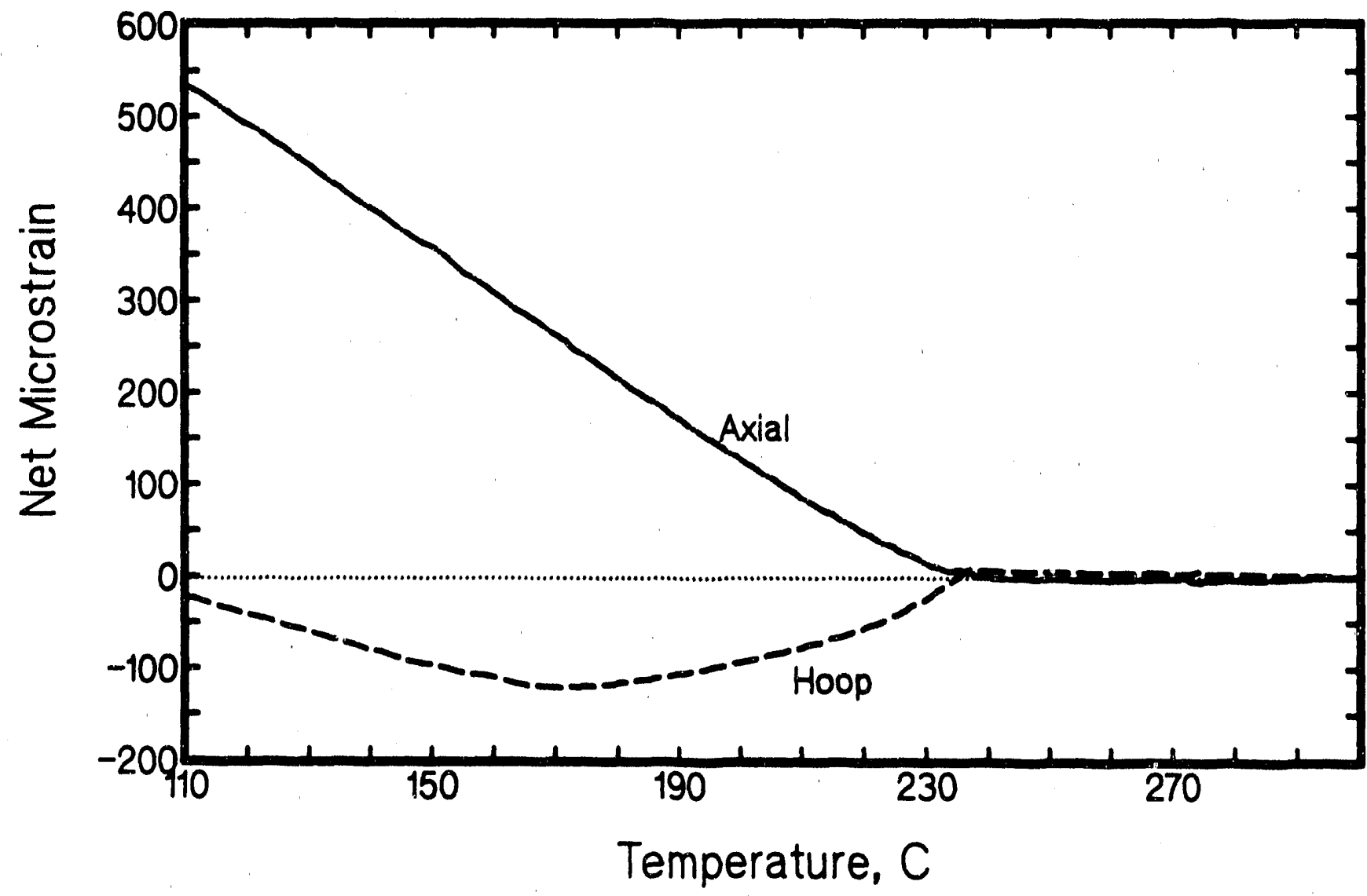

Figure 2-44. Measured Mechanical Strain on the Stainless Steel Container as a Function of Temperature During the Freeze Cycle of a Discharged SNL Lab Cell $(O C V=1.9$ V.).

to the temperature-dependent interaction of the material properties, especially the thermal expansion coefficients. Numerical and experimental comparisons have shown qualitative agreement but the quantitative agreement necessary to validate the models must await more accurate material property knowledge. Numerical experiments, utilizing the finite-element code to determine the unknown material properties, have provided some estimates of property values, but the complex material interaction makes this process more difficult than usual.

To aid in the process to validate the numerical model, an analytical solution has been developed that enables the displacement and strain fields in the sodium/sulfur lab cell to be directly calculated. This activity was performed in late 1988 and was described very briefly in the 1988 ETD Annual Report. It is based on a classical solution for thermal stresses in a long hollow cylinder [4]. This solution is for the radial displacement and stress in a long hollow cylinder subjected to a uniform temperature change. The deformation is assumed to be only a function of radial position, being constant circumferentially and along the cylinder length. During deformation, any plane cut perpendicular to the cylinder axis will remain plane which means that the axial strain is constant.

Using the appropriate boundary conditions, the classical solution was expanded to model the bchavior of three concentric cylinders with different material 
properties. An algebraic manipulator was then used to solve for the displacements and strain fields in strain expressions may be solved for unknown positive electrode properties.

Verification of this analytical model development was achieved by analyzing a lab cell response with the finite-element model using thermal expansion properties computed with the analytical solution. Figure 2-45 shows a comparison between the finite element analysis and the measured container hoop strain. The agreement is within a few percent. Better resolution could be obtained but the finite-element code is restricted to only eight piece wise linear segments for representation of the lab cell temperature-dependent material behavior. Eight piece wise linear segments are sufficient for most problems addressed by the finite-element code, but the complex material interactions associated with sodium/sulfur cells requires a more complete behavioral description. These results again demonstrate that the model has been refined to the point that reasonably accurate correlations can be made.

Following this verification exercise, bounding values of the coefficient of thermal expansion (CTE) for the positive electrode were calculated. Empirical equations were derived for both the hoop and axial strain for five different freeze cycles that showed widely variable responses. The exact solution was then employed with these equations to determine the how the CTE changed as a function of temperature and cycle.

Results for two of the cycles are shown in Figure 2-46. These calculated CTE values are higher than those measured for both the pure sodium polysulfides and the sodium-polysulfide/graphite composite (see next paragraph). However, their absolute value may not as important as the relative differences. At this point, it is difficult to rationalize that the such large changes in CTE could occur due to the slight differences in composition (fraction of sodium trisulfide) or phase (amorphous vs crystalline). Because of the excellent

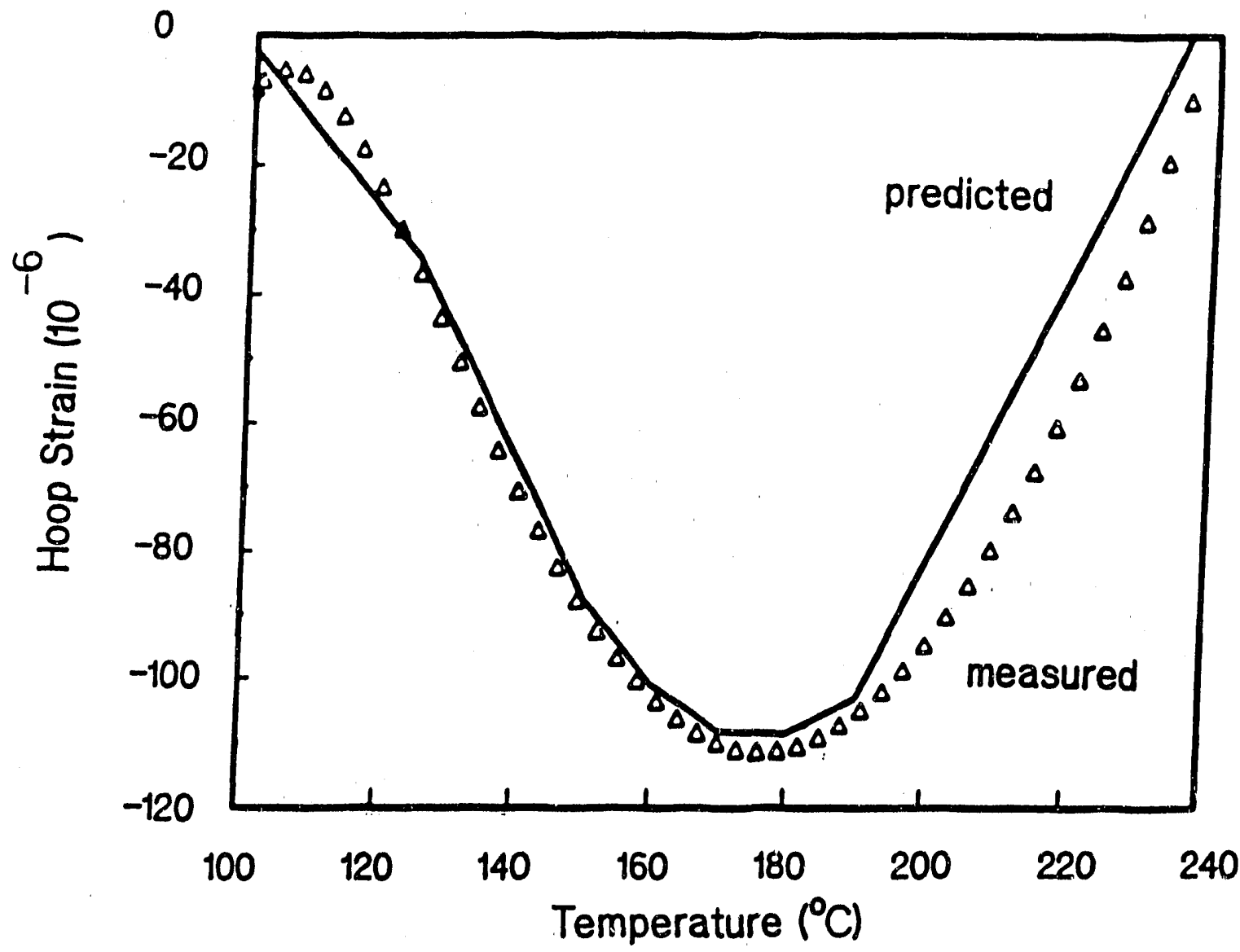

Figure 2-45. Comparison of Calculated and Measured Hoop Strain from the Freezing of a SNL Lab Cell. The calculations utilized a finite-element thermo-mechanical model and the model. 


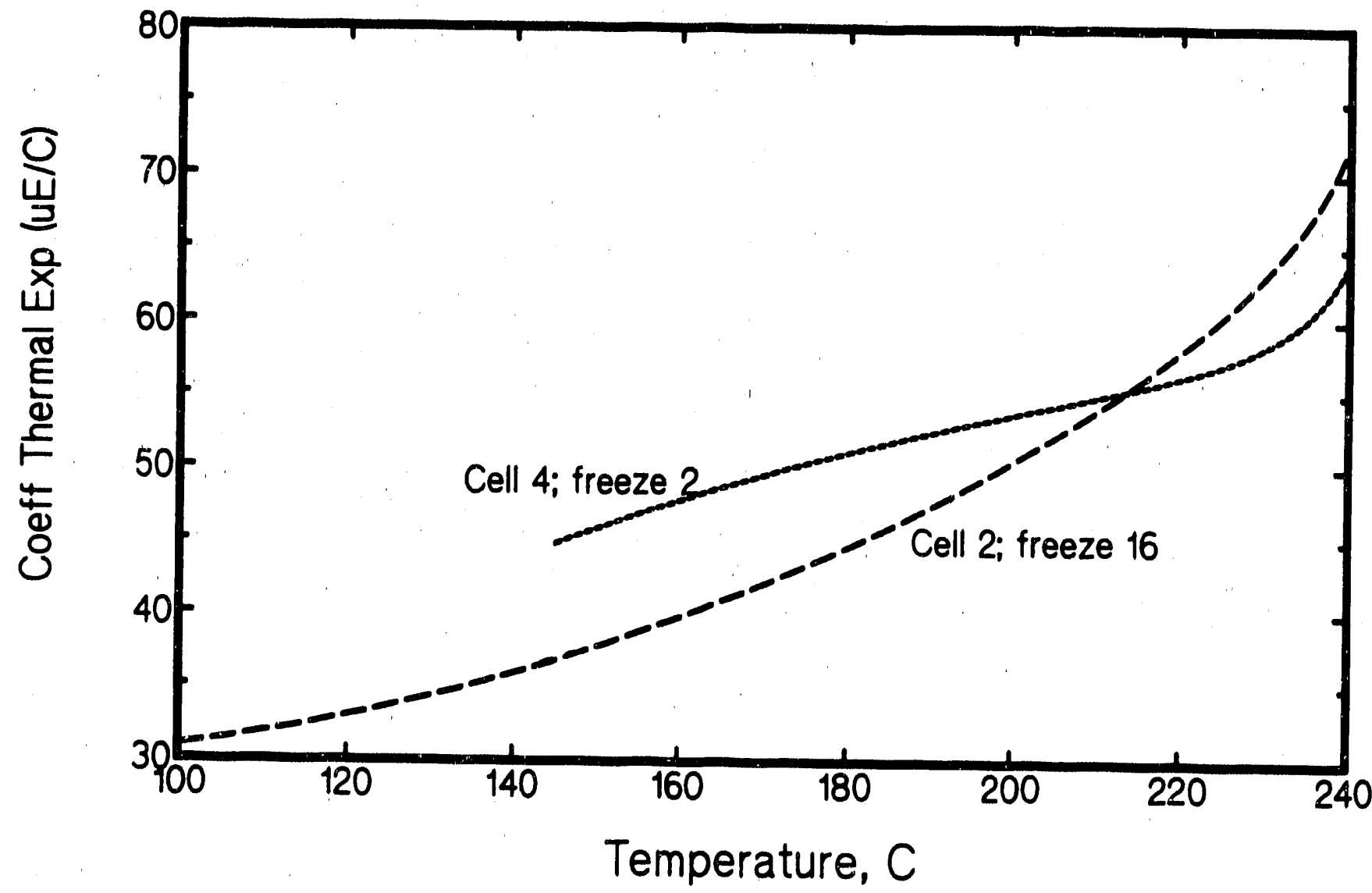

Figure 2-46. Calculated Coefiricient of Thermal Expansion for the Positive Electrode of SNL Lab Cells. Calculation used the measured strain from freeze cycles on two different cells.

agreement between measured and predicted results using the numerical solution, it would appear that the assumptions used in order to develop this one-dimensional model could yield significant errors. More investigation is underway.

Finally, the first physical-property measurements were completed during FY89 on sodium tetrasulfide/graphite composite samples. These results were not available for the modeling analysis described above. The samples used in these measurements were obtained with two different preparation techniques. 1) vacuumcasting, using the apparatus shown schematically in Figure 2-47, and 2) sectioning portions of the electrode material from a discharged CSPL-PB cell. ThermalMechanical-Analysis (TMA) was used to determine coefficient of thermal expansion values (CTE) and the elastic moduli were measured with the DynamicMechanical-Analysis (DMA) technique. DMA is preferred because it measures a more representative value than other available tcchniques (e.g., ultrasonic attenuation, compressive stress-strain). DMA could not be used with pure castings of sodium tetrasulfide because of a lack of large-scale integrity.

A selection of these very important results are shown in Figure 2-48. As can be seen, the elastic modulus is not very temperature dependent and not significantly different than the value that has been assumed in the modeling calculations ( $5 \mathrm{GPa}$ ). Similarly, the coefficient-of-thermal expansion (CTE) also has little temperature dependence. Not shown is a slightly disturing observation. The CTE results for the types of samples are markedly different. The CTE for the CSPL cell sample is approximately half of the CTE for the cast sample. Mathematical modeling is being used to determine if such differences are inconsistent with measured strain results and therefore if these results are suitable. 


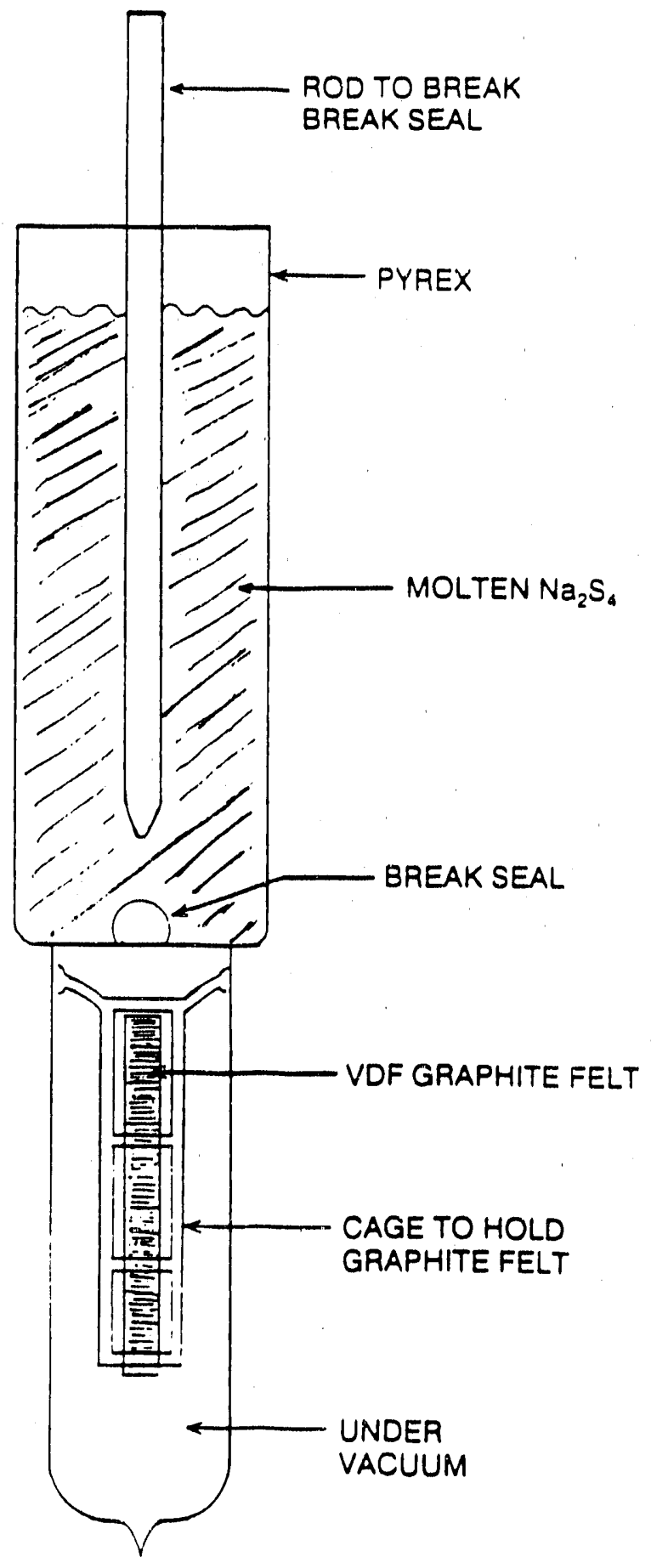

Figure 2-47. Schematic Diagram of the Apparatus Used to Vacuum-Cast a Sodium Tetrasulfide/Graphite Felt Composite Sample 


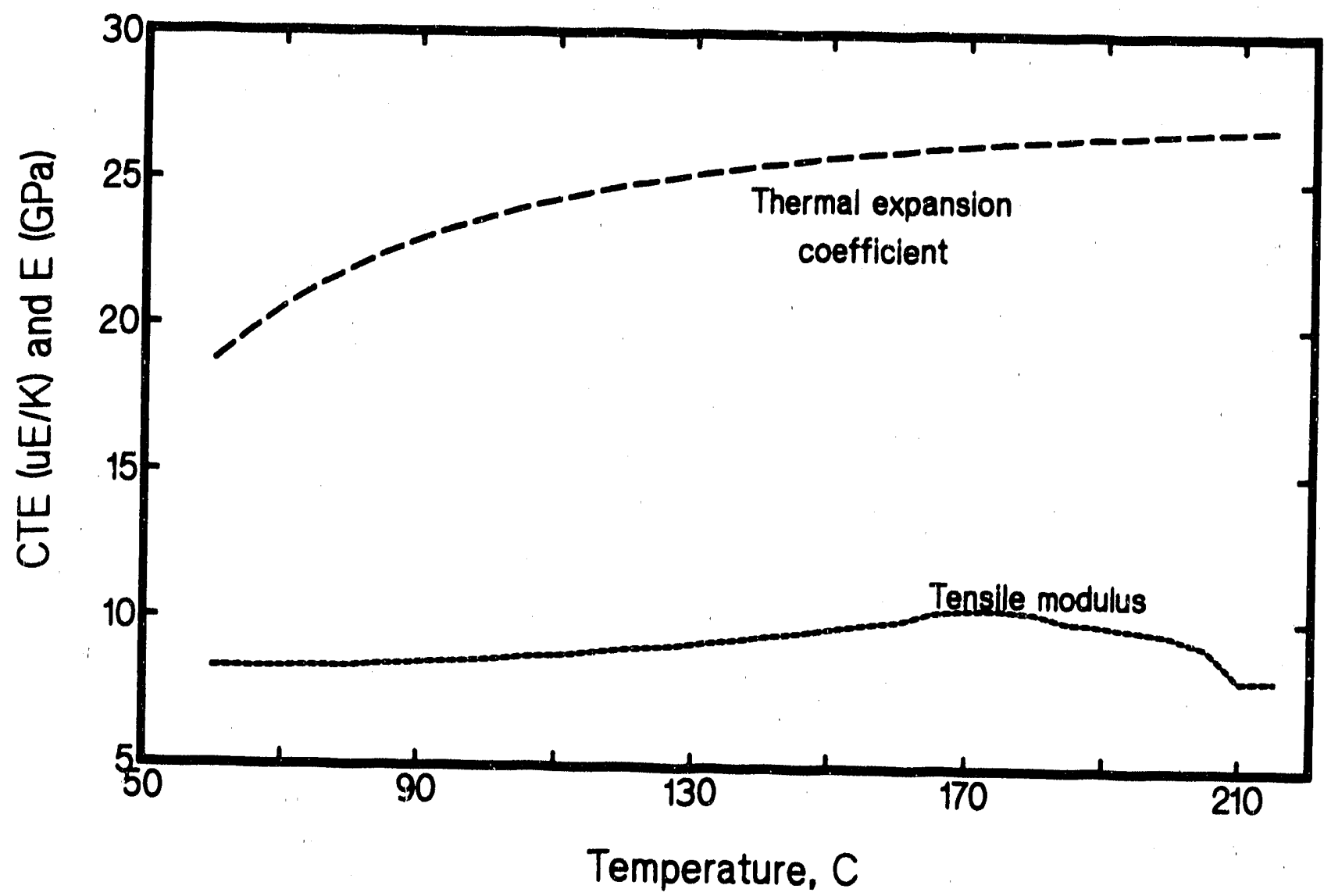
Figure 2-48. The Effect of Temperature on the Elastic Moduli and the Coefmcient-of-Thermal Expansion (CTE) for
a Cast Sodium Tetrasulfide/Graphite Felt Composite.

\section{Improved Chromium Plating of Sodium/Sulfur Cell Containers}

Container corrosion remains one of the life-limiting processes difficult because the container must be very corrosion resistant, have good electrical conductivity and mechan:cal properties, and yet be light weight and inexpensive. Corrosion is important not only because of its adverse effect on cell lifetime but also because corrosion products are known to affect long-term cell performance. These diverse and demanding requirements have forced developers to select and use composite marerials, usually an inexpensive substrate (e.g., aluminum, carbon steel, stainless steel) that has been coated, plated, or sheathed with at least one corrosionresistant material.

Because of its excellent intrinsic properties in molten sulfides, chromium-containing layers are usually preferred as the primary corrosion barrier. One of the candidate methods for applying chromium onto sodium/sulfur containers is by electroplating. This process can be cost effective and theoretically can produce deposits with good chemical, physical and mechanical properties.

Although many sodium/sulfur developers have studied and used chromium electroplating, techniques have not yet been identified that produce reliable and effective platings. CSPL is actively pursuing a number of options to improve its current corrosion prevention scheme (thermally chromized steel). Because of this lack of a suitable technique and CSPL's immediate needs, this study was initiated to develop new techniques that improve the quality and efficiency (reduce $\cos t)$ of chromium electroplating when applied to sodium/sulfur containers.

The specific objectives of this continuing activity are to develop improved techniques to electroplate chromium onto carbon and stainless steels and to identify methods to use these techniques to effectively plate containers used in the fabrication of the two cell designs being considered by CSPL:PB and XPB. 
This task is divided into four separate activities, the first three involving the optimization of different plating techniques and the fourth concerned with the evaluation of the platings. A more detailed description of the program plan is contained in the 1988 ETD Annual Report. For reference, the three plating method are as follows:

- Crack-free. The modification of a commercial electrolyte that produces crack-free deposits (CF-500) by adding vanadium pentaoxide.

- Pulse-plating. The development of pulse and pulse-reverse plating

- Highly-cracked. The investigation of the potential for producing and utilizing a highly cracked deposit.

Very encouraging results were obtained with the first electrolyte, the vanadium pentaoxide-modified commercial electrolyte that produces crack-free deposits. Analysis of the plating quality showed no cracking, no co-deposition of vanadium, and the stress in the deposit reduced to $300 \mathrm{psi}$ compressive (from 23 ksi tensile stress without vanadium). Cell containers plated with this technique were given a proprietary thermal treatment at CSPL and then fabricated into actual cells. Following electrical cycling, the cells were discharged and the containers allowed to corrode at a variety of temperatures. Results from post-mortem analysis showed that the performance of the treated electroplate is superior to that achieved with cells having CSPL's current corrosion protection scheme, thermal chromizing.

The second electrolyte contained a 100:1 ratio of chromium oxide to sulfuric acid and was chosen because it contains no additives that can mask the potential beneficial effects of pulse-plating. Various plating con. ditions were used to identify techniques to reduce deposit stress and increase deposition rates. To date, stresses have ranged from $40 \mathrm{ksi}$ tensile to $1.5 \mathrm{ksi}$ compressive and deposition rates from $0.4 \mathrm{mils}$ to $2.8 \mathrm{mils}$ per hour.

Because in-cell testing of the chromium platings is difficult and expensive, a screening procedure has been developed. An initial test has been completed to determine cell configuration and testing time and tempera- ture. The base material is Type $1018 \mathrm{steel}, 6.3 \mathrm{~mm}$ in diameter and $152 \mathrm{~mm}$ in length of which $76 \mathrm{~mm}$ is plated (see Figure 2-49). To fit into the testing apparatus, the rod is cut approximately $6.3 \mathrm{~mm}$ above the plated area and the cut surface is covered with a ceramic sealer. The rods were then exposed to sodium tetrasulfide for 2 weeks at $400^{\circ} \mathrm{C}$. After the corrosion test, the rod surface was examined using a scanning electron microscope and cross-sections were made to examine the chromium layer. During cool down of the test cell, a thick loosely adherent film developed on the surface (Figure 2-50). Surface analysis (Figures 2-51 and 2-52) of the rod reveal no pitting or areas of corrosion and compare favorably with the control samples that were not exposed to the sodium tetrasulfide (Figures 2-53 and 2-54). Cross sections confirmed that no pitting or general corrosion occurred on the surface or along the walls of cracks. It should be noted that surface cracking of these layers is normal-corrosion protection exists because the cracks do not penetrate to the surface of the steel. Auger sputter analysis (Figure 2-55) of the film from the rod detected $\mathrm{S}, \mathrm{C}, \mathrm{O}, \mathrm{Cr}$, and $\mathrm{Fe}$. The iron contamination probably came from the top of the rod where vapor phase corrosion was quite significant. A new procedure using $\mathrm{Cr}$ brush-plating should preclude this contamination in the future. Additionally, to further accelarate the aging process, longer times and higher temperatures will be employed.

The performance of platings produced with the third electrolyte will be determined using the accelerated technique at SNL. Also, twenty CSPL containers were plated and, if SNL results are favorable, will be tested in-situ. Although progress has been identified, it is still unknown if the desired long service life can be attainer.

Because of the positive results obtained with the CSPL thermal treatment, this study is being expanded to consider several electroless chromium processes. These processes involve a chemical reduction process and require no current, anode, or supporting fixture and result in better deposit uniformity on irregular shapes than electrolytic processes. The disadvantage with the electroless process is the thickness and speed of deposition. The thickness may not be a problem because the thermal treatment produces a very thin layer that makes up the needed corrosion barrier. 


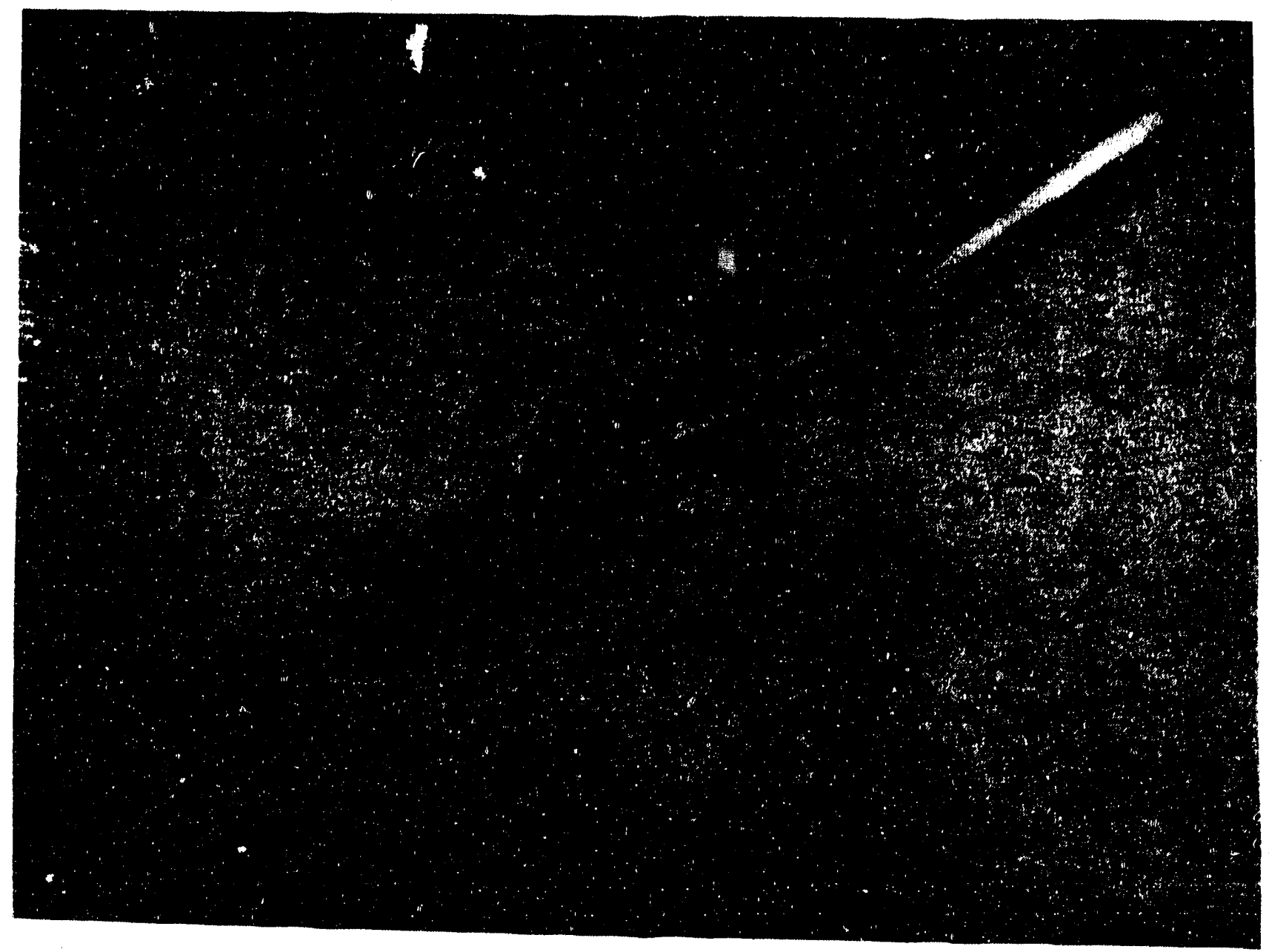

Figure 2-49. Chromium-Plated 1018-Steel Rod Prior to Corrosion Testing 


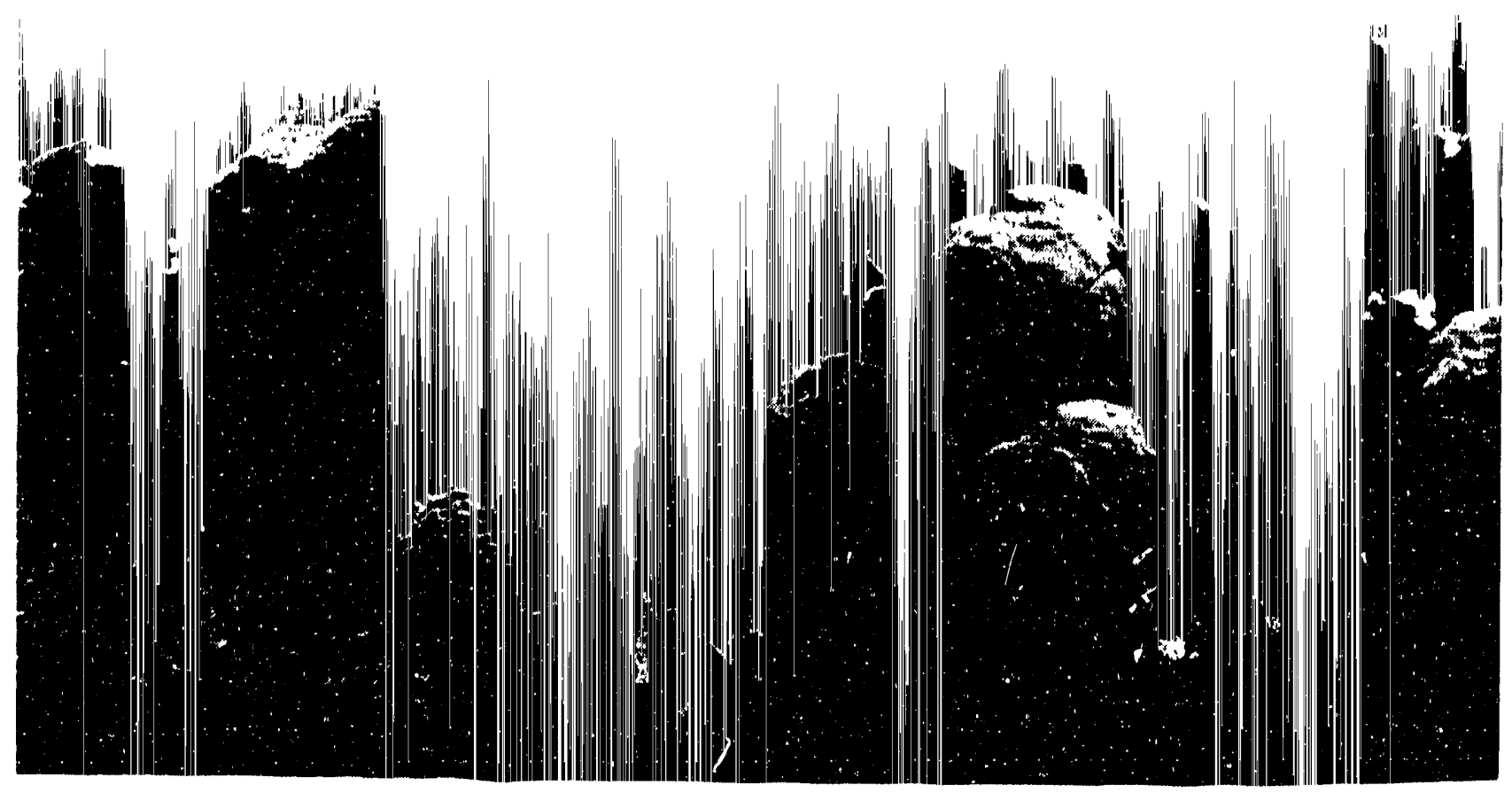

Figure 2-50. Scanning Electron Micrograph of Thick Film on Chromium Surface 
Figure 2-39. Corrosion of the Chromized Cell Case as a Function of Cycle dinate value of $-225 \mu \mathrm{m}$ represents one-half of the wall thickness for the chro

The corrosion of the 9327 cell case differed from the pattem sel by other cells because the quality 0 chromized coating on the upper extension was substandard. The maximum depth of penetration still occurred in the base section as a consequence of active material settling in the sulfur electrode. However, portions of the upper extension underwent substrate attack of nearly

comparable magn extension was $\pi$ variability in thic viously examine: chromizing treatm because a differen for the extension.

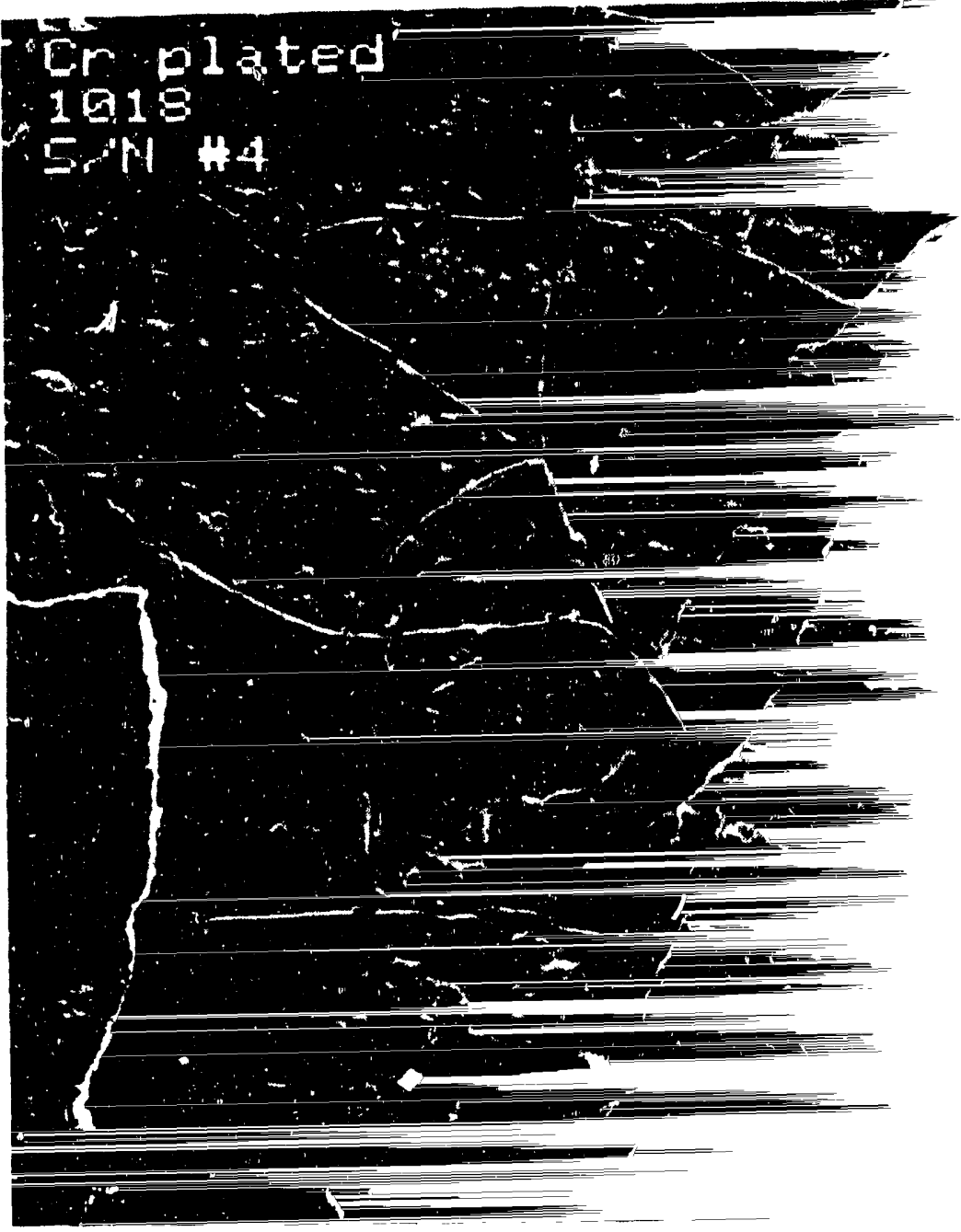

Figure 2-51. Scanning Electron Micrograph of Chromium Surface Under

Higure 2-51. Scanning Electron Micrograph orChromitm Surface Under

An on-line $\mathrm{pH}$ meter was installed in the anolyte flow system atter cycle 6 . The fiobe has continued to provide an accurate $\mathrm{pH}$ signal after almost 400 cycles and about 2 years of testing.

Material St

The plas lowed a ser project. The Since the new end assembly was installed the stack 


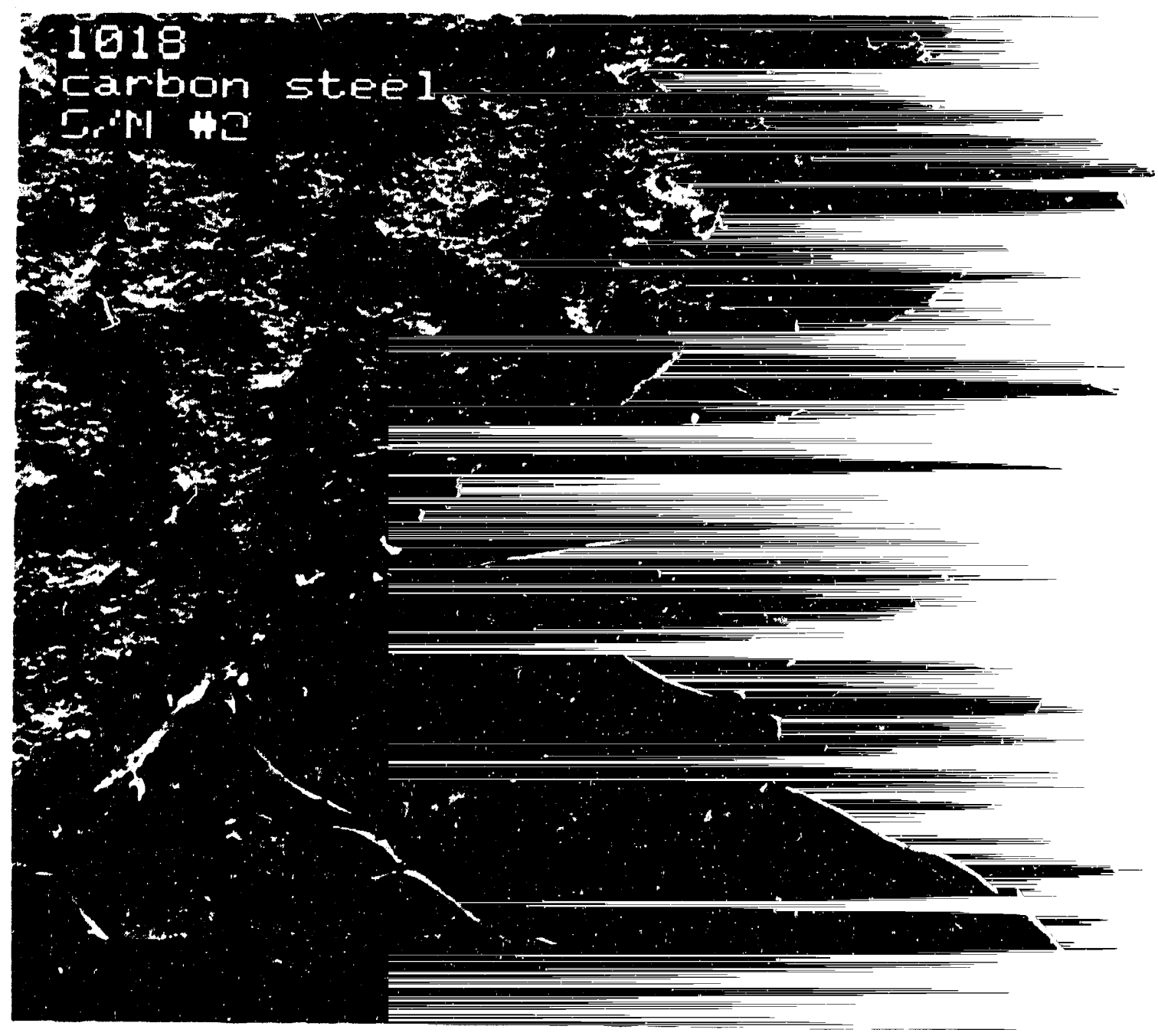

Figure 2-52. Scanning Electron Micrograph of Chromium Surface Under the Film 


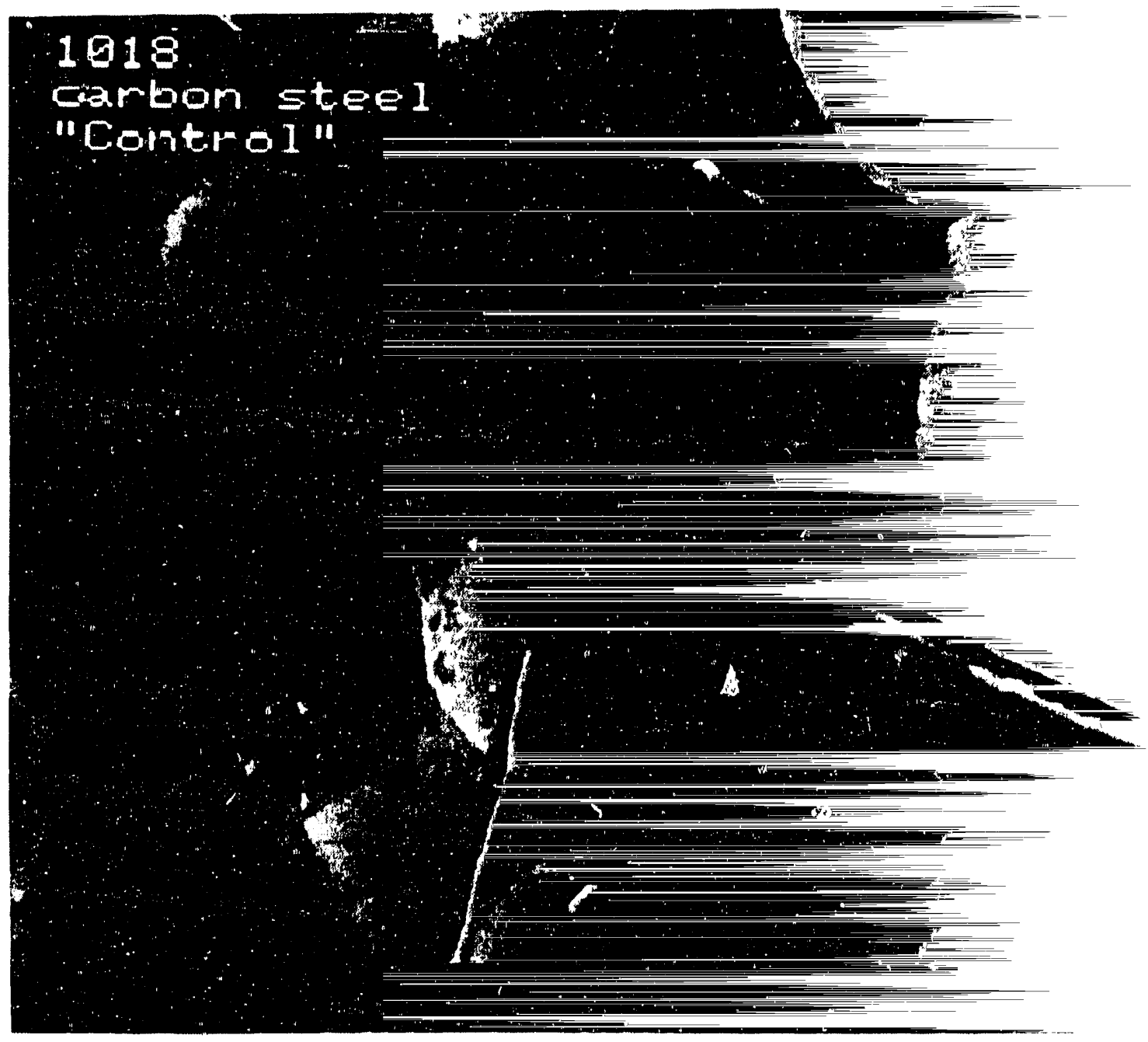

Figure 2-53. Scanning Electron Micrograph of the Control Sample 


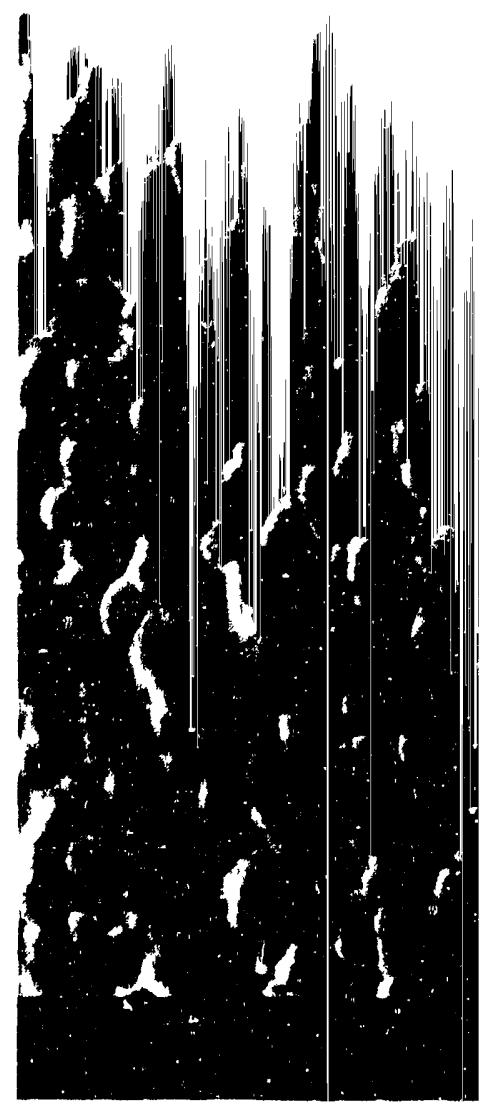

Figure 2-54. Scanning Electron Micrograph of the Control Sample 


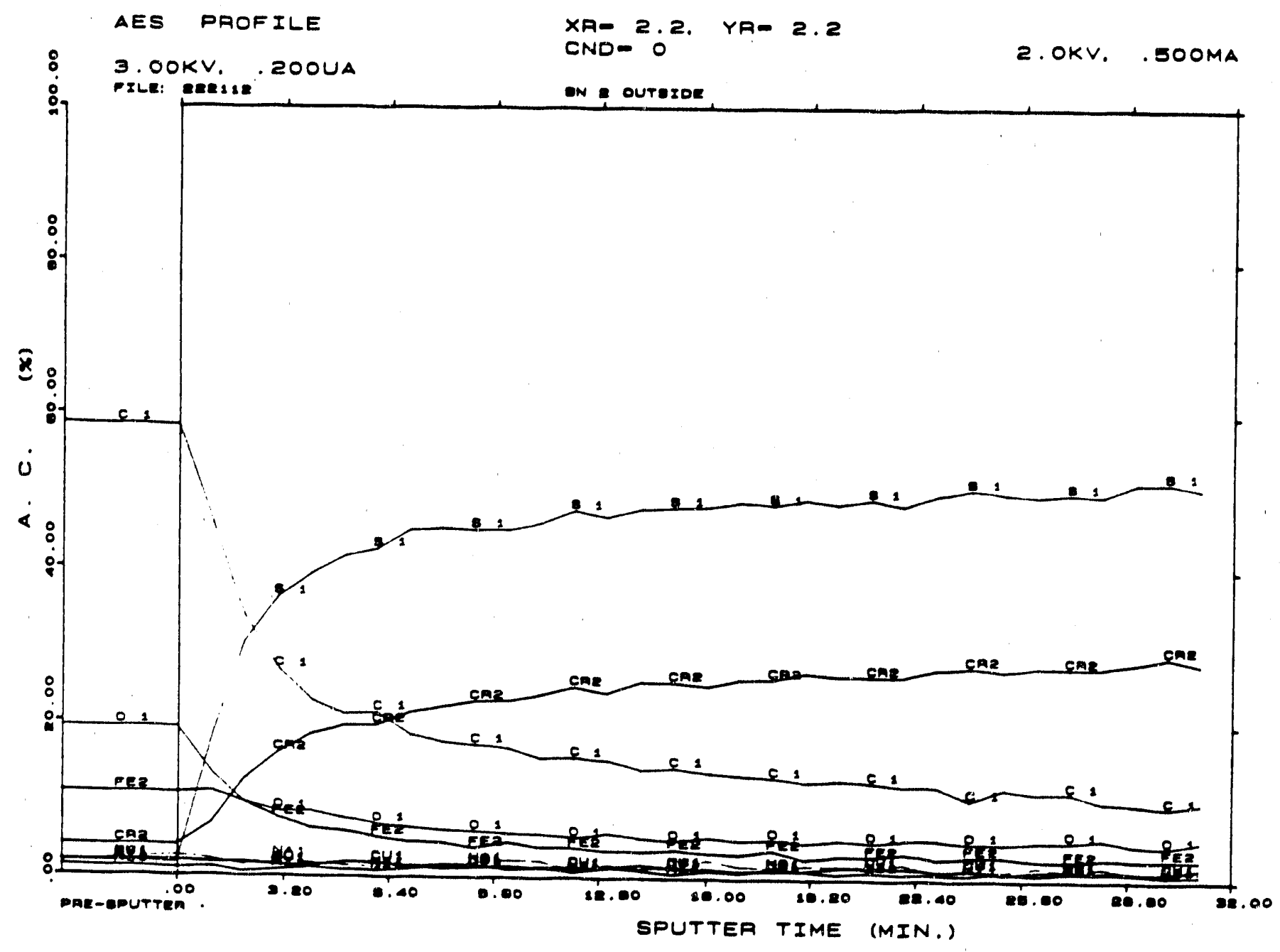

Figure 2-55. Auger Sputter Analysis of Film from Rod 


\section{Zinc/Bromine Technology}

In FY89, the zinc/bromine technology for stationary energy storage was primarily developed by industrial developers under contracts managed by SNL. As part of managing these development contracts, SNL accepted three battery deliverables for evaluation during FY89, and continued testing an FY88 battery deliverable. Life cycle testing was performed in order to ascertain possible failure mechanisms. Information gained by the cycle testing program at SNL has assisted the developers with battery stack and system design. The Exploratory Battery Technology Development and Testing Project supports technology improvement programs at SNL pertaining to the battery stack separator and the materials of construction. These research areas have been identified by SNL as areas where SNL may have a major impact on the zinc/bromine technology in terms of energy efficiency and battery lifetime.

\section{Technology Development}

During 1989, the Exploratory Battery Technology Development and Testing Project continued to support the zinc/bromine advanced secondary battery system. The largest zinc/bromine battery development program was with Energy Research Corporation (ERC). This $\$ 5.1 \mathrm{M}$ development program, comprised of a $\$ 4.7 \mathrm{M}$ contract from SNL and $\$ 0.4 \mathrm{M}$ in cost sharing by ERC, began in September 1985 and will be completed in December 1989. The objective of this project is to improve the core technology and perform the engineering and evaluation of a 18-kWh zinc/bromine proof-of- concept battery for stationary applications. The core technology is the basic and supporting research, qualification of materials, component development, and testing of auxiliary equipment. In July 1988 , a smaller $\$ 50,000$ development program was initiated with Johnson Controls Incorporated $(\mathrm{JCI})$ to evaluate a $20-\mathrm{kWh}$ zinc/bromine battery in their load management facility. $\mathrm{JCI}$ 's $20-\mathrm{kWh}$ battery is an adaptation of an electric vehicle battery developed under another DOE program.

\section{Zinc/Bromine Battery Development - ERC}

The goal of the Battery Development Program at ERC is to develop a zinc/battery module that could be used as a building block for a stationary energy storage facility. Activities in the last year of the program have centered on evaluation of new hardware in cell and stack tests, as well as continued testing of stacks with the earlier hardware design. Material stability studies were also continued, focusing on plastic materials of construction as well as cell components. The following sections describe the hardware testing and development activities as well as the results of the material stability studies.

\section{Harctware Development}

\section{Stack Clamping Assembly}

The zinc bromine battery stack consists of a bipolar pile of electrode/flow frame assemblies, shown schematically in Figure 3-1.

The stack of frames is held together by compressive force, which is applied by tie bolts. The tie bolt tension is distributed over the flow frame area by clamping hardware at each end of the stack. Distribution of the load is accomplished with a $1.3 \mathrm{~cm}$ thick steel strongback, which has stiffening ribs to ensure even distribution of the clamping force. A PVC end plate is used at each end of the stack, between the steel strongback and the stack of flow frames. The end plate contains the end electrode current collector and provides for the flow connections to the stack. The end electrode is a $0.6 \mathrm{~cm}$ thick titanium plate with a centrally located current collecting post. Contact with the first working carbon-plastic bipolar electrode is made by placing a carbon felt contact interface between the bipolar plate and the end electrode. The felt makes uniform electrical contact between the electrodes, compensating for any slight misalignment between the plates.

During operation of 5-cell stacks in the program, problems have been encountered in the end electrode connections. In the initial version of this design, insufficient support was built into the felt contact area. The hydraulic pressure of the electrolyte on the working side of the end bipolar electrode led to cracking of the end flow frames in the stack. The end contact system was redesigned by increasing the compression level of the carbon felt contact distributor.

After extended testing with this end design a problem was obseryed with the elastomer gaske! which was 


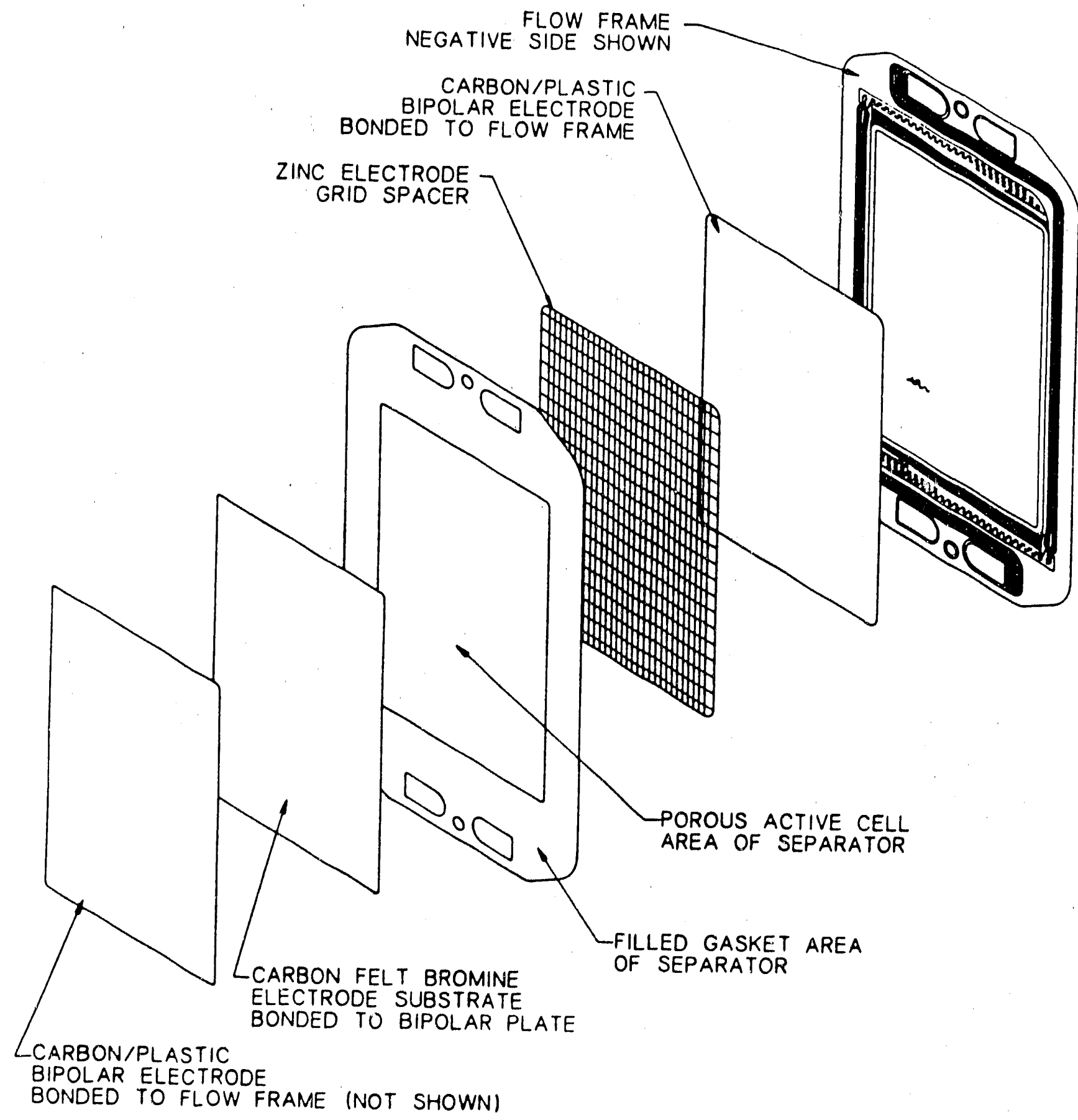

Figure 3-1. Exploded View of $1,500 \mathrm{~cm}^{2}$ ERC Zinc/Bromine Battery

used to seal the end assembly to the stack of flow frames. The gasket was found to swell and clog flow channels. The end assembly was redesigned, eliminating the gasket. The seal between the end assembly and the flow frames was made with a solvent bond. This was done by machining the sealing ridges on the nonworking (dry) side of the flow frame to create a flat sealing surface. The bonded subassembly then consisted of the PVC end plate (with the end electrode and flow connections) on one side and the first working flow frame on the opposite side.

This design was used in 5-cell and 30-cell stacks with $872 \mathrm{~cm}^{2}$ and $1,500 \mathrm{~cm}^{2}$ active cell areas. Initial performance was good; however, with time, leak paths developed through the solvent bond. There was also 
some concern that the large amounts of solvent used could attack the PVC frame material. The solvent bond dried to a hard layer of PVC material, and the uniformity of this layer thickness could not be assured. In one stack test, a high spot in the bond layer is believed to have caused the development of hairline cracks in some of the flow frames.

In addressing these issues, an end assembly design was developed which utilized a room-temperaturecuring silicune instead of PVC cement to glue the end flow frame to the PVC end block. The final thickness of the silicone bond was about $3 \mathrm{~mm}$. Also included in this design revision was the use of thin polypropylene support ribs in the dry carbon felt contact layer area. This was to provide additional support against the hydraulic pressures on the working side of the electrode.

This design relied on the resiliency of the silicone layer to accommodate any variations in the bond layer thickness during stack compression. In the first build utilizing the new design (the first $1,500 \mathrm{~cm}^{2}$ 52-cell stack) the design provided excellent sealing; however, in subsequent builds, high spots in the bond layer caused cracking in the flow frames. The design was revised by reducing the thickness of the bond layer to $1 \mathrm{~mm}$. The sealing ridges on the bond side of the end flow frame were machined to provide two flat bonding surfaces. This design has performed well in $1,500 \mathrm{~cm}^{2}$ stacks which are currently on test at SNL and ERC.

\section{$1,500 \mathrm{~cm}^{2}$ Stack Test Results}

The first $1,500 \mathrm{~cm}^{2}$ multi-cell stack tested was a five-cell stack designated 1500-5-1. The stack was built with machined flow frame prototypes before molded frames were available. Most of the cycle testing was done on a $150 \mathrm{mAh} / \mathrm{cm}^{2}$ regime which utilized a five hour, $35 \mathrm{~mA} / \mathrm{cm}^{2}$ charge followed by a discharge at 37.5 $\mathrm{mA} / \mathrm{cm}^{2}$ to a six volt cut off. Although it is anticipated that stacks built with the new frames can be cycled at $200 \mathrm{mAh} / \mathrm{cm}^{2}$, the rating of the modules is based on 150 $\mathrm{mAh} / \mathrm{cm}^{2}$ since limited cycle testing has been done on stacks at the higher loading level. The stack was tested for 85 cycles, with variations in operating parameters which were done to assess the performance responses. It was found that the battery required higher flow than predicted to achieve acceptable performance. It was also found that the voltaic efficiency of the battery could be increased by compressing the carbon felt electrodes, indicating that the electrodes were not compressed to the design level in the cell channels. With continued testing the battery exhibited coulombic, voltaic, and energy efficiencies of 85,71 , and $60 \%$. The low voltaic efficiency was due to the lower felt compression level.
Stack 1500-5-1 was taken off test so that the test station could be used to evaluate the first injection molded flow frame samples. The first molded parts had regions in the comers of the active cell area where the mold had not properly filled, but it was desired to evaluate the new parts as soon as possible. The partially filled areas were filled with the PVC cement bonding material and the frames were built into stack 1500-5-2.

The initial performance of the stack was very good. Coulombic, voltaic, and energy efficiencies of 87.5 , 76.8 , and $67.2 \%$ were obtained initially. With continued testing, however, the poorly molded areas in the flow frames developed cracks which allowed cross leaking of the negative and positive electrolytes. Figure 3-2 shows efficiency data for the cycle tests, which were stopped after 9 cycles.

By the time the 1500-5-2 tests were stoppecl, flow frame samples from the completed injection mold tooling were available. A third five-cell stack was built with the new flow frames, designated 1500-5-3. Voltage performance data for the stack on cycle test is shown in Figure 3-3.

After the first sixteen cycles, a test was run on the stack to determine the level of polybromide built up in the felt channels. During the charge portion of the cycle a certain quantity of polybromide complex is formed and trapped in the carbon felt bromine electrodes. The polybromide, because of its bromine releasing properties, increases the rate of self discharge of the battery. The quantity of polybromide in the felt electrodes is measured by charging the battery and then discharging with the catholyte pump off. By discharging the stack with the catholyte pump off, only the bromine stored in the cell channels is available for reaction. The void volume of each bromine electrode is about $310 \mathrm{cc}$. The aqueous electrolyte in a fully charged battery should have a bromine concentration of from 10 to $13 \mathrm{~g} / \mathrm{l}$, so at most only 4 grams of $\mathrm{Br}_{2}$ would be detected if no polybromide were present in the electrodes. In tests run on the $872 \mathrm{~cm}^{2}$ flow frame hardware, cell bromine inventories of 80 to 90 grams were typically found.

The polybromide inventory test was run on cycle number 17. The stack was given a full charge and then discharged with the catholyte pump off and the anolyte pump on a low speed. The battery was discharged at the baseline rate $(56.25 \mathrm{~A})$ to a voltage cut off, and then discharged at lower rates to remove the remaining bromine capacity. A bromine inventory of 148 grams $\mathrm{Br} 2$ per cell was measured, which is about equivalent to the 80 to $90 \mathrm{~g} / \mathrm{cell}$ inventory detected in the $872 \mathrm{~cm}^{2}$ tests. This result indicates that the higher, more narrow cell geometry of the $1,500 \mathrm{~cm}^{2}$ cells does not cause any additional polybromide build up. 


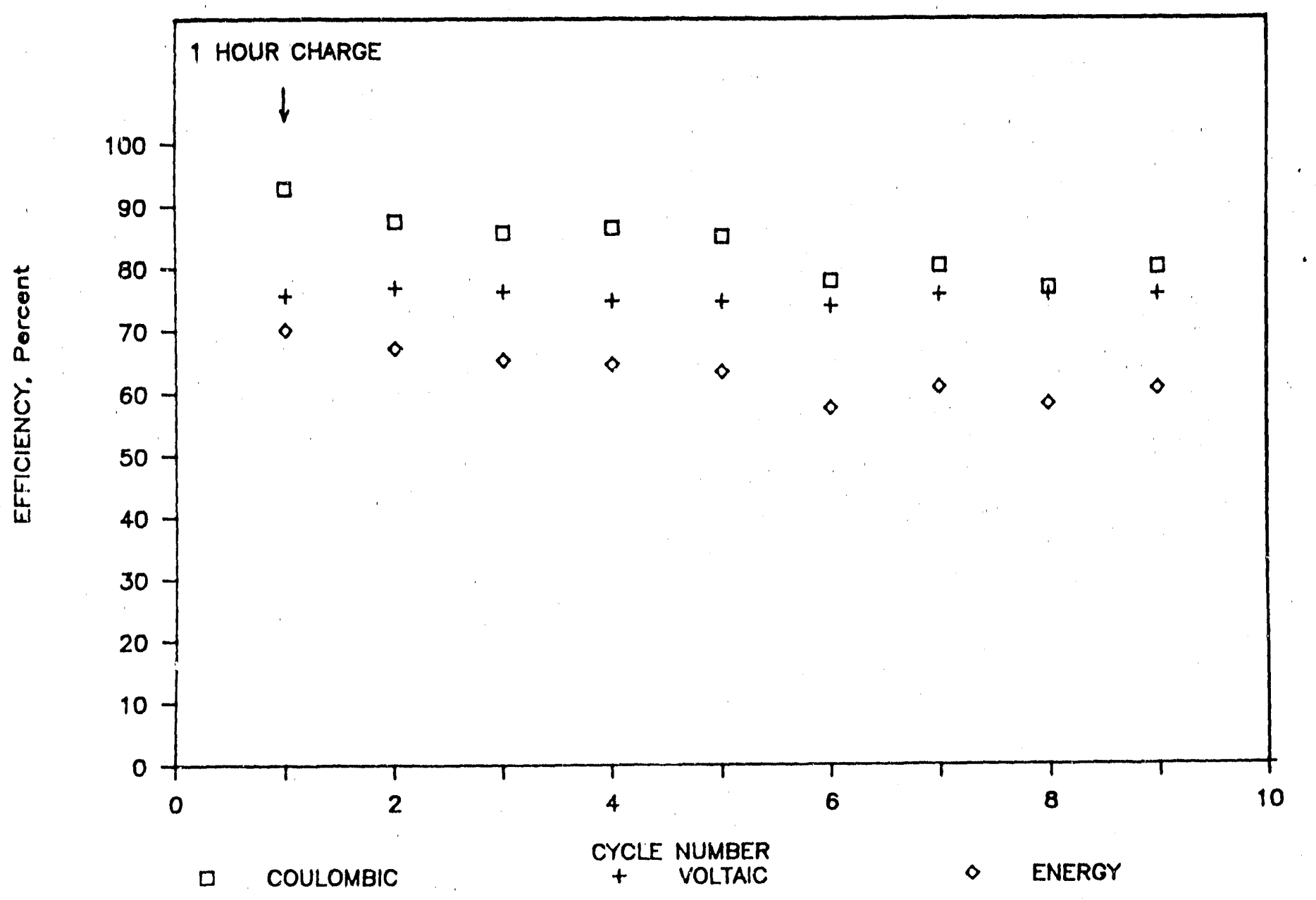

Figure 3-2. Cycle Performance, 5-cell, $1,500 \mathrm{~cm}^{2}$ Battery, 1500-5-2

Figure 3-4 shows efficiency data for the 54 cycles of testing that were run on the stack.

At cycle 40, coulombic efficiency dropped to about $70 \%$ and then became erratic from cycle to cycle due to variations in the electrolyte flow pressures. Electrolyte flow pressures and rates had to be increased steadily over the test to maintain performance. Initial cycling was done with catholyte and anolyte flow pressures of 5 to $7 \mathrm{psi}$, but by cycle 39 the operating electrolyte pressures had been raised to 12 to $13 \mathrm{psi}$. Because of the erratic performance of the stack it was decided to stop testing and tear the system down.

The teardown indicated that the positive end current collecting assembly had leaked and the titanium current collector had been wet with electrolyte. Closer inspection showed that the flow frames had developed hair line cracks near the catholyte outlet manifold. The cracks had developed in the area where through holes are drilled to connect the catholyte outlet flow channel to the catholyte outlet manifold. In most cases the cracks were only on the catholyte side, and they did not extend through to the anolyte side. In the case of the catholyte end flow frame, the cracks extended through the frame, causing the leak into the dry end contact assembly once the frame has cracked.

The end electrode contact assembly used in 1500-53 was the design in which the frame was bonded to the PVC end block with a solvent bond. In the teardown it was observed that the PVC solvent bond was nonuniformly distributed over the area of the end block, with high spots and areas without coverage. The high spots are believed to have contributed to the frame cracking problem, and the areas with no bond layer provided leak paths to the dry end contact area.

A different end contact design was developed after the fabrication of $1500-5-3$ which utilizes a silicone 


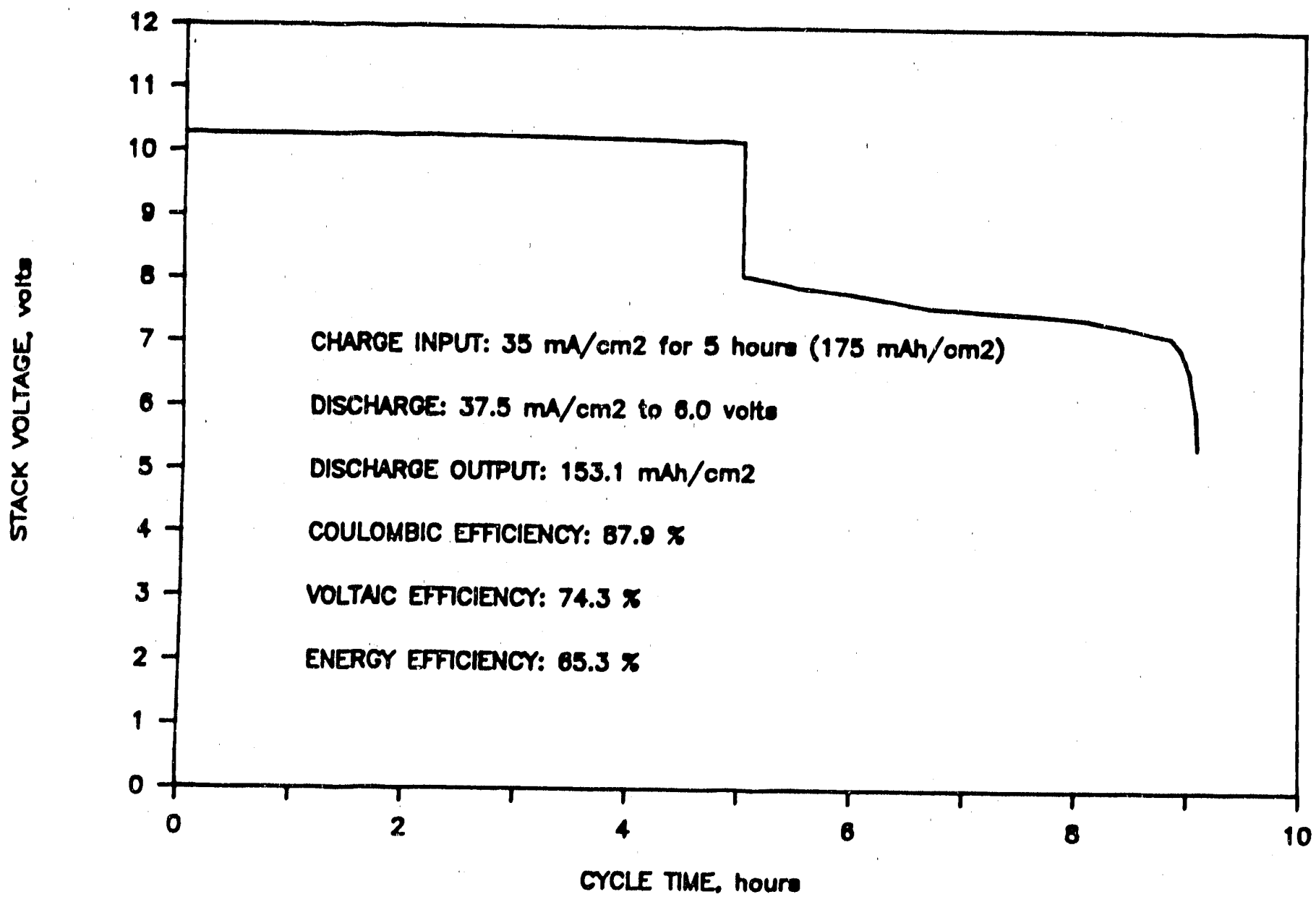

Figure 3-3. Cycle Performance 1,500 $\mathrm{cm}^{2}$, 5-cell Battery, 1500-5-3

based RTV bond between the flow frame and the PVC end block (see section 2.1). The RTV design was built into the first $1,500 \mathrm{~cm}^{2} 52$-cell battery, $1500-52-1$, which has not exhibited any leaking in the 51 cycles of testing conducted to date.

In the first tests run on the 52-cell system, the battery exhibited a very high resistance to current flow. It was initially assumed that the separators had not been completely wet, so a second wet down procedure was done. After this a series of cycles was run with low charge time or low current density to allow the separators to wet. An increasing voltaic efficiency indicated that the separators were wetting.

The battery has been on test for just over 50 cycles, and the efficiency performance of the system is shown in Figure 3-5.

An observation made in the initial testing is that the flow pressure required to achieve the design catholyte flow rate was higher than that observed in testing of the $5-\mathrm{cell} 1,500 \mathrm{~cm}^{2}$ stacks. Flow pressures were increased as the cycle testing progressed in order to determine the optimum operating conditions. By cycle 15 the electrolyte circulation pumps were being operated at relatively high pressures ( $16 \mathrm{psi}$ catholyte $/ 20 \mathrm{psi}$ anolyte with 13 psi anolyte back pressure). This gave a catholyte flow rate of 8 to $10 \mathrm{gpm}$ (depending on state of charge) and an anolyte flow rate of $16 \mathrm{gpm}$. The design flow rates for the system are $9 \mathrm{gpm}$ for the catholyte and $13 \mathrm{gpm}$ for the anolyte. The $16 \mathrm{gpm}$ anolyte flow rate and 13 psi anolyte back pressure were required to balance crossover.

In cycles 20 through 26 the flow pressures were varied to determine the system response and the efficiency data exhibit a high degree of variability as a result. In particular, the catholyte flow rate on discharge was found to be critical to the efficiency performance of the system. On those cycles run with the 


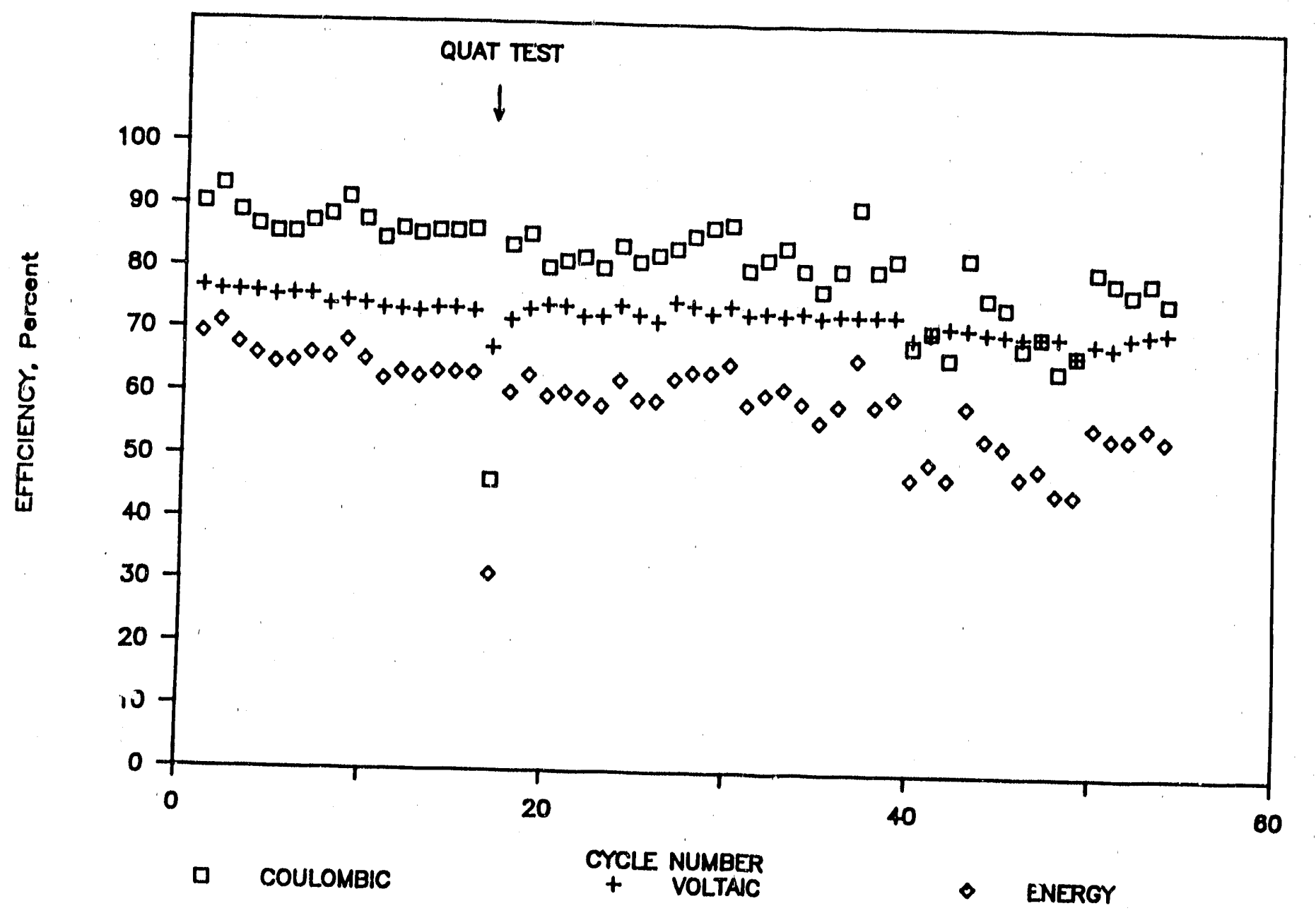

Figure 3-4. Cycle Performance, 5-cell, $1,500 \mathrm{~cm}^{2}$ Battery, 1500-5-3

higher electrolyte flow rates (at least during the discharge period) the coulombic efficiency tended to be about $80 \%$ for cycles with 5 hours of charge and $84 \%$ for cycles with 4 hours of charge.

On cycle 32 the electrolyte in the battery was replaced with fresh electrolyte in order to eliminate the effect of impurities, such as the methanol wetting agent, on the battery performance. Efficiency was actually reduced after the electrolyte change. It was determined that the bromine level in the electrolyte was low due to bromine removed with the original electrolyte. At cycle 39 bromine was added to the catholyte and coulombic efficiency rose to about $80 \%$ again. In subsequent tests the efficiency has increased slightly, and the system is currently operating at about $60 \%$ energy efficiency.

From the first stack tests run with the $1,500 \mathrm{~cm}^{2}$ frame (1500-5-1) it was observed that voltaic efficiency was lower than expected because the extra zinc electrode gap tolerance in the new frame was being transferred to the bromine electrode gap. This resulted in flow bypassing the electrode, which lowered the electrode performance unless the anolyte pressure was raised or the catholyte flow rate was increased. Late in the core technology program this issue was addressed by producing $3.4 \mathrm{~mm}$ thick felt electrodes. The first evaluation of the thicker electrodes has been in a 5-cell deliverable battery tested at SNL. In initial cycle tests on the system the battery has delivered 65 to $68 \%$ energy efficiency. Further testing will be required to verify that the performance can be maintained; however, the initial results indicate that the cause of the voltaic efficiency problem has been identified and addressed with the thicker felt electrode. Based on these results, a second 52-cell stack is being fabricated with the new electrode specification. 


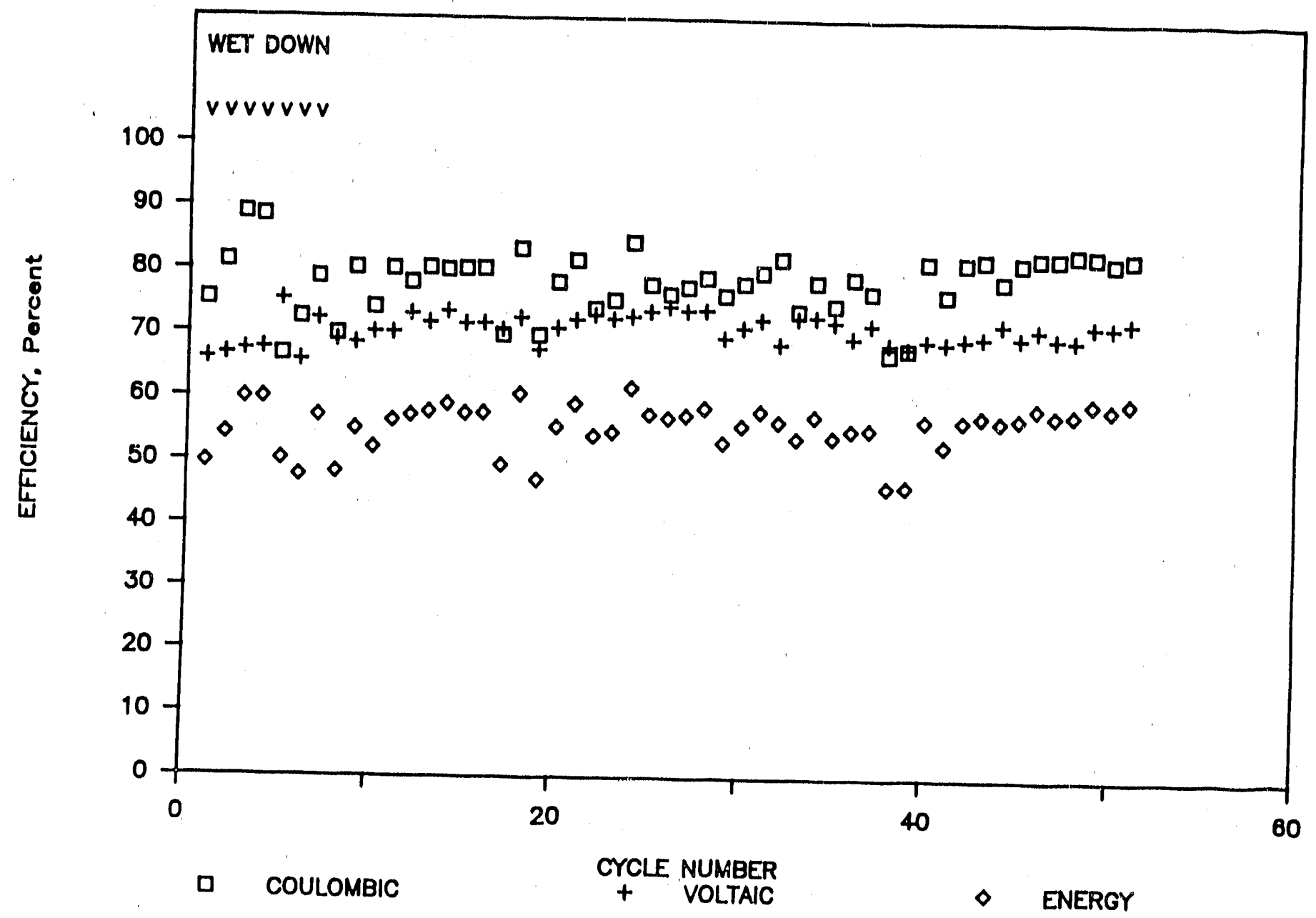

Figure 3-5. Cycle Performance, 52-cell, $1,500 \mathrm{~cm}^{2}$ Battery, 1500-52-1

\section{$872 \mathrm{~cm}^{2}$ Battery Testing}

System and component designs were evaluated in continuing 5-cell and 30-cell battery tests using the 872 $\mathrm{cm}^{2}$ flow frame hardware. The standard cycle test consists of a 5 hour charge at 30 amperes $\left(172 \mathrm{mAh} / \mathrm{cm}^{2}\right.$ charge) followed by a 30 ampere discharge to a voltage cutoff $(1.2$ volts/cell). Typical discharge capacity on the baseline regime is $150 \mathrm{mAh} / \mathrm{cm}^{2}$. After each discharge a brief low-rate discharge is usually conducted, followed by an open circuit stand period to remove residual zinc.

Stack SNL-5-4 was built with .025" thick Daramic separators and the gasket seal in the end assembly. The battery was the first to incorporate the two-loop flow system design and variable frequency pump motors. The system also included the first LVDT electrolyte level sensor, and the battery was used to evaluate automatic pump speed control techniques. Figure 3-6 shows efficiency data for the stack on cycle test.

On test for more than 400 cycles, SNL-5-4 has gone through two end electrode design revisions. The first end electrode modification was to increase the level of compression on the dry carbon felt contact in the end electrode. This was installed after 108 cycles had been run on the stack. No cracked frames were observed; however, performance improved after the end plate was installed due to the improved end contact.

After cycle 160 the catholyte bromine level was adjusted to replace $\mathrm{Br}_{2}$ which had evaporated throughout the test period. Coulombic efficiency increased to above $90 \%$. A subsequent decline in efficiency was observed which was determined to be caused by low overnight temperatures in the test area, which resulted 


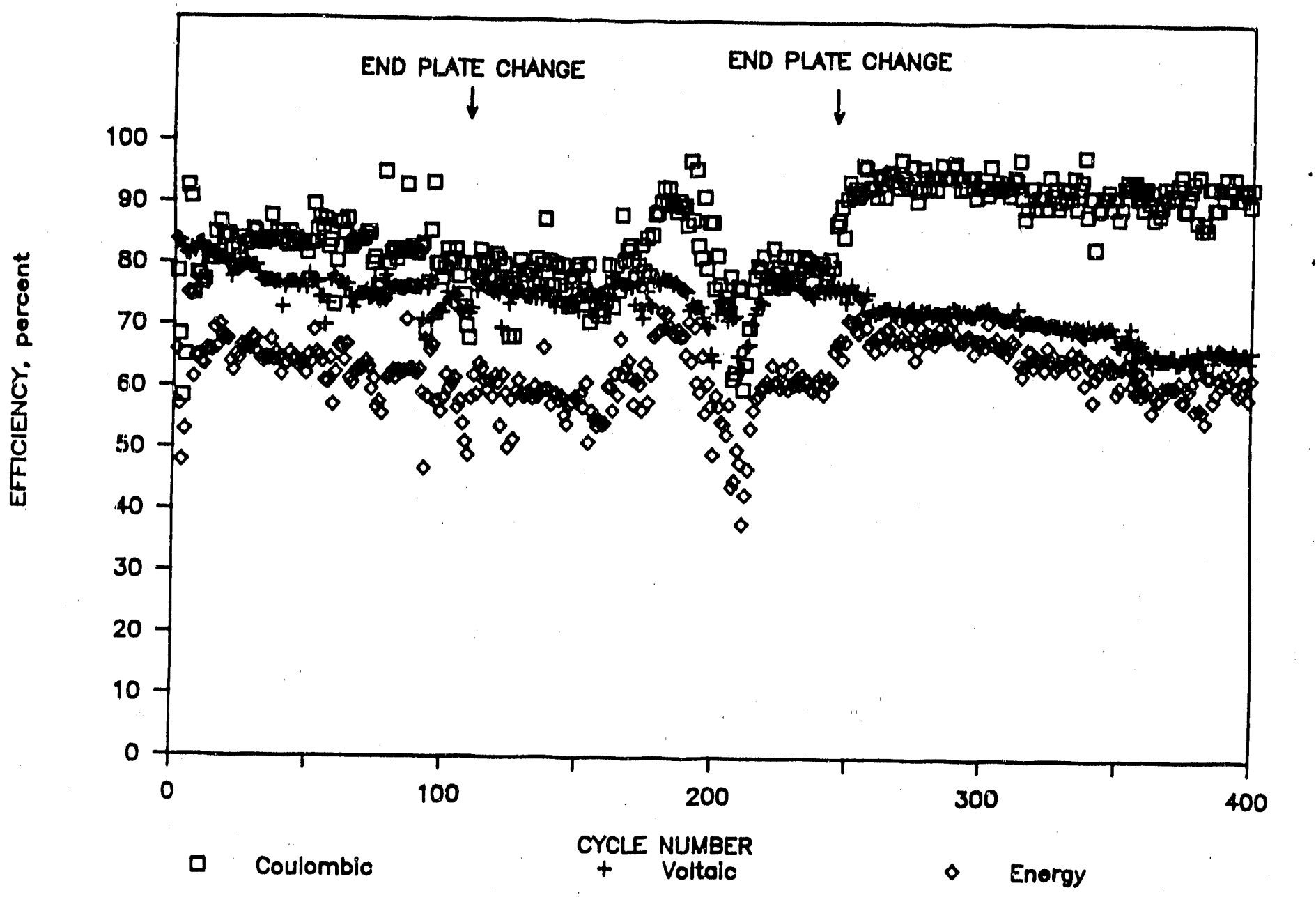

Figure 3-6. Cycle Performance, 5-cell, $872 \mathrm{~cm}^{2}$ Battery, SNL-5-4

in electrolyte salt precipitation and flow channel clogging. After the temperature was raised, performance recovered, but only to a level of about $60 \%$ energy efficiency.

By this time in the program, the end assembly gasket swelling problem had been identified and the first end assembly design without the gasket had been developed. In this design a PVC solvent cement was used to bond the end flow frames to the PVC end plate. This end design modification was installed in SNL-5-4 after cycle 244 . In the first forty cycles after the end assembly was installed coulombic, voltaic, and energy efficiencies averaged $93.5,73.7$, and $68.9 \%$ respectively. In subsequent tests voltaic efficiency has declined, and the stack is currently on test at coulombic, voltaic, and energy efficiency levels of 92,66 , and $61 \%$. Evaluation of other batteries with the PVC cement end assembly bond has shown that leak paths eventually develop though the bond layer, and this is probably the cause of the reduced voltaic efficiency.

Testing has also continued on 30-cell stack SNL$30-2$, which also used the two flow-loop system, and which used Daramic separators that are .035" thick, the current baseline. The stack has been on test for more than 400 cycles. The efficiency performance over the cycle test is shown in Figure 3-7.

This stack has also gone through two end electrode assembly design revisions. The newest end assembly design (eliminating the elastomer gasket) was installed in the stack after 263 cycles. In installing the new end assembly the effect of the flow channel clogging could be seen, as salts had built up in the end cell which had been starved of electrolyte because of the swelling gasket. The salts had built up to a level beyond the cell channel gap thickness, cracking the bipolar electrodes 


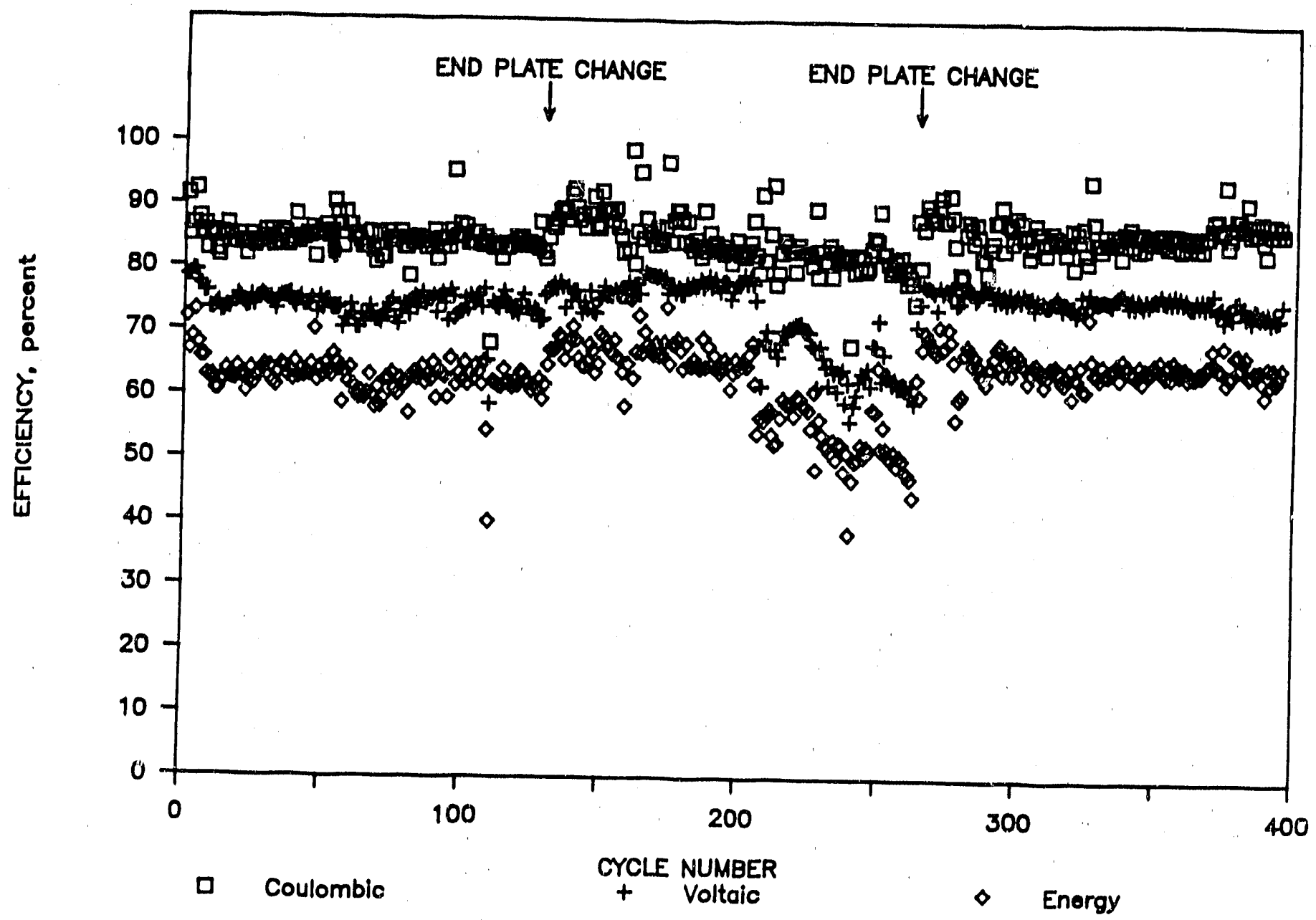

Figure 3-7. Cycle Performance, 30-cell, $872 \mathrm{~cm}^{2}$ Battery, SNL-30-2

of the two cells adjacent to the positive end cell. The first five flow frame assemblies at the positive end of the stack were replaced and the stack was rebuilt. Over the history of the test coulombic, voltaic, and energy efficiencies have averaged $85.1,73.9$, and $63.0 \%$ respectively. Since the installation of the new end assemblies these efficiencies have averaged 86.2, 75.6 and 65.2\%. As is the case with the five cell tests, energy efficiencies as high as $75 \%$ have been obtained by operating the stack at lower capacity densities (below the 150 $\mathrm{mAh} / \mathrm{cm}^{2}$ baseline) or lower current densities.

While SNL-30-2 was on test, a deliverable battery at SNL had failed because of the electrolyte salt-out problern described above. A similar problem was encountered in testing at Murdoch University. An electrolyte design was chosen which addressed the salt precipitation problem, and the electrolyte in SNL-30-2 was replaced with the new electrolyte after 240 cycles. No performance impact was observed due to the new e'sctrolyte, but it has been established that the electrolyte has a much wider operating temperature range.

The 30 cell SNL-30-2 system has also been used as the test bed for a variety of system instrumentation and control strategies. The LVDT electrolyte level control system was installed in the system after 6 cycles and was demonstrated to work well. The system controlled the levels within a bandwidth of liquid heights due to the response of the LVDT float to the changing specific gravity of the electrolyte. After 129 cycles of testing the LVDT float unit was configured inro a constant liquid level section of the flow system, to be used as a statc-ofcharge indicator. The first of the infrared optical probe systems was installed to control the electrolyte liquid levels. Both the optical probe level control and the LVDT state-of-charge systems have worked well in continued tests. 
An on-line $\mathrm{pH}$ meter was installed in the anolyte flow system atter cycle 6 . The F.ube has continued to provide an accurate $\mathrm{pH}$ signal after almost 400 cycles and about 2 years of testing.

Since the new end assembly was installed the stack has periodically been tested on an automatic cycle regime, logging two baseline cycles per day. It has been found that after running 6 to 8 cycles couiombic efficiency declines to about $80 \%$ due to buildup of residual zinc. This occurs because the open circuit stand time between cycles is not sufficient to strip sidual zinc from the elestrodes. In ongoing tests an xtended stripping cycle is done after every 5 cycles and coulombic efficiency is maintained above $85 \%$.

The tests conducted on $872 \mathrm{~cm}^{2} 5$-cell and 30-cell stacks have provided valuable data with respect to the battery capabilities and the limitations of iterations of the battery design. The end assembly design has been a critical factor in the perfomance of these batteries, and successive rebuilds of ongoing units have been used to address problems in this component design. The SNL5-4 and SNL.-30-2 stacks remain on test beyond the 400 cycle point, with logged calendar time of more than 2 years. The flow frames, bipolar electrodes, and carbon felt electrodes are still performing well after this extended test. The separators in the stacks were usually replaced when the stacks were rebuilt to install new end assembly designs. The separators in SNL-5-4 have been on test for more than 270 cycles, and those in SNL-30-2 have been on test for 140 cycles. There is no indication of a problem in the separator performance, with the exception that some of the silicone gasket filler has been found to have leached out of the separators. This has not yet occurred to an extent which would cause a seal failure.

The electrolyte pumps in both stacks are the original pumps installed in the system, and they have operated for the duration of the 400 cycles and two ye urs without incident. The $\mathrm{pH}$ probe in SNL-30-2 has been on test for almost the entire 400 cycles, as has the LVDT float unit (first as a level control and now as a SOC indicator). The optical probe level indicator has worked well for 270 cycles.

These observations illustrate the potential of the battery system and the progress that has been made in identifying stable cell and syster: component designs. The major life limiting problems in these tesis have been hardware issues, and these are being addressed in continued design optimization.

\section{Material Stability Studies}

The plastic stability tests conducted in 1989 followed a series of screening tests run earlier in the project. The screening tests had examined the stability of a number of plastic materials, including polyolefins, polyvinylchloride (PVC), and chlorinated polyvinylch:oride (CPVC). The PVC and CPVC materials exhibited the greatest stability in the screening tests; however, high levels of tin were found to leach out of the CPVC, ruling out the use of this material. The screening tests were very severe $\left(60^{\circ} \mathrm{C}\right.$ temperature with $100 \mathrm{~g} / 1$ $\mathrm{Br} 2$ concentration), and it was decided to study the most stable materials on an expanded test matrix. The test matrix includes three immersion temperatures: 35,45 , and $55^{\circ} \mathrm{C}$. The solutions used are electrolyte with $10 \mathrm{~g} / 1$ $\mathrm{Br}_{2}$, electrolyte with $20 \mathrm{~g} / 1 \mathrm{Br}$, electrolyte with $30 \mathrm{~g} / \mathrm{l}$ $\mathrm{Br}_{2}$, and the polybromide complexing agent. In addition some samples are aged in air at temperatire to separate chemical changes from other aging phenomena.

Three materials are on test, all injection molding grades of PVC. The materials are designated PVC-1, PVC-4, and PVC-6. PVC-1 is the baseline material which has been used in all $872 \mathrm{~cm}^{2}$ flow frames. PVC-4 was the most stable material in the screening tests; however, one of the material components is a tin based stabilizer which could affect cell performance if it leached into the electrolyte. PVC-6 also exhibited improved stability in the screening tests compared to the baseline PVC-1, and has the additional advantage of not containing any tin. PVC-6 was selected for use in the $1,500 \mathrm{~cm}^{2}$ frame mold based on the earlier screening tests.

The samples used were molded tensile test bars which were immersed in tubes of electrolyte. A small quantity of polybromide was placed at the bottom of each tube, below the sample, to maintain $\mathrm{Br} 2$ levels in the event of evaporation or absorption into the sample. All of the samples were annealed before being immersed. When removed from tubes, samples were tested for size, weight, and tensile strength changes.

Samples have bee" removed and analyzed for weight and size changes after 4,16 , and 60 weeks of immersion. Strength data have been taken on samples immerse ic iur up to 16 weeks. Figure 3-8 shows weight gain $\operatorname{tr} . .$. for the three materials when inmersed in electini. th $20 \mathrm{~g} / 1$ bromine at $45^{\circ} \mathrm{C}$ for up to 60 weeks. 
The general stability ranking is the rame as that observed in the earlier screening tests, with PVC-4 the most stable and PVC-1 the least stable. The PVC-1 material also exhibited the most length gain, although the dimensional changes were very small for all three materials, as shown in Figure 3-9.

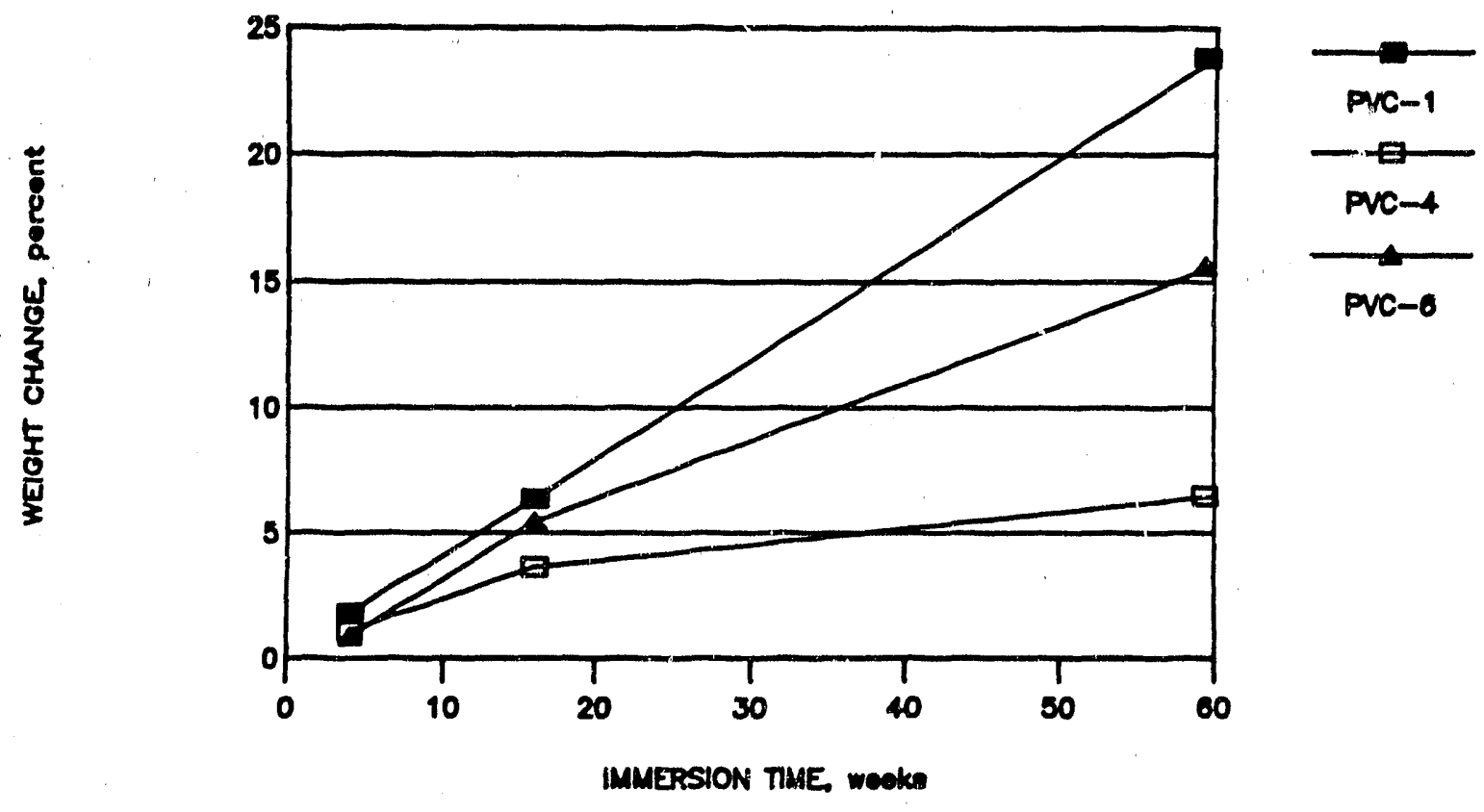

Figure 3-8. Material Weight Gain, $20 \mathrm{~g} / \mathrm{l} \mathrm{Br}, 45^{\circ} \mathrm{C}$

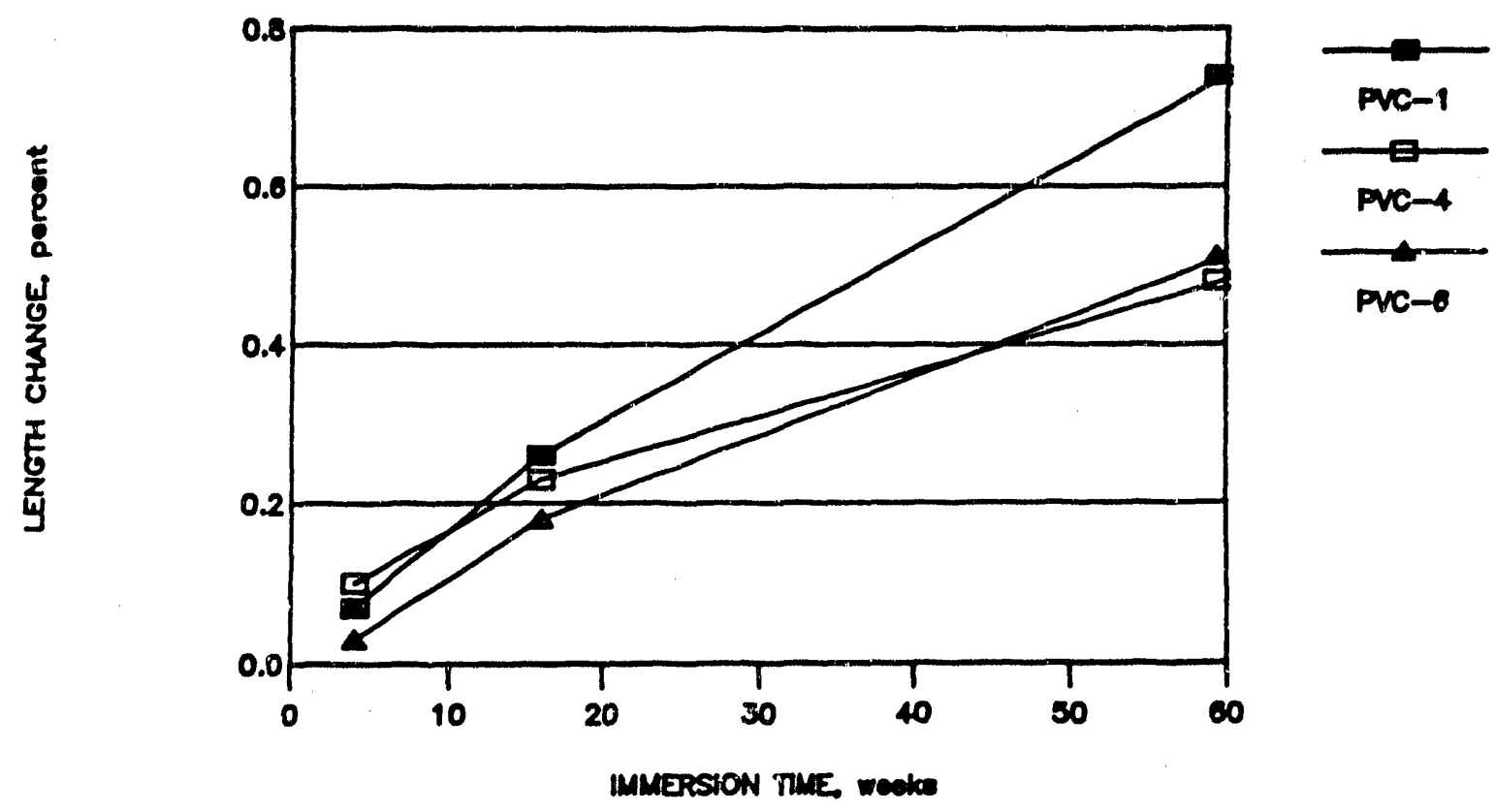

Figure 3-9. Material Length Gain, $20 \mathrm{~g} / \mathrm{B} \mathrm{Brz}, 45^{\circ} \mathrm{C}$ 
The weight gains exhibited for all three materials were fairly high, ranging from 5 to $40 \%$ for some of the higher temperature immersions. The degree of acceleration due to elevated temperatures can be scen in Figure 3-10, which shows weight gain for PVC-6 at three different temperatures.

At $35^{\circ} \mathrm{C}$ the weight gain is about $5 \%$, and it increases by about two and one half times for each $10^{\circ} \mathrm{C}$ rise in temperature.

The strength changes have all been fairly small except for PVC-1, which exhibited a 5 to $20 \%$ strength decrease over the temperature and concentration range in brominated electrolyte. Figure 3-11 shows the effect of the immersion solution on strength changes in the materials.

Only PVC-1 exhibits any significant change over the range of test conditions. All of the samples exhibited a 3 to $4 \%$ strength increase when aged in air at $55^{\circ} \mathrm{C}$ for 16 weeks, which is probably due to a continued annealing affect. For these plastic materials, immersion in the polybromide complexing agent caused very little change in properties. This is in contrast to the bipolar plate interial, which exhibits greater changes in polybronaide immersion than in the aqueous brominated electrolytes.
Analyses conducted by ERC on the molecular weight of the materials showed no conclusive trend of degradation with immersion. Analyses conducted at SNL also showed no evidence of direct attack of the PVC polymer. The data indicate that the additives in the plastics (thermal stabilizers and plasticizers required for melt processing) are the components which are affected by the immersion solutions.

The results of the expanded stability tests (which will continue, with samples scheduled for up to 120 weeks immersion, beyond the current program) have indicated that the choice of PVC- 6 as the new baseline frame material was valid. The stability ranking of the three materials is the same as that observed in the earlier screening tests. The most stable of the materials is the tin-stabilized PVC-4, however this material was shown to leach up to $8 \mathrm{mg} / 1$ of tin into the high temperature immersion solutions, and this would impair the performance of the zinc electrode. The other materials leached lead into the high temperature immersion solutions, however there is no evidence that lead will poison the electrolyte. In any event, no lead has been detected in stack electrolytes using frames made of PVC- 1 for up to 300 cycles of testing.

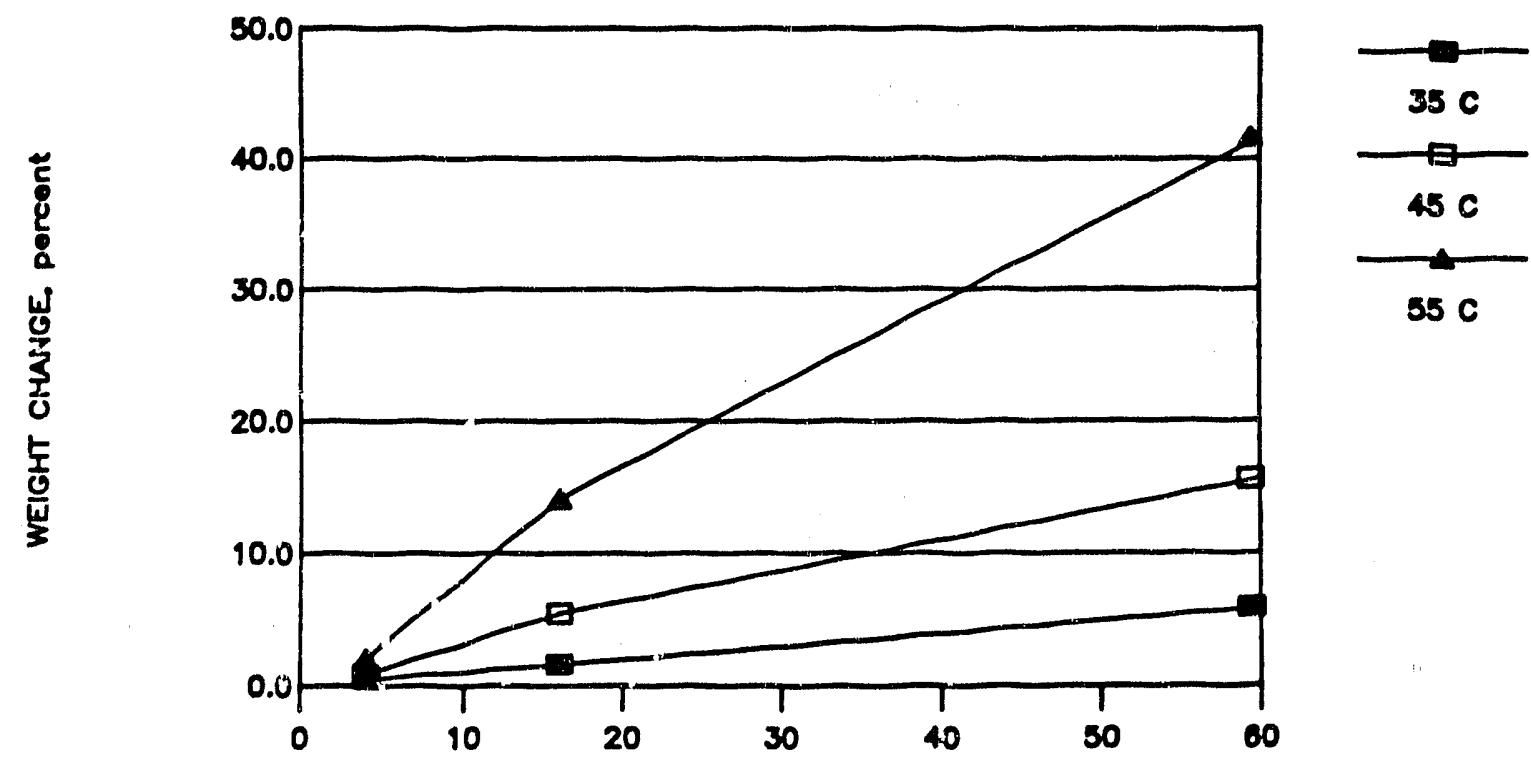

Figure 3-10. Material Weight Gain, PVC-6, 20 g/l Brz 


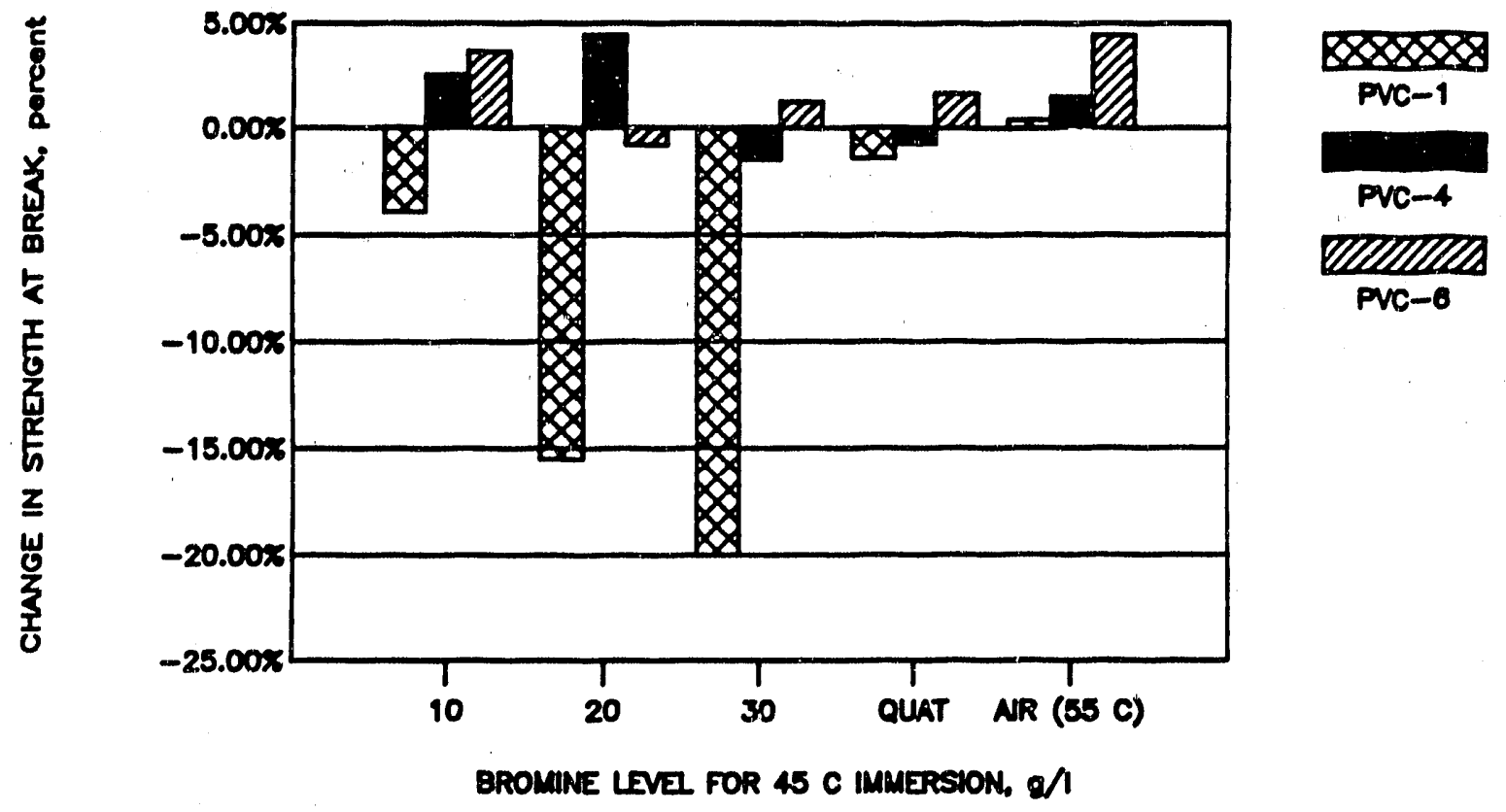

Figure 3-11. Material Tensile Strength, 16 Weeks

As the immersion tests continue, if significant changes in the strength of PVC- 6 are detected, an estimation of the useful life of the material in flow frame, tank, and piping components will be made. Based on the data presently available, there are no stability concerns regarding the material for the duration of stack tests in the development program.

\section{Development of a Zinc/Bromine Load Management Battery - JCI}

The Load Nanagement Program is aimed at adapting electric vehicle battery technology for load leveling applications. Due to delays in the electric vehicle program, some program goals in the load management program have been postponed. During 1989, evaluation of a $20-\mathrm{kWh}$, Z-design zinc/bromine battery (Z-20LL) was completed. Evaluation of this battery was initiated under a previous SNL contract in March 1987.

\section{Load Leveling Z-20LL Battery}

The Z-20LL battery used co-extruded polypropylene-based electrodes, glass-filled polypropylene flow frames, and W. R. Grace separators. The sealing method for this battery, as with all Z-design hatteries. was adhesive/bolt construction. The adhesive was painted onto the frames, with plastic-coated steel bolts holding the frames within a pair of thick plastic endblocks. Z-20LL was designed with two 78-cell stacks wired and plumbed in parallel. With a recoverable capacity of 84 amp-hours for each stack (at $.090 \mathrm{amp}$-hours $/ \mathrm{cm}^{2}$ zinc loading and $80 \%$ coulombic efficiency), and an average discharge voltage of $1.42 \mathrm{~V}$ per cell, the actual delivered energy was $1.42(84)(78)(2)$ $=18,608$ wat - hours per cycle. Figure $3-12$ is a photograph of the overall system. The two electrode stacks are visible in the plotograph between the two electrolyte reservoirs.

The pumps are located behind the two stacks. The electrolyte reservoirs were designed to hold 400 liters of electrolyte. In later testing of the battery only 300 liters of electrolyte were used, with no decline in performance. Pumping energy was supplied by two centrifugal pumps, each rated at $1 / 5 \mathrm{HP}$. The pumps were sized larger than they needed to be; in operation, the outflows from the pumps were throttled to maintain the desired electrolyte level in the reservoirs. The pumps were left on 24 hours a day. They could as easily have been turned off during stripping, except for perhaps 5 minutes of rurning every $1 / 2$ hour. The actual losses from pumping are calculated as follows.

$$
0.2 \mathrm{HP} \text { (2 pumps)(.742 kW/HP) }(24 \mathrm{hr})=7.12 \mathrm{kWh}
$$




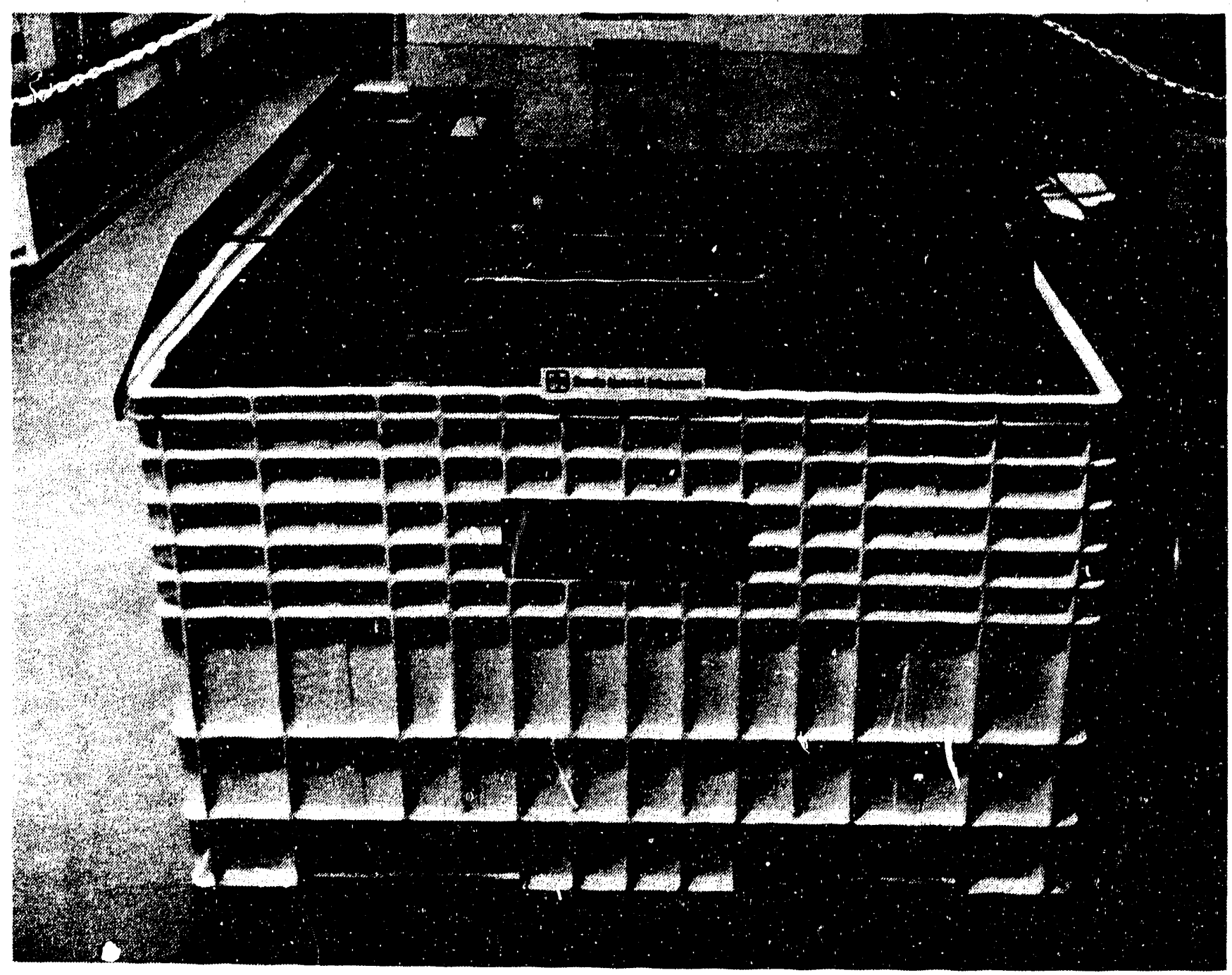

Figure 3-12. 20-kWh JCI Load Leveling Battery

If the pumping losses are treated as a fraction of the total system input energy assuming 24 -hr pump operation, they amount to:

\section{$7.12 \mathrm{kWh} /[(18.6 \mathrm{kWh} / .60$ stack efficiency) $+7.12 \mathrm{kWh}]=18.7 \%$}

These pumping losses are excessive. Theoretical calculations, assuming $45 \%$ efficiency for the pump/motor combination and 10-hour/day pump operation, indicate that adequate pumping should require only $1.6 \mathrm{k}$ 'Nh.

The inechanical/electrical devices (in addition to the pumps) included an actuator for reversing catholyte flow approximately 2 minutes every $1 / 4$ hour, and an actuator for opening the catholyte complex valve during discharge. Both actuators consumed negligible power.
Heat exchange was accomplished very simply by running cold tap water through a PVDF heat exchanger in the anolyte rescrvoir. The flow of cooling water was thermostatically controlled by a flow regulator valve, which consumed negligible parasitic energy. During a typical cycle, the electrolyte temperature at the start of charge was $62^{\circ} \mathrm{F}$ and at the end of a charge was $80^{\circ} \mathrm{F}$. The inflow water temperature was approximately $55^{\circ} \mathrm{F}$ and the flow rate approximately 1 gallon per minute. Outflow temperature was not measured, but an estimate of $65^{\circ} \mathrm{F}$ would give a continuous heat removal rate of about $83 \mathrm{BTU} / \mathrm{min}$., equivalent to $1.5 \mathrm{~kW}$. This was adequate to deal with the total waste heat of ap. proximately $15 \mathrm{kWh}$ generated by stack inefficiencies plus frictional energy resulting from pumping during each 24-hour day. 


\section{0-LL Test Results}

The cycling regime consisted of a 5-hour charge at 40 amps, followed by a one minute open-circuit period, followed by a 56-amp discharge to one volt per cell, usually lasting about 3 hours. At the start of FY89, testing of Z-2(i) L tad been suspended due to problems with the inverrote eletronics at the Load Management Facility. The tattery at this point had been cycled 180 times. Aside from an interval of about 10 cycles during which air bubbles apparently became trapped in the shunt current protection system, the average coulombic efficiency had been about $79 \%$ and the average energy efficiency about $60 \%$. The overall performance of $\mathbf{Z 2 0}$ LL over 182 cycles is shown in Figure 3-13.

Again, it should be emphasized that this level of performance was obtained with polypropylene electrodes and an inefficient separator. After one more uneventful cycle, an external short developed on one of the electrode stacks. The short resulted from slow external leakage near one of the terminals. At the time, there were tentative plans to videotape the effects of a catastrophic short, but these effects proved to be very unspectacular. Small intermittent arcs caused small areas of charring at the battery terminals. Several efforts to correct the problem were unsuccessful.

\section{Other Activities}

In other work performed under this contract, JCl's computer model was used to explore effects of variables in the design of an improved (V-type) load-levelling battery. Under operating conditions similar to those used for Z-20LL, results indicated that a separator thickness of .025 " onitinized the energy efficiency. The energy efficiency proved to be very insensitive to the thickness of the electrodes, suggesting that thicknesses of .100 " or greater could conceivably be used to offset the tendency for electrodes to expand and warp.

Polyvinylidene fluoride (PVDF) based carbon plastics initially gave promising results in bromine expansion tests. After short periods in bromine vapor, PVDF electrodes expanded considerably less than extruded glass-filled polyethylene-based electrodes. After prolonged exposure, the PVDF materials expanded to about half the extent of PE materials. Later, PE-based

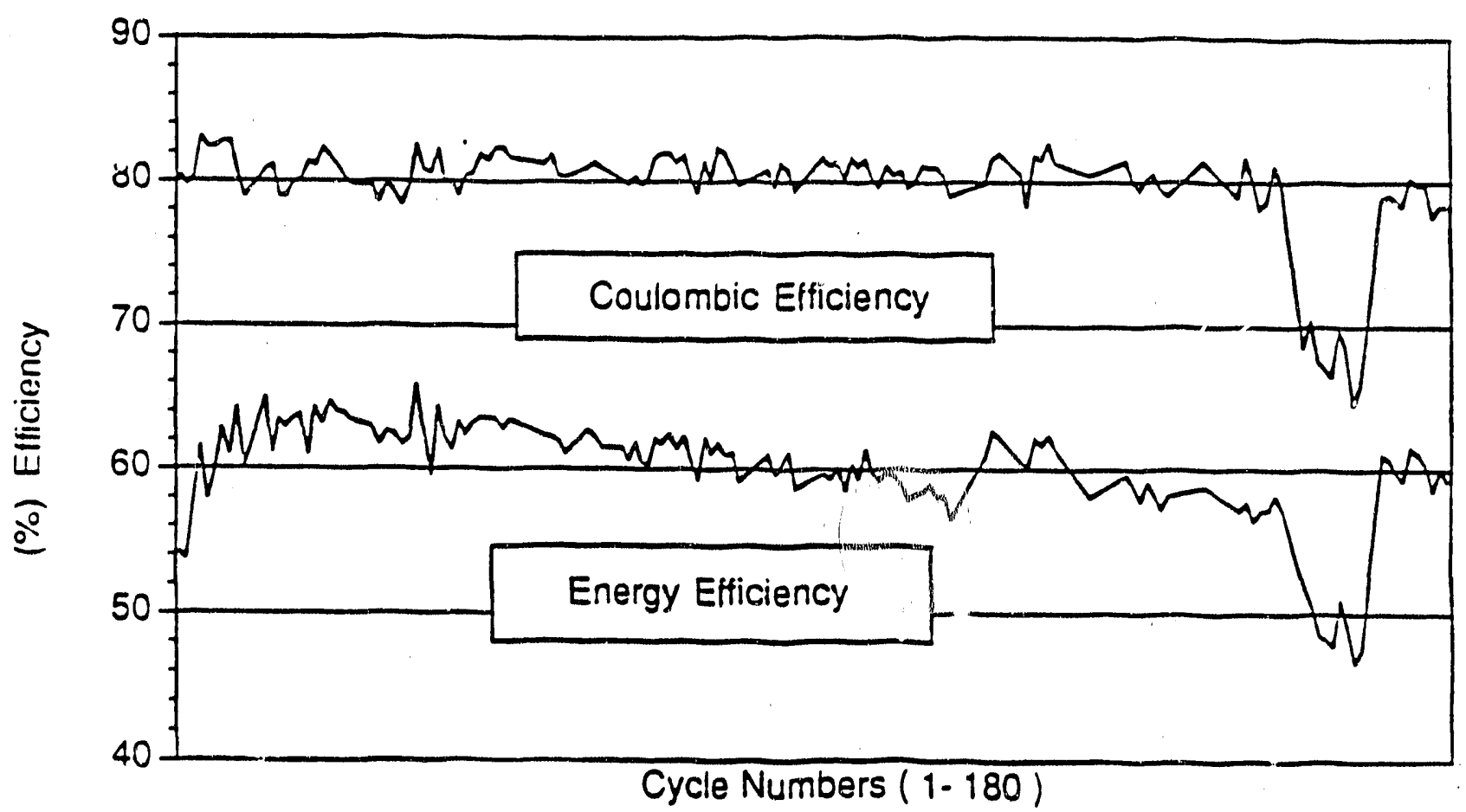

Figure 3-13. 20-kWh Battery Cycle Performance 
electrodes with $40-50 \%$ loadings of glass fiber were found to be better than the PVDF electrodes with respect to expansion.

A single-cell Z-battery (ZS-56) was used to study the effect of JCI's proprietary plating additives on battery efficiency. Results were inconclusive.

An 8-cell Z-battery (Z1-51) made with improved components (polyethylene electrodes and Asahi SF-600 separator) was cycled with load-levelling type electrolyte $(2.25 \mathrm{M}$ zinc bromide, $0.5 \mathrm{M}$ zinc chloride, and $1.0 \mathrm{M}$ quaternary salt) and attained 415 cycles before its capacity gradually declined due to electrolyte contamination from a metal spring in the catholyte reversing valve. The average energy efficiency of this battery up to cycle 300 was approximately $70 \%$. A partial summary of its performance is shown in Figure 3-14.

\section{Technology Evaluation}

SNL continued evaluation of three zinc/bromine batteries from ERC, batteries 456,459 and 481 , during FY89. Table 3-1 summarizes the characteristics of and the SNL evaluation results on these batteries. This table shows the following for each battery:

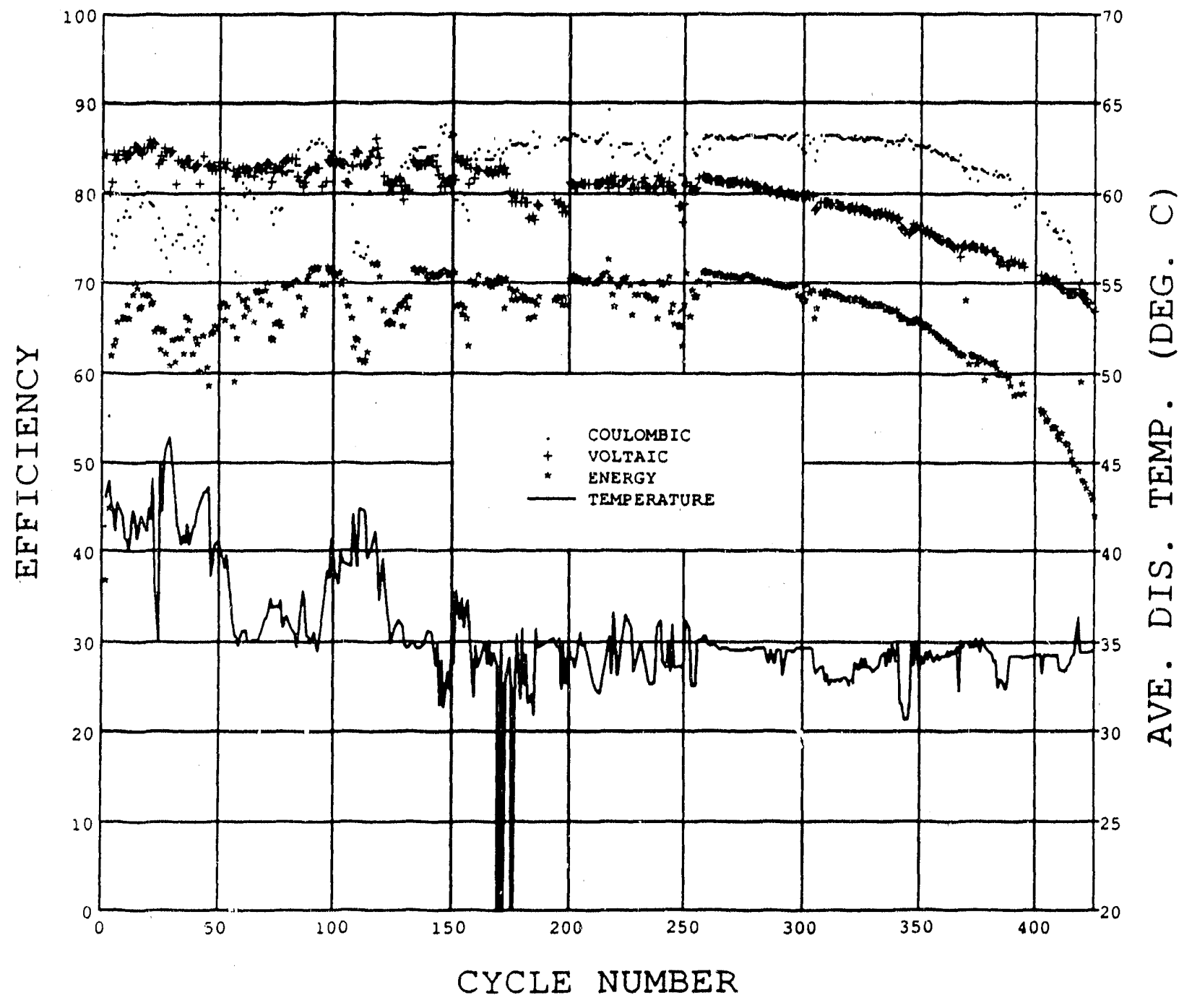

Figure 3-i4. i-kwīn Battery C'ycle Performance 


\section{Table 3-1. SNL Test Results for ERC Load-Leveling Zinc/Bromine Batteries}

\begin{tabular}{|c|c|c|c|c|c|}
\hline $\begin{array}{l}\text { SNL ID } \\
\text { Number }\end{array}$ & $\begin{array}{l}\text { Number } \\
\text { of Cells }\end{array}$ & $\begin{array}{c}\text { Rated } \\
\text { Capacity } \\
\text { (Ah) }\end{array}$ & $\begin{array}{l}\text { Accumlated } \\
\text { Cycles }\end{array}$ & $\begin{array}{c}\text { Test } \\
\text { Regime }\end{array}$ & $\begin{array}{c}\text { Average } \\
\text { Energy } \\
\text { Efficiency (\%) }\end{array}$ \\
\hline $\begin{array}{l}456 \\
1+59 \\
481\end{array}$ & $\begin{array}{r}5 \\
30 \\
5\end{array}$ & $\begin{array}{l}125 \\
125 \\
200\end{array}$ & $\begin{array}{r}100 \\
92 \\
52\end{array}$ & $\begin{array}{l}\text { baseline } \\
\text { baseline } \\
\text { baseline }\end{array}$ & $\begin{array}{l}61 \pm 2 \\
35 \pm 6 \\
57 \pm 2\end{array}$ \\
\hline
\end{tabular}

- identification number

- type

- number of cells

- rated capacity

- cycles completed

- tests performed

- average energy efficiency

A discussion of the performance for each of the three batteries during this reporting period follows.

\section{Battery 456}

Evaluation of the $872-\mathrm{cm}^{2}$ five-cell stack (battery 456) was completed in December 1988. This stack is similar to previously tested ERC units, except that it has improved end electrodes, electrolyte reservoir and two electrolyte pumps. This battery completed 100 cycles at SNL before it was dismantled on January 10, 1989. Prior to dismantling the battery experienced a substantial drop in performance during cycles 98 and 99 . ERC suggested that the anolyie be replaced with a slightly different solution. Because of the possibility of precipitation of potasium salts from the original electrolyte, the replacement anolyte had a reduced potasium concentration. The last cycle, (cycle 100) was run after the new electrolyte had been circulated in the battery system for several days. But the new electrolyte did not improve battery performance. Voltaic efficiency decreased about $9 \%$ from cycle 99 .

After the battery was disassembled in January, it was found that the primary cause for failure was a melted separator adjace th to the bromine-end electrode. The melted separator was severely deformed and prevented electrolyte flow to both the bromine and zinc electrodes. The melting of the separator may have been caused by the enlargement of the gasket due to bromine exposure. As the gasket enlarged it partially blocked electrolyte channels for certain cells, which could have heated the separator to near its melting point of about $80^{\circ} \mathrm{C}$. In addition, the bromine-end electrode had cracked in the flow-channel area. This crack was in the same location as that observed in two previous failures.

\section{Battery 459}

The battery was examined by ERC in May 1989, and it was determined that the gasket in this battery enlarged in a manner similar to battery 456 , as described above. Both end plates and the first three positive electrodes were replaced. Flow pressures were readjusted and cycling resumed. A total of 18 additional cycles was completed on the battery on the battery bringing the total number of cycles on the battery to 92 . The cfficiencies for these cycles fluctuated considerably and for this reason, testing was halted. A posttest analysis will be conducted on the battery to determine the cause of these fluctuations.

\section{Battery $\mathbf{4 8 1}$}

On May 24, 1989, ERC delivered and installed a new 5-cell battery. The electrode size of this battery was increased from $872 \mathrm{~cm}^{2}$ (previous ERC battery size) to $1,500 \mathrm{~cm}^{2}$. The rated capacity of this battery is 200 Ah at the $C / 4$ rate. The charge/discharge rates for this battery were $52 \mathrm{~A} / 56 \mathrm{~A}$. The charge/discharge current diensities were 35 and $38 \mathrm{~mA} / \mathrm{cm}^{2}$ and the zinc loading was $140 \mathrm{~mA} / \mathrm{cm}^{2}$. This battery completed 52 cycles before being removed from test due to poor efficiencies. A comparison of the efficiencies for this battery early in cycle life vs end-of-life are listed in Table 3-2. A posttest analysis will be conducted on this battery to determine the cause of failure. 


\section{Table 3-2. Coulombic, Energy, and Voltaic Efficiencles for Battery 481}

(All Values Are in Percentages)

$\begin{array}{ccc}\text { Efficiency } & \text { Cycle 1 } & \text { Cycle 52 } \\ \text { Coulombic } & 89.3 & 61.7 \\ \text { Energy } & 65.0 & 36.0 \\ \text { Voltaic } & 73.7 & 58.8\end{array}$

\section{Technology Improvement}

SNL assists the program developers on specific tasks that are better suited to be addressed at SNL. During 1989, technology improvement issues concerning the battery stack separator and the materials of construction have been specifically addressed at SNL owing that these issues may have a major impact on the viability of the technology in terms of energy efficiency and battery lifetime. Materials durability is a critical issue in connection to the 10 year design lifetime of the battery stack. If the stack lifetime can be extended the economics of a zinc/bromine load-leveling facility may become more favorable. The cell membrane has been identified as a critical area for enhancing the energy efficiency of the battery system. If the bromine transport across the separator can be reduced while maintaining a low membrane resistivity, the coulombic efficiency will be enhanced. A review of these 1989 SNL activities follows.

\section{Materials Durability Study}

The factors that must be considered when selecting a flow-frame material for the zinc/bromine battery include; (1) cost; (2) ease of fabrication; (3) durability toward the electrolyte; (4) response to mechanical stress; and (5) long term reliability. Currently, flow frames are made from polyolefins and poly(vinylchloride) (PVC). These thermoplastics are inexpensive and easy to fabricate but may not be sufficiently durable or reliable for the long term. Polyolefins, for example, are susceptible to oxidative attack by the electrolyte and PVC requires the incorporation of organometallic and other types of additives for thermal stability and mechanical strength. Leaching of these additives by the electrolyte can result in loss of mechanical strength and, in some cases, loss of efficiency due to contamination of the electrolyte. The purpose of the our current studies at SNL is to 1) determine the extent of degradation of the most recently fabricated flow frames under real-time conditions, and (2) identify alternative materials for polyolefins and PVC.

Accelerated aging studies are often carried out in an effort to predict the lifetimes of materials in a given application. In these studies, the materials are heated to accelerate the degradation process; the rates of degradation are then extrapolated to the lower temperatures which the materials are exposed to during service. Reliable extrapolations are obtained only when (1) one does not promote other degradation mechanisms at the higher temperatures, (2) the Arrhenius relationship between reaction rates and temperature apply, and (3) one knows how much degradation must occur for the material to fail to perform its intended function. An accelerated aging study was recently initiated at Energy Research Corporation (ERC) in an attempt to determine the service life of three PVC formulations: PVC-1, PVC-4, and PVC-6. In these tests, ASTM tensile specimens were exposed to the aqueous phase of a two phase catholyte which contained $20 \mathrm{~g} / \mathrm{l}$ of free bromine. These tests were carried out at three temperatures: 35,45 and $55^{\circ} \mathrm{C}$. At the $45^{\circ} \mathrm{C}$ temperature, additional specimens were aged at 10 and $30 \mathrm{~g} / 1$ bromine. Runs were also carried out in air and in the pure quaternary bromine phase at $45^{\circ} \mathrm{C}$. When this study is completed, the applicability of the Arrhenius model will be determined.

In earlier studies, we determined the extent of degradation of PVC-1 and PVC -4 by a new technique known as modulus profiling. In this technique, one can measure the modulus of a very small section of a material ( $\infty 1$ square micron). This technique is invaluable for degradation processes which are diffusion controlled and result in het-rogeneous degracation. The degradation mechanism of the zinc/bromine battery flow frame was confirmed to be diffusion controlled in earlit $r$ studies. For example, large percentage losses of modulus at the edge of PVC-4 were observed after this material was exposed to a bromine containing electrolyte at $60^{\circ} \mathrm{C}$ 
after 18 weeks. The modulus in the bulk of the sample was essentially unchanged. It is believed that the degradation of PVC-1 was also diffusion controlled, but this could not be ascertained by modulus profiling. After 18 weeks, the moduli were low across the entire thickness dimension of the flow frame specimen. Degradation rates were apparently higher for PVC-1 than PVC-4.

During 1989, the modulus profiling technique was applied to a flow frame made from PVC-1 that had been exposed to a bromine-containing electrolyte in an ERC 5 -cell, 1-kWh battery stack that had undergone approximately 100 charge-discharge cycles. The purpose was to compare the extent of degradation of the PVC-1 flow frame under true operating conditions with those results obtained under the accelerated conditions cited above.

Modulus profiles were determined at 3 positions on the flow frame. The first profile was determined across the thickness dimension at a location about 2 inches from one of the flow channels, a second profile was taken directly beneath one of the small flow channels, and a third profile was taken from the plenum area where the electrolyte is distributed across the electrode. As shown in Figure 3-15, there was essentially no change in modulus as a function of depth. What was surprising, however, was the variation in average modulus at the three locations evaluated. The average modulus varied by more than $100 \%$ from one location to another. This variation is believed to be due to processrelated variations caused during the molding operations rather than chemical degradation. PVC- 1 is a composite material composed of at least $10 \%$ inorganic and organometallic additives. If the additives are not uniformly distributed during the molding process, variations in the mechanical properties might occur. Another possible explanation for this behavior might be temperature and pressure gradients during the molding process that could result in variations in density or degree of crosslinking. These property variations, which were detected in a complex molded part, highlight the unique capabilities of modulus profiling as an analytical tool. Another very interesting observation that was made was

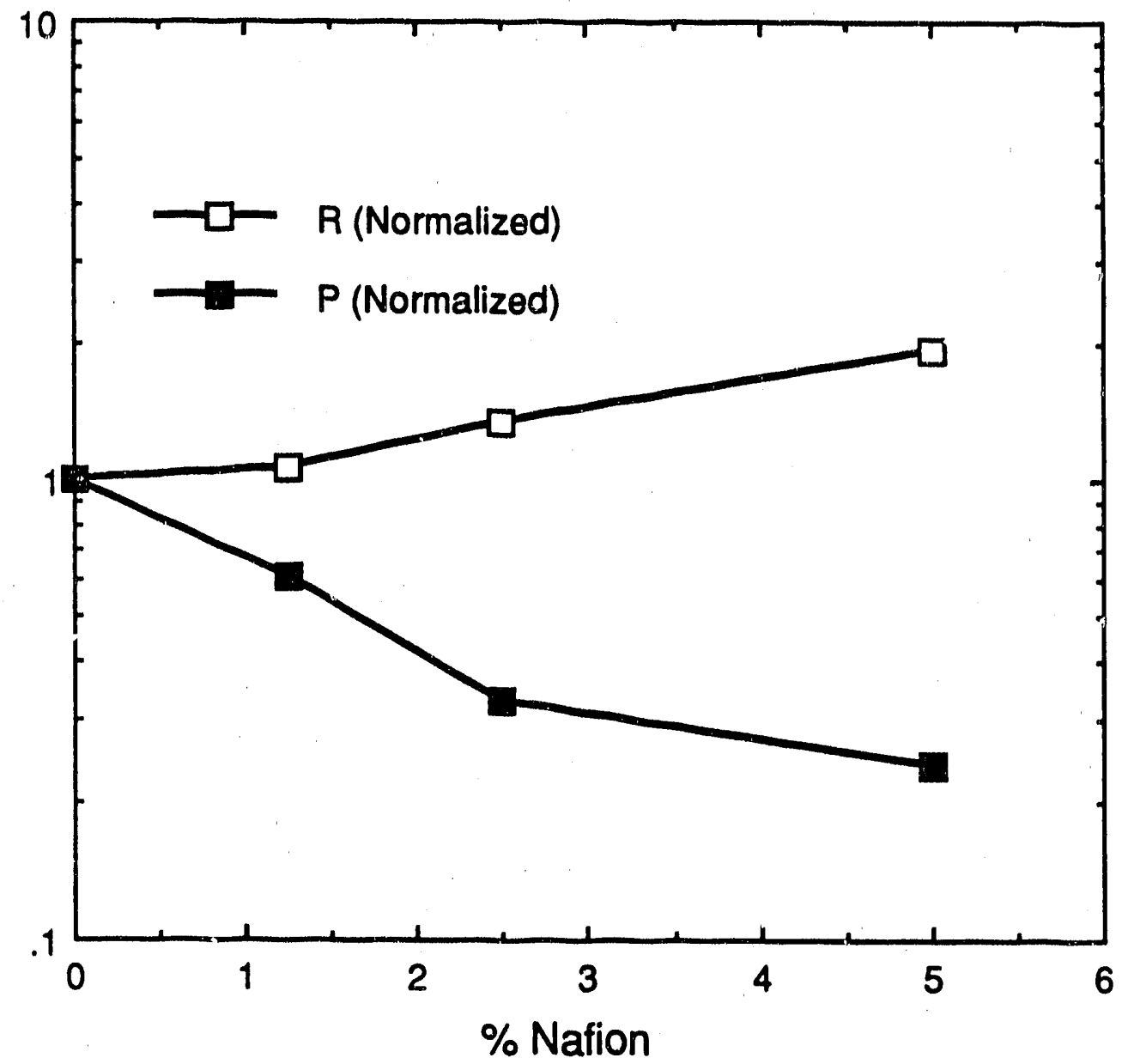

Figure 3-15. Modulus Measurements of Battery 456 Flow Frame 
that the surface modulus was one to two orders of magnitude less that the bulk modulus. The modulus of the unexposed surface of the flow frame only $66.3 \mathrm{MPa}$ versus 1,125 to $2,440 \mathrm{MPa}$ in the bulk. This suggests that the surface of the flow frame is rather crusty and friable. Low moduli were also observed in the flow channels which had been exposed to the electrolyte. It is not clear whether the difference in moduli of exposed and unexposed surface are attributable to degraulition since baseline measurements were not taken. Modulus profiling and measurement of surface moduli of unused flow frames is in progress for purposes of comparison and confirmation.

In an effort to identify alternate flow frame materials for zinc/bromine batteries, accelerated aging tests were carried out with the following plastics. PVC1, PVC-4, I'VC-6, pure PVC and Tefzel. Small samples of these materials (2.5" by $0.5^{\prime \prime}$ by $\left.0.125^{\prime \prime}\right)$ were in the aqueous phase of a two-phase zinc/bromine catholyte containing $20 \mathrm{~g} / \mathrm{l}$ bromine. Properties moritored were shear modulus, weight gain and any qualital. ve changes in chemical structure or composition. The latter were determined by Fourier Transform Infrared Analysis (FTIR). In the last annual we reported the results of aging after two weeks exposure. We now report the results after 18 weeks of exposure. Sorption (weight gain) of the electrolyte was high for all of the PVC specimens including pure PVC (21-31\%). In contrast, the with gain observed for Tefzel was only $1 \%$. Tef$z e l$ is $1 / 1$ copolymer of ethylene and tetrafluoroethylene made by DuPont. FTIR analysis indicated that a large fraction of the weight gain observed in the PVC samples was water. Very little if any water was detectable in Tefzel. As shown in Figure 3-16, whereas the shear moduli of the PVC samples decreased markedly after the 18 week exposure, the shear modulus of Tefzel was essentially unchanged. In addition Tefzel is a strong, ductile plastic which has high fracture toughness, is moldable in complex shapes, can be heat bonded or ultrasonically welded and contains no additives that can be leached out. The only disudvantage of Tefzel is cost. The price of Tefzel was quoted as $\$ 12 / \mathrm{b}$. Although this cost is significantly inigher than PVC (\$1-2/lb), the cost of Tefzel is comparable to that of Kynar (poly(vinylidene) fluoride), which is an electrode component used the ERC battery design.

\section{Advanced Membrane Development}

Silica-filled microporous polyethylene separators are currently used in zinc/bromine flow batteries. These separators are not selective in that both positive, negative and neutral species in the electrolyte can permeate between the catholyte and anolyte compartments with more or less equal ease. The arrival of free bromine or negatively charged bromine complexes at the anode results in self-discharge and a loss of coulombic efficiency. Permeation of free (elemental) bromine is minimized by the presence of quaternary ammonium bromide salts in the electrolyte which greatly reduce the concentration of bromine in the aqueous phase. Further reduction in bromine transport will have to be achieved by improving the membrane. Since there are cost constraints, our approach has been to modify or treat the microporous separators now being used. These separators have cost advantages and are mechanically robust. In previous work, it has been demonstrated that large reductions in the rate of bromine diffusion can be achieved with only a small sacrifice of increased resistivity by the introduction of cationic exchange type polymers into the pores of the separator. The enhanced selectivity of these modified separators is attributable to physical closure of the pores and rejection of negatively charged bromine current carriers brought about by the presence of fixed negative sites along the backbone of cation exchange resin. The cation exchange resin used for this purpose was sulfonated polysulfone (SPS). The choice of SPS was based on earlier work in which it was demonstrated that cast SPS membranes were viable replacements for Nafion in the zinc/ferricyanide battery, a flow battery which is similar in some respects to the zinc/bromine battery. In this summary we describe the results of our evaluation of the above described composite membranes in single-cell cycling experiments. We also describe the preparation and evaluation cf composite membranes made from perfluorinated ionomers, now available in solution form, and preliminary results on the use of plasma polymerization techniques to coat microporous separators.

Conversion of the microporous separators (10 and 25 mil Daramic) to composite membranes was accomplished by (1) immersion of the separator in a $20 \%$ solution of SPS in dimethylformamide (DMF) at ambient conditions, i.e., room temperature and pressure, followed by removal of DMF; and (2) vacuum impregnation of the separator at $90^{\circ} \mathrm{C}$ for ten minutes followed by removal of the solvent (DMF). The latter technique was considered preferable in that a more uniform tistribution of SPS across the thickness dimension of the separato: was achieved. These membranes were evaluate using an automated test cell that was equipped with a $90 \mathrm{~cm}^{2}$ bipolar electrode. This cell was charged to $90 \mathrm{mAh} / \mathrm{cm}^{2}$ at a current density of $17 \mathrm{~mA} / \mathrm{cm}^{2}$ and discharged at a current density of $28 \mathrm{~mA} / \mathrm{cm}^{2}$. The flow rate of the electrolyte was $140 \mathrm{~mL} / \mathrm{min}$. Efficiency data on treated and untreated 10 and 25 mil thick samples of Daramic are summarized in Table 3-3. 


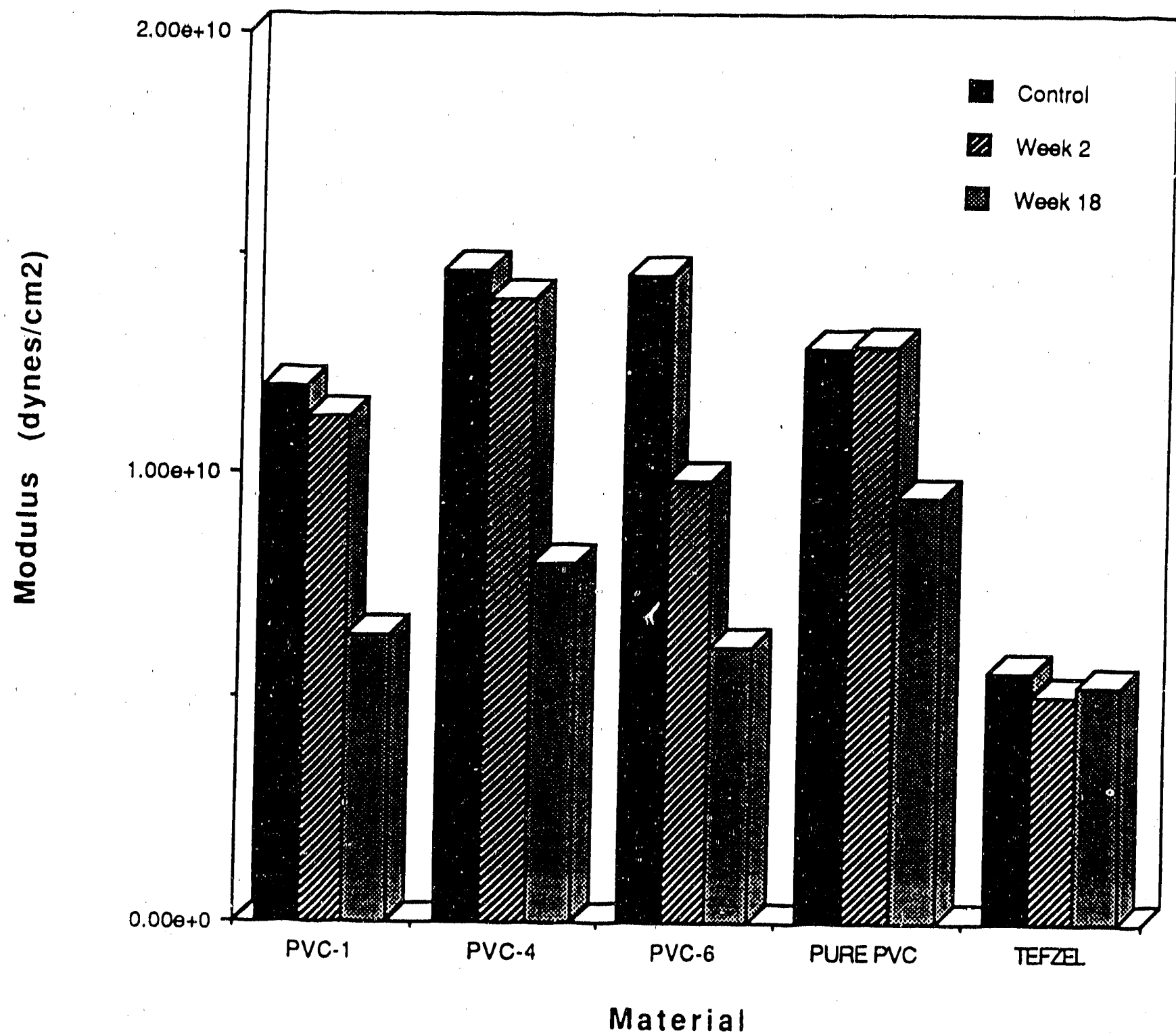

Figure 3-16. Modulus of Aged Materials

Table 3-3. Single Cell Test Results (Average Efficiencies Over All Cycles)

\begin{tabular}{llccc}
\multicolumn{1}{c}{ Membrane } & $\begin{array}{c}\text { Coulombic } \\
\text { Efficiency }\end{array}$ & $\begin{array}{c}\text { Voltaic } \\
\text { Efficiency }\end{array}$ & $\begin{array}{c}\text { Energy } \\
\text { Efficiency }\end{array}$ & $\begin{array}{c}\text { Total } \\
\text { Cycles }\end{array}$ \\
Daramic (25 mil) & $76 \pm 3$ & $67.0 \pm 2.0^{*}$ & $51.0 \pm 3.0$ & 37 \\
H-SPS Daramic (25 mil) & $79 \pm 3$ & $67.0 \pm 2.0^{*}$ & $53.0 \pm 3.0$ & 53 \\
Daramic (10 mil) & $78 \pm 1$ & $79.4 \pm 0.2$ & $61.7 \pm 0.8$ & 34 \\
H-SPS Daramic (10 nil) & $75 \pm 2$ & $79.7 \pm 0.8$ & $59.0 \pm 2.0$ & 66
\end{tabular}

- Voltaic Etficiency decreased at the rate of $0.3 \% / c y c l e$. 
Essentially no difference between SPS-treated and untreated separators was discernible within the experimental error. Higher energy efficiencies were ob. tained with the thinner $(10 \mathrm{mil})$ membranes. Empirical models on the effect of membrane thickness on efficien. cy losses predicted that this should occur for composite membranes (see FY88 annual report). It is noteworthy that for the $25 \mathrm{mil}$ Daramics, the voltaic efficiency decreased at the rate of $0.3 \% /$ cycle. The reason for this is not known.

These single cell data did not correlate well with early laboratory screening tests on SPS-treated membranes. Based on these tests, in which bromine diffusion rates were reduced by a factor of ten and the area resistivity increased by a factor of only 2.5 after treatment with SPS, we expected to see a large increase in coulombic efficiency and a small decrease in voltaic efficiency. It should be noted that large increases in coulombic efficiency for the $25 \mathrm{mil}$ SPS-treated membranes were observed in those cycles which did not immediately follow a complete discharge. The average coulombic efficiencies for these cycles was $93 \%$ vs only $83 \%$ for the untreated separator. Unfortunately, the average coulombic efficiencies of cycles which immediately followed a complete discharge were lower for the SPS-treated membranes (77\% vs $81 \%$ ). These low efficiency cycles canceled the improvements observed in the high efficiency cycles. A sludge was released into the electrolyte when SPS-treated membranes were cycled. In some runs this led to clogging of the lines. It is speculated that the oily bromine phase may have softened the SPS making it more susceptible to leaching by the electrolyte. SPS is not soluble in the aqueous phase of the electrolyte.

Possible causes for the lower than expected performance of SPS are as follows: (1) electromigration of bromine-bearing species in the electrolyte resulted in bromine permeations rates that were higher in working battery cell than in a diffusion cell where electric currents are absent; (2) energy efficiencies might be very sensitive to small increases in area resistivity; (3) contamination problems due to the reiease of SPS sludge.

Because of the problems encountered with SPS, it was decided to investigate the effect of other cationic resins. One of the resins evaluated was perfuorosulfonate (Nafion) which is available from Solutions Technology Corp. A series of composite membranes was prepared in which the concentration of Nafion in the impregnating solution was varied. The microporous separator used was SF-400, a silica-filled polyethylene obtained from Asahi Co. This separator is similar to Daramic but is reported to give better performance in vehicular type applications. As shown in Figure 3-17, a significant reduction in the rate of bromine permeation was achieved at a cost of somewhat higher area resistivity. The results are similar to those observed for SPStreated separators except that the effects are realized at much lower concentrations of Nafion. We are now in the process of evaluating Nafion modified membranes in single cell cycling tests. The results obtained to Jate are not conclusive because the membrane was punctured by the plastic screen used to hold it in place. After removal of the Nafion-treated membrane from the test cell, it was observed that the membrane was not stained by the bromine. In contrast, red stains were observed with untreated SF-400. This suggests that Nafion might be repellant to bromine and/or the oily bromine complexes. The entrapment of these species on or in the membrane is generally regarded as undesirable since entrapped bromine could eventually find its way into the anolyte.

It is well known that relatively thin pin-hole free coatings can be deposited using plasmas. In this technique, polymeric coatings are produced by activation of gaseous monomers under the influence of an electric field. One advantage of this technique is that it can be carried out with a variety of monomers that cannot be otherwise poiymerized. To deposit an ionic polymer, one geiserally uses an ionogenic monomer such as acrylic acid. We have demonstrated that one can deposit an ionic polymer using a non-ionogenic monomer, such as styrene, by simply introducing sulfur oxychlorides into the plasma. Unfortunately, these coatings were found to dissolve in the electrolyte. We are currently trying to overcome this problem by introducing bifunctional monomers such as divinylbenzene into the plasmas.

Future efforts on advanced membrane development will focus on the following approaches: (1) enhance the stability of SPS-treated membranes by crosslinking; (2) continue our evaluation of Nafion and other impreg. nable ionic resins; and (3) explore the effect of coatings with particular emphasis on plasma deposited coatings. 


\section{PROFILES}
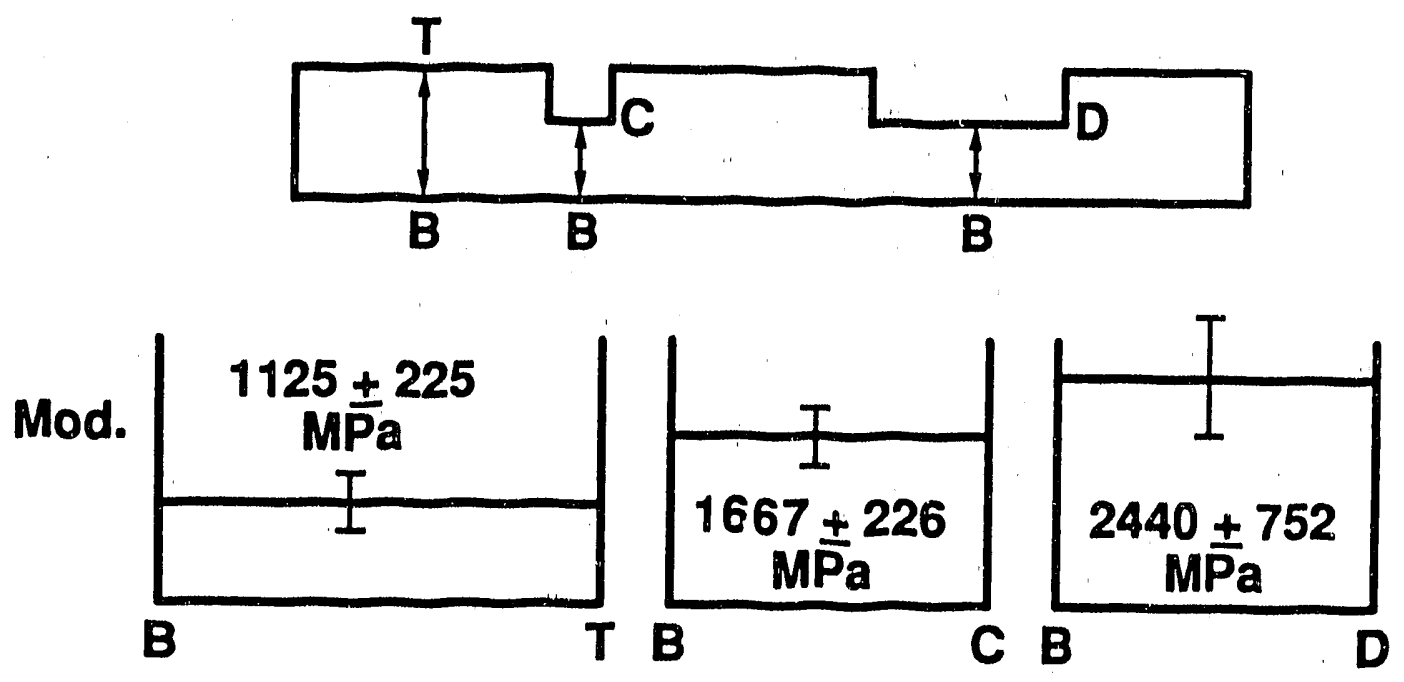

\section{SURFACE MEASUREMENTS}

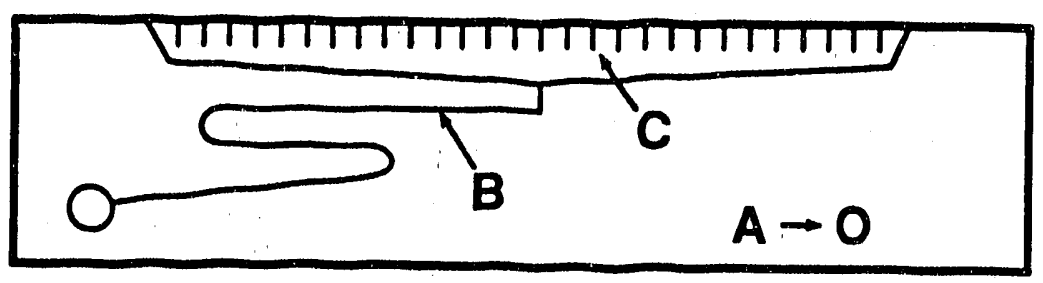
A. Unexposed surface
B. Small channel (exposed)
$66.3 \pm 12.1 \mathrm{MPa}$
C. Large channel (exposed)
$166.0 \pm 16.8 \mathrm{MPa}$
$34.5 \pm 3.9 \mathrm{MPa}$

Figure 3-17. Normalized Resistance and Permeation of Nafion Impregnated Asahi SF-400 


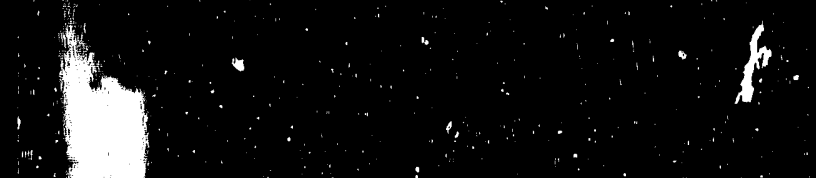

\section{Aluminum/Air Tech}

$\therefore \%$ 


\section{Nickel/Hydrogen Technology}

A program to design and develop a nickel/hydrogen battery for photovoltaic and other terrestrial applications is continuing under a cost-sharing contract between JCI and SNL. Nickel/hydrogen batteries have been successfully used for many years with satellite photovoltaic systems and are noted for their long life, reliable performance, and maintenance-free operation. The prirnary challenge of this pirogram is to dramatically reduce the first-cost of the battery to make it economically competitive on a life-cycle cost basis with other energy storage batteries, without compromising these favorable characteristics.

In a previous contract with SNL, 53-8334 completed in March of 1988, a 7 kilowatt-hour ( $k W h$ ) nickel/hydrogen battery using a common pressure vessel (CPV) design was delivered to SNL for testing at their photovoltaic facility. The CPV design represented a radical departure from standard aerospace desigrs which required a separate "individual" pressure vessel (IPV) for each cell. The delivered battery was composed of four nominal $1.75 \mathrm{kWh}, 10$-cell stacks, each encapsulated in its own stainless steel boilerplate vessel. Results of the testing at SNL are included in the Evaluation section of this chapter.

In addition to developing further cost reductions, one of the key objectives of the present contract is to duplicate the excellent performance of the $7 \mathrm{kWh}$ deliverable, while demonstrating a practical fielddeployable pressure vessel.

\section{Technology Development}

The primary goal of the core technology development effort is to reduce battery component cost without compromising performance. The current selling price estimate of $\$ 676 / \mathrm{kWh}$ for a $15 \mathrm{MWh}$ annual production level reflects the continued progress on this program (Figure 4-1) and is already believed to be cost competitive with other battery systems on a life cycle basis. Technical efforts continue with the goal of demonstrating a $\$ 375 / \mathrm{kWh}$ selling price capability.

\section{Negative Electrode}

Ongoing efforts have focused on the negative electrode, which represents over $30 \%$ of the battery material cost, as the most addressable component for cost reduction. The negative electrode is composed of a nickel screen substrate with a hydrophobic teflon membrane on its back face and a platinum catalyst film on its front face. Previous efforts had already achieved significant cost reductions by replacing the expanded metal substrate screen with an electroformed version, and by adopting a carbon supported catalyst that required only $10 \%$ of the previous catalyst loading.

Last year development efforts identified several additional approaches to further reducing the negative electrode cost without compromising performance. These included: (1) the reduction of the supported catalyst loading, (2) the use of a new binary catalyst which demonstrated improved polarization performance and has the potential to be more stable at $25 \%$ of the cost of the standard catalyst, (3) the replacement of the purchased hydrophobic negative backing material with a homentade equivalent, and (4) the complete elimination of the hydrophobic backing membrane. Part of the core technology effort in fiscal year 1989 was devoted to the ongoing demonstration of the performance of these improvements in laboratory test cells, to provide qualification for future inclusion in full-size batteries. In general, at least 500 cycles of well demonstrated cell performance is considered a minimum prior to consideration for battery level application.

Table 4-1 provides a summary of the ongoing testing of cells with design variations related to the negative electrode. Cell 140 is a standard cell that has been on test for an extended period and acts as a milestone for comparison. Performance had been steady at over $80 \%$ energy efficiency for over 1,750 cycles at which point the cell was accidentally driven into reversal for several hours when a cycler failed. The subsequent performance displayed a step decline but quickly reestablished a new steady continuing level of performance at $74 \%$ energy efficiency. It is believed that, if not for the severe reversal, this cell would still be operating at over $80 \%$ efficiency after more than 2,000 cycles.

Cells 186 and 187, which have exceeded 650 fulldischarge cycles, contain variations of the negative design with no hydrophobic backing membrane. In order to provide structural integrity and to provide the required hydrophobic properties to avoid overwetting by electrolyte, the amount of Teflon binder used in the catalyst film was increased by a factor of three. This 


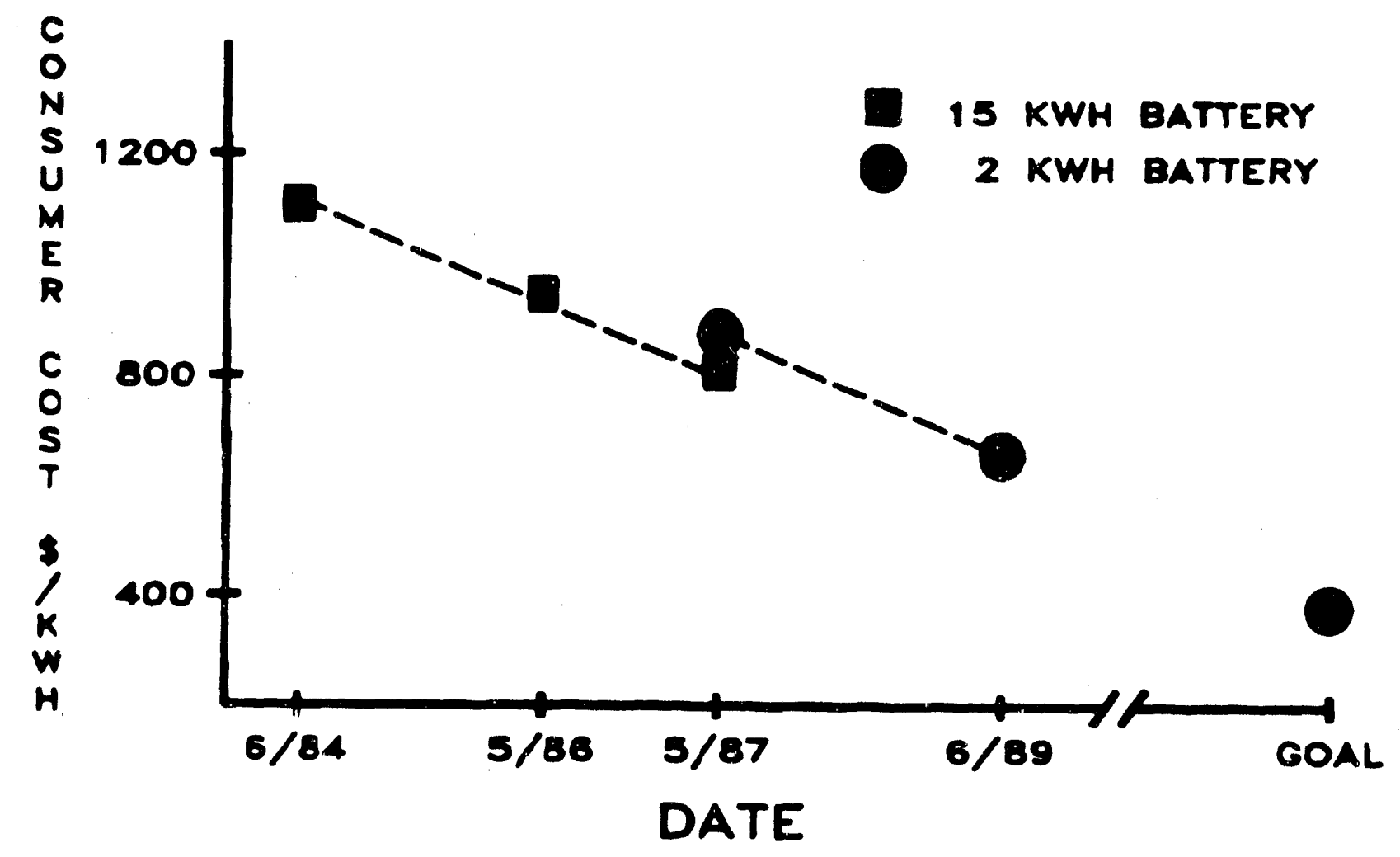

Figure 4-1. Price of a Nicke//Hydrogen Battery

design represents a $\$ 50 / \mathrm{kWh}$ savings. Cell 187 also provides demonstration of retained performance at the lower catalyst loading.

Another cell, 185, which contains the less expensive JCl backing membrane, was delivered to SNL and has now completed 264 cycles. This design also represents a savings of $\$ 50 / \mathrm{kWh}$ but the material is somewhat difficult to process on a laboratory scale. Another inexpensive polyethyiene backing material option, available from a different supplier, has also been identified as a possible candidate for application in the nickel/hydrogen battery negative. It would provide a similar cost benefit, while bridging the gap between current laboratory production levels and commercial mass production levels.

\section{Separator}

Environmental concerns regarding the use of fuelcell grade asbestos separator material, and its uncertain availability with the associated prospect of escalating cost, have prompted the effort to find a replacement material. Screening tests had provided several promising alternatives. Several of these materials have progressed to the miniature cell (15.5 Amp-hour) testing stage. Results are summarized in Table 4-2. Only the asbestos control has survived after 500 full-discharge cycles. However, one of the other materials looked particularly promising in early cycling, actually outperforming asbestos. It is believed that variations on a composite layer approach using this material with a reenforcing layer to enhance its strength and durability 


\section{Table 4-1. Negative Design Variation Cell Testing}

\begin{tabular}{|c|c|c|c|c|c|}
\hline \multirow[b]{3}{*}{ Cell No. } & \multicolumn{4}{|c|}{ Early Cycle } & \multirow[b]{3}{*}{ Cycle } \\
\hline & \multirow{2}{*}{$\begin{array}{c}\text { Nominal Ah } \\
\text { Design } \\
\text { Capacity }\end{array}$} & \multicolumn{3}{|c|}{ Average Efficiency (\%) Discharge } & \\
\hline & & Coulombic & Energy & Voltaic & \\
\hline 140 & 120 & 97.4 & 82.3 & 1.267 & 2,083 \\
\hline 186 & 160 & 95.6 & 80.8 & 1.255 & 659 \\
\hline 187 & 160 & 94.5 & 78.6 & 1.243 & 663 \\
\hline 188 & 160 & 98.4 & 86.5 & 1.292 & 549 \\
\hline
\end{tabular}

\section{Recent Cycle}

\begin{tabular}{|c|c|c|c|c|}
\hline \multirow[b]{2}{*}{ Cell No. } & \multicolumn{3}{|c|}{ Average Efficiency (\%) Discharge } & \multirow[b]{2}{*}{ Features } \\
\hline & Coulombic & Energy & Voltaic & \\
\hline 140 & 95.9 & 73.6 & 1.187 & Standard Cell \\
\hline 186 & 97.5 & 83.0 & 1.261 & $\begin{array}{l}\text { No backing membrane, } 3 \times \\
\text { binder }\end{array}$ \\
\hline 187 & 96.8 & 81.0 & 1.247 & $\begin{array}{l}\text { No backing membrane } 3 x \\
\text { binder }\end{array}$ \\
\hline 188 & 98.0 & 82.7 & 1.250 & Binary Catalyst \\
\hline
\end{tabular}

might lead to an acceptable long-life replacement for asbestos. Other materials tested also performed at an acceptable 'evel prior to their carly failures.

The results of a full-size cell containing a potassium titanate (KT) fiber separator is also displayed in Table 4-2. This cell performed very well for almost 1,200 cycles. Unfortunately, the Japanese producer of the KT fiber has discontinued sales due to safety concarns since the KT fiber has a similar aspect ratio as that of asbestos. A material from Zircar has also demonstrated good performance in previous testing but is very expensive, and would only be used in a terrestrial battery as a last resort.

\section{Miscellaneours Studies}

Table 4-3 provides a summary of the ongoing testing of two other cells, one with no lithium hydroxide ( $\mathrm{LiOH})$ in the electrolyte, and the second with what has proven to be a quite successful altemative absorber material. These tests provide further evidence of the steady long-life performance of the nickel/hydroger cells.

\section{Pressure Vessel}

Development of the pressure vessel has been focused on a vessel consisting of a fiber/epoxy winding around a metal sheli. The continuous fiber winding provides the required strength, while the metal shell acts as a hydrogen barrier. A burst pressure of over $2,000 \mathrm{psi}$ was demonstrated, easily exceeding the 5-10-1 safety factor required for the maximum operating pressure of $350 \mathrm{psi}$. An alternative design with a plastic (Saran) liner was temporarily discontinued due to difficulties encountered in bonding the end domes and cylinder to form the liner.

The winding process introduced some concerns regarding elect:olyte retention because the cell cases are inverted as the vessel is slowly rotated around the cylinder axis. Since there is some free electrolyte in the cases, the potential existed for leakage around the perimeter of the cell vent which is slip fit into a hole in the case cover. To avoid this potential problem, a small patch of a hydrophobic Teflon membrane was sealed over the vent hole on the inside face of the case cover, prior to sealing the cover to the cell case. Cell testing indicated that the design allowed inversion of the cell 


\section{Table 4-2. Separator Material Cell Testing}

\begin{tabular}{|c|c|c|c|c|c|}
\hline \multirow[b]{3}{*}{ Cell No. } & \multicolumn{4}{|c|}{ Early Cycle } & \multirow[b]{3}{*}{ Cycle } \\
\hline & Design & Average & iciency ( $\%$ & harge & \\
\hline & Capacity & Coulombic & Energy & Voltaic & \\
\hline 189 & 15.5 & 91.6 & 78.7 & 1.265 & 170 failed \\
\hline 190 & 15.5 & 88.7 & 74.1 & 1.244 & 170 failed \\
\hline 191 & 15.5 & 96.7 & 83.0 & 1.271 & 449 \\
\hline 192 & 15.5 & 95.3 & 83.4 & 1.282 & 466 failed \\
\hline 193 & 15.5 & 91.9 & 78.7 & 1.267 & 433 failed \\
\hline 143 & 120.0 & 97.0 & 80.1 & 1.267 & 1,458 failed \\
\hline
\end{tabular}

\begin{tabular}{|c|c|c|c|c|}
\hline \multirow[b]{2}{*}{ Cell No. } & \multicolumn{3}{|c|}{ Average Etficiency (\%) Discharge } & \multirow[b]{2}{*}{ Features } \\
\hline & Coulombic & Energy & Voltaic & \\
\hline 189 & 一 & - & - & Celgard \\
\hline 190 & - & - & - & RAI/KC absorber composite \\
\hline 191 & 97.9 & 82.5 & 1.253 & Asbestos control \\
\hline 192 & - & - & - & RAI \#1 \\
\hline 193 & - & - & - & RAI \#2 \\
\hline 143 & - & - & - & KT separator \\
\hline
\end{tabular}

\section{Table 4-3. Miscellaneous Cell Testing}

\begin{tabular}{|c|c|c|c|c|c|}
\hline \multirow[b]{3}{*}{ Cell No. } & \multicolumn{4}{|c|}{ Early Cycle } & \multirow[b]{3}{*}{ Cycle } \\
\hline & $\begin{array}{l}\text { Nominal Ah } \\
\text { Design }\end{array}$ & Average & iciency ( $\%$ & harge & \\
\hline & Capacity & Coulombic & Enargy & Voltaic & \\
\hline $\begin{array}{l}165 \\
170\end{array}$ & $\begin{array}{l}120 \\
120\end{array}$ & $\begin{array}{l}97.5 \\
98.6\end{array}$ & $\begin{array}{l}78.8 \\
85.4\end{array}$ & $\begin{array}{l}1.240 \\
1.275\end{array}$ & 855 \\
\hline
\end{tabular}

\section{Recent Cycle}

\begin{tabular}{c} 
Cell No \\
\hline 165 \\
170
\end{tabular}

165
170

Average Etficiency (\%) Discharge

\begin{tabular}{|c|c|}
\hline & \\
\hline $\begin{array}{l}98.9 \\
99.5\end{array}$ & $\begin{array}{l}81.1 \\
86.3\end{array}$ \\
\hline
\end{tabular}

\begin{tabular}{c} 
Voltaic \\
\hline 1.234 \\
1.276
\end{tabular}

\section{Features}

No LIOH

New absorber 
case without loss of electrolyte, and further, that the use of the Teflon membrane did not restrict hydrogen access to or from the cell during subsequent cycling.

\section{Thermal Model}

An ANSYS finite element analysis model was developed for the present $2 \mathrm{kWh}$ battery design. The model is empirically based, relying on extensive thermal data gathered from laboratory battery testing to define the magnitude of thermal transfer through convective links between the cell components and the cell case, and between the cell case and the inner vessel wall. The model is particularly useful for analyzing thermal design trade-offs, such as considering the effect of varying the thermal conductivity of various battery components. The model has been used to identify the cell case as the most significant bottleneck in the thermal transfer pathway, allowing focus on this component for future design work.

\section{Future Direction}

Due to the continuing success of the program, the technical effort under contract 57-4683 has been extended through June 30,1990 . The extension includes the development of a detailed paper design for a $40-100$ $\mathbf{k W h}$ nickel/hydrogen system intended as a system building block for remote village and other terrestrial applications. In addition the baseline core technology efforts will be continued with the goal of demonstrating further battery cost reductions. Original plans for the delivery of the four $2 \mathrm{kWh}$ batteries to SNL have been revised based on the opportunity to deliver and test them outside of a laboratory environment. Two of the four batteries will be delivered to the Southwest Residential Experiment Station (SWRES) in Las Cruces, New Mexico, while the other two will be delivered to the Southeast Regional Experiment Station (SERES) in Cape Canaveral, Florida. Both sets of batteries will be delivered in early 1990 and coupled to existing photovoltaic arrays for testing.

\section{Technology Evaluation}

The contract for the development of nickel/hydrogen batteries at JCI provides for the delivery of cells and batteries to SNL periodically for evaluation. Typically these represent state-of-the-art technology, or contain experimental components modified to reduce cost or improve performance. Four nickel/hydrogen cells and four battery modules were on test. Table 4-4 lists the configuration of the cells, as well as the cycle test conditions. Each battery module contained four cells configured the same as $S / N$ 144. The battery modules were connected in several series/parallel arrangements, and used mainly for solar tests.

\section{Cycle Tests}

Cells 23, 144, and 185 were on the standard cycie test consisting of a discharge to $1.0 \mathrm{volt} / \mathrm{cell}$, followed by a charge until the pressure slope, in psig/Ah, drops to $75 \%$ of the linear value. Cell 161 was subjected to a shallow cycle test, with occasional standard cycle tests to check capacity. Table 4-5 summarizes the standard cycle test results, and includes baseline performance in parentheses.

Cell 23 - This cell, representing 1986 technology, has a nominal capacity of $120 \mathrm{Ah}$. Capacity at the end of FY89 was $124 \mathrm{Ah}$, down $8 \mathrm{Ah}$ from FY88. It has accumulated a total of 1,626 deep cycles. High voltage $(1.7 \mathrm{~V})$ has been observed occasionally during charging, and it has not been determined whether it is a battery or tester problem.

Cell 144 - A slow leak developed through the pressure transducer during cycle testing in June, and it was necessary to install a new one. Standard cycle testing was resumed, but capacity was much lower. During a set of 16 cycles, it varied between 116 and 119-Ah compared with 192-Ah reported last period. JCI suggested conducting an activation cycle which consists, basically, of a low rate charge with the cell vented to the atmosphere, and a discharge connected io a hydrogen bottle at a cotsstant 50-psig.

Following the activation cycle with cell 144, cycling was resumed charging first with a constant $150 \mathrm{Ah}$, then $160 \mathrm{Ah}$, and finally to $75 \%$ of the linear pressure slope. On the initial charge for the last sequence, the pressure reached $330 \mathrm{psig}$, and it was necessary to reduce the precharge pressure. When the standard cycling was resumed, capacity was over $190 \mathrm{Ah}$. Capacity vs cycle number is plotted in Figure 4-2a; this covers the period before and after the activation cycle. The EOC and EOD pressure for the same cycles are plotted in Figure 4-2b. At the end of FY89, a total of 1,250 cycles had been accumulated, and the capacity was $193.7 \mathrm{Ah}$ compared with 194.9 last year.

Cell 161 - This was the first cell to use the thicker 90-mil positive electrodes. Initial tests at JCI had indicated that the distribution of the positive active material was not uniform, and this may have been a factor in the declining capacity reported last year. This year the cell was put on a shallow cycle test to investigate the effect of depth of discharge (DOD) on the trend of 


\section{Table 4-4. Configuration and Test Conditions}

\begin{tabular}{|c|c|c|c|c|c|c|c|}
\hline $\begin{array}{c}\text { Cell No. } \\
S / N\end{array}$ & $\begin{array}{l}\text { Cell } \\
\text { Mods }\end{array}$ & $\begin{array}{l}\text { Positive } \\
\text { Th. (in) }\end{array}$ & $\begin{array}{r}\mathrm{Li} \\
\text { Add. }\end{array}$ & $\begin{array}{l}\text { Gortex } \\
\text { on Neg. }\end{array}$ & $\begin{array}{c}\mathrm{KOH} \\
(\%)\end{array}$ & $\begin{array}{l}\text { Coolant } \\
\text { (C) }\end{array}$ & $\begin{array}{l}\text { Current (A) } \\
\text { Chrg/Disch. }\end{array}$ \\
\hline 23 & 7 & .070 & Yes & Yes & 33 & 10 & 25/25 \\
\hline 144 & 9 & .070 & Yes & Yes & 24 & None & $\begin{array}{l}25 / 25 \\
25 / 25\end{array}$ \\
\hline $\begin{array}{l}161 \\
185\end{array}$ & $\begin{array}{l}7 \\
9\end{array}$ & $\begin{array}{l}.090 \\
.070\end{array}$ & $\begin{array}{l}\text { Yes } \\
\text { Yes }\end{array}$ & $\begin{array}{l}\text { Yes } \\
\text { No* }\end{array}$ & $\begin{array}{l}24 \\
24\end{array}$ & None & $\begin{array}{l}25 / 25 \\
25 / 25\end{array}$ \\
\hline
\end{tabular}

" JCI TFE Film

Table 4-5. Summary of Test Results (September 28, 1989)

\begin{tabular}{|c|c|c|c|c|c|c|c|}
\hline \multirow[b]{2}{*}{ Cell } & \multirow[b]{2}{*}{ Cycles } & \multicolumn{2}{|c|}{ Capacity (Ah) } & \multicolumn{2}{|c|}{ Effic. (\%) } & \multirow{2}{*}{$\begin{array}{l}\text { Mid Point } \\
\text { Disch v/c }\end{array}$} & \multirow{2}{*}{$\begin{array}{l}\text { Pres (psig) } \\
\text { EOD/EOC }\end{array}$} \\
\hline & & Nominal & Latest & AH & WH & & \\
\hline 23 & 1,626 & 120 & $\begin{array}{r}124.2 \\
(135.7)\end{array}$ & $\begin{array}{c}94.6 \\
(90.9)\end{array}$ & $\begin{array}{c}78.0 \\
(76.7)\end{array}$ & $\begin{array}{c}1.242 \\
(1.264)\end{array}$ & $23 / 193$ \\
\hline 144 & 1,250 & 150 & $\begin{array}{c}193.7 \\
(176.0)\end{array}$ & $\begin{array}{c}93.6 \\
(91.6)\end{array}$ & $\begin{array}{c}76.1 \\
(77.8)\end{array}$ & $\begin{array}{c}1.235 \\
(1.266)\end{array}$ & $69 / 302$ \\
\hline 161 & $1,775^{*}$ & 160 & $\begin{array}{c}114.7 \\
(169.8)\end{array}$ & $\begin{array}{c}83.8 \\
(87.1)\end{array}$ & $\begin{array}{c}67.8 \\
(72.3)\end{array}$ & $\begin{array}{c}1.221 \\
(1.248)\end{array}$ & $130 / 306$ \\
\hline 185 & 228 & 160 & $\begin{array}{c}188.2 \\
(177.2)\end{array}$ & $\begin{array}{c}95.7 \\
(92.5)\end{array}$ & $\begin{array}{c}81.2 \\
(78.0)\end{array}$ & $\begin{array}{c}1.255 \\
(1.264)\end{array}$ & $16 / 119$ \\
\hline
\end{tabular}

Notes:

- Cell 161 - includes 1,100 cycles at 20\% DOD

Baseline performance in parentheses

end-of-discharge (EOD) pressure to increase with cycling. This undesireable trend has been noted previously during deep cycle testing.

The cell was first subjected to 1,000 cycles between 0 and 20\% state-of charge (SOC). A cycle consisted of a 32-Ah charge and a discharge to $1.2 \mathrm{~V}$. EOD pressure vs cycle number is plotted in Figure 4-3a for 140 continuous cycles over which time the pressure increased $11.4 \mathrm{psig}$ for an average of $0.08 \mathrm{psi} / \mathrm{cycle}$. Next 100 cycles were conducted between 80 and $100 \%$ SOC. This cycle consisted of a charge to $75 \%$ of the linear pressure slope and a 32-Ah discharge. EOD pressure vs cycle number for this "top of charge" cycle test is plotted in Figure 4-3b with a pressure rise of about $0.1 \mathrm{psi} / \mathrm{cycle}$, quite similar to the data shown above. This rise in hydrogen pressure with cycling is not desirable, and ways to control it are being investigated at JCI.

Following the last shallow cycle set, the cell was subjected to 5 standard cycles. The average capacity 


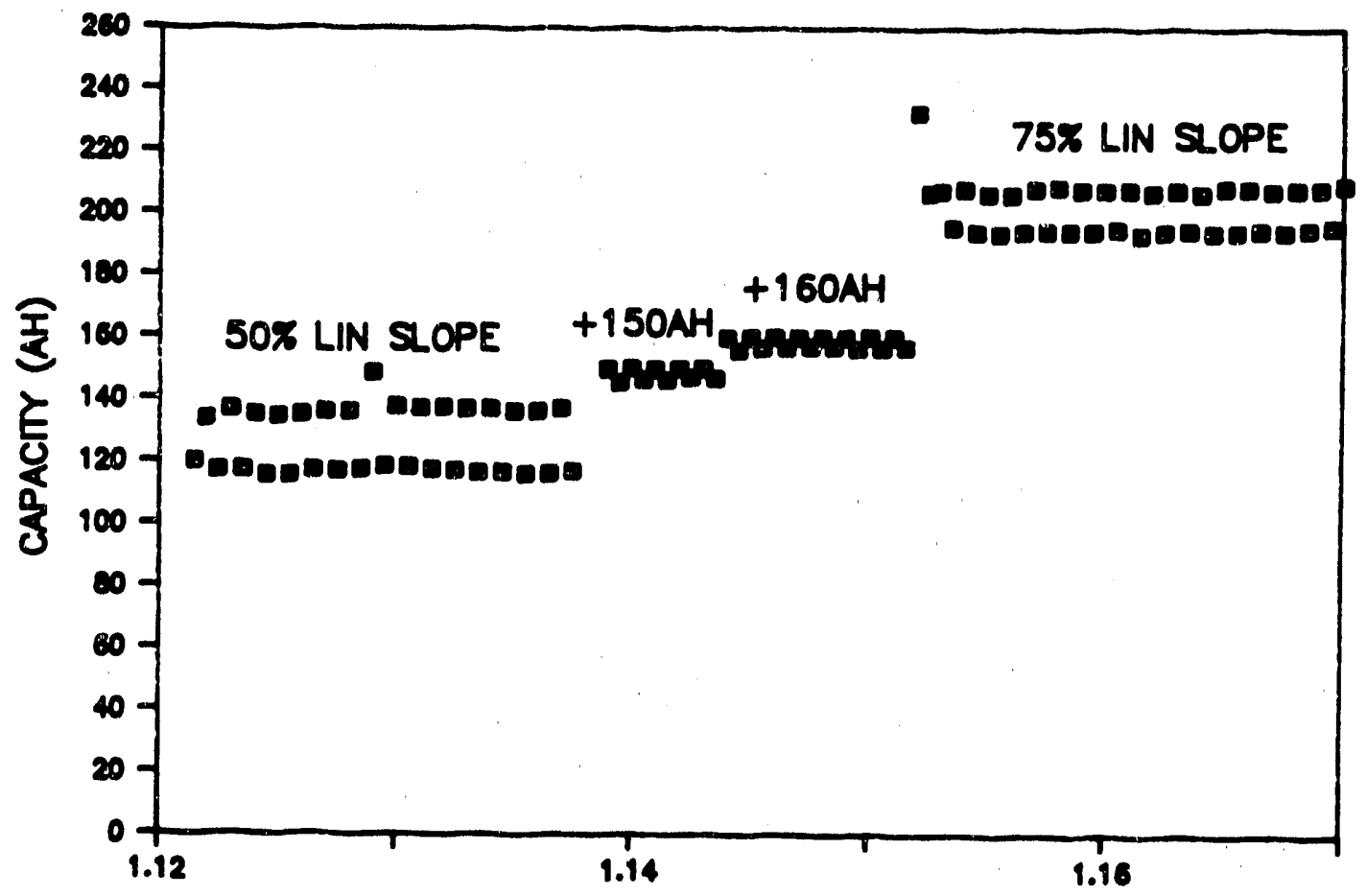

Figure 4-2a. Capacity vs Cycle Number, Cell $\# 144$

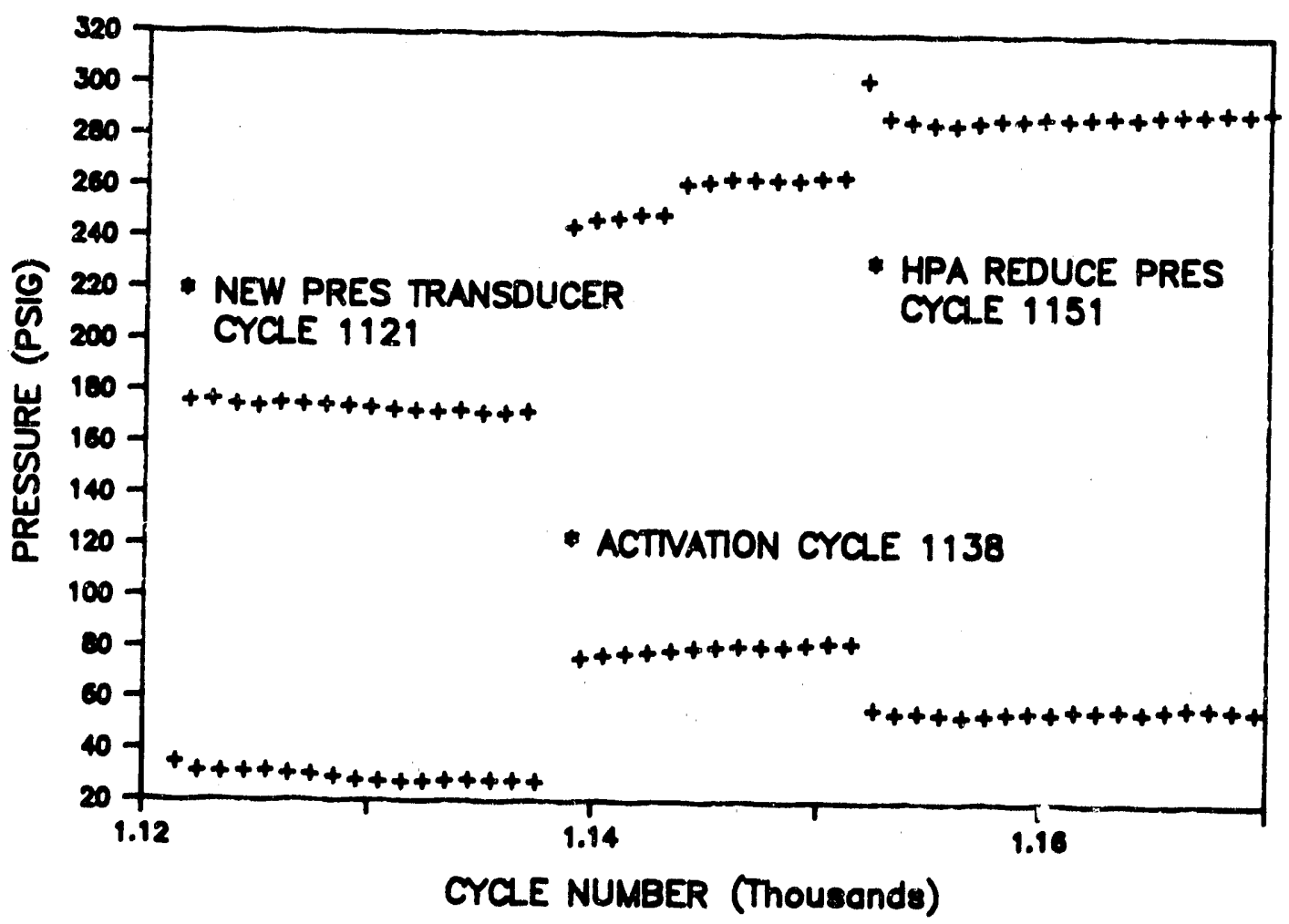

Figure 4-2b. Pressure vs Cycle Number, Cell \#144 


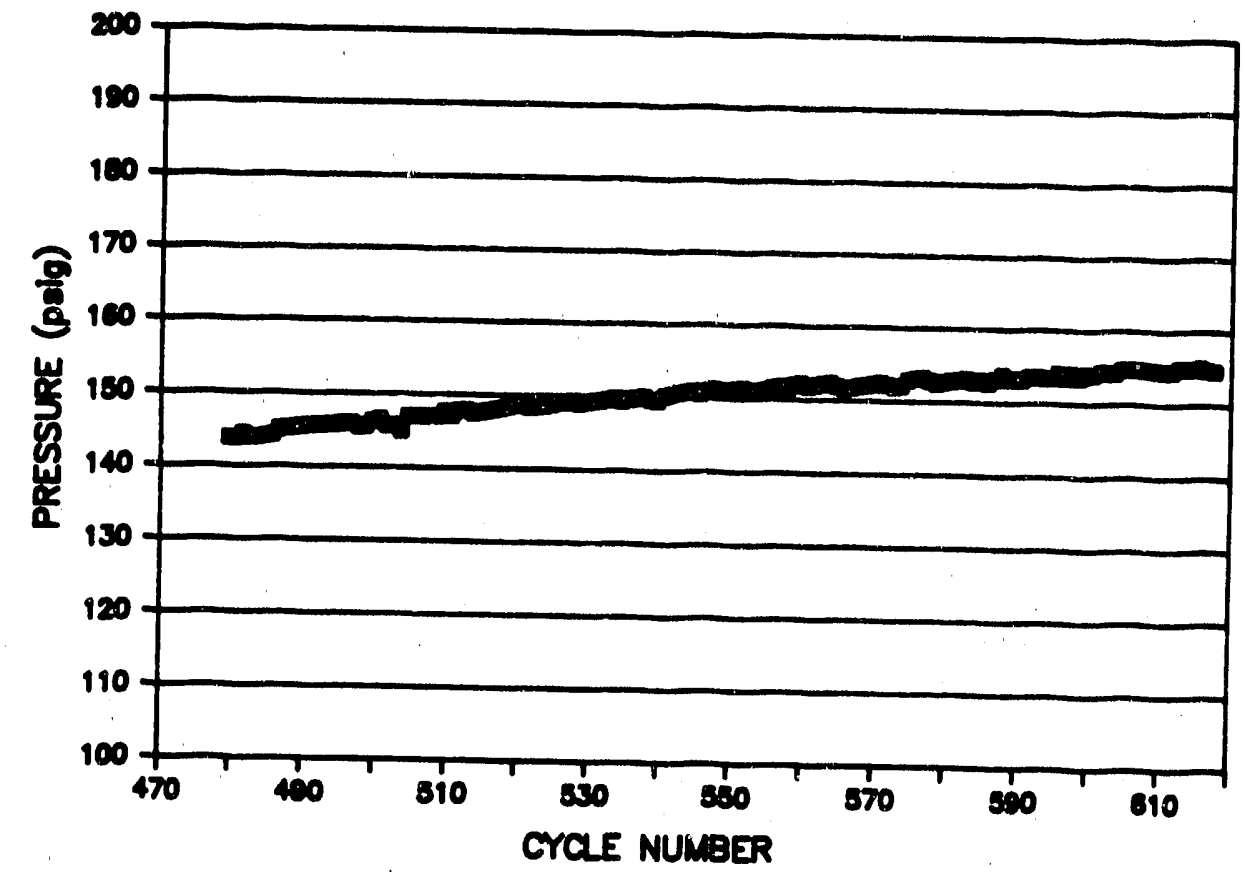

Figure 43a. EOD Pressure vs Cycle Number, Cell \#161; Cycle 20-0-20\% SOC

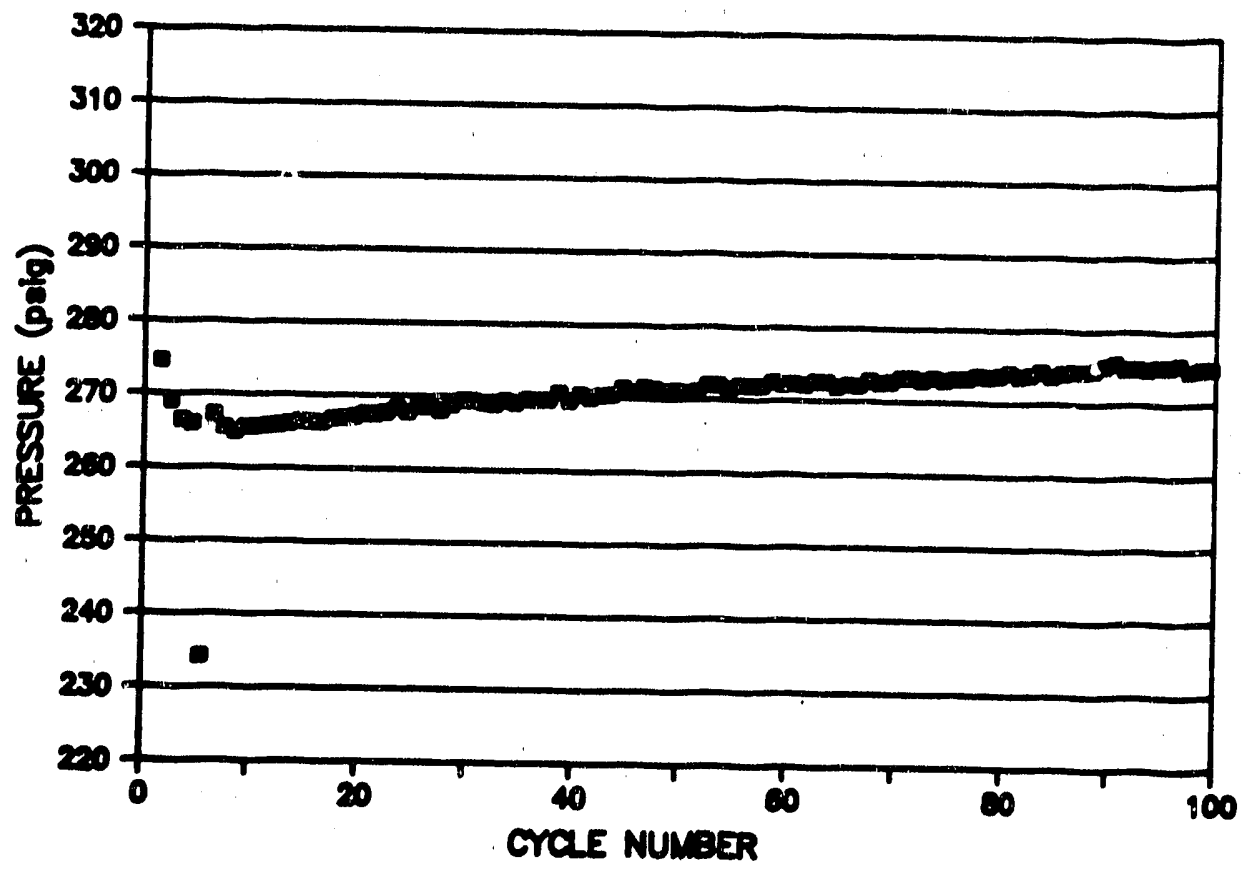

Figure 4-3b. EOD Pressure vs Cycle Number, Cell *161; Cycle 100-80-100\% SOC 
was $11 \mathrm{~S} \mathrm{Ah,} 28$ Ah less than reported last year. The cell has been removed from test for examination.

Cell 185 - This cell was received from JCI and put on test in February. It has the lower cost JCI porous fluoroplastic film on the negative electrode. To date it has accumulated 228 standard cycle:; the latest capacity is 188.2 Ah, an increase of $11 \mathrm{Ah}$ over the initial tests. During July, 43 deep cycles were accumulated during which time the EOD pressure increased a significant 18 psi for an average of $0.42 \mathrm{psig}$. During August the EOC pressure reached $330 \mathrm{psig}$, and the cell was swithed to monitor. EOC and EOD pressure vs cycle number are plotted in Figure 4-4 for roughly the last 100 cycles before reaching $330 \mathrm{psig}$, and shows the gradual increase in pressure with cycling. As mentioned above, the cause and control of this phenomenon is being investigated by $\mathrm{JCl}$ under the development contract.

\section{Solar Tests}

Last year, solar tests were described in which the four battery modules were connected in a series/parallel arrangement resulting in a 24-volt, 300 Ah battery. Subsequantly, the four modules were connected in parallel which gave a nominal 12-volt, 600 Ah battery; this permitted using 12-VDC loads such as a refrigerator and fluorescent lights. The daily range of the SOC was quite small reflecting the relatively large battery capacity compared to the load. This year, a series of tests were run with two modules in parallel for a better battery-to-load match.

Typical results were obtained un.ing April when modules 2 and 4 were connected in parallel, with the load again consisting of the 12-volt refrigerator and fluorescent lights. For the first week four lights were in the circuit, three for the second week, and, finally, two during the third week.

Load current vs time for the three week period is plotted in Figure 4-5a. With the four lights on, the total current was about 10-amps, of which 3.3-amps was the current to the refrigerator, which was cycled on and off by its thermostat.

Figure 4-5b is a plot of the state-of-charge during the same period. The lights were shed at 50\% SOC and reconnected at 55\% SOC. A change of slope can be seen as the SOC is declining. For the first two weeks the range of the SOC is relatively constant. While there

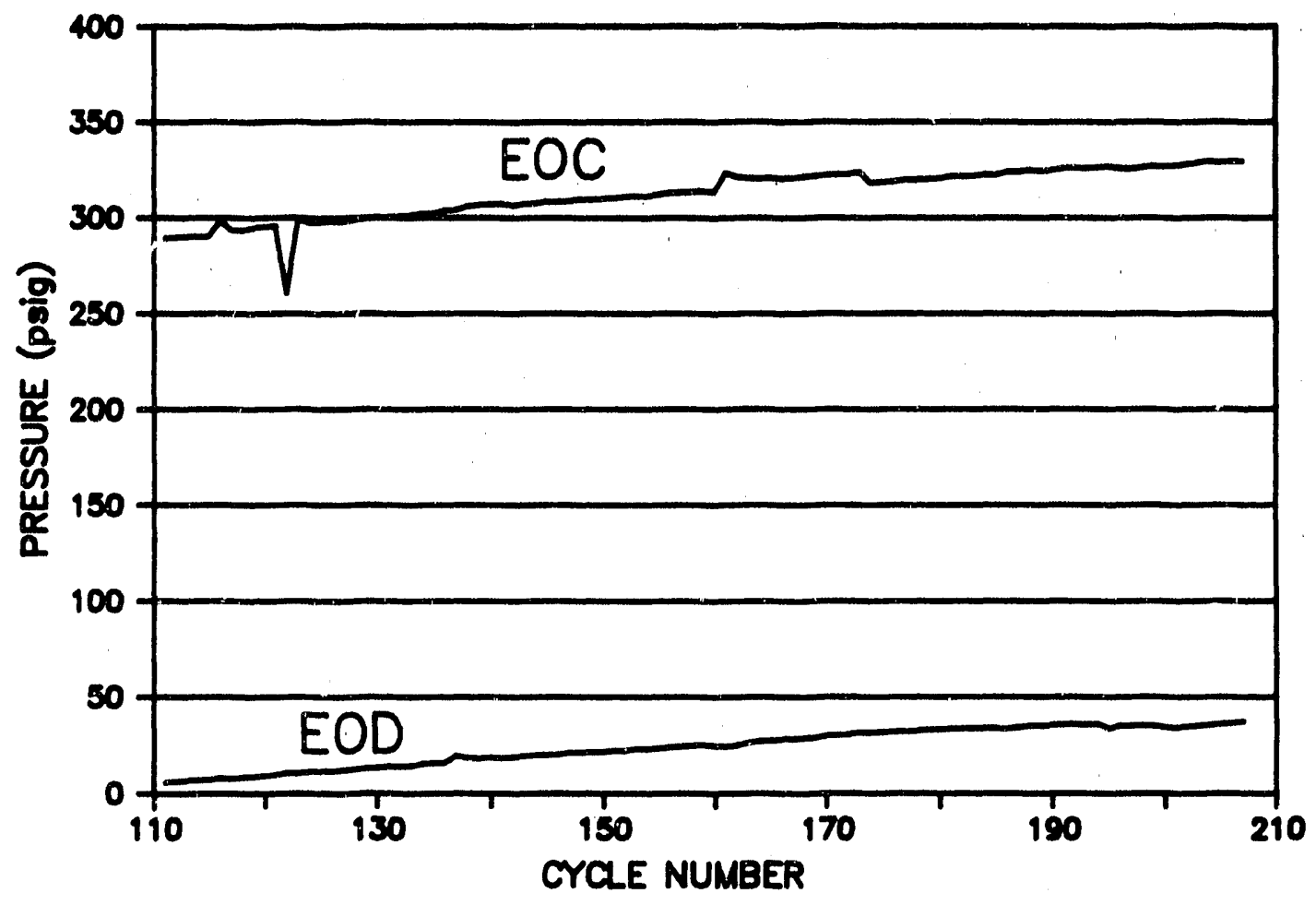

Figure 4-4. Pressure vs Cycle Number, Cely *185 


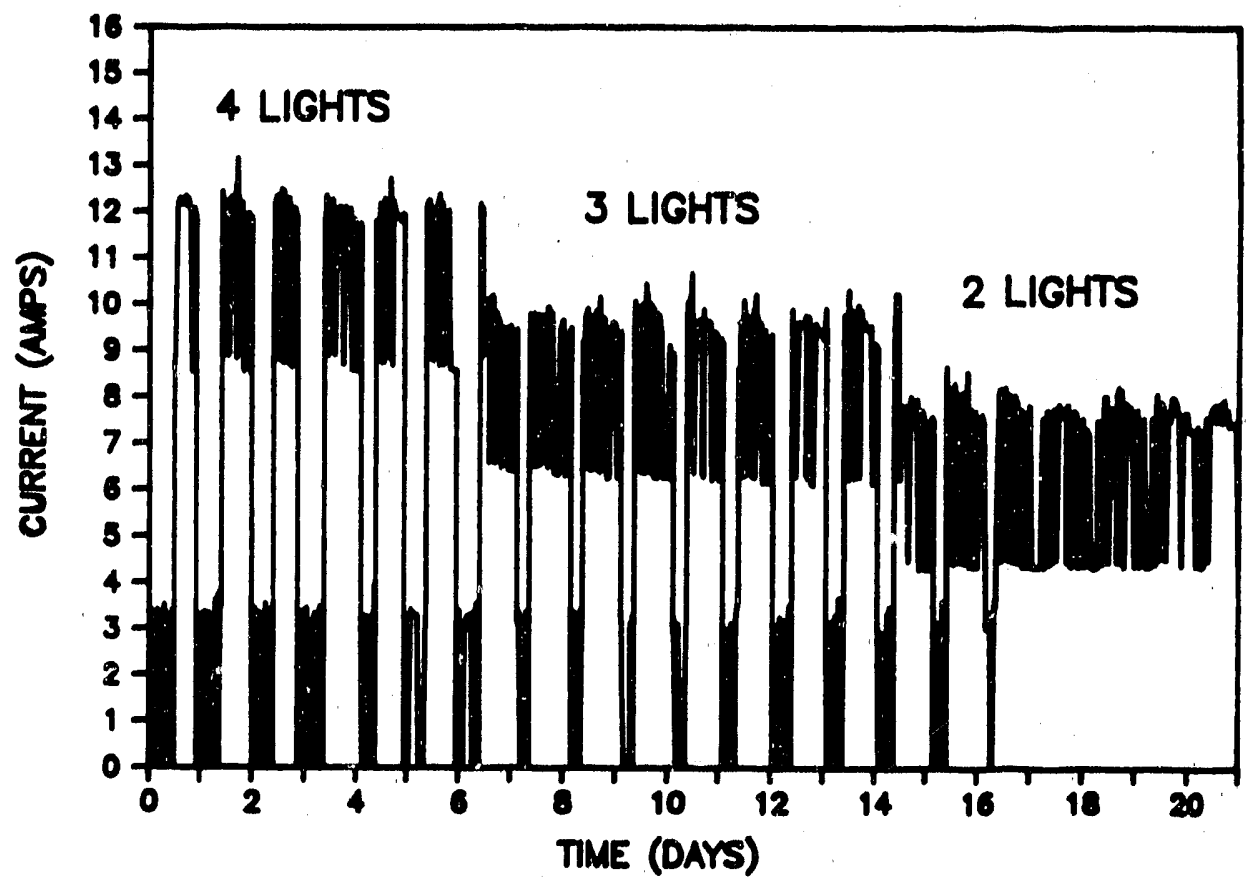

Figure 4-5a. Load Current vs Time, 3.5 kWh Battery

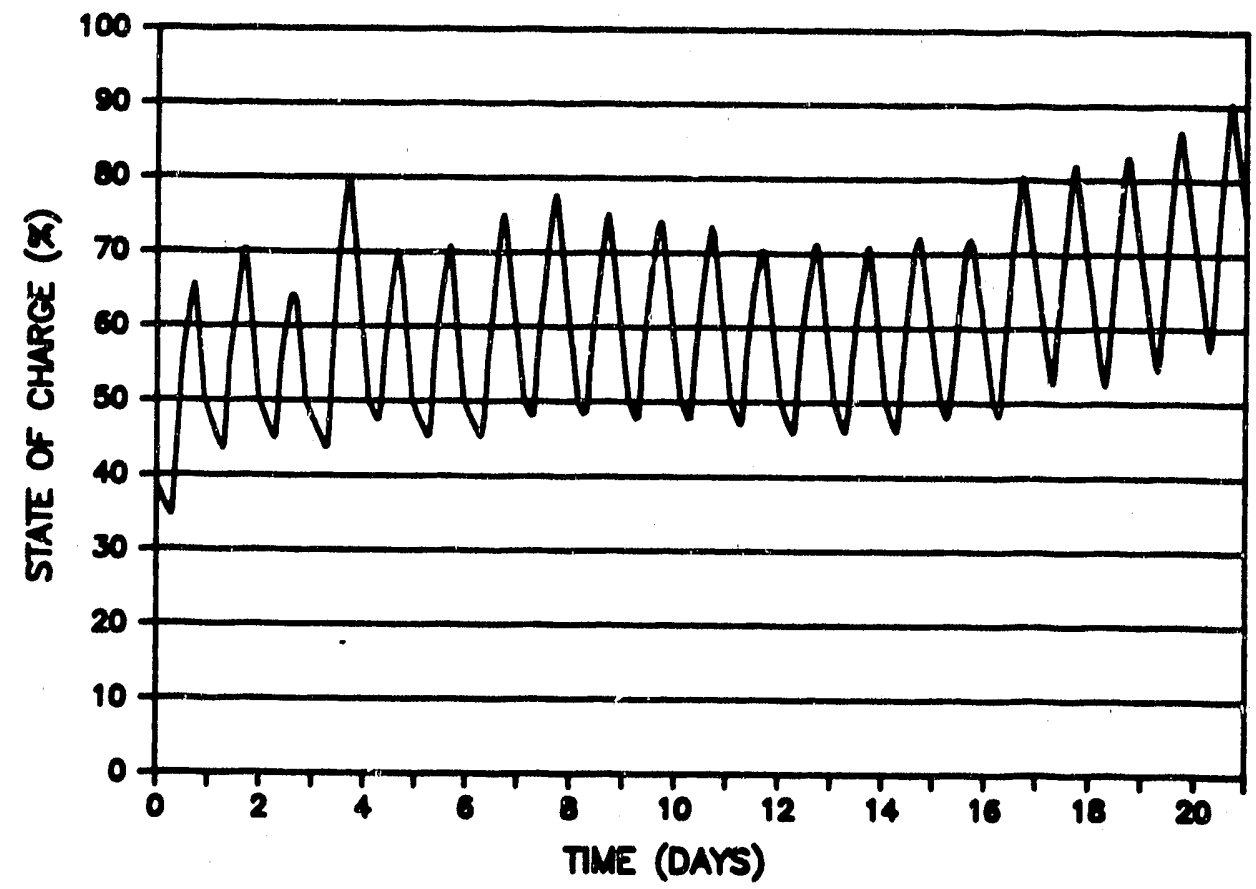

Figure 4-5b. State-of-Charge vs Time, 3.5 kWh Battery 
were only three lights on during the second week, they were on for a longer time.

This is also indicated in Figure 4-6a which is a plot of amp-hours per day from the array and total to the loads. In Figure 4-6b, daily kilowatt hours are plotted, and the consumption of the refrigerator and lights is shown separately. Some totals are tabulated in Table 4-6.

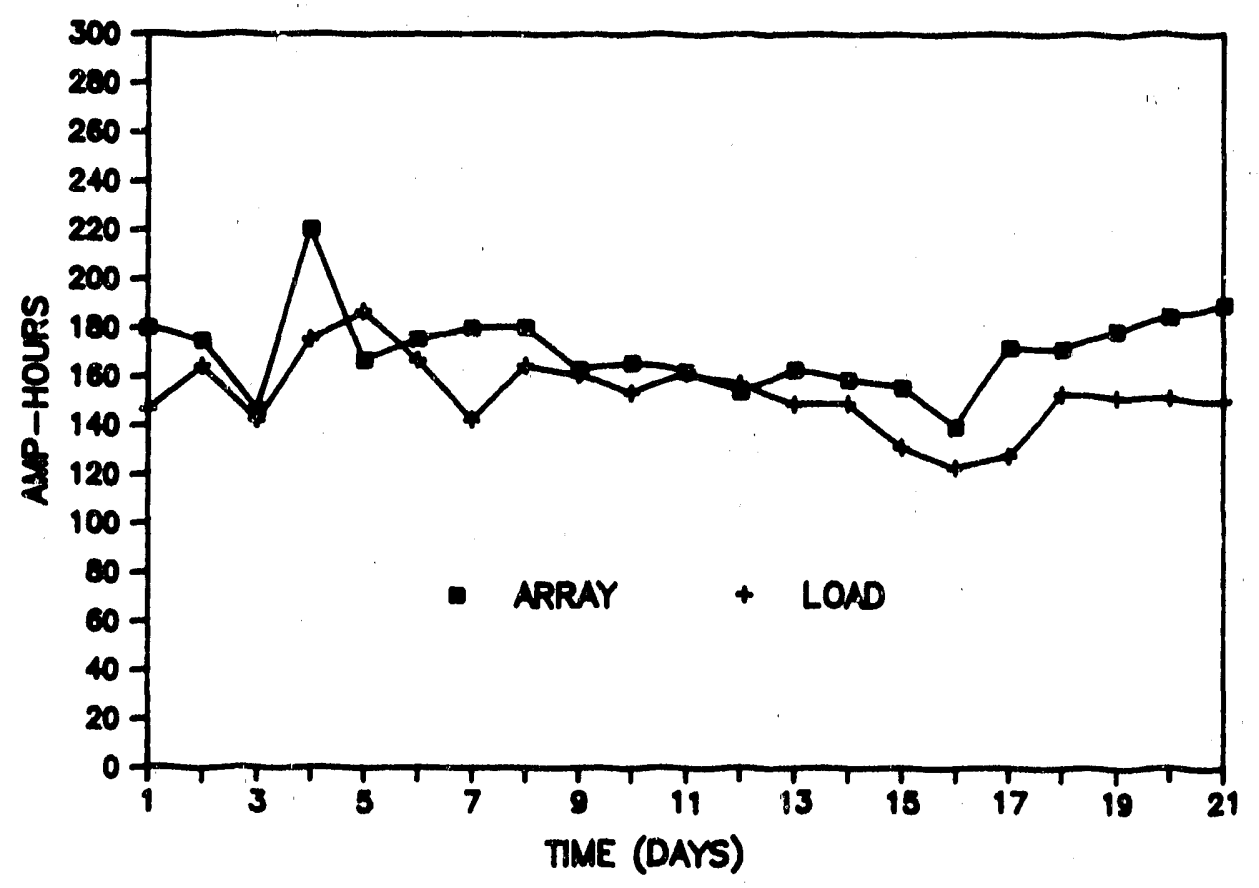

Figure 4-6a. Array and Load Ah vs Time, 3.5 kWh Battery 


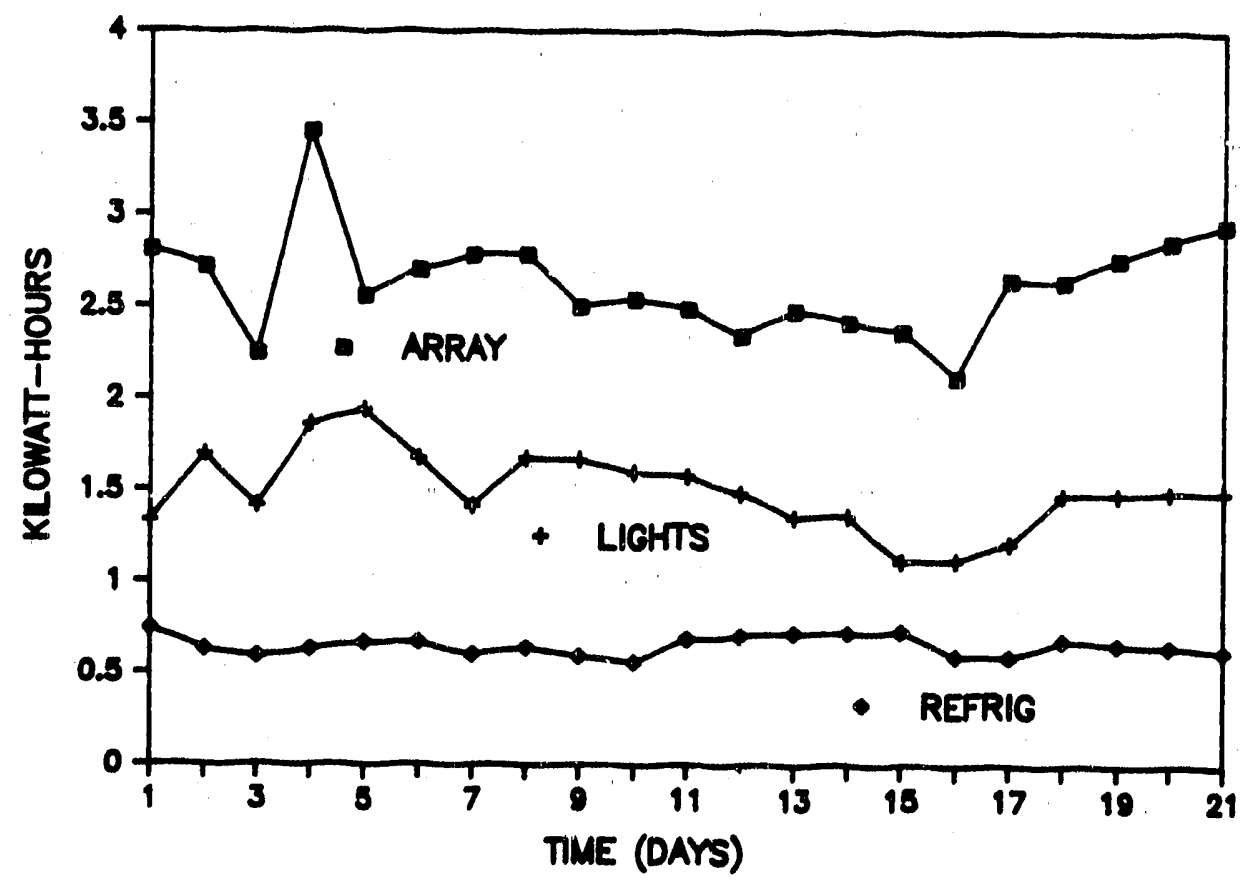

Figure 4-6b. Array and Load kWh vs Time, $3.5 \mathrm{kWh}$ Battery

Table 4-6. Dally Average Kilowatt-hours

\begin{tabular}{cccc} 
Week & Array & Refrig & Lights \\
\hline 1 & 2.76 & 0.65 & 1.65 \\
2 & 2.58 & 0.65 & 1.55 \\
3 & 2.60 & 0.66 & 1.35
\end{tabular}




\section{Aluminum/Air Technology}

A 2.5-year cost sharing contract was awarded to Eltech Research Corporation in August 1937 to develop an aluminum/air battery for electric vehicle applications. Work is being conducted at Eltech and at two sub-contractors, Case Western Reserve University and Helipump Corporation. Eltech is involved in the design, construction and characterization of the batteries; Case Western is modeling a single cell; and Helipump is investigating solid separation techniques. An a.jvaned cell desigin was evaluated at SNL during FY89, and a 12-volt battery was characterized at Eltech.

\section{Technology Development}

An alternative to a secondary battery as the power source in an electric vehicle is a fuel cell, i.e., a cell that generates power by consuming a mixture of a fuel and oxygen from the air. Metals such as lithium, aluminum, zinc and iron may be used in a fuel cell and aluminum is a particularly attractive candidate. The thetal offers high energy and power densities, is environmentally acceptable (as are the products of the cell reaction), is easy to handle and has a large industrial base for production and distribution.

The present program is a continuation of the research and development conducted jointly by the Department of Energy and Eltech Research Corporation since 1980. A longer term objective of the prograrn is to install and evaluate an aluminum/air battery syrtem in an electric vehicle. The present progri.n contairs two phases:

Phase I: Design and optimization of the aluminum/air cell

Phase II: Design and optimization of the auxiliary system, including the heat exchange unit, separation of solids, removal of carbon dioxide from the air-feed stream and disposal of hydrogen gas. (See Figure 5-1.)

The characterization of the performance of the aluminum/air cell is being carried out at Eltech Research Corporation, including definition of operating conditions, electrolyte composition and fluid flow rates. Modification to the design of the cell and/or components of the cell are also being addressed at Eltech, together with the tasks focusing upon Phas: It, the auxiliary system. Specific researcb objectives have been subcontracted by Eltech to Case Western Reserve University, to Helipump Corporation and to Kaiser Center for Technology.

\section{Cell Design}

The werige cell was primarily developed to address the need for a "rapidly rechargeable battery." Although promising levels of performance were achieved, the need for a sealed, lighter and more compact battery was clcarly identified. Eltech developed the B-300 cell (Figure 5-2), reducing both weight and voluine relative to the wedge cell. This design was selected for use in the present program.

The B-300 cell has proven to be a useful unit, and a single cell of this design was delivered to SNL in May 1988. Several changes have been made to the cell in the course of the program to improve performance and to facilitate replacement of the anode plate. A multi-cell (12 voit) battery, based upon the B-300 cell design, was fabricated, assembled and operated at Fairport. This battery showed stable performance with uniform metal dissolution within each of the cells, indicating that the distribution of electrolyte and air was satisfactory. Details concerning the battery testing are given in the Evaluation section that follow. It was evident that the weight and volume of the battery were too large to be considered viable for a vehicie. Independent programs at Eltech Research Corporation have focused upon the development of a stnaller, sealed aluminum/air cell, with dissolution from both sides of the anode plate, therefore requiring external current collection in contrast to the B-300 cell. A simpler method for replacement of the anode was also incorporated into the nev: cell.

Concepts have been developed for a multi-cell array of this advanced dcsign, with modularized busswork and refined electrolyte distribution. A comparison of the weights and volumes for cells and a battery using the B-300 and the new AT-400 showed that incorporation of this new cell design offers significant advantages.

\section{Mathematical Mociel of the B-300 Cell}

A mathematical model of the B-300 cell, based upon a boundary layer approach, has been developed by 


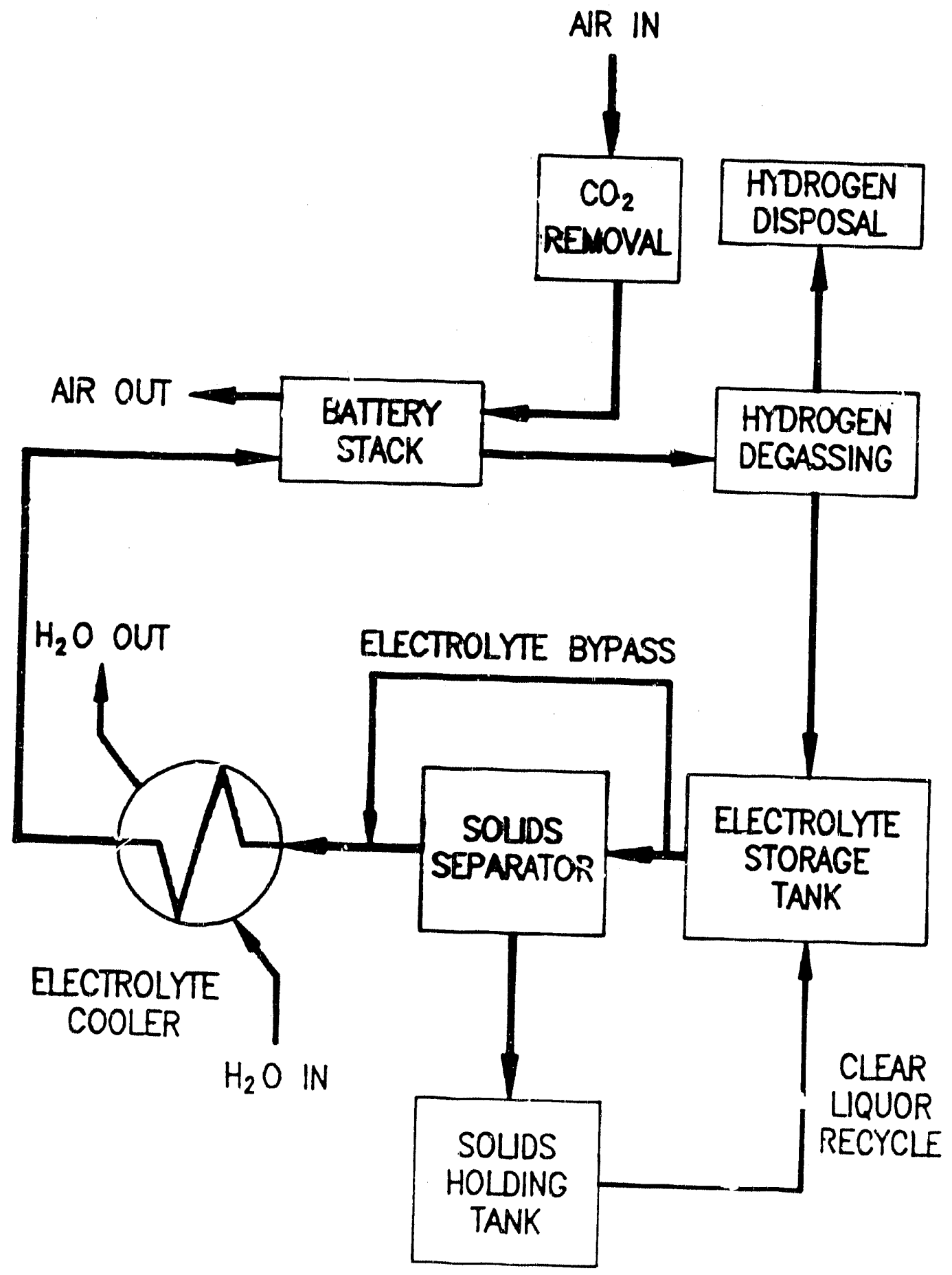

Figure 5-1. Atuminum/Air Battery Process Schematic

$\overline{s-2}$ 


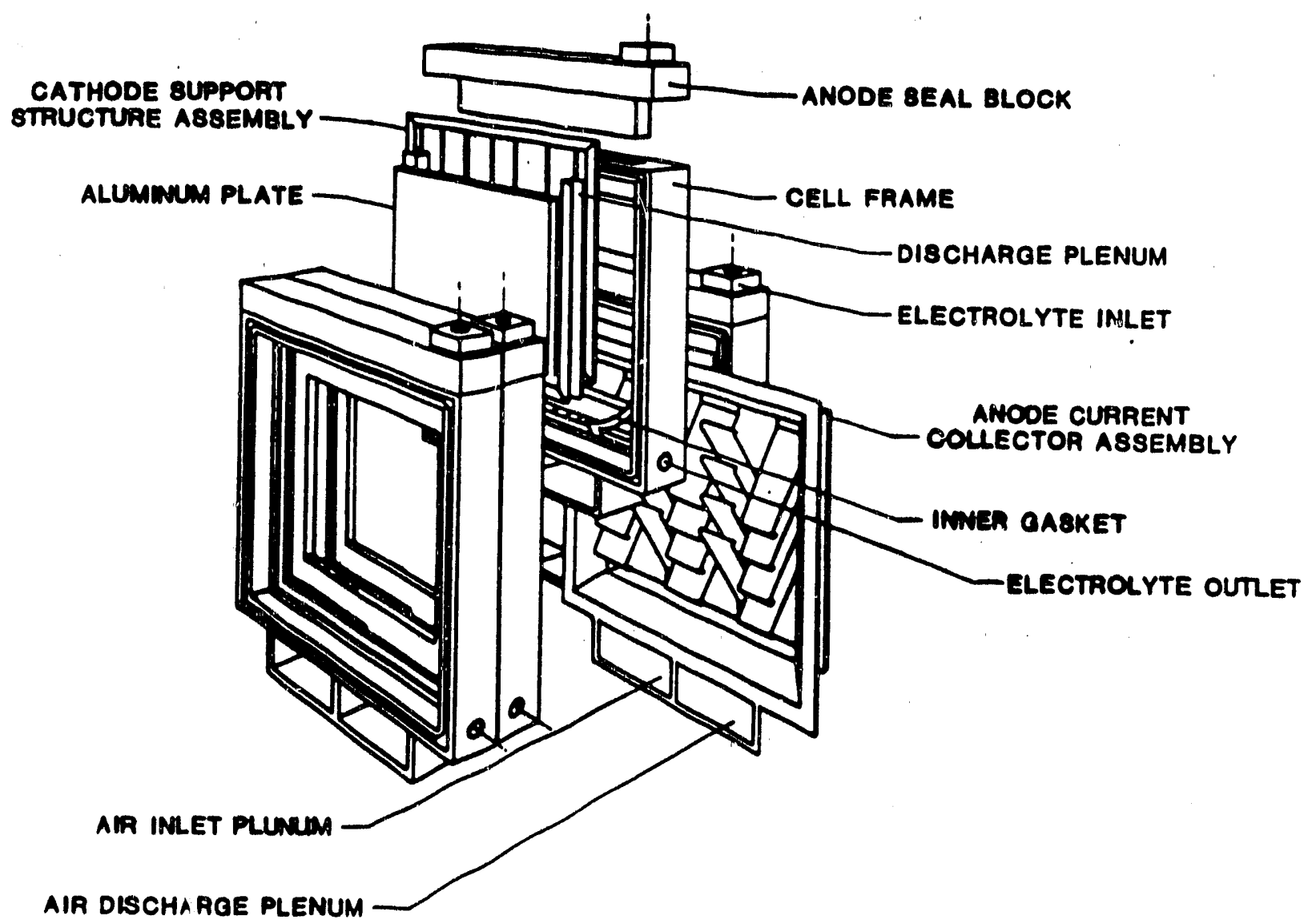

Figure 5-2. Aluminum/Air Bipolar Battery

Dr. R. Savinell at Case Western Reserve University. The model successfully correlated results obtained from the study of the fluid flow rates and continues to be used to identify operating conditions and cell design features that impact performance. The model is also readily modified to mathematically describe the advanced cell introduced into the program.

An experimental program is presently in progress to Jevelop fundamental kinetic data for the dissc : $u$ : $n n$ and cortosion reactions occurring at the aluminurn anote. These studies utilize a rotating cylindrical electrode to ensure uniform and controlled hydro-dynamic conditions at the surface. Hydrogen gas is collected to provide a direct measure of the parasitic corrosion reaction.

\section{Electrolyte Management}

In a program review in September 1988, it was recommended that definition of the composition of the electrolyte be approached in a manner different from that originally proposed. In contrast to an experimental. ly designed study, a series of tests using both the single B-300 cell and the 12-volt battery was completed,

a) with a "batch electrolyte," i.e., replacing the electrolyte at the onset of the formation of solids, and

b) to establish "steady-state," where the electrolyte attains a dynamic equilibrium in terms of conductivity and the concentratinns of free hydroxide and dissolved aluminum. 
In addition, a simulated B-300 cell and system was used to determine the physical (abrasive and/or cementation) effects of circulating an electrolyte containing particles of aluminum hydroxide.

Although operation with a "batch electrolyte" may simplify the electrolyte management system, one major advantage of the aluminum/air battery, i.e., extended range, can only be realized using the "steady-state" approach. The various single cell tests indicated that the dynamic equilibrium was dependent upon tempera ture, the initial concentration of the alkali metal hydroxide, the nature of the alloy and the electrolyte.

It was also shown that as the concentration of aluminate in the electrolyte increases, and particularly approaching "steady-state," two effects are observed:

a) the couductivity of the electrolyte decreases significantly,

b) there is an increase in the overpotential at the anode.

These two effects tend to limit the performance of the aluminum/air cell with respect to the high current densities usually obtained. At $60^{\circ} \mathrm{C}$ to ensure acceptable cell performance (particularly to realize peak power from the battery), the concentration of dissolved aluminum should probably be no more than $2.0-2.5 \mathrm{M}$, based upon $5 \mathrm{M}$ potassium hydroxide as the initial electrolyte. Several approaches to control the aluminate concentration are presently being considered:

a) the use of seed crystals

b) changes in temperature

c) acoustic effects

d) the use of mixed electrolytes (this approach may also lead to a higher conductivity at "steadystate").

A simulated B-300 single cell and system was constructed, through which slurries containing 2,5 , and 10 weight \% aluminum hydroxide (hydrargillite) in $5 \mathrm{M}$ potassium hydroxide were circulated continuously. For each test, over 1.700 hours of operation, there was no evidence of physical damage to the components of the cell or system.

At present, similar tests using a cyclic mode of operation ( 8 hours on $/ 16$ hours off) are in progress.

The program has focused upon two approaches to the removal of solids from the electrolyte (1) the use of the Helipump fluidizer impeller and (2) the use of acoustics to effect separation. The latter approach is considered proprietary to Eltech at this time. The characterization of the fluidizer impeller was completed using an experimental design study. A computer model was also developed and successfully correlated the results of the design study. The device is compact, insensitive to orientation and may require acceptably low parasitic power to operate. However, the low efficiency of separation with fine particles (less than 10 microns in diameter) limits the use of the device in the electrolyte management system.

\section{Absorption of Carbon Dioxide}

The performance of the air cathode in an alkaline electrolyte is sensitive to the presence of carbon dioxide in the air feed stream. Various technologies to absorb carbon dioxide were evaluated and in terms of size, weight and cost of an absorption unit based upon a particular technoiogy (including regenerable systems), the use of soda lime was clearly preferred. An experimental program was designed to determine the effects of temperature, relative humidity and superficial velocity upon the absorption capacity of soda lime columns. The initial results clearly indicate the importance of the relative humidity upon the absorption behavior (Figure 5-3). Preliminary designs for an absorption unit for an electric vehicle have been developed and appear reasonable in terms of size, weight and cost.

\section{Materials and Energy Balances (System Analyses)}

This study was initiated in December 1988 with the objective to generate material and energy balances, process flow diagrams, and perform system analyses for the aluminum/air battery system. Initial work focused on the evaluation of two operating scenarios: batch operation at $400 \mathrm{~mA} / \mathrm{cm}^{2}$, and steady state operation at $400 \mathrm{~mA} / \mathrm{cm}^{2}$. A complete set of calculations and documentation was generated for each base case. A spread-sheet was also developed (Lotus compatible), and utilized to evaluate the effects of critical system variables on overall battery system performance.

Although the initial base cases defined an operating current density of $400 \mathrm{~mA} / \mathrm{cm}^{2}$, it was decided that a more realistic operating mode was represented by the Simplified Federal Urban Drive Schedule (SFUDS). A summary of the system operation under the SFUDS regime is illustrated in the flow schematic shown in Figure 5-4, showing the flow rates, concentrations and temperature of the major streams. All values are time weighted averages for SFUDS operation. 


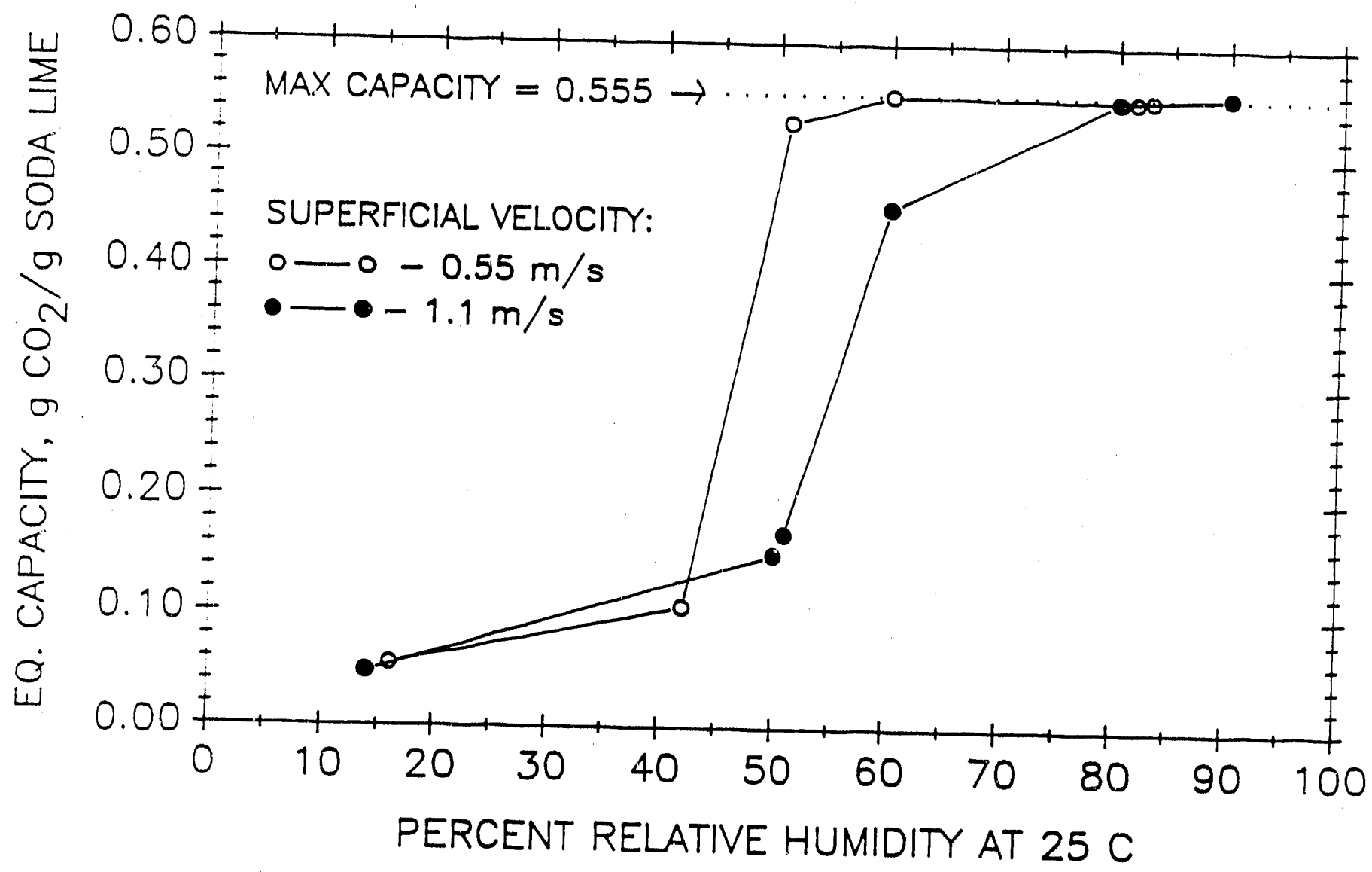

Figure 5-3. Equilibrium $\mathrm{CO}_{2}$ Capacity of Soda Lime at $25^{\circ} \mathrm{C}$

The system model (spread-sheet) was utilized to make projections of battery system energy density and vehicle range, operating under the SFUDS drive cycle. Results of these studies are summarized below.

a) Solids Concentration:

1) Solids content ranges from $0.1 \mathrm{wt} \%$ at $75 \%$ separation efficiency to $0.3 \mathrm{wt} \%$ at $25 \%$ separation efficiency.

2) Solids concentration ranges from $0.1 \mathrm{wt} \%$ under SFUDS operation to $0.5 \mathrm{wt} \%$ at a current density of $300 \mathrm{~mA} / \mathrm{cm}^{2}$.
Thus, it is not necessary to have a high efficiency solids separator to maintain a low level of solids in the system.

b) Parasitic Power:

1) Parasitic power losses range from 0.3 to 1.2 $\mathrm{W} / \mathrm{kg}$ as electrolyte flow varies from 75 to 150 liters/min.

2) Parasitic power losses range from 0.4 to 0.8 $\mathrm{W} / \mathrm{kg}$ as current density varies from the SFUDS base case $\left(65 \mathrm{~mA} / \mathrm{cm}^{2}\right)$ to 300 $\mathrm{mA} / \mathrm{cm}^{2}$. 


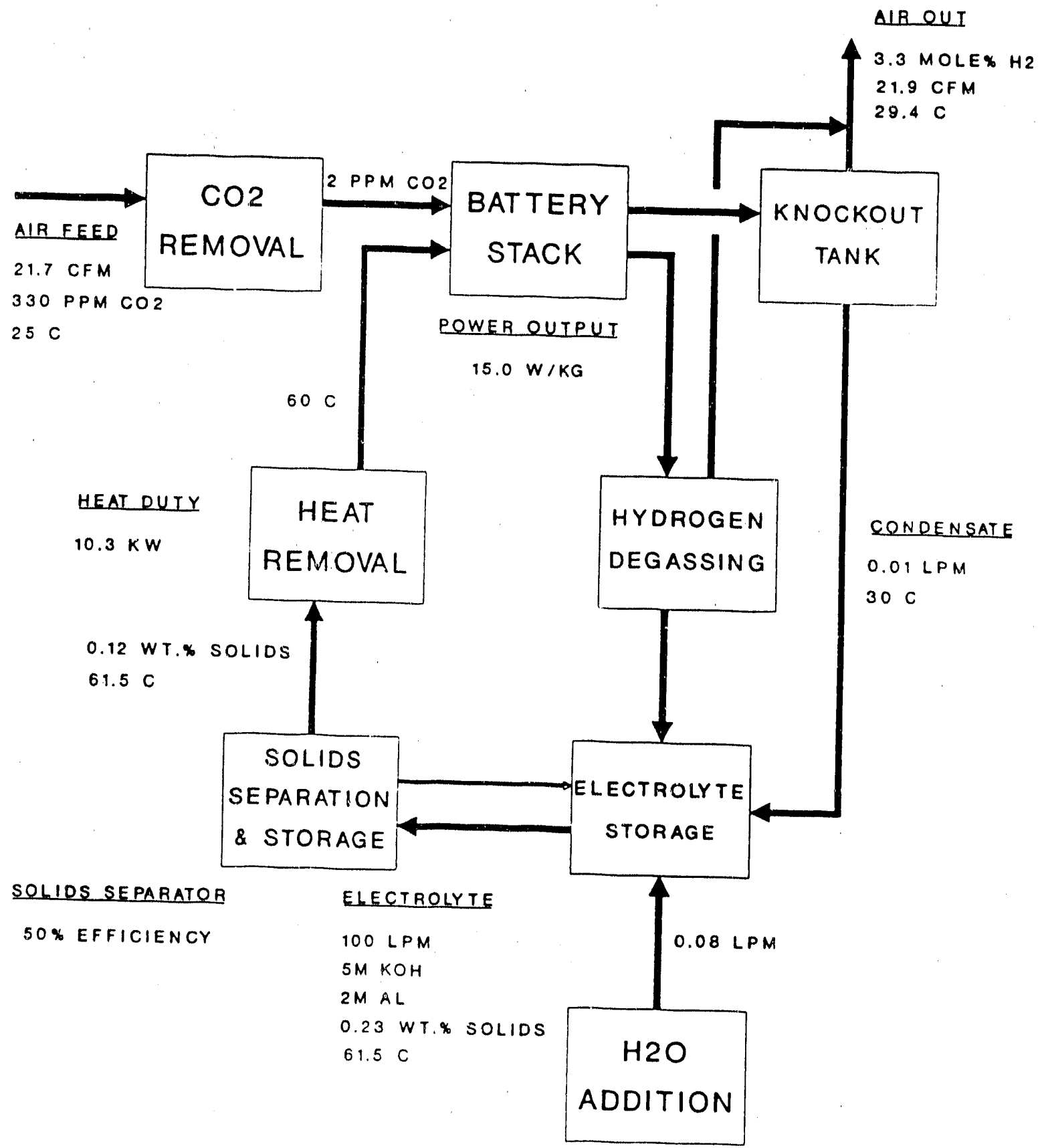

Figure 5-4. Aluminum/Air Battery System SFUDS Base Case 
In all cases, parasitic power consumption is less than $10 \%$ of tue total average battery stack power output.

Energy Density and Range Projections.

1) Driving under the SFUDS cycle, using a high performance alloy, the projected energy density is $290 \mathrm{Wh} / \mathrm{kg}$.

2) Under the same conditions as stated above, the projected range is 350 miles.

\section{Technology Evaluation}

A modified B-300 aluminum/air cell was evaluated at SNL with a total of 29 runs cond cted, including an SFUDS discharge. A 10-cell battery was evaluated at Eltech during a series of six tests. These evaluations are discussed separately below.

\section{Modified B-300 Cell (SNL)}

Eltech personnel visited SNL during February 1989 and installed a new single cell (479). The flow system from the first Eltech cell was reused. The unit consisted of a modified B-300 cell stack, one replaceable $99.995 \%$ pure aluminum anode $\left(300 \mathrm{~cm}^{2}\right)$, one electrolyte reservoir, one pump, a carbon dioxide scrubber, and associated piumbing and sensors. Solids separation equipment was not included. Recharge was accomplished mechanically by removing the depleted anode and inserting a new one. When fully charged with aluminum (approximately $350 \mathrm{~g}$ ), the cell had a theoretical capacity of about 1,040 Ah. Most tests were run at $175 \mathrm{~mA} / \mathrm{cm}^{2}$, with periodic polarization scans ranging from 64 to $337 \mathrm{~mA} / \mathrm{cm}^{2}$. The initial electrolyte concentration was $5 \mathrm{M} \mathrm{KOH}$, with no dissolved aluminum. Initially, about 36 liters of electrolyte (density $1.2 \mathrm{~g} / \mathrm{ml}$ ) were used. All tests were run with an electrolyte flow rate of $1.5 \mathrm{~J} / \mathrm{min}$ and an air flow of four times the stoichiometric requirement. The cathode air backpressure was approximately 24 inches of water.

The new cell was a modified B-300 design incorporating cross air flow for more uniform anode dissolution. Also, there were stronger (and heavier) cell case parts to reduce the cracking and degradation observed in the first cell. The modular air cathode was installed in the new cell using screws and replaceable seals rather than adhesive. This improvement represented a sigrificant savings of time when cathode replacement was required. The cell weighed $17.62 \mathrm{~kg}$ without electrolyte.

Twenty-nine runs were accomplished on the new cell. Twenty-eight anodes were consumed; only the first two runs utilized the same anode plate. Over 150 hours of run time were accumulated. One air cathode was used for the entire test. The average performance observed during these tests is given in Table 5-1. The last run (29) was an SFUDS discharge, and it is included as a separate item.

Several changes were made to the system because of the unusual performance experienced. This unexpected behavior included high and inconsistent corrosion rates and severe pitting in the aluminum plates. Pitting of the anodes disappeared after the electrolyte was replaced after run 10 . The volume of the electrolyte reservoir was reduced to 16 liters. This was done to more rapidly investigate the impact of aluminate supersaturation on cell performance.

Several different lots of anode material were used. Corrosion rates were higher than observed in previous cell tests at the same discharge rates. Some non-uniformity in aluminum dissolution was noted, particularly along the bottom edge of the anode plate.

\section{Table 5-1. Eltech Aluminum/Air Cell Tests at SNL}

Cell 479 - June 30, 1989

\begin{tabular}{|c|c|c|c|c|c|c|c|}
\hline \multirow[b]{2}{*}{ Quarter } & \multirow{2}{*}{$\begin{array}{c}\begin{array}{c}\text { Run } \\
\text { Number }\end{array} \\
\end{array}$} & \multicolumn{2}{|c|}{ Discharge } & \multirow[t]{2}{*}{$\begin{array}{l}\text { Al Elect. } \\
\text { Efficiency } \\
\text { (\%) }\end{array}$} & \multirow{2}{*}{$\begin{array}{c}\text { Al } \\
\text { Energy } \\
\text { Whg) }\end{array}$} & \multirow[t]{2}{*}{$\begin{array}{c}\text { Corrosion } \\
\text { Rate } \\
\left(\mathrm{mA} / \mathrm{cm}^{2}\right)\end{array}$} & \multirow[t]{2}{*}{$\begin{array}{l}\text { Anode } \\
\text { Util. } \\
(\%)\end{array}$} \\
\hline & & Ah & Wh & & & & \\
\hline $\begin{array}{c}\text { 2nd FY88 } \\
\text { 3rd FY89 } \\
\text { SFUDS }\end{array}$ & $\begin{array}{c}1-8 \\
9-28 \\
29\end{array}$ & $\begin{array}{r}2,948 \\
11,321 \\
38.8\end{array}$ & $\begin{array}{r}3,050 \\
9,500 \\
51.9\end{array}$ & $\begin{array}{l}72 \\
79 \\
12\end{array}$ & $\begin{array}{l}2.28 \\
1.99 \\
4.00\end{array}$ & $\begin{array}{r}117 \\
77 \\
268\end{array}$ & $\begin{array}{r}36 \\
38 \\
4\end{array}$ \\
\hline
\end{tabular}


It was also observed that as the electrolyte became saturated with aluminate, the cell voltage became depressed. This effect slowly limited the maximum discharge rate that could be applied to the cell. With fresh electrolyte, discharge rates exceeding $600 \mathrm{~mA} / \mathrm{cm}^{2}$ were possible. By the time precipitates formed, the maximum achievable current density was about $300 \mathrm{~mA} / \mathrm{cm}^{2}$. Reference electrode data was not definitive, but indicated that the aluminum electrode was the cause of the voltage loss. The effect could be temporarily reversed by adding $5 \mathrm{M} \mathrm{KOH}$ to the electrolyte.

A cold start-up test was conducted to determine whether the cell could operate at ambient room temperature. Starting at about $25^{\circ} \mathrm{C}$, the cell was discharged at a low rate (about $5 \mathrm{~mA} / \mathrm{cm}^{2}$ ). The cell provided about $0.5 \mathrm{~V}$ initially, and the voltage rose as the electrolyte heated up. After 7 hours, the discharge current was just over $200 \mathrm{~mA} / \mathrm{cm}^{2}$, and the cell temperature was $198^{\circ} \mathrm{C}$. No extra thermal insulation was provided to the cell plumbing during this test. The corrosion rate was very low, about $3 \mathrm{~mA} / \mathrm{cm}^{2}$, due to the reduced operating temperature. The results indicated that cold start-up is feasible.

The final test was an SFUDS discharge. Because of test equipment limitations, the maximum discharge rate was $100 \mathrm{~A}$. The battery weight was scaled to maintain the discharge rate below this limit (the maximum SFUDS power requirement is $79 \mathrm{~W} / \mathrm{kg}$ ). A battery weight of $1.72 \mathrm{~kg}$ was used, which is much smaller than that of the actual cell. The electrolyte was $5 \mathrm{M} \mathrm{KOH}$. The test ran as scheduled for $4 \mathrm{~h}$, and 41 SFUDS repetitions were completed. The cell provided the required load for the entire test. The aluminum corrosion rate was very high during the test because of the frequent open-circuit stand periods in the SFUDS profile. Thus, while the cell performed well on this test, improvements will be required for minimizing open-circuit corrosion of the aluminum anode.

\section{The 12-V Battery (Eltech)}

The 12-volt battery incorporated 10 modified B-300 cells, similar to cell 479 described above. The battery stack and support system, including a small plate and a frame heat exchange unit, were brought "on-line" in April, and the preliminary tests were successfully completed. The first test was run with an electrolyte volume of 20 liters of initial composition 5M potassium hydroxide. The anodes were high purity, non-alloyed aluminum (lot 62240) and the cathodes were the $\# 33$ Special type. The electrolyte flow rate to each cell was $1.01 / \mathrm{min}$ and the electrolyte temperature was maintained at $60^{\circ} \mathrm{C}$. The scrubbed air flow rate was $4 \mathrm{x}$ stoichiometric for each particular current density.

An initial polarization scan was recorded (stack voltage vs current density) before operating the battery for a total of four hours at a current density of 350 $\mathrm{mA} / \mathrm{cm}^{2}$ with excursions to $500 \mathrm{~mA} / \mathrm{cm}^{2}$ for five minutes in each hour. During the fourth hour of operation, the higher current density was limited to 400 $\mathrm{mA} / \mathrm{cm}^{2}$. A summary of the data is presented in Table 5-2 and in Figure 5-5.

Cooling water flow rates to the heat exchanger system ranged from 0.1 to $0.25 \mathrm{gal} / \mathrm{min}$ and were unexpectedly low, probably due to heat losses from the system, e.g., electrolyte tank, plumbing, hydrogen knock-out pipe, etc.

Anode dissolution was uniform from cell to cell, with weight losses ranging from 157.5 to 160.2 grams,

Table 5-2. Summary of 10-Cell Battery Test 1

$\begin{array}{rccccc}\begin{array}{r}\text { Time } \\ \text { (min) }\end{array} & \begin{array}{c}\text { Current } \\ \text { Density } \\ \left(\mathrm{mA} / \mathrm{cm}^{2}\right)\end{array} & \begin{array}{c}\text { Conductivity } \\ (\mathrm{mS} / \mathrm{cm})\end{array} & \begin{array}{c}\text { Total } \\ \text { OH } \\ (\text { moles/l) }\end{array} & \begin{array}{c}\text { Al } \\ (\text { moles/l) }\end{array} & \begin{array}{c}\text { Voltage } \\ \text { V) }\end{array} \\ 5 & 350 & 742 & 5.00 & 0.48 & 10.40 \\ 57 & 500 & 652 & - & - & 7.99 \\ 60 & 350 & 651 & 5.06 & 1.14 & 10.29 \\ 117 & 500 & 541 & - & - & 6.67 \\ 120 & 350 & 531 & 5.08 & 1.77 & 9.25 \\ 177 & 500 & 450 & - & - & 4.87 \\ 180 & 350 & 445 & 5.02 & 2.47 & 8.18 \\ 237 & 400 & 365 & - & - & 4.20\end{array}$



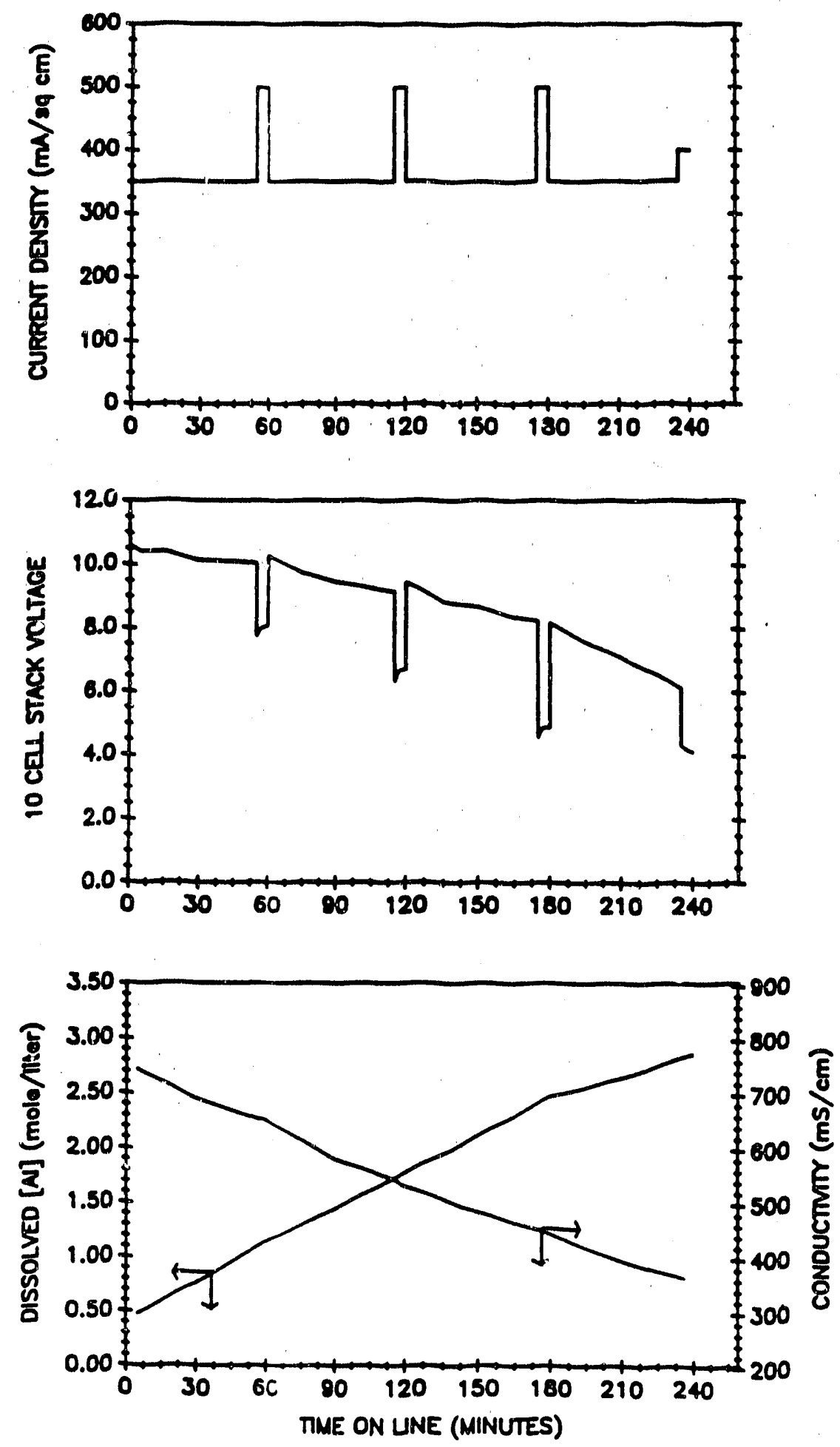

Figure 5-5. Eltech Ten Cell B-300 Tests - Test 1 
with the average weight loss being 158.4 grams. The profiles were also measured and showed no significant variation across the plate or from plate-to-plate. These results indicate that uniform fluid distribution was achieved within the 10 cells.

Five additional tests were conducted to complete the initial battery evaluation. Test variables included current density, electrolyte composition, and electrolyte concentration.

Limiting current behavior was again observed with the battery as with the single B-300 cell. The magnitude of the limiting cu/rent appears to be dependent upon the concentration of dissolved aluminum in the electrolyte. To obtain current densities of $500-600 \mathrm{~mA} / \mathrm{cm}^{2}$ (which represents the peak-power condition for a vehicle) with the minimum number of cells per stack, it is evident that the concentration of aluminate should not exceed 2.0M. The data obtained with the 10 -cell battery using $5.0 \mathrm{M}$ potassium hydroxide as the initial electrolyte agree well with those obtained with the single cell.

Operation of the battery using $7.5 \mathrm{M}$ potassium hydroxide as the initial electrolyte appears to give superior performance. A comparison of the data obtained at a current density of $150 \mathrm{~mA} / \mathrm{cm}^{2}$ shows a significant advantage in terms of battery voltage by operating with the higher concentration of hydroxyl ions, particularly after $3-4$ hours on 1 ine. This advantage is not due to the high conductivit of the 7.5M KOH electrolyte, and indicates that the polarization behavior of the electrodes may be sensitive either to the concentration of free hydroxyl ions or to the solubility of aluminate.

Although both Test 1 and Test 2 used 5M potassium hydroxide as the electrolyte and similar operating current densities, the battery voltages were significantly different. The anode plates for Test 2 were selected randomly from several lots so that the "average" polarization behavior is likely to be different from that of an individual lot. However, this difference should be smaller than that observed, i.e., smalier than the 60-100 millivolts per cell.

With respect to the crystallization of aluminum hydroxide from solutions of aluminate, different behavior was observed when sodium hydroxide was used initially. In the more concentrated solutions of sodium aluminate, precipitation of hydrargillite occurred onto components in the system, e.g., the flow meters. The anode plates also showed arcas of a white film and soljds accumulated at the edges of the plate between the nickel foil and the aluminum. Despite the apparent ease of precipitation, the solids content of the electrolyte at the end of the test was only $0.6 \mathrm{wt} \%$. 


\section{Appendix: Presentations and Publications}

\section{Presentations}

Auxer, W., "Sodium Sulphur Batteries for Stationary Energy Storage - A Conceptual Design," Second International Conference on Batteries for Utility Energy Storage, July 25-27, 1989.

Auxer, W., "Sodium Sulphur Battery Commercialization" Ninth Battery and Electrochemical Contractors' Conference, November 1989, p. 38.

Arnold, C., Jr., and R. A. Assink, "Research and Develupment of Ionic Membranes for Storage Batteries," Proceedings of the Joint Sandia/Los Alamos Meeting on Chemistry of Organic Materials, August 25, 1989, (INVITED).

Braithwaite, J. W., "Sodium/Sulfur Studies at SNL," Ninth Battery and Electrochemical Contractors' Conference, November 1989, p. 54.

Davenport, R. L., and M. Featherby, "Real Time XRadiography of Operating Sodium Sulphur Cells," Twenty-fourth IECEC Conference August 6-11, 1989.

Diegle, R. B., "Exploratory Battery Technology Development and Testing Project Overview," Ninth Battery and Electrochemical Contractors' Conference, U.S. Department of Energy, Alexandria, Virginia, November 13$16,1989$.

Diegle, R. B., "Overview of Sandia's Exploratory Battery Technology and Testing (ETD) Project," Asea Brown Boveri, Heidelberg, Federal Republic of Germany, June 19, 1989.

Diegle, R. B., and N. J. Magnani, "Batteries as a Partner for Renewable Energy," Proceedings of the International Renewable Energy Conference, Honolulu, Hawaii, September 19-23, 1988.
Diegle, R. B., and J. E. Quinn, "Status of the U.S. Department of Energy Program on Advanced Batteries for Load Leveling Applications," Proceedings of the Second International Conference on Batteries for Utility Energy Storage, Newport Beach, California, July 24-28, 1989.

DeLuca, W. H., and A. F. Tummillo, "Sodium/Sulfur Battery Testing at Argonne National Laboratory," Ninth Battery and Electrochemical Contractors' Conference, November 1989, p. 60.

Freese, J. M., "Sodium/Sulfur Evaluation at SNL," Ninth Battery and Electrochemical Contractors' Conference, November 1989, p. 71.

Homa, A. S., and E. J. Rudd, "The Development of Aluminum-Air Batteries for Electric Vehicies," Proceedings of the Twenty-Fourth Intersociety Energy Conversion Engineering Conference, Washington, August 1989.

Johnson, P. J., and A. A. Koenig, "Polarization Measurement in Sodium Sulphur Cells," Fourth Battery Conference on Applications and Advances, 1989.

Jones, I. W., and S. MacLachlan, "The Development of Sodium Sulphur Cells and Batteries," Secondary Battery Conference, November 1989.

Leo, A., Development of Zinc/Bromine Battery Development at Energy Research Corporation, Proceedings of the Twenty-Fourth Intersociety Energy Conversion Engineering Conference, Washington DC, August 6-11, 1989.

MacLachlan, S., and C. O'Neil Bell, "The Development of a Metal:Ceramic Seal for Sodium Sulphur Cells," Secondary Battery Conference, November 1989. 
McNamee, M., and F. M. Stackpool, "Sodium Sulphur for Technology Development," Ninth Battery and Electrochemical Contractors' Conference, November 1989, p. 33.

Murphy, K. D., and R. B. Diegle, "tan Grerview of Advanced Battery Development at Sandia $\mathrm{Na}$ tional Laboratories," Proceedings of the Second International Conference on Rechargeable Batteries, Deerfield Beach, Florida, March 7-9, 1988.

Quinn, J. E., P. C. Symons, D. R. Brown, W. Auxer, and G. Atherton, "Batteries for Electric Vehicle and Utility Load Levelling Applications," Twentyfourth IECEC Conference, August 6-11, 1989.

Rudd, E. J., "Development of Aluminum-Air Batteries for EV's," Electric Vehicle Developments, Vol. 8, No. 2, pp. 50-53, 1989.

Rudd, E. J., "The Development of Aluminum-Air Batteries for Electric Vehicles," Proceedings at the EV Battery Session oi the 1989 Conference of the Society of Automotive Engineers, Vancouver, August 1989, Published by SAE as Sp793 "Recent Advances in EV Technology," p. 27.

\section{Publications}

Arnold, C., Jr., and R. A. Assink, "Preparation and Evaluation of Composite Membranes for Zinc/Bromine Redox Storage Batteries," Proceedings of the ACS Division of Polymeric Materials. Science and Engineering, Miami Beach, Florida, Vol. 61, p. 876, Fall Meeting, 1989.

Arnold, C. Jr., R. A. Assink, and P. C. Butler, "Membrane and Durability Studies for the Zinc/Bromine Battery," Proceedings of the Ninth Battety and Electrochemical Contractors' Conference, Alexandria, Virginia, CONF-891132-Summs., November 12-16, 1989.

Diegle, R. B., "Exploratory Battery Technology Development and Testing Project Overview," Extended Abstracts. Ninth Battery and Electrochemical Contractors' Conference, U.S. Department of Energy Report CONF-891132Summs. (DE89016837), November 1989, p. 23-29.
Singh, P., and A. Leo, Development of Zinc-Bromine Battery systems for Stationary Energy Storage, Proceedings of the Second Annual International Conference on Batteries for Utility Energy Storage, Newport Beach, California, July 24 $28,1989$.

Smaga, J. A., "Sodium/Sulfur Post-Test Analysis at ANL" Ninth Battery and Electrochemical Contractors' Conference, November 1989, p. 79.

Stackpool, F. M., "Advances in Sodium Sulphur Cell Safety," One Hundred Seventy-sixth Meeting of Electrochemical Society, October 1989.

Stackpool, F. M., W. Auxer, M McNamee, M. F. Mangan, "Sodium Sulphur Battery Development, Twenty-fourth IECEC Conference, August 6$11,1989$.

Diegle, R. B., and J. E. Quinn, "Status of the U.S. Department of Energy Program on Advanced Batteries for Load Leveling Applications," Proceedings of the Second International Conference on Batteries for Utility Energy Storage, Newport Beach, California, July 24-28, 1989.

Johnson, P. J., "The Impedance of Sodium Sulphur Cells at Very Low Frequencies," Journal of Power Resources, February 1989.

Helfand, M., C. R. Clayton, and R. B. Diegle, “An XPS Study of the Anodic Inhibition of an Amorphous Co-20P Alloy," Corrosion, Electrochemistry, and Catalysis of Metallic Glasses, eds. R. B. Diegle and K. Hashimoto, The Electrochemical Society, Inc., Pennington, New. Jersey, 1988, pp. 104-117. 
Helfand, M. A., C. R. Clayton, N. R. Sorensen, and R. B. Diegle, "The Nature and Composition of the Passive Film Formed on Ni-P-Cr Metallic Glasses," Extended Abstracts of the Electrochemical Society, Inc., Vol. 88-2, Abstract No. 142, p. 205, October 1988.

Helfand, M. A., C. R. Clayton, N. R. Sorensen, and R. B. Diegle, "The Effect of $\mathrm{pH}$ on the Nature and Formation of the Passive Film on Amorphous Ni-Cr-P Alloys," Extended Abstracts of The Electrochemical Society, Vol. 89-2, Abstract No. 331, p. 478, Uctober 1989.

Magnani, N. J., R. B. Diegle, J. W. Braithwaite, D. M. Bush, P. C. Butler, J. M. Freese, K. R. Grothaus, and K. D. Murphy, Exploratory Battery Technology Levelopment and Testing Report for 1987, Sandia National Laboratories Report SAND89-2154, August 1988.
Magnani, N. J., R. B. Diegle, J. W. Braithwaite, D. M. Bush, P. C. Butler, J. M. Freese, K. R. Grothaus, and K. D. Murphy, Exploratory Battery Technology Development and Testing Report for 1988, Sandia National Laboratories Report SAND89-3039, December 1989.

Sorensen, N. R., R. B. Diegle, S. T. Picraux, and G. C. Nelson, "Effect of $P$ Implantation on the Corrosion Behavior of $\mathrm{Fe}-\mathrm{Cr}$ Alloys," Corrosion, Eiectrochemistry, and Catalysis of Metallic Glasses, eds. R. B. Diegle and K. Hashimoto, The Electrochemical Society, Inc., Pennington, New Jersey, 1988, pp. 264-276.

Wild, B. E., M. Manohar, I. Chattaraj, R. B. Diegle, and A. K. Hays, "The Effect of Amorphous NickelPhosphorus Alloy Layers on the Absorption of Hydrogen into Steel," Corrosion, Electrochemistry, and Catalysis of Metallic Glasses, eds. R. B. Diegle and K. Hashimoto, The Electrochemical Society, Inc., Pennington, New Jersey, 1988, pp. 289-307.

\section{References (Cited in the Text)}

1. Virkar, A. V., "Ceramic Bodies Having Plurality of Stress Zones," U.S. Patent No. 4,656,071, April $7,1987$.

2. Virkar, A. V., and J. L. Huang, "Strengthening of Oxide Ceramics by Transformation-Induced Stresses," Journal of American Ceramics Society, Vol. 7, No. 3, pp. 164-170, (1987).
3. Virkar, A. V., J. F. Jue, J. J. Hansen, and R. A. Cutler, "Measurement of Residual Stresses in Oxide-ZrO2 Three-Layer Composites," Joumal of American Ceramics Society, Vol. 71, No. 3 pp. C148-C151, (1988).

4. Smaga, J. A., "Sodium/Sulfur Post-Test Analysis at ANL" Ninth Battery and Electrochemical Contractors' Conference, November 1989, p. 79 (repeated from page A-2) 

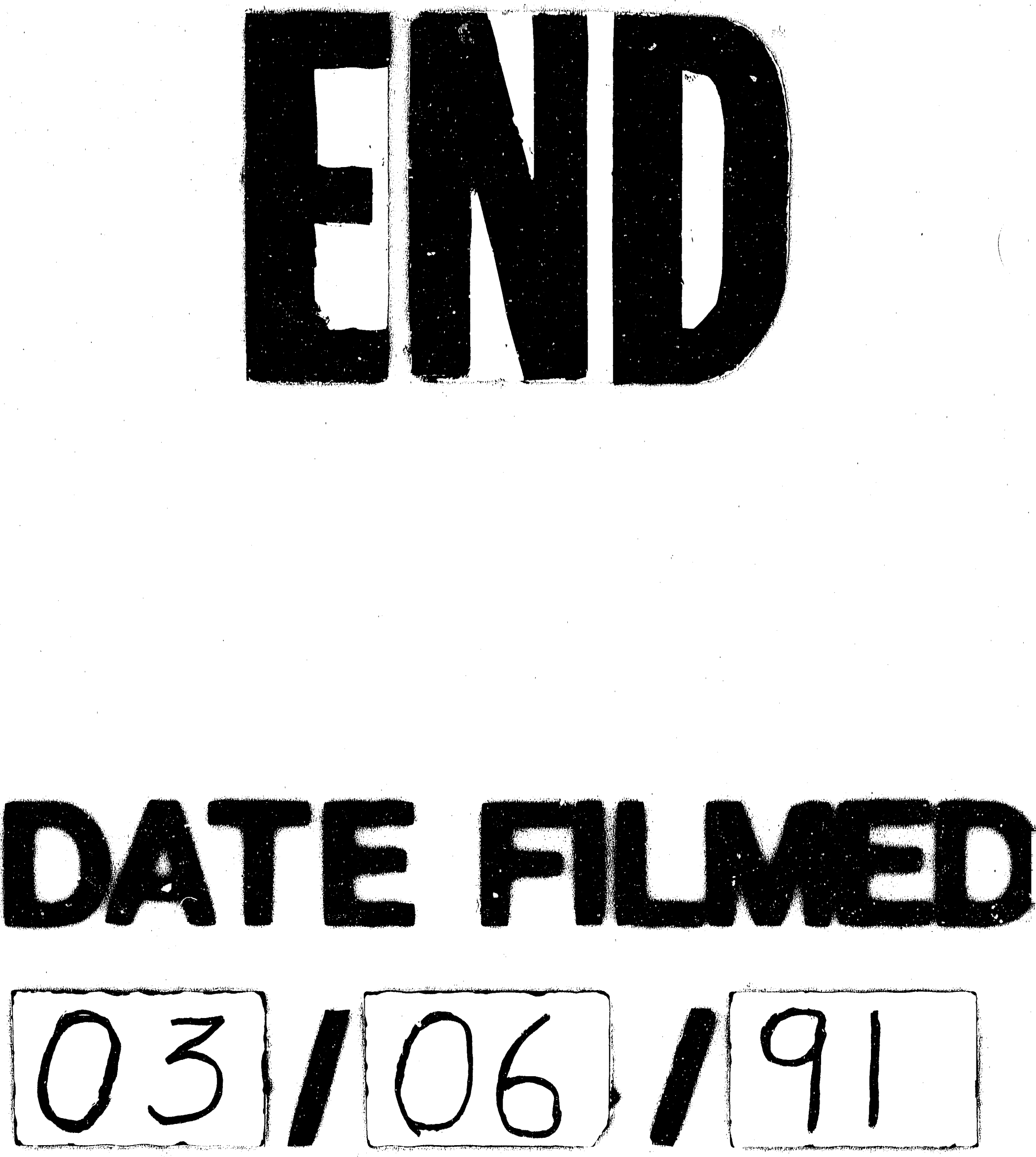